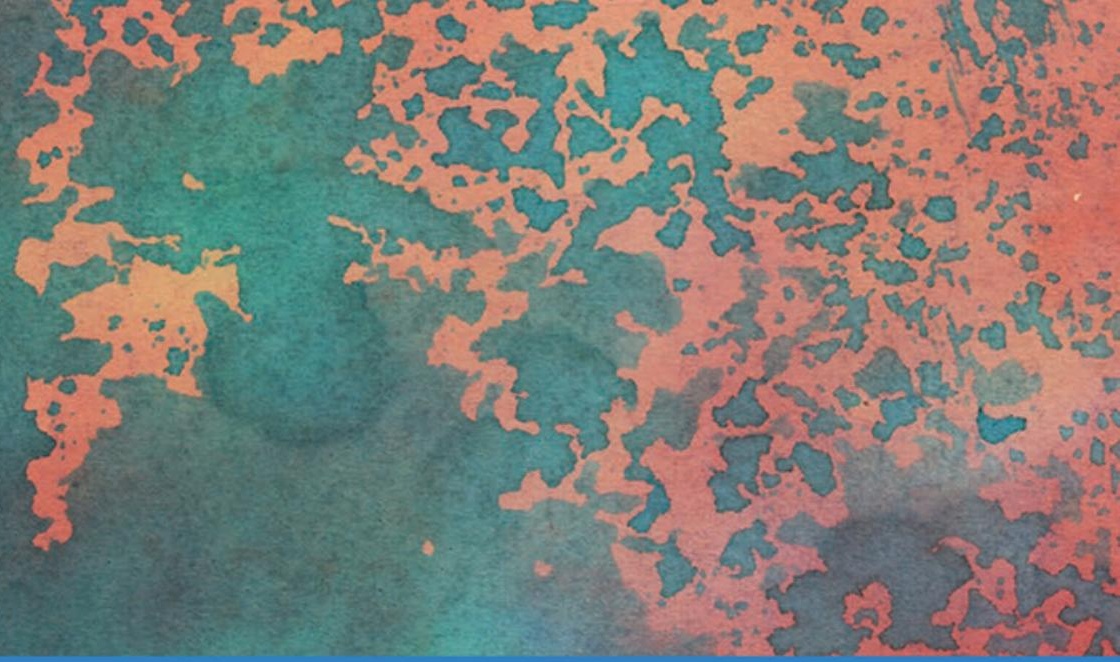

\title{
CLIMATE CHANGE AND THE HEALTH SECTOR
} HEALING THE WORLD

Edited by

Alexander Thomas, K. Srinath Reddy, Divya Alexander and Poornima Prabhakaran
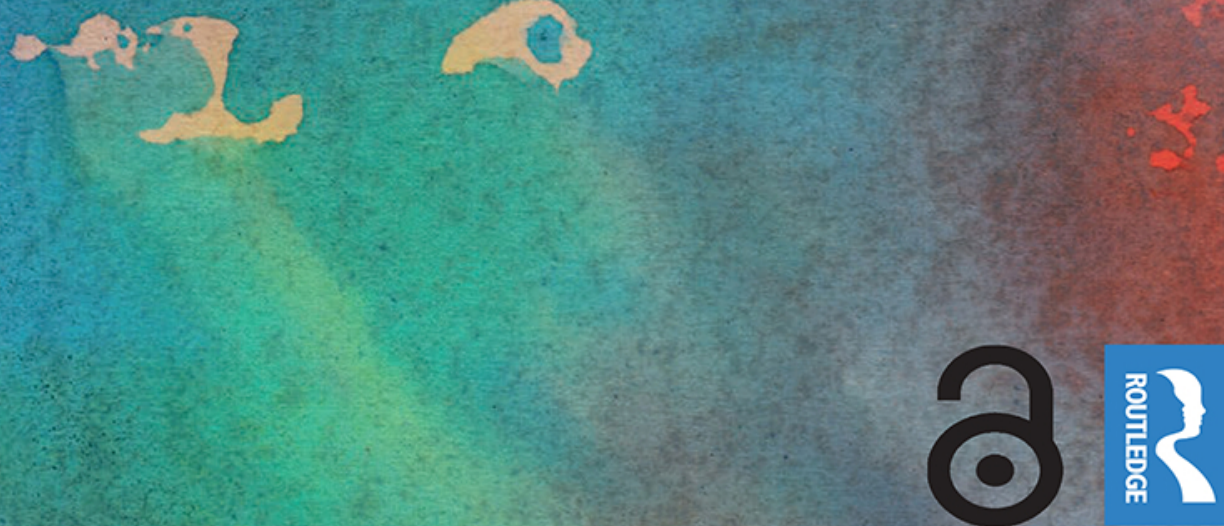
Climate change has exacerbated, and will continue to exacerbate, diseases and ill health amongst all the people of the world - but particularly the poor and the vulnerable. The healthcare profession stands at the frontline of this escalating health impact, and this book, Climate Change and the Health Sector: Healing the World, applies the understandings and learnings from the fight against climate change to an array of healthcare priorities. This book is a call to action for all healthcare professionals. It sensitizes them to the exacerbating impacts of climate change on people's health, and initiates their thinking on actions that can incorporate responses to these impacts in their own repertoire of approaches and tools to enhance human health. I commend AHPI for this great initiative, and in particular, congratulate Dr. Alex Thomas, Dr. Srinath Reddy, Ms. Divya Alexander and Dr. Poornima Prabhakaran for bringing together this volume.

Ajay Mathur, Member, Prime Minister's Council on Climate Change, and Director General, The Energy and Resources Institute (TERI), New Delhi

I applaud the editors for this very important addition to the field of medical education. In this book, the health sector's considerable impact on climate change is clearly and comprehensively described, along with ways to minimise that impact. I agree with the laudable premise that our sector should lead by example, and this book is an excellent place to begin. The communication book had a major impact on the medical fraternity; similarly, I hope this book paves the way for widespread awareness and policy development with regard to climate change.

Dr. Devi Shetty, Chairman, Narayana Health

It is now universally realised that the health sector is one of the major contributors to greenhouse gases leading to climate change. This carbon emission takes place during the process of care delivery, while procuring technologies, through the consumption of energy and transportation, and by the usage and disposal of products. Climate Change and the 
Health Sector: Healing the World teaches the custodians of health to start thinking differently to safeguard the planet with the goal of becoming carbon neutral. In order to generate awareness and to enable young minds to think about innovations to break free from this vicious cycle, NBE would definitely consider incorporating this need-of-the-hour topic in its medical curriculum. We praise the efforts by Dr. Alex Thomas, AHPI and PHFI to focus on this novel concept by publishing this book which will be hugely beneficial to the health sector in adopting positive changes to protect the climate and to effectively reduce its negative effects on individual health. We congratulate Dr. Alex Thomas and his team on the successful release of this book.

Dr. Abhijat Sheth, President, National Board of Examinations

The book titled Climate Change and the Health Sector: Healing the World addresses an important niche area. It enlightens the reader on the economic impact of climate change through its effects on health, especially the most vulnerable. It also enlightens the reader on the priorities spelt out by the Government in this regard. The editors, with years of experience, have contributed chapters and also compiled input from other experts in the field, bringing depth and insight to this book. It will be very useful to students of public health, policy makers and other stakeholders.

Lt. Gen. Madhuri Kanitkar AVSM VSM, Deputy Chief, IDS (Medical)

Climate Change and the Health Sector: Healing the World carefully interlaces a wide range of topics around how climate change affects the healthcare ecosystem. It is firmly grounded in evidence, and the practical examples take it beyond mere theory. The contributions by a diverse group of experts have been moulded into a cohesive and illustrative reference book for the healthcare community. This book is a valuable resource that describes how to promote sustainable operations in healthcare, and will particularly benefit any healthcare facility beginning its journey towards healthcare quality.

B. K. Rao, Chairman, National Accreditation Board for Hospitals and Healthcare Facilities (NABH)

A remarkable feat reminding us how climate change is intrinsically linked to public health, and the profound responsibility that state and society have to improve the standard of health and living. The volume 
will interest and inspire readers across different sectors, waking them up to the urgency of the now.

Dr. Uttam Kumar Sinha, Climate Change Expert, Manohar Parrikar Institute for Defence Studies and Analyses

With straightforward chapters and illustrative case studies written by prominent experts in the field of climate change and healthcare, this volume is very apt for the healthcare industry and especially for healthcare students, all of whom can benefit greatly from learning about this topic. The subject of climate change is not yet a part of the undergraduate medical curriculum, and this book fills a very important gap in their knowledge base.

Dr. M. K. Ramesh, President, Postgraduate Medical Education Board, National Medical Commission

Climate Change and the Health Sector: Healing the World is a comprehensive landmark resource book, with contributions from leading experts in climate change and public health. It examines the major contribution of the health sector towards the greenhouse gas emissions causing the climate crisis, as well as ways to mitigate the climate footprint in India. This book is compelling in its narrative and is a mustread for the multi-disciplinary health team.

Maj. Gen. Elizabeth John (Retd.), Former Additional DirectorGeneral, Military Nursing Service (ADGMNS) 
$\Longrightarrow$ Taylor \& Francis

Taylor \& Francis Group

http://taylorandfrancis.com 


\section{CLIMATE CHANGE AND THE HEALTH SECTOR}

The health sector is known to be one of the major contributors towards the greenhouse gas emissions causing the climate crisis, the greatest health threat of the 21 st century. This volume positions the health sector as a leader in the fight against climate change and explores the role of the health system in climate policy action. It delivers an overview of the linkages between climate change and the health sector, with chapters on the impact of climate change on health, its connection to pandemics, and its effects on food, nutrition and air quality, while examining gendered and other vulnerabilities. It delves into the different operational aspects of the health sector in India and details how each one can become climate-smart to reduce the health sector's overall carbon footprint, by looking at sustainable procurement, green and resilient healthcare infrastructure, and the management of transportation, energy, water, waste, chemicals, pharmaceuticals and plastics in healthcare.

Well-supplemented with rigorous case studies, the book will be indispensable for students, teachers, and researchers of environmental studies, health sciences and climate change. It will be useful for healthcare workers, public health officials, healthcare leaders, policy planners and those interested in climate resilience and preparedness in the health sector.

Alexander Thomas, President of AHPI, President of the Association of National Board Accredited Institutions (ANBAI), and Founder-President (2012-2017) and Patron of the Consortium of Accredited Healthcare Organizations (CAHO), has effected far-reaching policy changes within the healthcare landscape both at the national and the state level, pioneered many training initiatives, and received several awards for his contributions to the health sector. His recent publications include books on healthcare communication and healthcare quality, and white papers submitted to the Government of India.

K. Srinath Reddy, a Padma Bhushan awardee, is the President of the Public Health Foundation of India (PHFI), and formerly headed the Department of Cardiology at the All India Institute of Medical Sciences (AIIMS), New 
Delhi. He holds advisory positions in numerous national and international bodies, including the position of former President of the World Heart Federation (2013-2015), and has been awarded several prestigious national and international doctorates and fellowships. His recent publications include Make Health in India: Reaching a Billion Plus (2019).

Divya Alexander has over a decade of expertise in gender, health and public policy research, having drawn up policy recommendations and drafted healthcare legislation in India and abroad through her work with AHPI, UNFPA, and Amnesty International USA. She has co-edited two books and several papers on healthcare communication, adolescent health education, public policy and climate change. She read for her Master's degree at the University of Oxford as a Commonwealth Scholar and is a gold medallist from Bangalore University (Mount Carmel College), India.

Poornima Prabhakaran is Additional Professor and Head of Environmental Health; Deputy Director at the Centre for Environmental Health, Public Health Foundation of India; and Senior Research Scientist at the Centre for Chronic Disease Control. She leads work engaging the Indian health sector on environmental issues, including a strong advocacy movement towards climate-resilient and sustainable healthcare systems in India. She is a member of technical expert groups providing the health perspective to various national programs related to climate change, air pollution and urban resilience. 


\title{
CLIMATE CHANGE AND THE HEALTH SECTOR
}

\author{
Healing the World
}


First published 2022

by Routledge

2 Park Square, Milton Park, Abingdon, Oxon OX14 4RN

and by Routledge

605 Third Avenue, New York, NY 10158

Routledge is an imprint of the Taylor \& Francis Group, an informa business

(C) 2022 selection and editorial matter, Alexander Thomas; individual chapters, the contributors

The right of Alexander Thomas to be identified as the author of the editorial material, and of the authors for their individual chapters, has been asserted in accordance with sections 77 and 78 of the Copyright, Designs and Patents Act 1988.

The Open Access version of this book, available at www.taylorfrancis.com, has been made available under a Creative Commons Attribution-Non Commercial-No Derivatives 4.0 license.

Trademark notice: Product or corporate names may be trademarks or registered trademarks, and are used only for identification and explanation without intent to infringe.

British Library Cataloguing-in-Publication Data

A catalogue record for this book is available from the British Library

Library of Congress Cataloging-in-Publication Data

A catalog record has been requested for this book

ISBN: 978-1-032-03999-2 (hbk)

ISBN: 978-1-032-16252-2 (pbk)

ISBN: 978-1-003-19051-6 (ebk)

DOI: $10.4324 / 9781003190516$

Typeset in Sabon

by SPi Technologies India Pvt Ltd (Straive) 


\section{CONTENTS}

List of figures xii

List of tables xiv

Foreword by K. Kasturirangan $\quad$ xv

Preface xvii

Acknowledgements $\quad$ xix

Introduction

First, do no harm: Climate change and the health sector 1

DIVYA ALEXANDER

\section{SECTION 1}

Climate action by the health sector

1 Health sector leadership to combat climate change 7 ALEXANDER THOMAS, DIVYA ALEXANDER AND GIRDHAR GYANI

2 The role of health systems in the Indian and global context PREETI SONI AND MANISH PANT

3 Strengthening healthcare delivery systems in low-income countries

ZERIN OSHO AND JAGJEET SAREEN

4 The climate change policy framework and allied programs in India 


\section{SECTION 2}

The impact of climate change on health

5 Disease pandemics and the threat of microbial emergence

6 Climate change and its impact on human health: an overview POORNIMA PRABHAKARAN

7 Air pollution, climate change and the health sector: linkages and solutions

H. PARAMESH, D. J. CHRISTOPHER AND JYOTHI S. MENON

8 Nourish or perish: the effect of climate change on food, nutrition and health

MANU RAJ MATHUR, AMEEKA SHEREEN LOBO, HIMANSHI PANDEY, ANJALI GANPULE-RAO AND K. SRINATH REDDY

9 Gendered vulnerabilities and health inequities

VANITHA KOMMU, DIVYA ALEXANDER AND LAKSHMI LINGAM

10 The consequences of climate change on vulnerable populations RICHA SHARMA AND R. SRIKANTH

11 Prioritising climate change and health: the current status of heat-health in India

PRIYA DUTTA, MAHAVEER GOLECHHA AND DILEEP MAVALANKAR

\section{SECTION 3}

Reducing the climate footprint of the health sector

12 Climate-smart healthcare: what does it entail?

13 Green and resilient health infrastructure 
15 Water stress and the effective management of water in the health care sector

SHYAMALA MANI, SAMAYITA GHOSH AND R. SRINIVASAN

16 Sustainable ways to manage waste in healthcare facilities

17 Sustainable transport solutions in the health sector

18 Sustainable procurement in healthcare

\section{SECTION 4}

Climate action by allied sectors

19 Environmental sustainability in the pharmaceutical industry

SUMAN SHARMA AND ALBA TILEY

20 Chemicals and climate: challenges for the health sector

21 The paradox of plastics in healthcare and health

Conclusion

Causative and curative: the health sector's impact on climate change

DIVYA ALEXANDER

Editors

About the contributors

Index 


\section{FIGURES}

1.1 Eight steps to transforming your organization 13

2.1 Emissions across a value chain in the health sector 21

4.1 Climate change action in the health sector at global and national levels

5.1 Satellite data in Yemen, $2017 \quad 50$

6.1 World map of the global climate risk index, 2019

6.2 The impact of climate change on human health 60

8.1 Food security, climate change and human health nexus framework

8.2 Pathways: impact of climate change on food systems 80

8.3 Vulnerability of Indian agriculture to climate change (2021-2050)

8.4 Guiding principles for sustainable healthy diets 85

11.1 Daily temperatures and all-cause mortality correlation graph of Ahmedabad, Gujarat

11.2 Ahmedabad heat action plan strategies

11.3 The inter-agency emergency communication plan when the Ahmedabad Municipal Corporation (AMC) nodal officer activates a heat alert

12.1 Climate resilience and environmental sustainability in health care facilities

$\begin{array}{lll}\text { 12.2 } & \text { India's healthcare footprint split by GHG protocol scopes } & 124 \\ \text { 14.1 The modified KEBA sub-center layout } & 144\end{array}$

14.2 The modified KEBA sub-center

14.3 The boat clinics within which all health and general appliances are energy-efficient and solar powered

15.1 Treatment of waste water at Aravind Eye Hospital 156

15.2 A bird's-eye view of the facility

16.1 Different categories and classification of waste generated from healthcare facilities

16.2 Methods prescribed in the BMWM rules for different waste categories 
18.1 Lifecycle of materials and products from material extraction, manufacturing, distribution, use and end-of-life

18.2 NHS and social care England goods and services' carbon footprint - carbon hotspots 


\section{TABLES}

2.1 HCF in absolute terms, per capita and as a percentage of overall CF

2.2 Framework for a climate-resilient health system 24

4.1 The vision, goal and objectives of NPCCHH 38

4.2 Key strategies to adapt to heat-related illnesses in India 41

5.1 Pandemics caused by Influenza viruses 51

5.2 Epidemics and pandemics caused by Coronaviruses 52

7.1 Sources of pollutants in the health sector 68

11.1 Colour signals for heat alerts 111

12.1 Mitigating strategies applicable to the health sector 126

15.1 Toxin standards and associated health effects 152

15.2 Water requirements for buildings in the health sector 153

16.1 Policy framework for managing various types of waste generated in India

16.2 Colour-coded BMW categories along with their treatment and disposal methods

17.1 Health risks associated with transport related pollutants 174

17.2 Summary of case studies of climate change related measures on health

17.3 Benefits of core measures - land-use strategy

17.4 Impact of transport-related mitigation activities on climate and health

17.5 Impact of economic incentive measures on GHG savings in different countries

17.6 Energy consumption and cost savings of Narayana Health City, Bengaluru, India 180

21.1 Representative list of plastics used in medical applications 218 


\section{FOREWORD}

In the past few years, India has been ravaged by climate disasters. In 2019 , intense heatwaves scorched large parts of our country, followed by sparse rainfall in some areas and extreme rainfall in others, with floods across 22 states, despite which $30 \%$ per cent of the country's area faced drought, widespread thunderstorms and associated dust storms in northern and western India, almost 80,000 forest fires (a 113\% increase from 2018), and seven cyclones. In 2020 and 2021, these weather events have continued unabated against the backdrop of a crushing pandemic, causing even more death, displacement and destruction across the nation.

Climate change is no longer confined to the realms of scientific possibility at some vague point in the distant future. It is all too real, and too close for comfort, upending the delicate balance of our fragile ecosystem and slowly disrupting the basic requirements for human survival - air, water, and food. It has now entered the vast subject areas of international policy, economics, law, health and healthcare. A proper understanding of climate change is essential in order to appreciate its escalating impact on water security, food security, clean air, human health and the economy.

I have always believed that education is the key to change. The keywords of environmental health and climate change have been in the news for years now; yet, many Indians go on as before, or are content with making small changes in their lifestyle to save the planet. While these individual efforts may be a good starting point, they will not suffice to halt or even slow down the speed at which we are hurtling along this path of destruction. We need concerted, collective and coordinated action at all levels - individual, community and policy - if we are serious about dealing with climate change, the myriad challenges it has already created, and the countless that are still to come.

That is why I am elated about this book; here is a guide for an entire industry, the health sector, on how to lessen its own considerable contribution to emissions; how to arm and defend itself against the devastating effects of climate change, and how to strengthen its systems to prepare for the oncoming avalanche of climate change-induced health problems. Aptly titled Climate Change and the Health Sector: Healing the World, this book 
aims to educate every healthcare professional on how climate change affects them, their work, and the recipients of their care.

This book is essential reading for everyone connected to the health sector. To enable a wide reach, the editors have placed a prominent focus on the book's accessibility: it is available to download online free of cost, and every one of the editors and contributors have contributed their time and expertise pro bono.

Alex has always been concerned with the societal implications of anthropogenic activities in general, and health in particular. I have closely worked with him while he and one of his very accomplished colleagues, Dr. Devi Shetty, led a team of specialists to formulate the Public Health Policy for Karnataka. The extraordinary way in which they went about preparing this policy prompted me to request them again to provide a section in the recently accepted National Education Policy 2020, regarding professional medical education and its future for this country. With these benchmarks in my mind, I have great faith that this book will accomplish what it has set out to do, and more.

The previous book written by Alex and his team drew attention to a longneglected aspect of the health worker's skillset: healthcare communication. That book led to the inclusion of communication within medical education and quality accreditation standards, and connected with its readers in the health sector with its simple and direct style. If this book on climate change leads to the same sweeping changes at the policy and grassroots level, it will greatly benefit healthcare workers, the Indian health sector, and consequently, society at large. It is time for all of us to take a stand, and I believe that the health sector is an excellent choice to lead India's battle against climate change.

Dr. K. Kasturirangan

Chairman, Committee for the National Education Policy 2020 


\section{PREFACE}

Climate change, a pressing topic in today's world, is rapidly increasing the burden on the global health sector. However, the health sector, whose responsibility is to protect and improve human health, itself makes a major contribution towards the greenhouse gas emissions causing the climate crisis, the greatest health threat of the 21st century. Health workers and policy makers need to understand this link and learn how to mitigate the health sector's own climate footprint. This publication titled Climate Change and the Health Sector: Healing the World examines how to make India's health sector operationally climate-smart and reduce its carbon footprint, while simultaneously making it climate-resilient and preparing it to manage the associated health impacts. It is endorsed by the Association of Healthcare Providers - India (www.ahpi.in) and the Public Health Foundation of India (www.phfi.org).

The volume begins by positioning the health sector as a leader in the fight against climate change and explores the role of the health system in climate policy action. It delivers an overview of the linkages between climate change and the health sector, with chapters on the impact of climate change on health, its connection to pandemics, and its effects on food, nutrition and air quality, while examining gendered and other vulnerabilities. It delves into the different operational aspects of the health sector and details how each one can become climate-smart to reduce the health sector's overall carbon footprint, by looking at sustainable procurement, green and resilient healthcare infrastructure, and the management of transportation, energy, water, waste, chemicals, pharmaceuticals and plastics in healthcare.

The book is designed to be easy to read and understand, with clear objectives and key takeaways for every chapter, and case studies to interest and inspire the reader. It is aimed towards healthcare workers, healthcare students, public health officials, healthcare leaders, policy planners, and anyone interested in climate resilience and preparedness in the health sector.

The contributors to this book are renowned national and international experts from institutions of repute, with vast experience in the areas of climate change and healthcare. As chief editor, it is my privilege and honour to thank each one of them for contributing their knowledge and time to this 
project despite juggling busy schedules during an unprecedented pandemic. A complete list of chapter authors is presented on the next page, with their brief profiles available at the end of the book.

I would also like to record my deep appreciation for the valuable feedback and insightful comments provided by experts during our three-stage review process. The list of external reviewers is presented in the following pages.

I am indebted to Dr. K. Kasturirangan for his inspirational foreword that aptly captures our nation's battle with climate change while providing hope for the future.

This publication has been made available on an open-access platform, meaning that it is free to download and read anywhere in the world; this is due to the generous benefaction of Mr. Kris Gopalakrishnan and his philanthropic foundation, Pratiksha Trust, which has supported and championed many social causes. The striking cover of the South Asia print version of the book was designed by Mr. Ricky Kej, renowned environmentalist and Grammy award-winning musician.

Finally, I would like to thank my co-editors for the roles they played in developing this book in addition to contributing chapters in their areas of expertise. I am grateful to Prof. K. Srinath Reddy for laying the foundation by connecting me with many climate change experts and to Dr. Poornima Prabhakaran for also contributing to the structure of the book. I would like to especially recognise Ms. Divya Alexander and thank her for shouldering the main responsibility of building the book up to its present form, and without whom this project would not have come to fruition. My grateful thanks to Dr. V. C. Shanmuganandan, Mr. Shadrach Thangaraj and my colleagues in AHPI for their support. It was a pleasure working with the Routledge team, who made the publishing process quite smooth and enjoyable.

It is our hope that this book will galvanise the healthcare community into action to save our fragile and precious planet, and by extension, the humans it holds, fulfilling the primum non nocere tenet of our oath that binds us to "first, do no harm."

Dr. Alexander Thomas

Chief Editor 


\section{ACKNOWLEDGEMENTS}

On behalf of my co-editors, I would like to place on record our deep appreciation and grateful thanks to each of the chapter authors, the experts who reviewed individual chapters, and the experts who reviewed the complete manuscript.

\section{Contributing Authors}

- Ms. Divya Alexander Independent Consultant in Gender, Health and Climate Change

- Mr. Sundeep Singh Chauhan Director, Consulting Engineers' Group (CEG) India, Jaipur

- Mr. Yatin Choudhary Fellow, Sustainable Habitat Division, The Energy and Resources Institute (TERI), New Delhi

- Dr. D. J. Christopher Professor of Pulmonary Medicine, Christian Medical College, Vellore

- Dr. Priya Dutta Senior Consultant, Indian Institute of Public Health, Gandhinagar

- Ms. Tracey Easthope Founding Member and Senior Strategist, Health Care Without Harm

- Dr. Anjali Ganpule-Rao Post-Doctoral Research Fellow, Centre for Chronic Disease Control, New Delhi

- Ms. Samayita Ghosh Senior Research Associate, Centre for Environmental Health, Public Health Foundation of India, New Delhi

- Dr. Mahaveer Golechha Associate Professor and Lead, Climate Change and Health, Indian Institute of Public Health, Gandhinagar

- Dr. Girdhar Gyani Director-General, Association of Healthcare Providers - India

- Mr. Harish Hande Founder, SELCO and CEO, SELCO Foundation, Bangalore

- Dr. Gifty Immanuel Director, Centre for AIDS and Antiviral Research, Tuticorin, and Medical Division, Synergia Hospital, Bangalore

- Ms. Huda Jaffer Director, SELCO Foundation, Bangalore 
- Dr. Ishika Jharia Project Officer and Research Associate, Sustainable Health in Procurement Project, Centre for Chronic Disease Control, New Delhi

- Dr. Lalit Kant Independent Consultant and Former Head, Division of Epidemiology and Communicable Diseases, Indian Council of Medical Research, New Delhi

- Mr. Josh Karliner International Director of Program and Strategy, Health Care Without Harm

- Ms. Vanitha Kommu Research Scholar, Tata Institute of Social Sciences, Mumbai, and Consultant to the World Bank

- Mr. Hari Kumar South Asia Regional Coordinator of Geohazards International, and Head, GeoHazards Society of India, New Delhi

- Prof. Lakshmi Lingam Dean and Professor, School of Media and Cultural Studies, Tata Institute of Social Sciences, Mumbai

- Ms. Ameeka Shereen Lobo Senior Research Assistant, Public Health Foundation of India, New Delhi

- Dr. Shyamala Mani Senior Advisor, WASH and Waste Management, Centre for Environment Health, Public Health Foundation of India, New Delhi

- Mr. Shriram Manogaran Technical Program Coordinator, Centre for Chronic Disease Control, and Fellow, Centre for Environmental Health, Public Health Foundation of India, New Delhi

- Dr. Manu Mathur Head, Health Policy and Additional Professor, Public Health Foundation of India, New Delhi

- Dr. Dileep Mavalankar Director, Indian Institute of Public Health, Gandhinagar

- Dr. Jyothi S. Menon Senior Research Associate, Centre for Environmental Health, Public Health Foundation of India, New Delhi

- Dr. Jai Prakash Narain Senior Visiting Fellow, University of New South Wales, Sydney, and Former Director, Communicable Diseases, WHO Regional Office for South-East Asia

- Ms. Zerin Osho Project Lead, International Solar Alliance

- Ms. Himanshi Pandey Senior Research Assistant, Public Health Foundation of India, New Delhi

- Dr. Manish Pant Chief, Health and Governance Unit, United Nations Development Programme (India)

- Prof. Dr. H. Paramesh Pediatric Pulmonologist and Distinguished Visiting Professor, Divecha Center for Climate Change, Indian Institute of Science, Bangalore

- Dr. Poornima Prabhakaran Additional Professor, Head, Environmental Health; Deputy Director, Centre for Environmental Health, Public Health Foundation of India, New Delhi

- Dr. Megha Rathi Coordinator, Sustainable Health in Procurement Project, Health Care Without Harm 
- Mr. Swapan K. Ray Honorary Secretary and Member, Executive Council, Indian Centre for Plastics in the Environment

- Prof. K. Srinath Reddy President, Public Health Foundation of India, New Delhi

- Dr. Aditi Roy Research Scientist, Center for Environmental Health, Public Health Foundation of India, New Delhi

- Mr. Jagjeet Sareen Assistant Director-General, International Solar Alliance

- Dr. Richa Sharma Research Scientist, Centre for Environmental Health, Public Health Foundation of India, New Delhi

- Ms. Suman Sharma Director of Marketing (Sustainability) for the APAC Region, Centrient Pharmaceuticals, New Delhi

- Dr. Aakash Shrivastava Additional Director and Head, Centre for Environmental Health and Occupational Health, Climate Change and Health, National Centre for Disease Control, Ministry of Health and Family Welfare, Govt. of India

- Dr. Shailendra P. Singh NABET-certified independent consultant in environmental impact assessment

- Prof. S. Sivaram Honorary Professor and INSA Senior Scientist, Indian Institute of Science Education and Research, Pune

- Dr. Preeti Soni Head, Asian and Pacific Centre for Transfer of Technology, United Nations Economic and Social Commission for Asia and the Pacific (UNESCAP)

- Dr. Rameshwar Sorokhaibam Deputy Director, Centre for Environmental and Occupational Health, Climate Change and Health, National Centre for Disease Control, Ministry of Health and Family Welfare, Govt. of India

- Prof. R. Srikanth Head, Energy, Environment and Climate Change Program, and Dean, School of Natural Sciences and Engineering, National Institute of Advanced Studies, Bangalore

- Dr. R. Srinivasan Visiting Professor, Divecha Centre for Climate Change, Indian Institute of Science, Bangalore

- Ms. Ananya Tewari Senior Research Associate, Centre for Environment Health, Public Health Foundation of India, New Delhi

- Ms. Alba Tiley Sustainable Antibiotics Program Director, Centrient Pharmaceuticals (Global), New Delhi

- Dr. Shikha Vardhan Joint Director, National Centre for Disease Control, Ministry of Health and Family Welfare, Govt. of India

- Ms. Susan Wilburn Director of International Sustainability, Health Care Without Harm

\section{Individual chapter reviewers}

- Dr. Damodar Bachani Former Director General, NACO, Ministry of Health and Family Welfare, Govt. of India, New Delhi 
- Prof. V. Ramana Dhara Professor, Indian Institute of Public Health, Hyderabad

- Dr. Suman Gadicherla Associate Professor, M. S. Ramaiah Medical College, Bangalore

- Dr. Mahaveer Golechha Associate Professor and Lead, Climate Change and Health, Indian Institute of Public Health, Gandhinagar

- Dr. Habib Hasan Lead Faculty, Pharmaceutical Economics and Infectious Disease Epidemiology, Indian Institute of Public Health, Delhi, and Associate Professor, Public Health Foundation of India, New Delhi

- Ms. Mathsy K. Regional Manager, Infosys Limited and Climate Change Professional

- Mr. Bhargav Krishna Adjunct Faculty and Fellow, Centre for Environmental Health, Public Foundation of India, and Doctor of Public Health Candidate, Harvard T. H. Chan School of Public Health

- Dr. Bharati Kulkarni Senior Grade Deputy Director, Clinical Division, National Institute of Nutrition, Hyderabad

- Prof. Josyula K. Lakshmi Professor, Prasanna School of Public Health, MAHE, Manipal and Senior Lecturer, Faculty of Medicine, University of New South Wales, Sydney

- Dr. Shyamala K. Mani Senior Advisor, WASH and Waste Management, Centre for Environmental Health, Public Health Foundation of India; Professor (Retd.) and Sector Advisor, MPD 2041 and CSCAF Thematic Expert for Climate-Smart Cities

- Mrs. Almitra H. Patel Member, Supreme Court Committee for SWM (Solid Waste Management) and National Expert, Swachh Bharat Mission

- Dr. Sakthivel Selvaraj Director and Professor, Health Economics, Financing and Policy, Public Health Foundation of India, New Delhi

- Dr. Rameshwar Sorokhaibam Deputy Director, Centre for Environmental and Occupational Health, Climate Change and Health, National Centre for Disease Control (NCDC), Directorate General of Health Services, Ministry of Health and Family Welfare, Govt. of India

- Prof. R. Srikanth Professor and Dean, School of Natural Sciences and Engineering, National Institute of Advanced Studies, Bangalore

- Dr. Shailaja Tetali Associate Professor, Indian Institute of Public Health, Hyderabad

- Mr. Venkatesh Valluri Founder and Chairman, Valluri Technology Accelerators

\section{Complete manuscript review}

- Dr. Glory Alexander Founder and Director, ASHA Foundation, Bangalore

- Dr. Tara Anne John MBBS, Christian Medical College, Vellore 
- Sister Premila Lee Professor and Head of Department, Medical Surgical Nursing, Christian Medical College, Vellore

- Dr. Harini Nagendra Director, Research Centre, Professor of Sustainability, Azim Premji University

- Col. (Dr.) Divakaran Padma Kumar Pillay Research Fellow, Manohar Parikkar Institute for Defense Studies and Analyses

- Dr. Christopher Sudhakar Director of Quality, Manipal Academy of Higher Education (MAHE) and Professor, MCON Manipal, MAHE 
$\Longrightarrow$ Taylor \& Francis

Taylor \& Francis Group

http://taylorandfrancis.com 


\title{
Introduction
}

\section{FIRST, DO NO HARM: CLIMATE CHANGE AND THE HEALTH SECTOR}

\author{
Divya Alexander
}

The phrase "climate change" refers to a significant or abnormal difference in the long-term weather patterns of a region or of the planet as a whole. This is caused by the concentration of greenhouse gases that trap heat in the atmosphere, slowly raising the global temperature and consequently melting ice caps, raising sea levels, changing rainfall patterns and creating extreme weather events.

The advent of COVID-19 has thrown a glaring light on the interconnectedness of health and environment, bringing into stark relief the urgency needed for stringent climate action. While climate change does impact everyone, the impacts will not be borne equally or fairly. The most vulnerable, including low-income communities, women, indigenous peoples, the elderly and children, will bear the brunt of climate impacts (UN, 2019).

It is a little-known paradox that the health sector, whose primary role is to protect and improve human health, emits a significant amount of greenhouse gases and other pollutants, thus contributing to the global burden of disease. If the global health sector were a country, it would be the fifthlargest emitter on the planet (HCWH and Arup, 2019). Healthcare's most oft-repeated tenet, "first, do no harm" was originally intended to apply to patients but has a poignant significance in the context of climate change, emphasising the additional responsibility that should be taken by the health sector in ensuring that its operations do not harm the planet, and by extension, humankind.

The sector's considerable emissions come from the vast energy use, water consumption, waste generation and disposal, transportation and carbonintensive supply chains of healthcare facilities and hospitals that function ceaselessly all day every day to deliver care and cater to the health needs of the population. In recent times, the climate-induced changes in disease patterns in places like India have become more palpable, with an increase in the number of patients with respiratory diseases, cardiovascular disease, non-communicable diseases, heat stress and disaster-related injuries, as well as the continuously rising climate change-related death toll (Watts et al., 2020). Health facilities, especially those with weak infrastructure in developing countries, will be unable to shoulder this growing burden of daily 
care indefinitely, much less remain a stronghold for the community in times of natural disaster. It is becoming increasingly clear that the climate crisis is also a health crisis. Hence, it is imperative to strengthen the health sector against the impact of climate change with a two-pronged approach: firstly, practicing primary prevention and mitigating climate change by reducing the sector's greenhouse gas emissions in its daily operations, and secondly, fortifying itself in order to remain resilient and operational for the community during extreme weather events.

In 2015, the international community produced three landmark global agendas to work towards for a sustainable future: the Paris Agreement, the Sustainable Development Goals (the 2030 Sustainable Development Agenda) and the Sendai Framework for Disaster Risk Reduction, setting course for a transition to low-carbon, climate-resilient societies and economies (UN, 2017). Each of these has targets relevant to health and climate change.

The Paris Agreement is the centrepiece of global climate policy, bringing together the nations of the world under the common cause of mitigating climate change. Its aim is to hold the global temperature increase to well below $2^{\circ} \mathrm{C}$ above pre-industrial levels and to pursue efforts to limit it to $1.5^{\circ} \mathrm{C}$. Under the Paris Agreement, all signatory countries undertake Nationally Determined Contributions (NDCs) with a view to achieving this aim. They simultaneously also develop National Adaptation Plans (NAPs) to reduce their vulnerabilities to the adverse effects of climate change in the medium and long term. The Sendai Framework brings in resilience-building as the core target to be reached by 2030 . The 2030 Sustainable Development Agenda lays out 17 Sustainable Development Goals in total, with SDG 13 in particular tracking progress for urgent action on climate change.

The need for integration between adaptation, sustainable development and disaster risk reduction represented by each of the above three instruments is paramount when it comes to the health sector. In 2017, a study estimated that the healthcare sector generated 2.6 billion out of the 52 billion metric tons of CO2e globally emitted in 2011, or 5\% of global emissions (World Bank, 2017); it was calculated at 4.4\% in 2014 (HCWH and Arup, 2019). The 2019 report established the first-ever detailed estimate of healthcare's global footprint with detailed information from 43 countries throwing light on the sources of these emissions. It measured emissions across three scopes: scope 1 category of emissions emanating directly from health care facilities $(17 \%)$, scope 2 category of indirect emissions from purchased electricity, steam, cooling and heating $(12 \%)$ and scope 3 category of emissions derived from the healthcare supply chain such as the production, transport, use, and disposal of goods and services that the sector consumes (71\%) (HCWH and Arup, 2019).

These numbers indicate that health facilities will need to work together with manufacturers and suppliers of healthcare goods and services, as well as with governments and ministries, in order to achieve climate action that 
aligns with the goals of the Paris Agreement, while working in tandem to achieve the SGDs and the Sendai Framework goals. Ensuring rapid decarbonisation between now and 2030 needs to be the healthcare sector's immediate focus of attention to contribute to the $1.5^{\circ} \mathrm{C}$ target (HCWH and Arup, 2021).

This volume espouses the two-pronged approach that integrates the health sector's resilience (climate preparedness) with mitigation solutions (carbon footprint reduction), together known as the "climate-smart approach." This approach can be cost-effective without compromising on the quality of care, thus putting health systems on a climate-smart development path and aligning health development and delivery with global climate goals. Climate-smart healthcare will strengthen health sectors and communities by ensuring access to clean and independent energy, safe water, clean transport, and clean waste disposal mechanisms, while stimulating the development and supply of sustainable products, and simultaneously preparing the sector for a future of known and unknown health-related climate hazards (World Bank, 2017).

The 21 chapters in this book have been divided into four sections. The first section, titled Climate Action by the Health Sector, posits how the health sector can lead by example, strengthening the adaptive capacity of its health systems, equipping its community with the tools to become climateresilient, and advocating for health to remain at the centre of all climate action policy. The second section, titled The Impact of Climate Change on Health, examines the intricate linkages between climate change, disease pandemics, food security, air pollution, and how they relate to human health, with a focus on gendered health inequities and vulnerable populations. The third section, focused on Reducing the Climate Footprint of the Health Sector, outlines how every operational aspect of a healthcare facility can become climate-smart, beginning with green infrastructure, sustainable procurement, and the effective management of energy, water, waste and transportation in healthcare. The final section, on Climate Action by Allied Sectors, scrutinises how environmental sustainability can be pursued in three closely related industries to the health sector: pharmaceuticals, chemicals and plastics.

Healthcare workers are in a unique position to advocate for climate resilience and smaller carbon footprints in society. As first-hand witnesses to the health impacts of climate change, taking a stand for environmental sustainability further solidifies their commitment to protect and improve human health. As first responders to these health effects, they understand all too well the necessity of planning for environmental changes and expanded health threats. As thought leaders in the community, they have the ability to engage the general public on how to address climate change. As members of one of the most trusted professions in society, they can garner public support and advocate for state-level and national-level climate action policies centred around health. The healthcare community as a whole, thus, is a 
strong first line of defence against climate change, and its capabilities should be harnessed and deployed in order to secure a healthy, secure and sustainable future for all.

\section{References}

HCWH and Arup. (2019). Healthcare's climate footprint report. HWCH. https:// noharm-global.org/sites/default/files/documents-files/5961/ HealthCaresClimateFootprint_092319.pdf

HCWH and Arup. (2021). Global road map for healthcare decarbonisation. HWCH. https://www.arup.com/perspectives/publications/research/section/ healthcare-without-harm

UN. (2017). Opportunities and options for integrating climate change adaptation with the Sustainable Development Goals and the Sendai Framework for Disaster Risk Reduction 2015-2030. https://unfccc.int/sites/default/files/resource/techpaper_adaptation.pdf

UN. (2019). Climate justice. United Nations. https://www.un.org/sustainabledevelopment/blog/2019/05/climate-justice/

Watts, N., Amann, M., Arnell, N., Ayeb-Karlsson, S., Beagley, J., Belesova, K., ... \& Campbell-Lendrum, D. (2020). The 2020 report of The Lancet Countdown on health and climate change: Responding to converging crises. The Lancet. doi:10.1016/s0140-6736(20)32290-x

World Bank. (2017). Climate-smart healthcare: Low carbon and resilience strategies for the health sector. http://documents1.worldbank.org/curated/ en/322251495434571418/pdf/113572-WP-PUBLIC-FINAL-WBG-Climatesmart-Healthcare-002.pdf. 
Section 1

CLIMATE ACTION BY THE

HEALTH SECTOR 
$\Longrightarrow$ Taylor \& Francis

Taylor \& Francis Group

http://taylorandfrancis.com 


\title{
HEALTH SECTOR LEADERSHIP TO COMBAT CLIMATE CHANGE
}

\author{
Alexander Thomas, Divya Alexander and Girdhar Gyani
}

\section{Introduction}

The health of a community is inextricably linked with the climate of the region. Climate change threatens human health by affecting the social and environmental determinants of health - clean air, safe drinking water, sufficient food and secure shelter (WHO Fact Sheet, 2018).

When climate change has an adverse effect on the health of a population, people seek healthcare services from hospitals and other healthcare providers. Hospitals themselves are known to produce significant amounts of greenhouse gas (GHG) emissions by running $24 \times 7$ on fossil fuel consumption and purchased energy sources, as well as a carbon-intensive supply chain, thereby contributing to climate change both directly and indirectly. They also generate one of the most diverse and difficult-to-manage waste streams, generated in close proximity to human beings and posing a serious threat to the safety of hospital staff, patients, their associates and the community at large. Healthcare firmly sits among the "large-emitting" sectors: in 2019, the global healthcare sector had a climate footprint of the equivalent of 2.0 gigatons of carbon dioxide $\left(\mathrm{GtCO}_{2} \mathrm{e}\right)$, equivalent to $4.4 \%$ of global net emissions (HCWH and Arup, 2019). Hence, it is crucial for hospitals and healthcare organizations to address these concerns.

The health sector is widely seen as a trusted and well-respected segment of society, as well as being a major employer in the economy. It is uniquely positioned in the community to lead by example in reducing its carbon footprint and raising awareness about climate change among the public. The sector, therefore, has both a duty and a window of opportunity to achieve climate neutrality, efficiency and cost reduction all at the same time (Neira, Bertollini et al., 2008). For this to be achieved, effective and transformative leadership is required at all levels. This chapter will look at health sector leadership in three contexts:

- The leadership of the healthcare sector in reversing global warming at a sectoral and policy level. 
- The thought leadership of healthcare institutions and providers in a community, mobilised for public advocacy to raise awareness on climate change.

- The leadership and engagement required within an individual healthcare facility to make it carbon-neutral, climate-resilient and more aware of population vulnerabilities with regard to climate change.

\section{Leadership of the health sector at the policy and sectoral level}

Globally, the voice of the healthcare sector is beginning to be heard. In a 2018 Call to Action on Climate and Health, organizations representing more than six million doctors, nurses and public health professionals and 17,000 hospitals in over 125 countries made commitments to accelerate climate change mitigation and adaptation (Global Climate and Health Forum, 2018). With its diverse supply chains and significant purchasing power, the sector has the ability to trigger climate mitigation initiatives across other sectors including plastics, chemicals, pharmaceuticals, clinical waste disposal, e-waste recycling, energy, food sourcing and preserving biodiversity.

In India, healthcare is a driving component of the economy, representing a little over $5 \%$ of the country's total expenditure (Department of Economic Affairs, Ministry of Finance, Govt. of India, 2020). The Indian healthcare sector is the fourth-largest employer in the country and runs $24 \times 7$ all year, giving it substantial economic clout. As the only sector with a duty of care as its mission, it also has significant ethical and political influence. With this size and influence in India, the healthcare sector must create the driving leadership required to slow and then reverse global warming.

The healthcare sector, already battling against the casualties of climate change on the frontlines, can lead by example in reducing its own carbon footprint. There are many examples of efficient and effective healthcare delivery with a reduced carbon footprint. If health systems across the country whole-heartedly embraced the changes required for decarbonising, the total impact of the investments would not only be massive but also rouse other sectors into realising the benefits of such an initiative. Policymakers should promote an inter-sectoral approach with the relevant government agencies to identify carbon reduction targets and set goals for GHG emissions.

Apart from reducing its own carbon footprint, strengthening its own health systems and advocating for change in climate change policy using health information, the health sector can address climate change at the policy level by collaborating with other health-determining authorities in sectors such as water, environment, agriculture and disaster management to include health in their climate adaptation plans (WHO Framework, 2017).

As a signatory to the Paris Agreement, India has committed to cut its emission intensity of GDP by 33-35\% of 2005 levels by 2030 (Aggarwal, 2015). As called for by the World Health Organization, healthcare should be integrated into climate policy, and climate policy should be integrated 
into health policy at all levels - state, national and international. In India, the government has instituted a National Expert Group on Climate Change and Human Health with experts from ministries, institutions and nongovernmental organizations. The National and State Climate Action Plans should develop a specific roadmap for the health sector. The national objectives for health, economic growth and environmental sustainability should complement each other, rather than stand as individual goals.

One way of achieving this is by using existing platforms to raise a collective voice for climate advocacy (Box 1.1). The Association of Healthcare

\section{Box 1.1 Case study}

\section{The health sector leading policy action: National Health Conclave 2019}

The Association of Healthcare Providers - India (AHPI) and the Centre for Environmental Health (CEH), a centre of excellence set up by the Public Health Foundation of India (PHFI), organised the National Health Conclave 2019, where participants deliberated on the health impacts of climate change, risk mitigation and adaptation strategies focused in the health sector (EH News Bureau, 2019). The conclave brought together health professionals, research groups, academic experts, policymakers, government officials, international agencies and civil society to deliberate on how to make the health sector climate-smart and climate-resilient, developing an agenda and roadmap for action.

The recommendations from the conclave were compiled in a white paper and presented to Dr. Harsh Vardhan, the Minister for Health and Family Welfare, Government of India, on 23 November 2019. One of the recommendations was to bring in the missing component of environmental health and associated health impacts into the medical curriculum. Subsequently, in December 2019, the National Centre of Disease Control (NCDC), an institute under the Ministry, constituted an Expert Committee on the Inclusion of Health Impacts of Climate Change in the Medical and Allied Health Curriculum. The Ministry also directed the National Board of Examinations (NBE) to implement the inclusion of health and climate change into the postgraduate medical curriculum. The NBE has already facilitated the introduction of this topic into selected postgraduate courses.

The complete white paper titled Climate Change and Health: Role of the Health Sector (AHPI and CEH, 2019) can be accessed at: https://www.ceh.org.in/publication/white-paper-on-climate-changeand-health-role-of-health-sector/ 
Providers - India (AHPI), for example, which represents the vast majority of healthcare providers in India, advocates with the government, regulatory bodies and other stakeholders on issues affecting the health sector, including climate change. The Health and Environmental Leadership Platform (HELP), of the Public Health Foundation of India (PHFI), which has over 7300 healthcare institutions (both government and private) is another platform to share best practices and showcase leadership in the adoption of climate-smart strategies.

\section{Leadership in the community}

If hospitals and healthcare centres in a community bring in clean, renewable energy and invest in conservation strategies, they become a model of leadership for the rest of the community. As major energy consumers and highly respected anchor institutions in their communities, health systems have a unique opportunity to bring about change and contribute to green local economies. By significantly ramping up investment in energy efficiency, clean energy generation and water conservation projects, health systems can initiate ideas and actions that will spread quickly into the wider economy. On seeing hospitals responding proactively to the threat of global warming, the immediate community can gain a sense of the urgency surrounding the issue.

Healthcare institutions and their employees are often considered "thought leaders" of their community. This means that any messaging around climate change that comes from health professionals contains an added value for the general public, policymakers, local leaders and media. Health sector voices can thus be used for advocacy and mass sensitisation to play a big role in policy changes. This impact must be mobilised for public advocacy to educate the general public about climate change, and in turn pressure governments to take urgent action to combat this crisis.

Health professionals need to understand how the destruction of ecosystems, decline in crop yields, and acidification of the oceans could reverse recent advances in global health, with special attention to vulnerable populations, especially those in low-income countries (Ramanathan and Haines, 2016). For all this to take place effectively, the healthcare community itself needs to be empowered through appropriate capacity-building initiatives. These initiatives should be promoted and facilitated by climate leaders from within the healthcare community (Box 1.2). During this process, it is important to involve government, academia and the private sector so that they can jointly review, identify and fill the capacity-building needs and gaps in order to achieve collective climate action.

The World Health Organization has exhorted the health community across the world to show strong leadership in tackling climate change (WHO Conference on Climate Change and Health, 2016). Healthcare providers need to be prepared on how to respond to climatic health 


\section{Box 1.2 Case study}

\section{Healthcare professionals leading change in their community: Doctors for clean air initiative}

The Lung Care Foundation, in partnership with Health Care Without Harm and Every Breath Matters, launched an initiative called Doctors for Clean Air in India, which is a collective of pulmonologists, paediatricians, cardiologists, surgeons, radiologists, etc., who are Clean Air Champions representing every state in India (HCWH Global, 2020). Having seen the alarming increase in poor health as an impact of air pollution, these medical professionals have come together to educate and advocate for better air quality in their communities. The movement describes doctors as "motivated motivators" because they see first-hand the effect of air pollution on the public, and have the ability to influence and educate their patients as they come from a position of strength.

emergencies and treat unfamiliar conditions, and sensitised in how climate change affects disease patterns and population vulnerabilities. The medical education curricula should also be modified to include climate change and its associated health impacts for healthcare students (medical, nursing, allied health and paramedical sciences).

\section{Leadership in the healthcare facility}

In any healthcare facility, effective leadership is vital for the provision and delivery of quality healthcare. The issue of leadership is even more critical for the development and maintenance of a green healthcare facility that promotes sustainability among its staff and community.

While there is no global definition or single standard of a green hospital, the ideal green hospital can be described as one that promotes public health by reducing its environmental impact and ultimately eliminating its contribution to the burden of disease. Its governance, strategy and operations all reflect the important connection between environment and human health (Karliner and Guenther, 2011). In a healthcare facility, actions and measures for carbon-neutrality and climate resilience need to be integrated into the organization's culture and placed within the context of the larger health system. This integration cannot take place without dedicated and sustained leadership and engagement.

In addition to the overarching benefit of reducing their environmental impact, leaders of healthcare facilities should consider all the other benefits of going green. The later chapters in this book describe measures and actions (in water use, waste treatment, sustainable procurement, energy use, 
indoor air quality, green housekeeping, building design, etc.) that increase operational efficiency to minimise wasteful processes and reduce GHG emissions right from the design stage. The positive impact of these measures and actions has long been established: they result in reduced staff stress and fatigue, and improved health outcomes, thereby improving patient safety (Ulrich et al., 2004). There is also a significant reduction in operational costs when hospitals practice measures to save water, electricity, gases and other consumables, eliminate unnecessary purchases, choose environmentally friendly chemicals and adopt environmentally friendly process. This brings in a financial benefit: environmentally sustainable hospitals can help to lower the cost of healthcare delivery. The leadership and top-level management of a hospital needs to be fully apprised of these benefits, which will motivate them to start implementing the measures in their facility.

Any major change initiative such as this needs the complete engagement and visible backing of the organizational leader in order to generate the desired result. Figure 1.1 lists out eight important actions that leaders must take for a successful transformation.

Climate action within a healthcare facility needs direct intervention by its leaders for two reasons: firstly, it affects the community at large as a key part of the organization's corporate social responsibility (CSR), and secondly, it impacts the hospital's bottom line. If climate action measures are categorised only as support functions, they may not be given the top priority. This is why those in charge of the healthcare facility need to lead this function from the front (Box 1.3).

A hospital leader should be adept at formulating SMART objectives, communicating through hierarchies, empowering teams, undertaking reviews and rewarding good results to keep employees motivated. Once the leadership has identified the areas of concern and developed the objectives to be achieved, the rest can be achieved by putting systems in place, and defining processes and responsibilities.

To make a healthcare facility green, a hospital leader should:

- Develop a green hospital vision and goals document laying out all the initiatives to be undertaken in each department with clearly defined roles.

- Empower the staff by conducting regular training programmes on climate change, green hospital education, organizational action and the role to be played by each employee.

- Encourage ownership by holding regular interventions such as annual and mid-term reviews, both top-down and bottom-up, to monitor and evaluate progress on the climate control vision and goals document, ensuring that standards for quality and timeliness are met.

- Adopt sustainable public procurement, which is described in detail in the chapter titled Sustainable Procurement in Healthcare. 


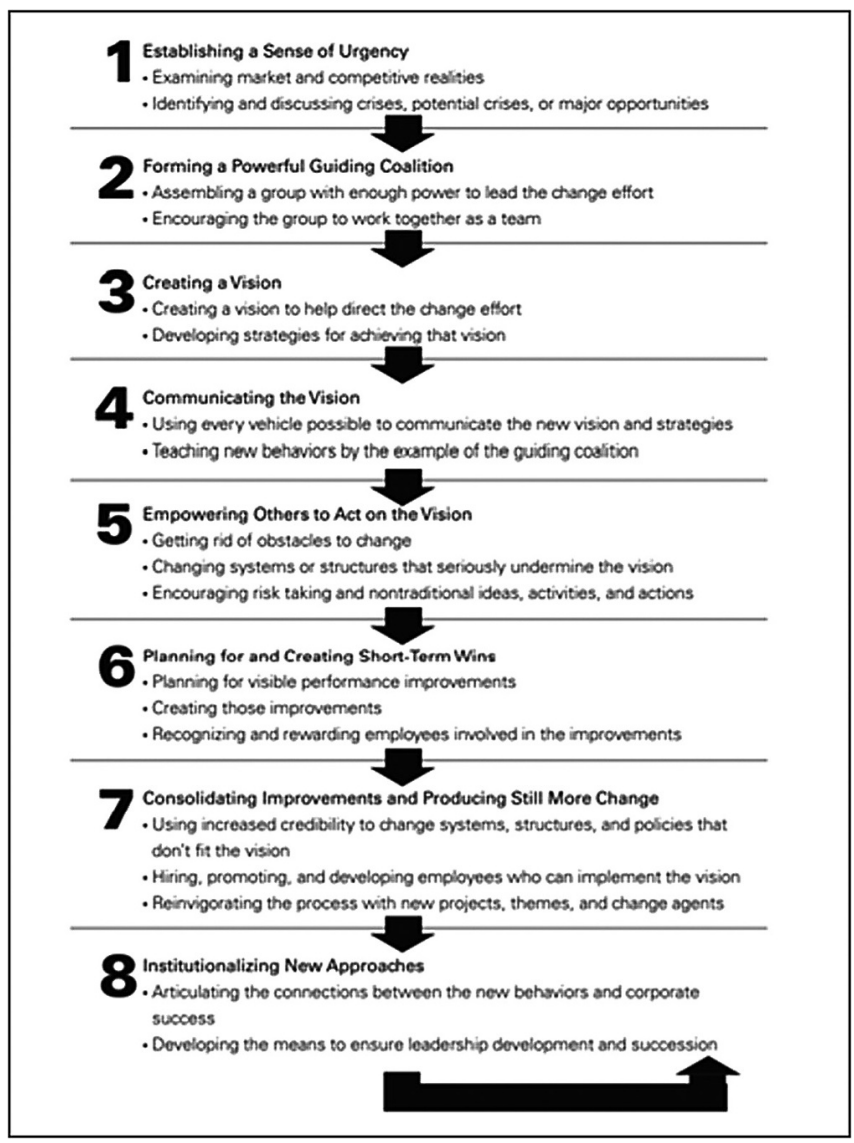

Figure 1.1 Eight steps to transforming your organization.

Source: Reprinted with permission from "Leading Change: Why Transformation Efforts Fail" by John P. Kotter. Harvard Business Review, Jan 2007. Copyright 2007 by Harvard Business Publishing; all rights reserved.

The key aspects that need to be specifically considered by hospital leaders while implementing climate action measures in their facility are summarised below:

1. Develop, document and implement a basic environment management system: identify significant aspects (such as air emissions, water discharges, chemical consumptions, etc.), set the objectives for each, and assign people to be in charge of achieving these objectives.

2. Designate a person with authority to coordinate the development and implementation of a roadmap through a shared decision-making process, so that all employees take collective ownership of the objectives. 


\section{Box 1.3 Case study}

\section{Leadership in individual health facilities: Bhagat Chandra Hospital, Dwarka, New Delhi}

The Bhagat Chandra Hospital implemented energy-saving measures right from the construction stage to make the hospital eco-friendly. In 2014, the hospital management conducted a cost-benefit analysis before exchanging all compact fluorescent lamps (CFLs) and bulbs in the hospital for light-emitting diodes (LED) lamps. The significant economic benefit of this initiative encouraged the management to introduce more lighting and solar energy initiatives to reduce the hospital's carbon footprint and invest in clean energy. In 2015, another cost-benefit analysis was done before installing $20 \mathrm{~kW}$ solar panels connected to the hospital grid, after which they saw a substantial reduction in the energy bill. In 2016, they added another $30 \mathrm{~kW}$ set of solar panels. From 2016 to 2018, the installed capacity has reduced $20-30 \%$ of the hospital's grid electricity consumption and conserved about 93,000 kilograms of $\mathrm{CO}_{2}$ emissions.

The director of the hospital and the staff of the hospital's electric department are directly involved in monitoring and evaluating the initiative. The staff who maintain the solar panels were trained by the vendor responsible for installing the solar panels. The hospital staff as a whole have been empowered to become advocates for reduced energy usage and cost savings.

Source: Global Green and Healthy Hospitals (GGHH) Case Studies, 2019.

The roadmap will be a long-term plan from which annual goals can be derived and acted upon.

3. Conduct a thorough environment assessment of the facility to identify areas and activities which are likely to have an impact on the environment: this should include relative-risk environmental impact assessment system to prioritise sustainable facility operations.

4. Define the criteria in each area of the facility, for example:

- Environment-friendly construction: this will include the selection of site for new buildings, and the evaluation and acceptance of environment-friendly material.

- Heating, Ventilation and Air-conditioning (HVAC) in the facility should protect the environment and not contaminate it in any way.

- Map the usage and conservation of water, energy and waste according to statutory norms, including actions for measurement, reduction, recycling and audits. 
5. The environment or climate control system must be integrated with the hospital's management system, including business review. If it is seen as a separate or stand-alone system, it will not deliver the desired objectives.

There have been initiatives in India to establish standards for greening health facilities. Hospitals and healthcare facilities can look to these for guidance on going green. Some of these initiatives are listed below:

- The Standard for Green and Clean Hospitals (AHPI, 2015) was established by the AHPI in 2015 and included the concepts of mitigation through resource efficiency and efficient waste management as well as measures for infection control.

- The Indian Green Building Council (IGBC) subsequently provided the IGBC Green Healthcare Facilities Rating system in 2016 which covered additional features of site selection, building material, resources and innovative design (IGBC, 2016).

- A more recent endeavour to evolve more comprehensive standards that cover all the above areas, in addition to procurement (including sustainable production and consumption), housekeeping and leadership, has been completed by the Health and Environment Leadership Platform (HELP) under the Centre for Chronic Disease Control (CCDC) and the Public Foundation of India. This will be evaluated as a complete accreditation standard for green healthcare facilities through various accreditation bodies including the National Accreditation Board for Hospitals and Healthcare Providers (NABH) and the Quality Accreditation Institute (QAI).

\section{Key takeaways}

- Climate change directly impacts the health of patients and communities. The interdependence between climate change and healthcare represents a unique opportunity for the healthcare sector to reduce climate change as well as combat it.

- The healthcare sector can be an example to other sectors by aggressively embracing climate-smart strategies, and using its collective voice for climate action at the policy level.

- The path taken by the healthcare facility affects the wellbeing of a community at large. Healthcare workers need to be sensitised about climate change and its associated impacts through the appropriate capacitybuilding interventions, so that they in turn can educate the community.

- When it comes to carbon-neutrality, going green and adopting climateresilient strategies, the leadership level of a healthcare facility needs to lead from the front. 


\section{References}

Aggarwal, M. (2015, October 3). India pledges $33-35 \%$ cut in carbon emission intensity by 2030. Livemint. https://www.livemint.com/Politics/ ZD2z2vwZktGNlzhrLujmyO/India-unveils-emission-targets-for-2030-in-UNclimate-submis.html

Association for Healthcare Providers, India. (2015). The standard for green and clean hospitals. https://www.scribd.com/document/357186023/AHPI-Standardfor-Green-Clean-Hospital

Association of Healthcare Providers India and the Centre for Environmental Health. (2019). Climate change and health: Role of the health sector [White Paper]. https://www.ceh.org.in/publication/white-paper-on-climate-changeand-health-role-of-health-sector

Department of Economic Affairs, Ministry of Finance, Govt. of India. (2020). Economic survey 2019-2020, volume II. Chapter 10: Social infrastructure, employment and human development, p. 275. https:/www.indiabudget.gov.in/ economicsurvey/doc/vol2chapter/echap10_vol2.pdf

EH News Bureau. (2019, April 1). National Health Conclave 2019 organised in Delhi.ExpressHealthcare.https:/www.expresshealthcare.in/news/national-health-conclave2019-organised-in-delhi/410386/

Global Climate and Health Forum. (2018). Call to action on climate and health. https://www.globalclimateandhealthforum.org/call-to-action

Global Green and Healthy Hospital Case Studies. (2019). A solar energy initiative to reduce cost and carbon emission: Bhagat Chandra Hospital, India. https:// www.hospitalesporlasaludambiental.net/wp-content/uploads/2018/05/SolarEnergy-Initiative-India.pdf

Healthcare Without Harm and Arup. (2019). Healthcare's climate footprint: How the bealth sector contributes to the global climate crisis and opportunities for action [Green Paper Number One], p. 4. https://noharm-global.org/sites/default/ files/documents/files/5961/HealthCaresClimateFootprint_092319.pdf

Healthcare Without Harm Global. (2020). Healthcare sector in India rises to the dual challenge of air pollution and climate change. https://noharm-global.org/ articles/news/global/health-care-sector-india-rises-dual-challenge-air-pollutionand-climate- 0

Indian Green Building Council. (2016). IGBC green healthcare facilities rating system. https://igbc.in/igbc/html_pdfs/IGBC_Green_Healthcare_Facilties.pdf

Karliner, J., \& Guenther, R. (2011). A comprehensive environmental health Agenda for hospitals and health systems around the world (p. 6). Global Green and Healthy Hospitals, HCWH. https:/www.hospitalesporlasaludambiental.net/wpcontent/uploads/2016/07/Global-Green-and-Healthy-Hospitals-Agenda.pdf

Kotter, J. P. (2007). Leading change: Why transformation efforts fail. Harvard Business Review.

Neira, M., Bertollini, R., Campbell-Lendrum, D., \& Heymann, D. L. (2008). The year 2008: A breakthrough year for health protection from climate change? American Journal of Preventive Medicine, 35(5), 424-425.

Ramanathan, V., \& Haines, A. (2016). Healthcare professionals must lead on climate change. $B M J, 355$, i5245. doi: $10.1136 /$ bmj.i5245 
Ulrich, R. S., Zimring, C., Quan, X., Joseph, A., \& Choudhary, R. (2004). The role of the physical environment in hospitals of the 21st century: A once in a lifetime opportunity. Robert Wood Johnson Foundation.

WHO Fact Sheet. (2018). Climate change and health. https://www.who.int/newsroom/fact-sheets/detail/climate-change-and-health

World Health Organization. (2016). Second global conference on bealth and climate: Conference conclusions and action agenda. https://www.who.int/globalchange/conference-actionagenda-final.pdf?ua $=1$

World Health Organization. (2017). Framework for action in building bealth systems resilience to climate change in South-East Asia Region 2017-2022, 6. https:// apps.who.int/iris/bitstream/handle/10665/258953/9789290226109-eng.pdf;jsess ionid=7FBDE165A6886DB03D51A2BEE26515AF ?sequence $=1$ 


\title{
THE ROLE OF HEALTH SYSTEMS IN THE INDIAN AND GLOBAL CONTEXT
}

\author{
Preeti Soni and Manish Pant
}

\section{Introduction}

Climate change leads to significant challenges for the health sector as it brings additional health concerns, demanding a concrete response from the sector. Climate change impacts health systems in various ways - infrastructural damage due to extreme flooding and precipitation, the rising burden of diseases, and disrupted supply chains leading to shortages of drugs and other medical commodities, to name a few. Health systems must be robust in order to meet increasing demands, and resilient so that they may survive the impacts of climate change. As healthcare providers and healthcare facilities are on the frontline, they need to be appropriately strengthened. In poorer countries, the already weak human resource structures and inadequate financing for health could stretch the health system to breaking point unless they undergo preparation to become climate-resilient. This chapter deals with:

1. The connections between climate change and health systems, providing an overview of the interlinkages and examining health systems using two case studies.

2. The need to address climate change and health issues in an integrated manner.

\section{The impact of health systems on climate change}

Health systems cause stress on the environment through their consumption of large quantities of energy, water and materials, and their generation of considerable emissions and waste. In the health sector, hospitals are the largest contributors to carbon emissions, accounting for 39\% of the sector's total in the United States (Chung and Meltzer, 2009). Hospitals need all-day use of medical devices for sterilisation, medical and laboratory services; and equipment for heating, cooling, computing, refrigeration, laundry and food services. Hospitals also generate greenhouse gas (GHG) emissions associated with waste disposal and transportation. Other contributors to the overall carbon footprint of health systems are the prescription drugs sector 
$(14 \%)$, physician and dental services (13\%), equipment $(12 \%)$ and nursing homecare services (8\%) (Chung and Meltzer, 2009).

Healthcare delivery has grown significantly over the years. Increasing incomes, ageing populations, epidemiological transition and advanced technologies have led to healthcare contributing to a higher percentage of national GDPs, ranging from $17 \%$ in the USA to $3.5 \%$ in India (World Bank data (n.d.)). Health systems of most countries, particularly in the developed world, have become large and energy-intensive in the twenty-first century. For example, in the United States, hospitals are the second-most energyintensive users after the food industry (USEIA, 2012). It is evident that as healthcare expenditures increase, the energy consumption in this sector will increase. Coupled with the contribution from consumption of other resources, materials and chemicals, this will add significantly to the carbon footprint.

\section{Health carbon footprint}

Estimating the health carbon footprint (HCF) is not easy or straightforward, as health services represent an outcome of the cumulative $\mathrm{CO}_{2}$ emissions of its proximal components. These include infrastructure, technology, transport, manufacturing processes, supply chains, etc. In absolute terms, India's health sector is the seventh-largest emitter of $\mathrm{CO}_{2}$ after China, USA, European Union (EU), Japan, Russia and Brazil, as seen in Table 2.1. However, its emission per capita and its $\mathrm{HCF}$ as a percentage of national CF is lower than others. In all these countries, domestic emissions contribute over $70 \%$ of the total HCF. The main sectors in healthcare contributing to $\mathrm{CO}_{2}$ emissions include sectors associated with heating, water and electricity consumption and those associated with transport. Approximately $10 \%$ of the $\mathrm{CO}_{2}$ emissions also directly occur in the pharmaceutical and chemical sectors (Pichler et al., 2019).

Table 2.1 HCF in absolute terms, per capita and as a percentage of overall CF

\begin{tabular}{lccc}
\hline Country & HCF $(M t)$ & HCF/Cap $(t)$ & Share of CF $(\%)$ \\
\hline USA & 547 & 1.72 & 7.6 \\
CHINA & 342 & 0.25 & 3.0 \\
EU & 249 & 0.49 & 4.7 \\
JAPAN & 103 & 0.81 & 6.4 \\
RUSSIA & 76 & 0.53 & 4.0 \\
BRAZIL & 44 & 0.21 & 4.4 \\
INDIA & 39 & 0.03 & 1.5 \\
\hline
\end{tabular}

Source: Pichler, Peter-Paul \& Jaccard, Ingram \& Weisz, Ulli \& Weisz, Helga. (2019). International comparison of healthcare carbon footprints. Environmental Research Letters. 14. doi: 10.1088/1748-9326/ab19e1. 


\section{Determinants of health carbon footprint}

HCF is a reflection of the national Carbon Footprint, as GHG emissions and expenditure (GDP) are linked. Three key determinants of HCF are:

1. Carbon intensity of the domestic system - defined as $\mathrm{CO}_{2}$ emission as a part of total final energy consumption (TFC)

2. Energy efficiency of national economy - defined as a ratio of TFC to GDP, and

3. National healthcare expenditure per capita

More specifically, the determinants of HCF include a myriad of services, processes and products that contribute to GHG emissions. The Greenhouse Gas Protocol Initiative is a global, multi-stakeholder partnership of governments and non-governmental organizations that has established accounting and reporting standards for accepted GHGs. These standards are used by various organizations including those in healthcare and classify emissions under three categories (called Scopes).

Scope 1 - Direct GHG Emissions from the activities of an organization that are under their control, including fuel combustion in owned and controlled gas boilers, fleet vehicles, furnaces, air-conditioning, etc.

Scope 2 - Indirect GHG Emissions from the generation of purchased electricity consumed by the health sector. These emissions physically occur at the facility where electricity is generated even though they drive energy consumptions at other locations.

Scope 3 - Other Indirect GHG Emissions from activities of the healthcare sector, occurring from sources that it does not own or control, including transportation, procurement and supply chains, waste management, etc. Scope 3 has the greatest share of emissions in the health sector (HCWH and Arup, 2019).

Figure 2.1 demonstrates the relationship between the three scopes and how they combine to produce GHGs.

Since its climate impact is so vast, the health sector can play a major role in mitigation efforts around the world. Health systems need to use efficient technologies and waste management techniques that can contribute to GHG mitigation efforts. The most efficient way to reduce HCF is by decoupling domestic energy systems from healthcare expenditure. For this to occur, national health systems should transition to greener options that reduce GHG emissions while maintaining a high quality of health services. This includes better designed and energy-efficient buildings that deploy low energy-consuming technologies for heating and cooling, and energy-saving medical equipment. In addition, global and national partnerships must be 


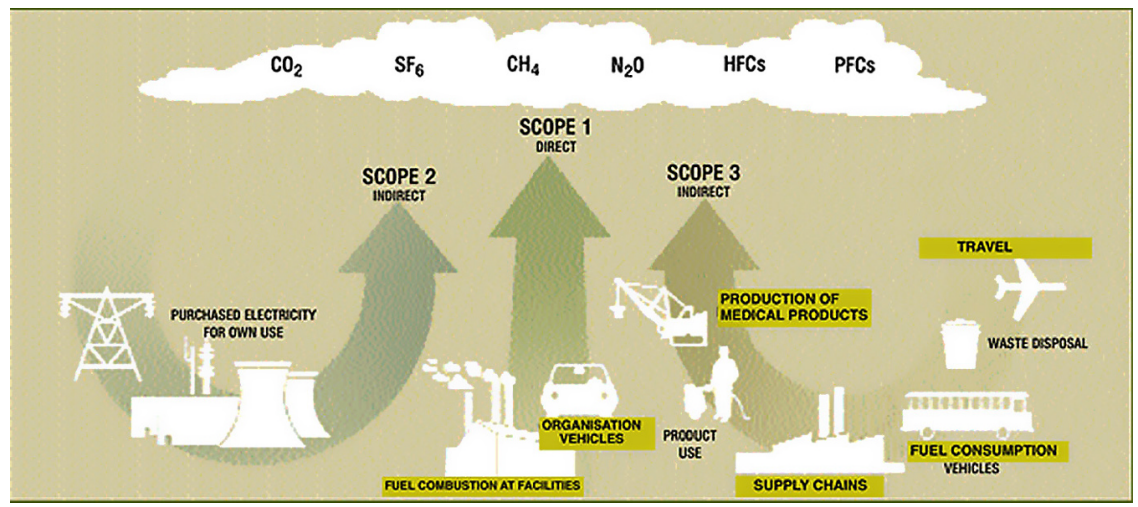

Figure 2.1 Emissions across a value chain in the health sector.

Source: World Resources Institute and World Business Council for Sustainable Development (2004). The greenhouse gas protocol: A corporate accounting and reporting standard. Revised edition. https://ghgprotocol.org/sites/default/files/standards/ghg-protocol-revised.pdf.

created in order to work towards developing a greener and sustainable production and supply chain for medical products.

\section{The impact of climate change on health systems}

Broadly speaking, climate change impacts the various aspects of a national health system through three overarching pathways that are interlinked:

- Direct impacts - these are caused by extreme weather events like floods or droughts which directly affect health infrastructure, workforce and patient load. Thus, increased mortality and morbidity can be expected due to heatwaves or fires.

- Indirect impacts - these are caused by the environment-mediated effects of climate change leading to higher humidity or variable rainfall such as air pollution, food, water-and vector-borne diseases, etc.

- Socioeconomic impacts - these arise due to disruptions in the social and economic networks of humans leading to reduced food production, large scale migrations, slowing economic growth, and increased poverty.

\section{How can the health sector address climate change?}

The health sector can play an essential part in mitigating the effects of global climate change by taking steps to limit its own significant climate footprint. The World Health Organization has identified seven key 
strategies for health systems to become more climate-friendly, while at the same time, saving money and generating significant health, economic and social co-benefits. Many of these strategies can be implemented by a shift in procurement policies and practices in the health systems and the health sector (PAHO, 2017). Indeed, several initiatives are being taken in hospitals and health systems around the world in this direction.

1. Energy efficiency - reduce hospital energy consumption and costs through efficiency and conservation measures.

2. Green building design - build hospitals that are responsive to local climate conditions and optimised for reduced energy and resource demands.

3. Alternative energy generation - produce and/or consume clean, renewable energy onsite to ensure reliable and resilient operations.

4. Transportation - use alternative fuels for hospital vehicle fleets; encourage walking and cycling to the facility; promote staff, patient and community use of public transport; site healthcare buildings to minimise the need for staff and patient transportation.

5. Food - provide sustainably grown local food for staff and patients.

6. Waste - reduce, re-use, recycle, compost; employ alternatives to waste incineration.

7. Water - conserve water; avoid bottled water when safe alternatives exist.

The collective problems of GHG emissions, local pollution and financial strain are experienced by most health systems around the world, though they may differ in some respects. There are clear co-benefits to mitigation efforts in health systems. The cost of not doing it, in terms of health alone, is enormous. The health sector's energy use and resulting toxic emissions undermine the health of the people they are meant to serve. The United States' health sector uses 73 billion kWh of conventional electricity, adding over US\$ 600 million per year in increased health costs, including asthma, respiratory illnesses and hospital emergency department visits (WHO and Healthcare Without Harm Discussion Draft, 2015). In addition, the United States health sector's 341 trillion BTUs (or British thermal units) for heat and cooling contributes to even more polluting emissions, adding billions of dollars more in healthcare bills and hundreds of billions more in indirect costs to society (WHO and Healthcare Without Harm Discussion Draft, 2015). A reduction in energy emissions that also contribute to air pollution will have a widespread impact on human health.

Moreover, the practices that contribute to climate change and undermine public health can also have a serious impact on the financial resources of health systems. For instance, health systems around the world face high energy prices. With the cost of fossil fuels set to increase further in the years to come, conservation, efficiency and alternative energy measures will carry long-term financial benefits (Box 2.1). 


\section{Box 2.1 Case study}

\section{Solar energy for low-emission and resilient health systems}

Using solar energy contributes to improved resilience of health systems as a consistent source of energy, as well as contributing to the reduction of GHG emissions by reducing electricity costs and decreasing the health system's carbon footprint. In India, Primary Health Centers (PHCs) and/or Community Health Centers (CHCs) are largely responsible for the last mile delivery of healthcare services at the village level. They form the base of the government-funded public health system. Many PHCs/CHCs face the challenge of inadequate infrastructure and unreliable or even absent power supply, affecting their capability to provide effective healthcare services. In remote areas, stand-alone diesel-powered generators are used for powering PHCs, backed up by kerosene lamps, candles or flashlights. Generators, however, are expensive to operate, as well as maintaining and adding to emissions.

Under a GEF-GOI-UNDP project, the strengthening of rural health systems has been supported by using solar energy. The project helped demonstrate the use of solar energy by installing solar rooftop photovoltaic systems in the facilities to improve their performance and cost-effectiveness. In the state of Jharkhand, nine battery-backed roof-top solar systems were installed on nine CHCs in rural areas as pilot projects to demonstrate the viability and benefits under the project. It was demonstrated that an average $6-10 \mathrm{kWp}$ solar plant with a storage system can help meet basic critical power requirements (regular power supply and running most critical medical equipment during power cuts). If replicated across all CHCs, it is estimated that $3.20 \mathrm{MW}$ of rooftop solar systems would be installed in the rural and peri-urban healthcare segment alone, which will generate $5045 \mathrm{MWh}$ per annum and abate $4844 \mathrm{tCO} 2$ every year, along with providing continuous power supply for effective healthcare service delivery.

Source: GOI-UNDP programme "Improving Healthcare through Reliable Supply of Solar Energy in selected CHCs across Jharkhand" under the Project on "Market Transformation and Removal of Barriers for Effective Implementation of the State Level Climate Change Action Plans." The project aims to reduce GHG emissions achieved through the implementation of renewable energy and energy efficiency solutions in the states of Jharkhand and Manipur. 


\section{The health sector's response to the effects of climate change: building resilient health systems}

Climate change threatens to undermine several gains made in the health sector which will negatively impact the achievement of Universal Health Coverage (UHC) and the United Nation's Sustainable Development Goals (SDG) overall. It can have unpredictable and complex effects on health systems; underprepared systems will find it very difficult to respond to climate shocks in the future. The World Health Organization defines climate resilience in the health sector as one that can "anticipate, respond to, cope with, recover from and adapt to climate-related shocks and stress, so as to bring sustained improvements in population health, despite an unstable climate" (WHO, 2015).

The WHO describes the essential elements of a resilient health system as laid out in Table 2.2 (WHO, 2015). These elements are interlinked across

Table 2.2 Framework for a climate-resilient health system

\begin{tabular}{|c|c|c|}
\hline $\begin{array}{l}\text { Building } \\
\text { Blocks }\end{array}$ & Components & Key Interventions \\
\hline $\begin{array}{l}\text { Leadership and } \\
\text { Governance }\end{array}$ & $\begin{array}{l}\text { Leadership and } \\
\text { Governance }\end{array}$ & $\begin{array}{l}\text { Policies that prioritise integrated } \\
\text { approaches to climate change and } \\
\text { healthcare management of } \\
\text { emergencies. }\end{array}$ \\
\hline $\begin{array}{l}\text { Human } \\
\text { Resources for } \\
\text { Health }\end{array}$ & Health Workforce & $\begin{array}{l}\text { Enhance skills and competencies of } \\
\text { health workforce on climate change } \\
\text { and health. Develop communication } \\
\text { plans to improve awareness of various } \\
\text { health professionals on climate change } \\
\text { risks. }\end{array}$ \\
\hline \multirow[t]{3}{*}{$\begin{array}{l}\text { Health } \\
\text { Information } \\
\text { Systems }\end{array}$} & $\begin{array}{l}\text { Vulnerability, } \\
\text { Capacity and } \\
\text { Adaptation } \\
\text { Assessment }\end{array}$ & $\begin{array}{l}\text { Understand the key population risks } \\
\text { around climate change, identify } \\
\text { weaknesses in health systems, conduct } \\
\text { investment case studies to identify } \\
\text { cost-effective programmes and the } \\
\text { interventions needed to respond. }\end{array}$ \\
\hline & $\begin{array}{l}\text { Integrated Risk } \\
\text { Monitoring and } \\
\text { Early Warning }\end{array}$ & $\begin{array}{l}\text { Scale up the use of hazard detection } \\
\text { tools including epidemiological } \\
\text { surveillance and remote-sensing } \\
\text { technologies creating an early-warning } \\
\text { system to better anticipate and } \\
\text { respond to health emergencies. }\end{array}$ \\
\hline & $\begin{array}{l}\text { Health and } \\
\text { Climate } \\
\text { Research }\end{array}$ & $\begin{array}{l}\text { Develop a national agenda using basic } \\
\text { and applied multidisciplinary research } \\
\text { with the aim of identifying climate } \\
\text { risks to health, identifying local } \\
\text { solutions and technologies, and } \\
\text { assessing broader determinants. }\end{array}$ \\
\hline
\end{tabular}

(Continued) 
Table 2.2 (Continued)

\begin{tabular}{|c|c|c|}
\hline $\begin{array}{l}\text { Building } \\
\text { Blocks }\end{array}$ & Components & Key Interventions \\
\hline $\begin{array}{l}\text { Essential } \\
\text { Medical } \\
\text { Products and } \\
\text { Technologies }\end{array}$ & $\begin{array}{l}\text { Climate Resilient } \\
\text { and Sustainable } \\
\text { Technologies } \\
\text { and } \\
\text { Infrastructure }\end{array}$ & $\begin{array}{l}\text { Strengthen health infrastructure through } \\
\text { building codes that address climate } \\
\text { risks such as heat waves, and } \\
\text { improving water and sanitation } \\
\text { facilities to tackle floods. In addition } \\
\text { to essential medicine and diagnostics, } \\
\text { health facilities should be equipped } \\
\text { with antidepressants and } \\
\text { antipsychotics to address the mental } \\
\text { health impact of climate change. }\end{array}$ \\
\hline \multirow[t]{3}{*}{ Service Delivery } & $\begin{array}{l}\text { Management of } \\
\text { the } \\
\text { Environmental } \\
\text { Determinants of } \\
\text { Health }\end{array}$ & $\begin{array}{l}\text { Develop multisector programming } \\
\text { across different ministries reflecting } \\
\text { climate change adaptation and } \\
\text { mitigation strategies. Health can be } \\
\text { integrated into other sectors such as } \\
\text { transport, environment, energy, } \\
\text { housing, etc. }\end{array}$ \\
\hline & $\begin{array}{l}\text { Climate-Informed } \\
\text { Health } \\
\text { Programmes }\end{array}$ & $\begin{array}{l}\text { Various health departments can } \\
\text { integrate climate-informed strategies } \\
\text { for a stronger response; these include } \\
\text { communicable and non-communicable } \\
\text { diseases, water and sanitation, } \\
\text { nutrition, mental health, emergency } \\
\text { healthcare, etc. }\end{array}$ \\
\hline & $\begin{array}{l}\text { Emergency } \\
\text { Preparedness } \\
\text { and } \\
\text { Management }\end{array}$ & $\begin{array}{l}\text { Strengthen national disaster response } \\
\text { systems including mechanisms for } \\
\text { public health emergencies like } \\
\text { outbreaks, extreme weather events } \\
\text { and community preparedness. }\end{array}$ \\
\hline Health Financing & $\begin{array}{l}\text { Climate and } \\
\text { Health } \\
\text { Financing }\end{array}$ & $\begin{array}{l}\text { Increased investments from governments } \\
\text { and external donors like GEF and } \\
\text { UNFCCC are needed to fund } \\
\text { interventions in the above system } \\
\text { elements. }\end{array}$ \\
\hline
\end{tabular}

Source: Adapted from WHO, 2015

six building blocks. Each component needs a set of interventions that contribute to the overall resilience of the health system. A critical component of this framework is increased healthcare financing - both public and private to cost for developing climate-friendly technologies, energy-efficient buildings and infrastructure, and a more skilled and competent health workforce that is knowledgeable on climate crises and efficient service delivery mechanisms. Box 2.2 demonstrates the important and effectiveness of skilled healthcare workers. 


\section{Box 2.2 Case study}

\section{Skilled human resources build resilient health systems}

The Government of India has established a digital platform to manage the vaccine supply chain across all health facilities in the country, called the Electronic Vaccine Intelligence Network (eVIN). A well-trained cadre of health staff is placed in every district, skilled in programme management and the use of digital technology at the last mile. Over 50,000 health workers are trained and retrained on the effective supply chain management of vaccines and where possible, other medical commodities as well. Over a period of time, eVIN has helped streamline and optimise vaccine stock management from national to subdistrict levels. It has also empowered the health workers to dedicate themselves fully to ensure immunisation service delivery at all times.

These digitally skilled workers have played a major role in India's successful rollout of Covid vaccines through the implementation of the CoWIN platform across the country (https://www.cowin.gov.in/). This health workforce has also played a crucial role during monsoon season in ensuring that all vaccine stocks are kept safe in the event of health facilities getting flooded. Using the digital platform, they have been able to plan in advance for the redistribution of vaccine stock in a systematic manner to facilities in non-flooded areas, and to ensure some level of continuity on service delivery when possible. Digitally skilled frontline workers can also serve as building blocks of real-time surveillance for disease outbreaks during disasters, leading to a better and nuanced response by authorities.

Strengthening health systems to address the additional health risks of climate change is critical in order to reduce current and future health burdens. Reducing and managing health risks over the next few decades will require modifying health systems to prepare for, cope with, and recover from the health consequences of climate variability and change (adaptation). Adaptation will be required across the century, with the extent of mitigation being a key determinant of health systems' ability to manage risks projected later in the century (Smith et al., 2014). The most effective vulnerability reduction measures for the health sector in the short term are programmes that implement and improve basic public health measures, such as the provision of clean water and sanitation, securing essential healthcare including vaccination and child health services, increasing capacity for disaster preparedness and response, and alleviating poverty (IPCC, 2014).

Health systems will need to implement measures to help them adapt and cope with the new challenges and risks. Some key steps in this direction should include: 
- Advancing research to enhance understanding of the linkages between climate change and health systems.

- Developing climate risk and vulnerability assessments to identify the health impacts of climate change, as they include both epidemiological and climate data. These assessments can help identify weaknesses in health systems and define strategic response interventions to strengthen the systems.

- Developing and deploying early warning systems to monitor and provide information on the impacts of climate change on the transmission of vector-borne and other diseases.

- Developing emergency preparedness and management plans to ensure that health systems can function during extreme events and to prepare them to cope with economic and social disruption (such as pandemics, migration, food shortages, etc.) from climate change. This can reduce risks, save lives, and minimise the impact of climate emergencies in communities.

- Developing tools in health programming and operations that include current climate variability as well as future projected climate change; these tools are crucial to make health programmes climate-resilient.

Climate change-related actions can affect current and future population health. Overall, the health sector will have to provide leadership in advocating for climate-friendly and resilient health systems in policies, and promoting equity and good governance in national and regional policies. This would also imply the need for

- Strong information systems that collect timely and relevant data on climate-vulnerable populations and regions, and the incidence and geographic range of climate-sensitive health outcomes.

- Human and financial resources to protect individuals and communities from the health impacts of climate change by providing training and capacity building for professionals and the public to support efforts to reduce health risks and providing effective service delivery during crises and disasters.

\section{Key takeaways}

- Health systems cause stress on the environment and add to GHG emissions, resulting in most health systems, nationally and globally, having a high health carbon footprint.

- The health sector can play a major role in mitigation efforts around the world by using efficient technologies and waste management techniques.

- Climate change significantly affects current and future demands and the effectiveness of the health systems. The impacts may be direct, indirect or socio-economic. 
- Healthcare providers and healthcare facilities will be on the frontline and need to be capacitated in dealing with the impacts of climate change.

- There are a number of strategies to strengthen the resilience of health systems and reduce their climate footprints, of which two have been demonstrated using case studies.

\section{References}

Chung, J. W., \& Meltzer, D. O. (2009). Estimate of the carbon footprint of the US health care sector. Journal of the American Medical Association, 302(18), (1970-1972).

Health Care Without Harm \& Arup. (2019). Health care's climate footprint. Green paper number one. https://noharm-global.org/

IPCC. (2014). Summary for policymakers. In Climate Change 2014: Impacts, Adaptation, and Vulnerability. Part A: Global and Sectoral Aspects. Contribution of Working Group II to the Fifth Assessment Report of the Intergovernmental Panel on Climate Change.

PAHO. (2017). Climate change and health (leading by example: Transforming health systems to tackle climate change). https://www.paho.org/salud-en-las-americas2017/mhp-climate.html

Pichler, P.-P., Jaccard, I. S., Weisz, U., \& Weisz, H. (2019). International comparison of health care carbon footprints. Environmental Research Letters, 14(6), 0640004.

Smith, K. R., Woodward, A., Campbell-Lendrum, D., Chadee, D. D., Honda, Y., Liu, Q.,... \& Sauerborn, R. (2014). Human health: Impacts, adaptation, and cobenefits. In C. B. Field, V. R. Barros, D. J. Dokken, K. J. Mach, M. D. Mastrandrea, \& others (Eds.), Climate change 2014: Impacts, adaptation, and vulnerability; Part A: Global and sectoral aspects. Contribution of working group II to the fifth assessment report of the intergovernmental panel on climate change, chapter 11 (pp. 709-754). Cambridge University Press.

World Resources Institute and World Business Council for Sustainable Development. (2004). The greenhouse gas protocol. A corporate accounting and reporting standard. Revised edition. https://ghgprotocol.org/sites/default/files/standards/ghgprotocol-revised.pdf.0

The World Bank. (n.d.) Retrieved on 20 July 2020. https://data.worldbank.org/

U.S. Energy Information Administration. (2012). Commercial buildings energy consumption survey. https://www.eia.gov/consumption/commercial/reports/2012/ energyusage/

WHO. (2015). Operational framework for building climate resilient health systems. W.H.O.

WHO and Healthcare Without Harm Discussion Draft. (2015). Healthy hospitals, healthy planet, healthy people, p. 5. https://www.who.int/docs/default-source/ climate-change/healthy-hospitals-healthy-planet-healthy-people. pdf?sfvrsn=8b337cee_1 


\title{
STRENGTHENING HEALTHCARE DELIVERY SYSTEMS IN LOW- INCOME COUNTRIES
}

\author{
Zerin Osho and Jagjeet Sareen
}

\section{Introduction}

As more and more African countries report spikes in their respective COVID-19 counts, there is a substantial increase in the number of reported cases from areas beyond capital cities (WHO, April 2020b). With over 8,500 new cases between 6 and 7 December 2020, Africa has a cumulative COVID-19 patient count of more than 1.5 million to date (WHO, December 2020c). The World Health Organization (WHO) estimates that if containment measures fail, over 190,000 people could die of coronavirus in Africa (WHO, May 2020a). Access to a reliable electricity supply and a cold chain infrastructure in healthcare centres is critical for marshalling an effective response to tackle COVID-19. However, roughly $70 \%$ of SSA health facilities do not have access to reliable electricity, and one in four health facilities have no electricity at all (Adair-Rohani, Heather et al., 2013). On the other hand, 1.5 million children are lost to vaccine-preventable diseases each year due to lack of a reliable vaccine cold chain network (SEforAll, 2020a).

The deployment of off-grid solar energy projects to power primary healthcare centres (PHCs) and the use of solar-powered cold chains for safe vaccine storage and last-mile distribution can help in building an effective healthcare delivery mechanism across low-income countries. At the International Solar Alliance (ISA), global efforts are being galvanised through the ISA Cares Initiative to provide financial and technical support to low-income countries for solarising PHCs and for the development of solar-powered cold chains. This would scale up the capacity of PHCs in LDCs to respond to the pandemic effectively. This chapter will:

1. Examine the current state of healthcare infrastructure across lowincome countries.

2. Explore how healthcare delivery in these countries can be strengthened despite having no access to reliable electricity.

3. Consider the solarisation of health centres to significantly reduce COVID-19 fatalities and ease the patient load on provincial health centres. 


\section{Current state of healthcare infrastructure across low- income countries}

Reliable electricity ensures that basic sustenance measures like fresh water, air conditioning, vaccine and blood refrigerators, lights and cell phone chargers are available, and that first responders to COVID-19 have adequate lighting to see patients and to safely use personal protective equipment such as masks, gloves and gowns. Despite significant steps, approximately 600 million people lack access to electricity in sub-Saharan Africa alone (SEforAll, 2019). On average, one in four health facilities in the SSA region has no access to electricity (World Bank and WHO, 2015). A study suggests that only $28 \%$ of health facilities and $34 \%$ of hospitals had access to "reliable" electricity (reliable in this context meaning without prolonged interruption in any given week) (ibid.). In the absence of grid connectivity, or a reliable source of electricity, the use of diesel generators to meet energy demands in PHCs is a common practice (World Bank, 2020). Combustion of diesel causes $P M_{2.5}$ emissions that cause public health crises such as cardiovascular diseases, cancers, respiratory illnesses and even premature deaths (CARB, 2015). Research has confirmed that $P M_{2.5}$ emissions increase the rate of mortality in COVID-19 patients (Pozzer et al., 2020). Estimates suggest that operating and maintaining diesel generators can cost up to $20 \%$ of the operating expense of PHCs that are already cash-crunched due to COVID-19 (World Bank, 2020). Diesel is also a source of black carbon emissions that are categorised as Short-Lived Climate Pollutants (SLCPs) (WHO, 2015a). Increased reliance on diesel may put PHCs in the difficult situation of having to decide between continuous electricity service and purchases of necessary medical supplies. Mitigation of SLCP emissions can reduce global warming by $0.4-0.5^{\circ} \mathrm{C}$ by $2040-2050$ (World Bank, 2013). WHO estimates that SLCP emissions have significantly contributed to more than 7 million premature air pollution-linked deaths annually (WHO, 2015a).

Without reliable energy, even the most fundamental medical services cannot be provided. For instance, in Tanzania, only $28 \%$ of immunisation health facilities have access to grid electricity (WHO and UNICEF, 2017). Desperate attempts to use fossil fuels to power health centres and vaccine refrigerators for a prolonged period cause localised air pollution, and increases fatality in COVID-19 patients (Pozzer et al., 2020). Each year, approximately 31 million children suffer from vaccine-preventable diseases, and more than a half million die due to lack of access to vaccines in the SSA region (WHO, 2019). Most vaccines need to be transported and stored between 2 and $8^{\circ} \mathrm{C}$ (WHO, 2015b). Cold chain disruptions cause the wastage of approximately $50 \%$ of freeze-dried, and $25 \%$ of liquid vaccines annually (SEforALL, 2020a). Lack of a reliable energy supply and access to cooling has historically forced health providers in SSA countries to use "absorption refrigerators" (Path and WHO, 2013). Powered by kerosene or 
gas, absorption refrigerators cause high localised pollution, are expensive to operate and maintain, and run the high risk of exposing vaccines to freezing temperatures (WHO and UNICEF, 2017). Accidental freezing of vaccines can be fatal. In 2017, improper storage of measles vaccines in South Sudan claimed the lives of 15 children (Rao, 2020). According to a study in 2014, GAVI reported that roughly $90 \%$ of health facilities lacked adequate cold chain equipment in GAVI-eligible countries (GAVI, 2020).

As pharmaceutical giants such as Pfizer, Moderna and University of Oxford/Astra Zeneca applied for emergency use authorisation of their COVID-19 vaccines, national governments and global health organizations prepared to develop an extensive vaccine delivery network. Though some of the vaccines required ultra-low temperatures, most could be stored, transported and administered at $2-8^{\circ} \mathrm{C}$ between 5 and 10 days (SEforALL, $2020 \mathrm{~b}$ ). The success of immunisation efforts depends in large part on maintaining cold chains.

\section{Solar energy as a force multiplier for an effective COVID-19 response}

Access to reliable energy cannot remedy the structural weaknesses of healthcare systems in low-income countries alone, but it is a key component in the overall delivery of healthcare. The use of off-grid solar energy to power PHCs and vaccine refrigerators can help in marshalling an effective response to the COVID-19 pandemic whilst achieving other developmental co-benefits.

Solar energy is reliable and affordable. With technological progress, the overall costs of solar off-grid solutions have reduced significantly (IRENA, 2016). Distributed solar power projects have been the backbone of electrification initiatives in low-income countries over the past decade (GOGLA and World Bank, 2020). The off-grid solar market currently serves 420 million people, most of whom reside in the SSA region (ibid.). Use of distributed solar, as a stand-alone solution in smaller health facilities, or as a hybrid solution for larger hospitals, can deliver more reliable, sustainable and affordable power for health facilities (Box 3.1). For small and mediumsized PHCs, a hybrid solar-diesel system can achieve lifetime savings on an order of $75-80 \%$ while ensuring a reliable power supply (World Bank and WHO, 2015). Solar energy as a reliable and affordable source of power is gaining traction. In Uganda, for example, approximately $15 \%$ of hospitals and $2 \%$ of other health facilities use the solar and grid hybrid model.

Off-grid solar can power PHCs to deliver life-saving healthcare while achieving Sustainable Development Goals. Off-grid solar solutions offer a clean, cost-effective, and reliable option for the electrification of PHCs while achieving the following Sustainable Development Goals (SDGs) SDG 1: No poverty; SDG 3: Good health and well-being; SDG 5: Gender equality; SDG 6: Clean water and Sanitation; SDG 7: Affordable and clean 


\section{Box 3.1 Case study \\ Solar energy powers hospitals in Afghanistan to save lives of COVID-19 patients}

Prolonged power outages in Herat, Afghanistan, risked the lives of COVID-19 patients that were dependent on medical appliances such as electric ventilators and other respiratory devices for breathing. Herat recorded the second-highest number of COVID-19 cases after the state capital, Kabul. As the pandemic hit the province, Afghanistan's national power utility company Da Afghanistan Breshna Sherkat (DABS) installed solar panels across ten hospitals in Herat to provide emergency power. The project was financed by the Herat Electrification Project in June 2020 and was capable of generating $75 \mathrm{~kW}$ of reliable energy to power operation theatres, critical COVID-19 equipment such as ventilators, defibrillators, and other patient monitoring devices. In Herat's Shaidayi Children's hospital, 36 solar panels were installed to generate $10 \mathrm{~kW}$ of energy to power the Intensive Care Unit (ICU) and 14 ventilators and lights to manage critical patients suffering from coronavirus. Similarly, 34 solar panels were installed in Obei Hospital that provide $10 \mathrm{~kW}$ of energy to power all the departments of the hospital.

Source: World Bank (2020)

energy; SDG 10: Reduced inequalities; SDG 11: Sustainable cities and communities; and SDG 13: Climate action.

Solar-powered cold chains can belp develop an equitable COVID-19 vaccine delivery mechanism. Access to reliable energy is critical for the elimination of vaccine-preventable diseases and to combat COVID-19. For protection against COVID-19, approximately 4.7-5.5 billion people, which represent $60-70 \%$ of the global population, would have to be inoculated through a vaccine to achieve herd immunity (WHO, 2020d). Currently, due to the lack of access to reliable energy at PHCs in low-income countries, vaccine refrigerators are powered through kerosene-based absorption refrigerators (WHO and UNICEF, 2017). Absorption refrigerators often expose vaccines to freezing temperatures, making them unstable and fatal for use (Rao, 2020). Furthermore, supplies or kerosene to power these refrigerators is subject to disruptions, making them unreliable for delivery of COVID-19 vaccines. The adoption of solar-powered direct drive (SDD) refrigerators can help build an effective vaccine delivery mechanism while mitigating greenhouse gas (GHG) emissions (Box 3.2). Even in terms of the overall annualised cost of ownership, SDDs are cheaper than kerosenebased vaccine refrigerators (WHO and UNICEF, 2017). 


\section{Box 3.2 Case study}

\section{Senegal uses solar powered vaccine refrigerators}

Prolonged power outages and failures of backup generators in Senegal have risked the safety and stability of vaccines. 15 SunDanzer solar refrigerators were installed at PHCs in Podor, Pete, and Richard Toll districts in the northern part of the country. It was observed that SunDanzer designed a unique solar installation - with the two solar panels facing East and West, respectively. This design helped the facility generate power earlier than other comparable facilities, which did not generate power until late in the evening. It was reported that all refrigerators performed reliably for over a year with no serious technical glitches. The remote temperature monitoring data revealed that all refrigerators cooled consistently even when they were in regular use and being opened frequently for vaccine storage and removal. On analysis of the combined data, it was found that the refrigerators maintained their target temperature range of $2-8^{\circ} \mathrm{C}$ nearly $99 \%$ of the time.

Source: WHO, PATH and Optimize (2013)

ISA Cares Initiative proposes to solarise primary healthcare centres in Africa to enable round the clock quality healthcare services. The International Solar Alliance (ISA) launched its ISA Cares Initiative at the Third ISA Assembly in response to the humanitarian crisis caused by COVID-19. Through this initiative, ISA aims to solarise one PHC in every district of 42 Least Developed Countries (LDCs) and Small-Island Developing States (SIDS) member countries from the African region. This initiative will solarise in total, $1,260^{1}$ PHCs across the targeted member countries of ISA. The initiative will help PHCs to deliver basic medical procedures to reduce patient load on provincial health centres while expanding diagnostic and testing facilities. Access to energy and lighting by solarisation of PHCs will allow for longer operational hours in a day and help health facilities run sterilisation and refrigeration appliances for better prevention. To implement this initiative and expand its coverage, ISA will raise USD 150 million jointly with UNAIDS and Health Innovation Exchange (HIX). To further reduce the overall cost of the initiative, maintain quality standards and build localised capacity, ISA will aggregate the overall demand from LDC and SIDS countries, empanel experts and enterprises to ensure quality control, and host regular training programmes to build local capacity for adequate operation and maintenance. 


\section{Key takeaways}

- Recovery from COVID-19 has given the world an unprecedented opportunity to build back better.

- Improvement in energy infrastructure to better serve health facilities can strengthen the global response to COVID-19 while achieving developmental co-benefits.

- The elimination of coronavirus is a mammoth task for which access to energy is a quintessential requirement.

- Solarisation of health centres can significantly reduce COVID-19 fatalities and ease the patient load on provincial health centres. Similarly, solar-powered cold chains are adept at delivering vaccines safely to rural communities in remote areas.

- The implementation and expansion of multilateral efforts such as ISA Cares initiative can help in building climate-resilient energy infrastructure to serve PHCs in low-income countries while achieving SDG 7.

\section{Note}

1 Assuming each LDC and SIDS country has 30 districts on average.

\section{References}

Adair-Rohani, H., Zukor, K., Bonjour, S., Wilburn, S., Kuesel, A.C., \& Hebert, R., Fletcher, E.R. (2013). Limited electricity access in health facilities of sub-Saharan Africa: a systematic review of data on electricity access, sources, and reliability. Global Health Science and Practice, 14;1(2):249-261. doi: 10.9745/GHSP-D13-00037. PMID: 25276537; PMCID: PMC4168575.

CARB. (2015). Summary: Diesel particulate matter health impacts. California Air Resources Board. https://ww2.arb.ca.gov/resources/summary-diesel-particulatematter-health-impacts

GAVI. (2020). Cold chain equipment optimisation platform. Gavi the Vaccine Alliance. https://www.gavi.org/sites/default/files/publications/Cold-chain-equipmenttechnology-guide.pdf

GOGLA and World Bank. (2020). Off-grid solar market trends report 2020. Lighting Global, World Bank Group. https://africa-energy-portal.org/sites/ default/files/2020-02/14005VIV_OFF-GRID-SOLAR-REPORT-V13-Exec-SumAW4vis.pdf

IRENA. (2016). Solar PV in Africa: Costs and markets. International Renewable Energy Agency. https://www.irena.org/publications/2016/Sep/Solar-PV-in-AfricaCosts-and-Markets

PATH and WHO. (2013). Direct-drive solar vaccine refrigerators - A new choice for vaccine storage. Optimise Evidence Brief. https://www.who.int/immunization/programmes_systems/supply_chain/optimize/direct_drive_solar_vaccine_refrigerator.pdf

Pozzer, A., Dominici, F., Haines, A., Witt, C., Münzel, T., Lelieveld, J. (2020). Regional and global contributions of air pollution to risk of death from COVID-19. Cardiovascular Research, 116(14), 2247-2253. doi: 10.1093/cvr/ cvaa 288 
Rao, R. (2020, April 21). Why a strong cold chain is more critical than ever to defeat COVID-19. Devex Global Views. https://www.devex.com/news/sponsored/ opinion-why-a-strong-cold-chain-is-more-critical-than-ever-to-defeat-covid19-97026

Sustainable Energy for All (SEforALL). (2019). Electricity for All in Africa. SEforALL.

Sustainable Energy for All (SEforALL). (2020a). Chilling prospects: Providing Sustainable Energy for All. SEforAll. https:/www.seforall.org/sites/default/files/ SEforALL_CoolingForAll-Report.pdf

Sustainable Energy for All (SEforALL). (2020b). Cooling for all: The role of cold chain in delivering a COVID-19 vaccine. SEforALL, University of Birmingham, Nexleaf Analytics, the International Institute for Energy Conservation, and the Basel Agency for Sustainable Energy. https://www.seforall.org/system/files/202011/Medical-Cold-Chains-Briefing-Note-SEforALL.pdf

WHO. (2015a). Reducing global health risks through mitigation of short-lived climate pollutants: Scoping report for policy makers. World Health Organisation. https://apps.who.int/iris/handle/10665/189524

WHO. (2015b). The vaccine cold chain. WHO. https://www.who.int/immunization/ documents/IIP2015_Module2.pdf

WHO. (2019). Experts caution against stagnation of immunisation coverage in Africa. WHO Regional Office for Africa. https:/www.afro.who.int/news/ experts-caution-against-stagnation-immunization-coverage-africa

WHO. (2020a, May). New WHO estimate: Up to 190,000 people could die of COVID-19 in Africa if not controlled. WHO Regional Office for Africa. https://www.afro.who.int/news/new-who-estimates-190-000-people-could-diecovid-19-africa-if-not-controlled

WHO. (2020b, April). COVID-19 pandemic expands reach in Africa. WHO Regional Office for Africa. https://www.afro.who.int/news/covid-19-pandemicexpands-reach-africa

WHO. (2020c, December). WHO Coronavirus COVID-19 Dashboard. WHO Health Emergency Dashboard. https://covid19.who.int/

WHO. (2020d). Science in 5, Episode \#1: Herd immunity: A conversation with Dr. Souwmya Swaminathan. WHO Media Resources. https://www.who.int/emergencies/diseases/novel-coronavirus-2019/media-resources/science-in-5/episode-1

WHO and UNICEF. (2017). Solar direct drive vaccine refrigerators and freezers. WHO and UNICEF Evidence Brief. https://apps.who.int/iris/bitstream/handle/10665/254715/WHO-IVB-17.01-eng.pdf;sequence=1

World Bank. (2013). Integration of short-lived climate pollutants in World Bank activities. The World Bank. https://documents1.worldbank.org/curated/ en/972571468326204977/pdf/804810WP0G80Re00Box0379805B00OUO090. pdf

World Bank. (2020). COVID-19 emergency power supply response. World Bank Strategy Note - Draft for Consultation. https:/www.seforall.org/system/files/ 2020-04/COVID19-emergency\%20power-supply\%20strategy-note.pdf

World Bank and WHO. (2015). Access to modern energy services for health facilities in resource-constrained settings: A review of status, significance, challenges and measurement. World Health Organisation. 


\title{
THE CLIMATE CHANGE POLICY \\ FRAMEWORK AND ALLIED PROGRAMS IN INDIA
}

\author{
Rameshwar Sorokhaibam, Shikha Vardhan and \\ Aakash Shrivastava
}

\section{Introduction}

Climate change has become a reality and is widely considered to be one of the biggest threats to humankind today. To address this threat, international cooperation is essential; all nations need to contribute to the global effort in order to significantly mitigate the effects of climate change. This chapter will provide

1. A brief overview of the initiatives and policy frameworks to address the threat of climate change both at the global and national levels.

2. An outline of the strategies proposed under India's National Program on Climate Change and Human Health (NPCCHH).

3. An exploration of areas for coordination and cooperation with allied programmes related to climate change and health.

\section{Climate change initiatives and policy frameworks at the global and national level}

The Inter-governmental Panel on Climate Change (IPCC), an international body created in 1988 for the purpose of assessing climate change, released its first scientific assessment report in 1990 (FAR, 1990). The report underlined the importance of international cooperation to tackle climate change and its consequences, and played a role in the creation of the United Nations Framework Convention on Climate Change (UNFCCC). The UNFCCC was adopted in 1992 and came into force on 21 March 1994 after receiving its fiftieth ratification. There are currently 197 Parties to the Convention, of which India is a part (UNFCCC, 2021). The UNFCCC is the parent treaty to the 2015 Paris Agreement and the 1997 Kyoto Protocol in which the Parties to the Convention have determined their obligations on Nationally Determined Contributions (NDCs) to limit their carbon footprint in the coming years (UNFCCC, 2020). 
Its long-term objective is 'to stabilise atmospheric greenhouse gas concentrations at a level that would prevent dangerous anthropogenic interference with the climate system in a time frame which allows ecosystems to adapt naturally and enable sustainable development.' In relation to climate change and health, there is an operational framework developed for climateresilient health systems under the World Health Organization (WHO), whose purpose is to provide guidance to health systems and public health programming on how to increase their capacity for protecting health in an unstable and changing climate.

To fulfil India's commitment to the UNFCCC (Article 12), an Initial National Communication was formed in 2004 (UNFCCC, 2004), leading to the formation of the high-level Prime Minister's Council on Climate Change (PMCCC) on 5 June 2007 (PMO Archives, 2007). India's Climate Change policy comes under the PMCCC to address issues arising from climate change in the diverse geo-climatic regions in the country. The policy advises on proactive measures to be taken, and facilitates inter-ministerial coordination and guides for the assessment, adaptation and mitigation of climate change in the country. The policy is reflected in the National Action Plan on Climate Change (NAPCC) of the Ministry of Environment, Forest and Climate Change (MoEFCC) that was released in 2008 (Pandve, 2009). India's Intended Nationally Determined Commitments (INDC) were submitted to the UNFCCC in 2015.

The NAPCC initially enshrined eight national missions (Solar Energy, Enhanced Energy Efficiency, Sustainable Habitat, Water, Sustaining the Himalayan Eco-system, Green India, Sustainable Agriculture and Strategic Knowledge for Climate Change) that represent multipronged, long-term and integrated strategies for achieving key goals in the context of climate change in the country. The PMCCC was reconstituted in 2015 and reviewed progress of the eight national missions proposed under the NAPCC of MoEFCC. Since health consequences were not addressed in any of the eight missions, the PMCCC proposed to expand missions under NAPCC and suggested four new missions, of which one was Health. Although MoEFCC is the overall nodal ministry for climate change in the country, the Ministry of Health and Family Welfare (MoHFW) is the nodal Ministry for the Health Mission on Climate Change. See Figure 4.1 for the global, national, state and district level bodies for climate change action in the health sector.

\section{National Program on Climate Change and Human Health}

Under the MoHFW, the National Centre for Disease Control (NCDC), New Delhi, is designated as a technical nodal agency for implementing the Health Mission on Climate Change in the country. The NCDC drafted the National Action Plan for Climate Change and Human Health (NAPCCHH) in 2018; this was approved by the MoHFW in February 2019. The action plan lays 


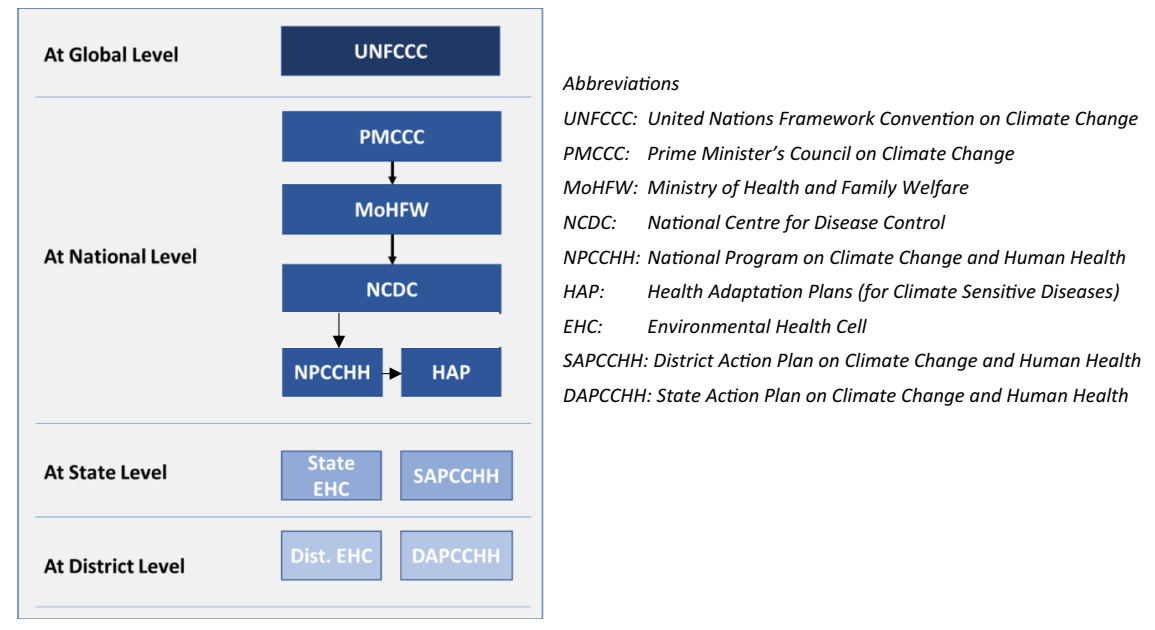

Figure 4.1 Climate change action in the health sector at global and national levels.

out the guiding principles for the national programme - National Programme on Climate Change and Human Health (NPCCHH - Table 4.1), which comes under the National Health Mission. The plan provides a detailed layout of the adaptation plans on health effects due to climate change.

Table 4.1 The vision, goal and objectives of NPCCHH

A climate-smart and-resilient health system that promotes health
and protects against climate risks among all citizens of India,
especially those who are vulnerable including children, women
and marginalised populations.
To strengthen healthcare services against the adverse impact of
extreme weathers, climate variability and change.
To strengthen healthcare services against the adverse impact of
climate change on health. The specific objectives are
1. To create awareness among the general population (vulnerable
communities), healthcare providers and policymakers regarding
impacts of climate change on human health
2. To build and strengthen the capacity of health systems to
address illnesses due to impacts of climate change on human
health
3. To strengthen health preparedness and responses to climate-
sensitive health risks
4. To develop partnerships and create synchrony and synergy with
other national missions on Climate Change for adequate
representation of health
5. To strengthen research capacity to fill evidence gaps on the
impact of climate change on human health


Under the NPCCHH, the following have been identified as Climate Sensitive Diseases (CSDs):

- Water-borne diseases

- Vector-borne diseases

- Air pollution-related illnesses

- Allergic disorders

- Cardiovascular diseases

- Nutrition-related illnesses

- Coastal climate-sensitive diseases

- CSDs in hilly and mountainous regions

- Occupational health

- Mental health

- Disaster-related illnesses

- Zoonotic diseases

- Heat stress and heat-related illnesses

With regard to the CSDs, Centres of Excellence (CoE) have been identified from across the country to play an important role to help NCDC develop specific health adaptation plans, training modules, guidelines, SOPs, etc., and to support State programme officers on climate change in developing disease-specific adaptation plans in the States. The case studies in boxes discuss NPCCHH programmes that address heat-related illnesses (Box 4.1) and air pollution-related illnesses in the country (Box 4.2), with Table 4.2 displaying the key strategies issued by NPCCHH for heat-related illnesses.

\section{Box 4.1 Case study}

\section{Addressing heat-related illnesses under the NPCCHH}

Under the MoHFW, the NPCCHH programme tracks the health effects due to heat in the country and has prepared guidelines on the prevention and management of heat-related illnesses. The public health actions required for managing heat-related illnesses are surveillance of heat-related illnesses morbidity and mortality, investigation of heat-related health events, pre-hospital and hospital care, logistics, training of doctors and nurses, awareness among the general public, coordination with multiple stakeholders, heat action plans for specific cities/rural districts, particularly for vulnerable population groups, and roping in of Non-Government Organizations (NGOs) for spreading awareness on heat-related illnesses. Since 2015, the Integrated Disease Surveillance Program (IDSP) under the MoHFW 
has collected and compiled data of heat-related illnesses from 17 vulnerable States: Andhra Pradesh, Bihar, Chhattisgarh, Delhi, Gujarat, Haryana, Jharkhand, Karnataka, Maharashtra, Madhya Pradesh, Odisha, Punjab, Rajasthan, Tamil Nadu, Telangana, Uttar Pradesh and West Bengal. In 2019, the vulnerable States increased to 23 in number, including Kerala, Goa, Uttarakhand, Jammu \& Kashmir, Arunachal Pradesh and Himachal Pradesh. Currently, information on morbidity and mortality of heat-related illnesses is being captured on a daily basis at the health facility level; this information is being compiled for all districts and from there to the states, and then further to the national level.

\section{Box 4.2 Case study \\ Addressing air pollution and its health impacts under the NPCCHH}

Due to the health impacts of air pollution, the MoHFW started a programme for Acute Respiratory Illnesses (ARI) surveillance in 2017 in six Central Government tertiary care hospitals in Delhi. The ARI data is being correlated with the daily air quality level, i.e. air quality index (AQI) of the respective area or city. The overarching goal of ARI surveillance is to minimise the impact of air pollution by providing useful information to public health authorities for the appropriate control and intervention measures, health resource allocation, and to make case management recommendations. Some action plans for air pollution-related health impacts are listed below:

1. All cities enlisted under the National Clean Air Program are selected with 2 to 4 tertiary hospitals for ARI surveillance in its first phase.

2. Capacity-building of health professionals on the health effects of air pollution is being conducted.

3. Information Education Communication (IEC) materials have been prepared for print media and social media and shared with the States to prepare and adopt protective measures on health effects due to air pollution; social media campaigns are running on the MoHFW and NCDC social media sites.

4. State/District/City Level Health Sector Adaptation Plans for Air Pollution and Health are being developed to ensure preparedness and coordination whenever air pollution arises, 
along with evaluation at regular intervals. The action plan will help in prioritising the most affected areas, vulnerable groups and resource allocations, and identifying and defining the roles and responsibilities of the stakeholders through operational flowcharts or tables.

5. Research topics related to air pollution have been proposed and shared with the Indian Council for Medical Research (ICMR), an example being interventions in the form of face masks and room air purifiers to protect health from air pollution.

Table 4.2 Key strategies to adapt to heat-related illnesses in India

1. Strengthening Heat and Human Health Surveillance Systems with feedback received on reporting formats from various stakeholders at States, institutes and experts working on heat-related illnesses.

2. Standardising investigation of deaths due to suspected heatstroke cases: at the state/district level the suspect heat-related death is investigated by a team of tehsildar, revenue officer, police officer and medical officer.

3. Developing climate-specific state/district/city-specific Heat and Health Action Plans due to diverse geographies for heat vulnerable areas, vulnerable populations, health infrastructures and resources, and stakeholder identification with defined roles and responsibilities. The action plan will help in preparedness before season, response coordination during season and evaluation after season. This will be also incorporated into state/district/city level heat action plans developed by revenue/disaster management teams.

4. Increasing public awareness and community outreach to disseminate messages on how to prevent extreme heat events. Efforts include the use of social media such as SMS, radio, WhatsApp, email, social media, caller tunes, etc., particularly to reach the vulnerable populations.

5. Developing measures for Early Warning System/Alerts and responses at the state, district and below the district level. As IMD shares a daily five-day forecast on its website, a formal communication channel is being strengthened to alert health agencies for early response.

6. Capacity-building with the help of training modules among all levels of healthcare professionals to recognise and respond to heat-related illnesses.

\section{Addressing health impacts of climate change at the state and district level in India}

India is a country with diverse geo-climatic conditions impacting the health of the people due to climate change. Thus, the programme envisages that every State develops a State-specific Action Plan on Climate Change and Human Health (SAPCCHH) and District Action Plan on Climate Change and Human Health (DAPCCHH) at the district level. Each state has created an Environmental Health Cell at the state and district level, supervised by a 
designated state/district nodal officer for climate change and human health with supporting officers and staff. The nodal officer will coordinate with the Centre, State and District officers to achieve the objectives of the programme. The state action plan should be based on the previous years' statistics and information on the burden of prevalent CSDs, distribution of vulnerable populations, health infrastructure and other available resources, roles of various healthcare professionals, and other inter-coordinating stakeholders. The District Action Plan on Climate Change and Human Health (DAPCCHH) will enable adaptation of the health effects at the district level, taking it up to even the most remote healthcare facilities in the country.

\section{The provision of green and climate-resilient healthcare facilities under the NPCCHH}

Extreme weather events are increasing in frequency and magnitude. These events lead to disasters that cause direct health impacts. The National Disaster Management Authority (NDMA) is the nodal agency in the country to track disaster events occurring in the country, along with the State and District level disaster authorities. The NDMA has developed various policies and guidelines to deal proactively with these disasters, including disaster risk reduction for the major types of disasters. In the health sector, the NPCCHH programme requires support and collaboration with the NDMA as it has to deal with the direct health impacts of climate change which affect almost every part of the country. This programme incorporates the concepts of Green and Climate Resilient healthcare principles in revising the Indian Public Health Service Guidelines, which deal with SubCentres, PHCs, CHCs, SDHs and District Hospitals in the country. Green healthcare facilities will help to minimise the carbon footprint while climateresilient facilities will help adapt to the increasing frequency and magnitude of extreme weather events due to climate change. These extreme events can impact healthcare facilities and can collapse or paralyze their normal functioning leading to injuries, deaths and psychological impacts. There is a plan to either retrofit or develop climate-resilient healthcare facilities in various geo-climatic regions in the country affected by increasing extreme weather events due to climate change like heavy precipitations, floods, cyclones, heatwaves, and extreme colds, etc., in the country. This topic is discussed further in the chapter titled Green and Resilient Health Infrastructure.

\section{Awareness and capacity building of health professionals under the NPCCHH}

One of the main objectives of the programme is to bring about awareness and capacity building of health professionals. Various medical and allied councils have been sensitised for the inclusion of health impacts of climate 
change, air pollution and heat and their adaptation plans in Medical, Dental, Nursing and AYUSH curricula. Six Councils, i.e. the Medical Council of India, the National Board of Examinations, the Dental Council of India, the Nursing Council of India, the Central Council of Homoeopathy and the Central Council of Indian Medicine have accepted the proposal of its inclusion and have set up committees for consideration, processing and approval. A related component under the programme is developing training materials and modules for health professionals on climate change and health including medical officers, nursing officers and community health workers such as ASHA workers, etc. Some states are conducting awareness and capacity building for their health professionals. Training materials and modules are also being developed with consultations from various stakeholders including NGOs. Training on acute respiratory surveillance due to air pollution was recently conducted for medical officers of the state of UP at NCDC with support from UNEP and WHO recently. An awareness programme was conducted for district nodal officers in the state of Madhya Pradesh in Bhopal in January 2020.

\section{Other allied programmes in the health sector in India}

The NPCCHH requires full support from other related Missions on Climate Change under PMCCC, various other Ministries and Departments, public health institutions in the Government as well as private sectors and other international and national NGOs in developing a climate-resilient health sector in the country. Inter-sectoral and intra-sectoral co-ordinations among these institutes will be vital in achieving the objectives of the programme. Various public health institutions in autonomous institutions are taking on crucial roles in addressing the health impacts of climate change for further strengthening of the policy on Climate Change and Human Health, by providing input to the Government and contributing in capacity building. IGNOU has launched a post graduate certificate course in climate change. Reputed public health institutions in various private sectors in the country are also starting courses related to climate change in the health sector for capacity building and policy inputs on the subject.

There exist some limitations in the implementation of these activities and objectives mentioned under the programme in various States and Union Territories in the country. Climate change is a global phenomenon that impacts every part of the country, although to variable degrees. The programme has just started being newly implemented and requires support and expertise from across the health and non-health sectors in order to achieve its objectives. This requires huge inter-sectoral and intra-sectoral coordination, collaboration and cooperation. It requires a robust comprehensive approach with stronger leadership, policies, financing, capacity building of skilled and trained health professionals and workers, developing early warning mechanisms for climate-sensitive diseases and awareness generation at 
every level. The programme needs to be integrated with other health and non-health sector programmes horizontally, vertically and diagonally so that the adverse impacts of climate change on human health can be dealt with holistically. These are the huge challenges the programme needs to overcome in order to move forward positively and strongly.

\section{Key takeaways}

- Globally, the threat of climate change is being addressed by the IPCC and the UNFCCC, a Convention to which India is a signatory.

- National mechanisms to address Climate Change are the Prime Minister's Council on Climate Change and NAPCC from MoEFCC.

- The Health Mission on Climate Change (in India) was added to India's policy on Climate Change after a review of the NAPCC in the reconstituted PMCCC.

- The National Program on Climate Change and Human Health (NPCCHH) under the nodal Ministry of Health and Family Welfare and nodal technical agency National Centre for Disease Control, was started in order to fulfil India's commitments in the international and national climate change policy framework and to build a climateresilient health sector.

- The state and district-level climate activities and centres are described.

\section{References}

PMO Archives. (2007). PM's council on climate change constituted. https://archivepmo.nic.in/drmanmohansingh/press-details.php? nodeid $=575$

FAR. (1990). https://www.ipcc.ch/reports/

Pandve. (2009). India's national action plan on climate change. Indian Journal of Occupational and Environmental Medicine, 13(1), 17-19. doi: 10.4103/00195278.50718

UNFCCC. (2004). India's initial national communication to the UNFCCC. https:// unfccc.int/resource/docs/natc/indnc1.pdf

UNFCCC. (2020). UN climate change secretariat has new organizational structure. https:/unfccc.int/news/un-climate-change-secretariat-has-new-organizationalstructure

UNFCCC. (2021). Status of ratification of the convention. https://unfccc.int/processand-meetings/the-convention/status-of-ratification/status-of-ratification-ofthe-convention 
Section 2

\section{THE IMPACT OF CLIMATE CHANGE ON HEALTH}


$\Longrightarrow$ Taylor \& Francis

Taylor \& Francis Group

http://taylorandfrancis.com 


\title{
DISEASE PANDEMICS AND THE THREAT OF MICROBIAL EMERGENCE
}

\author{
Lalit Kant, Gifty Immanuel and Jai Prakash Narain
}

\section{Introduction}

Climate is fundamental to life on earth and has a powerful impact on human health. Climate change-related infectious diseases have been evolving and spreading to areas that were, until now, free of them. Amongst infectious diseases, zoonotic diseases - those transmitted from animals to humans - are particularly impacted by climate change. Caused by viruses, bacteria, parasites, etc., zoonotic diseases are said to be responsible for $60 \%$ of all infectious diseases in humans, and $75 \%$ of all emerging infectious diseases (Cunningham, 2005). This chapter will explore:

1. How climate change has influenced the emergence of novel viruses following "cross-over," to which the human race has no immunity.

2. The profound implications in terms of health security and disease control following the emergence of disease-causing microbes that present an unprecedented challenge to global health.

3. How epidemics, pandemics and climate change affect humans, and the appropriate responses to these threats.

\section{Links between climate change and zoonoses}

In 2019, the world's population was about 7.5 billion. It took 200,000 years to reach the first billion, and only another 200 years to reach 7 billion (AMNH, 2016). In order to meet the food requirements and other needs of billions of people, human activities such as burning of fossil fuels (oil, coal, natural gas, etc.) for energy have increased manifold, releasing large amounts of greenhouse gases into the atmosphere. In addition, industrialisation, urbanisation, mining activities, logging, livestock farming and clearing of forests for the construction of infrastructure such as roads or dams, etc., have all forced a large number of animals to migrate to peri-urban areas in close proximity to human habitats.

Together, human activities and climate change inter alia drive wild animals closer to populated areas, creating opportunities for pathogens to 
move from animals to humans. If microbes are able to adapt themselves for efficient human-to-human transmission, the risk for an epidemic or a pandemic increases. According to an International Livestock Research Institute study, 13 zoonoses have been the cause of 2.4 billion cases of human disease and 2.2 million deaths per year, with the highest zoonotic disease burden in Ethiopia, Nigeria, Tanzania, and India (Grace et al., 2012). The true burden is difficult to estimate due to underreporting and under-diagnosis.

\section{New and emerging zoonotic diseases}

A previous chapter has discussed the evidence of a rise in atmospheric temperatures leading to the increased transmission of disease. Warmer temperatures and changes in rainfall have created favourable conditions for vectors and pathogens in some areas that did not previously support their survival. The glaciers, permafrost, icebergs, frozen lakes and seas that constitute the earth's cryosphere are highly sensitive to global warming (Margesin and Collins, 2019). Pathogens can transmit through environmental pathways with melted water and contaminated surfaces as a medium of transfer. Currently, about $37 \%$ of the northern hemisphere is covered by circumpolar permafrost (Dobricic and Pozzoli, 2019). 35 million people live in these permafrost zones (Oliva and Fritz, 2018). At the rate of global warming, a $60 \%$ thaw can be expected by 2100 (Biskaborn et al., 2019). Melting glaciers and thawing permafrost can release hidden microbes buried under layers of ice for long periods of time. The microbial threats arising from such melting repositories in ice pose a significant danger to human and animal health. Thawing could bring the host (such as humans and animals) in proximity to the contagion, facilitating transmission. Essentially, two scenarios could emerge: one is the re-emergence of known microbes, such as Bacillus anthracis, which caused a recent outbreak in reindeer herds and humans in Siberia (Stella et al., 2020); the other is the resurrection of previously unknown viruses, such as the giant virus Pithovirus sibericum with unknown infectivity that was isolated from a 30,000-year-old block of ice (Okamoto et al., 2017).

These hotspots of disease emergence are less visible but are increasingly relevant to global health.

\section{Viral threats}

Viruses are formidable disease-causing agents with a potential for largescale pandemics. The COVID-19 pandemic (discussed further on in the chapter) is caused by the virus now known as the Severe Acute Respiratory Syndrome Coronavirus 2 (SARS-CoV-2). The Spanish Influenza (H1N1A) killed nearly 40 million people worldwide in 1918. In a recent study, victims of the 1918 Spanish influenza who had been buried in a mass grave in the permafrost in Alaska were exhumed for analysis (Reid et al., 1999). Positive 
RNA material of the virus could be retrieved from their bodies. This finding presents a bleak scenario: that thawing permafrost can unearth corpses that harbour such lethal viruses. Increased human activity in such zones can amplify the chances of viral infection and spread. Similarly, the DNA of the smallpox virus Variola major was isolated from a 300-year-old corpse mummified in Siberian permafrost (Edwards, 2015). Meanwhile, migratory birds and artic penguins can deposit Influenza viruses in frozen lakes, which then act as reservoirs releasing viruses when they melt (Edwards, 2015).

\section{Bacterial threats}

Until recently, cold habitats were considered pristine environments. Studies involving sampling of ice and soil have shown antibiotic-resistant genes (Segawa et al., 2013). Temperature tolerant Escherichia coli and Streptococcus fecalis are frequently sampled in meltaway waters, increasing the chances of feco-oral transmission among polar tourists and climbers (Segawa et al., 2013). Cholera is a well-known climate-sensitive pandemic with a high mortality rate (Box 5.1). Meanwhile, the recovery of multiple antibiotic-resistant bacteria from the Siachen glacier poses a unique threat to the Indian sub-continent (Rafiq et al., 2017). Increased human activity, migratory birds and airborne dissemination have been suggested as drivers of disease emergence. These frozen zones can also act as reservoirs of

\section{Box 5.1 Case study \\ Weather satellite networks: An early warning system against pandemics}

NASA space technology is being used as an epidemiological tool for disease control, surveillance and prevention. Weather tracking satellites can help forecast disease emergence based on atmospheric, land and weather data. In 2017, NASA Earth-observing research satellites used machine learning and a Cholera Prediction Modeling System to predict with $92 \%$ accuracy, an evolving outbreak of cholera in Yemen (Figure 5.1). Several deaths were averted due to the early warning system and subsequent activation of field level initiatives. This disease prediction model was able to integrate the precipitation data, ocean temperatures and phytoplankton movements (phytoplankton - a marine algae - are reservoirs of the cholera bacteria). This free resource is of potential value to decision-makers by providing forecast and lead times. The programme is funded by the NASA Applied Sciences that permits all international institutions and individuals to use NASA data for disease prediction and forecast. 


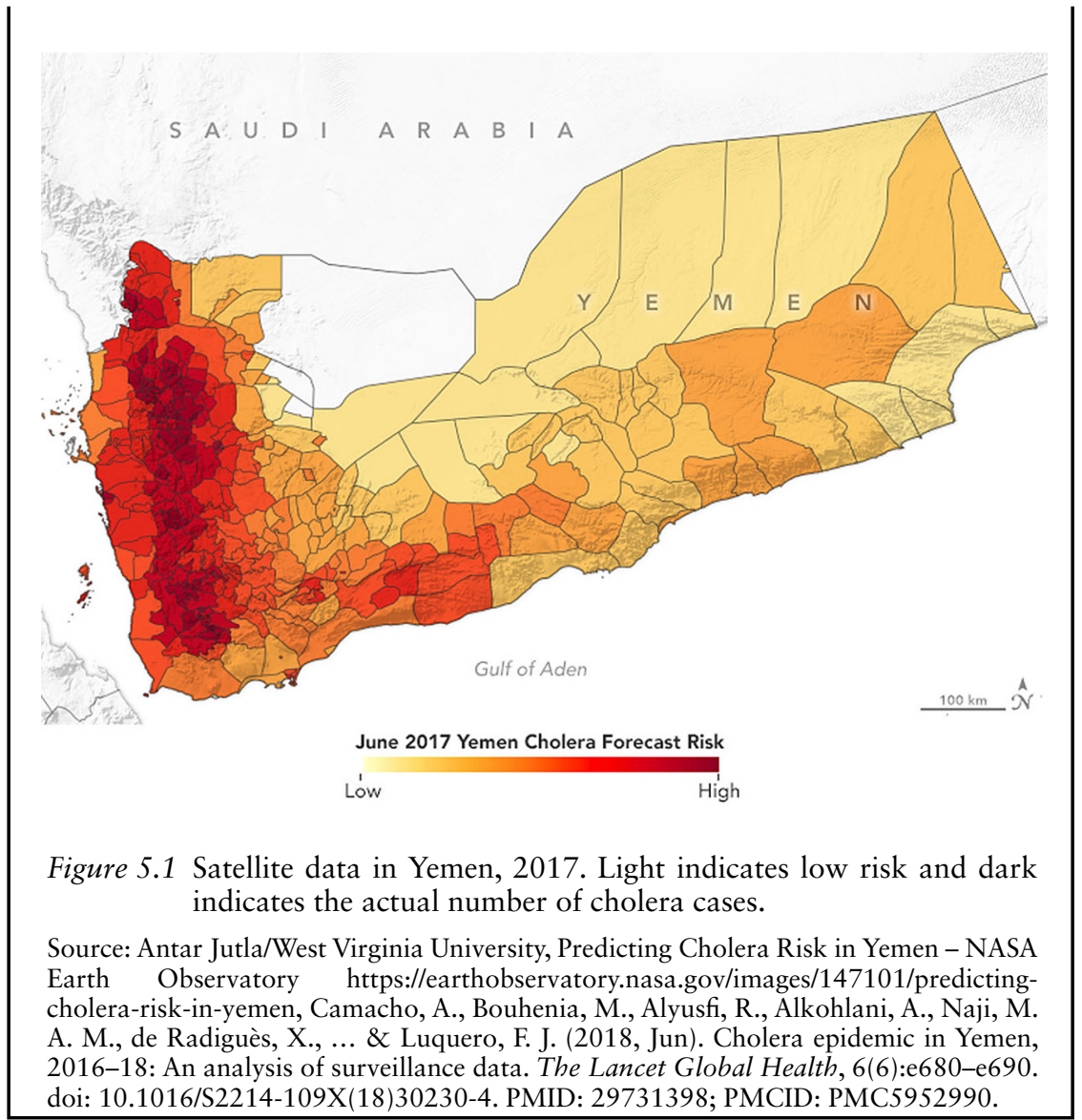

pathogenic drug-resistant bacteria impeding global measures to contain antimicrobial resistance (AMR). Another possibility is the release of lethal bacteria like Bacillus anthracis (described earlier) into human and animal populations with fatal consequences.

\section{Fungal threats}

Environmental fungi like Cryptococcus are notorious pathogens for the immuno-compromised (these could include people living with HIV/AIDS, those with kidney and liver diseases, those undergoing organ/stem cell transplants, and those undergoing cancer therapy) and, to a lesser extent, to a healthy population. Aureobasidium pullulans is another cold-adapted environmental fungus of medical importance due to its resistant nature (Edwards, 2015). Similarly, Candida auris is an emerging super fungus that displays multidrug resistance and is a major pathogen in hospital intensive care units. Fungal communities preserved in ice have undergone "adaptation" to higher 
temperatures as a result of global warming. This strategically helps them in overcoming human thermal barriers (Edwards, 2015).

The emergence of the West Nile virus, Rift Valley fever and Dengue fever in new geographical areas has been linked with the El Nino oscillation (Githeko et al., 2000). While Africa witnessed the emergence of new viruses like HIV, Ebola haemorrhagic fever and Rift Valley fever, South America saw a rise in the Zika virus. In North America, in particular the US, the zoonotic diseases of influenza, salmonellosis, West Nile virus, plague, emerging coronaviruses, rabies, brucellosis and Lyme disease have been listed as those of greatest concern (CDC, 2017). The avian flu (H5N1), SARS and Nipah viruses appeared in Asia. Europe saw a rise in cases of Tularaemia, Haemorrhagic fever with renal syndrome, Tick-borne encephalitis, Mad Cow disease, and West Nile fever (Vorou et al., 2007).

In India, the major public health zoonotic diseases are rabies, brucellosis, toxoplasmosis, cysticercosis, echinococcosis, Japanese Encephalitis (JE), leptospirosis, Scrub typhus, Nipah, Kyasanur forest disease (KFD) and Crimean-Congo haemorrhagic fever (Dhiman and Tiwari, 2018).

Among zoonotic viruses, influenza has led to the largest number of epidemics and even pandemics. Influenza viruses are found in humans and animals. These are of four types: Influenza A, B, C and D viruses. Influenza $\mathrm{A}$ has been responsible for seasonal epidemics and pandemics, and Influenza B causes only seasonal epidemics. Climate changes that influence wild waterbird habitats, migration, and stopover sites could be a factor in the global distribution of avian virus agents and possibly the emergence of a new pandemic influenza strain. Influenza viruses, by nature, are constantly evolving in multiple species and many different genetic and antigenic groups. A future pandemic of influenza is a strong possibility, although the timing and location are uncertain. As seen in Table 5.1, influenza viruses have been the cause of four pandemics in history (Dauphin, 2015).

In order to detect a potential pandemic influenza strain, the World Health Organization, the Food and Agriculture Organization, and the World Organization for Animal Health work together through a number of

Table 5.1 Pandemics caused by Influenza viruses

\begin{tabular}{llllll}
\hline Year & Strain & $\begin{array}{l}\text { Origin of } \\
\text { virus }\end{array}$ & $\begin{array}{l}\text { Pandemic } \\
\text { started in }\end{array}$ & $\begin{array}{l}\text { Name of } \\
\text { pandemic }\end{array}$ & Deaths \\
\hline 1918 & A(H1N1) & Avian & China & Spanish flu & $40-50 \mathrm{~m}$ \\
1957 & A(H2N2) & Avian & China & Asian flu & $1-2 \mathrm{~m}$ \\
1968 & A(H3N2) & Avian & China & Hong Kong flu & $0.5-2 \mathrm{~m}$ \\
2009 & A(H1N1) & Swine & Mexico & Pandemic flu & $\sim 0.57 \mathrm{~m}$ \\
\hline
\end{tabular}

$\mathrm{m}=$ million 
Table 5.2 Epidemics and pandemics caused by Coronaviruses

\begin{tabular}{llllllll}
\hline Year & Name & $\begin{array}{l}\text { Outbreak } \\
\text { started in }\end{array}$ & $\begin{array}{l}\text { Natural } \\
\text { host }\end{array}$ & Via & $\begin{array}{l}\text { Countries } \\
\text { affected }\end{array}$ & Cases & Deaths \\
\hline 2003 & SARS & China & Bat & $\begin{array}{c}\text { Civet } \\
\text { cat }\end{array}$ & 29 & $>8000$ & $>770$ \\
2012 & MERS & $\begin{array}{c}\text { Saudi } \\
\text { Arabia }\end{array}$ & Bat & Camel & 27 & $>2500^{\mathrm{a}}$ & $>800^{\mathrm{a}}$ \\
2019 & COVID-19 & $\begin{array}{c}\text { China } \\
\text { China }\end{array}$ & Bat & $?$ & $188^{\mathrm{b}}$ & $>16.7 \mathrm{m \#}$ & $>0.66 \#$ \\
\hline
\end{tabular}

aas of 31 March 2020; bcontinuing; \# as of 30 July 2020; m=million (Source of COVID-19 data: https://coronavirus.jhu.edu/map.html)

established detection and response frameworks (Saunders-Hastings and Krewski, 2016).

Another group of viruses that has been the cause of epidemics, and the most recent pandemic, are the coronaviruses. Coronaviruses are a group of viruses that cause diseases in animals and humans. A diverse array of bat and bird species are believed to be their natural hosts. They often circulate among animals such as camels, cats, cows, pigs etc. To date, seven coronaviruses have the ability to cause disease in humans. Four are endemic and usually cause mild disease, (regularly found and responsible for about $10-15 \%$ of common colds) but three (SARS, MERS and COVID-19) have caused severe disease. Table 5.2 gives further details.

The pandemic of COVID-19, resulting from a novel coronavirus named SARS-CoV-2, like SARS in 2002, also emerged from China (WHO, 2019). It has proven to be a highly contagious disease that spread around the world within a few weeks and devastated nations as never before. As a result of lockdown implemented by many countries to suppress the virus, schools, workplaces, shops and factories were shut, travel restricted and flights grounded for a long period of time. The tragedy unfolded in countries across the globe, causing untold misery and economic meltdown.

\section{Overlaps between pandemics and climate change in terms of impact and responses}

Although a pandemic like COVID-19 presents different challenges compared to climate change, there are many parallels between them. Pandemics know no boundaries, and neither do the effects of climate change. Both are a global problem with local consequences; addressing them requires a collaborative and coordinated set of solutions implemented locally, nationally, regionally and internationally. Their health and economic consequences are unequivocal and severe. Both are linked to human behaviour. Clearly, early action on both can save lives and any delay in response can increase the human and socioeconomic costs many times over. 
Pandemics and climate change both essentially impact all sectors of society and require concerted action that engages the "whole of society" in response. Both pandemics and climate change disproportionately impact those who are most vulnerable and marginalised in society - the poor, the old and the young, and those who have no or limited access to health services. Both trigger obligations of governments and others to protect them.

When faced with public health threats of a global scale, such as COVID-19 or climate change, nations are only as strong as their weakest health system. Universal health coverage through well-resourced and equitable health systems is essential in order to protect the public from both short- and longterm health threats. The global community has shown that it can act to address a crisis, by taking measures and changing behaviours in response to COVID-19. Faced with the multifaceted impacts of COVID-19 and climate change, multilateralism is the only way forward, requiring not only political commitment and use of science for policymaking, but also for all to unite as a single global community and respond in a coordinated manner.

Given that pandemics and climate change affect multiple sectors of society, countries need broad and sustainable multisectoral preparedness and response plans that outline their policies, strategies and operations to manage these emergencies. Social protection programmes are already in operation to help manage the risks and impacts of weather and climate extremes on the most vulnerable people (Kuriakose et al., 2013). This has been done in drought areas through cash transfers to vulnerable households. Similar social safety programmes have been effectively used to soften the twin health and economic shocks of COVID-19 (Gilligan, 2020).

To tackle both pandemics and climate change, it is important to have the capacity and capabilities to detect unusual events through an early warning system in order to mount an effective response. Examples of some global initiatives include:

- The Global Climate Observing System: Established in 1992 to ensure that the observations and information needed to address climate-related issues are obtained and made available to all users, this system integrates satellite observations, ground-based data and forecast models to monitor and forecast changes in the weather and climate.

- The Global Early Warning System for Major Animal Diseases including Zoonosis (GLEWS): In 2006, OIE, FAO, and WHO consolidated efforts to establish GLEWS. It became one of the mechanisms used for monitoring data from existing event-based surveillance systems and to track and verify relevant animal and zoonotic events.

- The Global Outbreak Alert and Response Network (GOARN): In 2000 , the WHO established the GOARN as a network of networks. It pools human and technical resources from more than 100 institutions around the world to rapidly identify, confirm, and respond to outbreaks of international importance. 
In India, the human component of zoonotic disease surveillance is steered by the National Centre for Disease Control, while the animal component is undertaken by the Indian Council of Agricultural Research.

Though pandemics and climate change share similarities, there are also differences. A pandemic is a natural or biological phenomenon, often caused by emergence of a new or novel pathogen against which people have no immunity. Its impact is generally of a shorter duration. On the other hand, climate change is a man-made disaster, a slow-moving tsunami. The threat from events linked to climate change will play out over longer timeframes.

\section{Learnings from pandemic control efforts for climate change}

The 2020 coronavirus pandemic has shown that political leadership and planning is critical, and that governments can even implement unpopular policies like lockdowns, in the interest of the public good. Radical changes are possible and can be taken quickly. Many of these have been transformative in the way that society lives and works. For example, working from home has contributed, at least temporarily, to reduced air pollution. Likewise, transformative changes are required in order to address climate change. As with COVID-19, several world leaders believed that climate change would not affect them as a nation. This perception needs to be countered. Governments must act with the same extraordinary co-operation and comprehensiveness against climate change, for which they acted against COVID-19. Calls and examples of collaboration and solidarity multiplied in the first few months of the coronavirus pandemic, and it is time that similar things were done for climate change as well. Well-resourced healthcare systems providing universal healthcare are essential for protection health threats of climate change. Trillions of US\$ will be spent globally in the next year or so to help jumpstart the economy. This stimulus should comprise green initiatives.

\section{The role of healthcare professionals}

Healthcare professionals have an important role to play - educating the patients and their families about the harmful effects of climate change on human health, and what they can do to minimise the impact. As trusted members of society, health professionals have both the authority and expertise to encourage the community to follow government advisories during pandemics as well as those for climate change. During the COVID-19 pandemic, if every person practiced preventive steps such as using masks correctly, maintaining physical distance, and frequently washing hands with soap and water, people can individually and collectively limit disease transmission to a great extent. Avoiding crowded public transport in favour of walking or using bicycles have the co-benefits of preventing COVID-19 as well as improving one's own health. Likewise, minimising the use of fossil 
fuels by switching to renewable energy sources like solar power, etc. can help decrease global warming.

One cannot and must not underestimate the power of social responsibility in reducing global warming and the spread of epidemics. Being socially responsible means that everyone needs to do their part, and that every person can make a difference.

\section{Key takeaways}

- Human wellness is inextricably linked to planetary health.

- Individually and collectively, humans have contributed to creating ecological conditions for zoonotic diseases to emerge and spread, while also being responsible for loss of biodiversity and consumption of fossil fuel leading to climate change.

- Earth's cold zones are massive repositories of microbes posing the threat of disease outbreaks. Permafrost microbes play a central role in climate change biology as well as disease emergence.

- Increased human activity and animal migration patterns have led to the deposition of antibiotic-resistant, highly lethal and exotic pathogens in these habitats.

- Next-generation methods need to be adopted to address this crisis.

- Raging zoonotic diseases, such as the pandemic Influenza of 1918 or COVID-19, are wake-up calls to the global community on the ultimate cost of inaction on the rapidly unfolding climate crisis.

- The human response to pandemics can demonstrate how to mount a more efficient response to threats of climate change. Everyone should proactively contribute to meet the dual challenge.

- It would be irresponsible to wait until the climate crisis reaches epidemic or pandemic proportions. In fact, addressing climate change now is in itself a mitigation action against future epidemics and pandemics.

\section{References}

American Museum of Natural History. (2016). Human population through time. https://www.amnh.org/content/search?SearchText=human+population+through+ time

Biskaborn, B. K., Smith, S. L., Noetzli, J., Matthes, H., Vieira, G., Streletskiy, D. A., ... \& Lantuit, H. (2019). Permafrost is warming on a global scale. Nature Communications, 10, 264.

Camacho, A., Bouhenia, M., Alyusfi, R., Alkohlani, A., Naji, M. A. M., de Radiguès, X., \& Luquero, F. J. (2018, Jun). Cholera epidemic in Yemen, 2016-18: An analysis of surveillance data. The Lancet Global Health, 6(6), e680-e690. doi: 10.1016/ S2214-109X(18)30230-4. PMID: 29731398; PMCID: PMC5952990.

CDC. (2017). Prioritizing zoonotic diseases for multisectoral, One Health collaboration in United States. Workshop summary. https://www.cdc.gov/onehealth/pdfs/ us-ohzdp-report-508.pdf 
Cunningham, A. A. (2005). A walk on the wild side - Emerging wildlife diseases. $B M J, 331,1214-1215$. doi: 10.1136/bmj.331.7527.1214

Dauphin, P. G.. (2015). WHO/FAO/OIE tripartite coordination for the control and prevention of zoonotic influenza viruses. Example of OFFLU, global network of veterinary expertise. Bulletin de l'academie Veternaire de France, 168(3). doi: $10.4267 / 2042 / 57932$.

Dhiman, R. C., \& Tiwari, A. (2018) Emergence of zoonotic diseases in India: A systematic review. Medical Reports and Case Studies, 3, 3. doi: 10.4172/2572-5130.1000163.

Dobricic, S., \& Pozzoli, L. (2019). Arctic permafrost thawing, UR 29940 EN, Publications Office of the European Union, Luxembourg, 2019, ISBN 978-9276-10182-6, doi: 10.2760/007066, JRC109379.

Edwards, A. (2015). Coming in from the cold: Potential microbial threats from the terrestrial cryosphere. Frontiers in Earth Science, 3, 12. doi: 10.3389/feart.2015. 00012

Gilligan, D.. (2020, June) Social safety nets are crucial to the COVID-19 response. Some lessons to boost their effectiveness. International Food Policy Research Institute. https://www.ifpri.org/blog/social-safety-nets-are-crucial-COVID-19-responsesome-lessons-boost-their-effectiveness

Githeko, A. K., Lindsay, S. W., Confalonieri, U. E., \& Patz, J. A. (2000). Climate change and vector-borne diseases: A regional analysis. Bulletin of the World Health Organization, 78(9), 1136-1147.

Grace, D., Mutua, F., Ochungo, P., Kruska, R., Jones, K., Brierley, L., Lapar, L., Said, M., Herrero, M., Phuc, P. M., Thao, N. B., Akuku, I., \& Ogutu, F. (2012). Mapping of poverty and likely zoonoses hotspots. Zoonoses Project 4. Report to the UK Department for International Development. ILRI. https://hdl.handle.net/10568/21161

Kuriakose, A. T., Heltberg, R., Wiseman, W., Costella, C., Cipryk, R., \& Cornelius, S. (2013). Climate-responsive social protection. Development Policy Review, 31(S2), o19-o34. https://www.climateinvestmentfunds.org/sites/default/files/Kuriakose_et_ al_2013.pdf

Margesin, R., Collins, T. (2019). Microbial ecology of the cryosphere (glacial and permafrost habitats): Current knowledge. Applied Microbiology and Biotechnology, 103, 2537-2549. doi: 10.1007/s00253-019-09631-3

Okamoto, K., Miyazaki, N., Song, C., Maia, F. R., Reddy, H. K., Abergel, C., ... \& Murata, K. (2017). Structural variability and complexity of the giant Pithovirus sibericum particle revealed by high-voltage electron cryo-tomography and energyfiltered electron cryo-microscopy. Scientific Reports, 7, 13291.

Oliva, M., \& Fritz, M. (2018). Permafrost degradation on a warmer Earth: Challenges and perspectives. Current Opinion in Environmental Science of Health, 5, 14-18.

Rafiq, M., Hayat, M., Anesio, A. M., Jamil, S. U. U., Hassan, N., Shah, A. A., \& Hasan, F. (2017). Recovery of metallo-tolerant and antibiotic resistant psychrophilic bacteria from Siachen glacier, Pakistan. PLOS ONE, 12(7), e0178180. doi: 10.1371/journal.pone.01781

Reid, A. H., Fanning, T. G., Hultin, J. V., \& Taubenberger, J. K. (1999, February 16). Origin and evolution of the 1918 "Spanish" influenza virus hemagglutinin gene. PNAS, 96(4), 1651-1656. doi: 10.1073/pnas.96.4.1651 
Saunders-Hastings, P. R., \& Krewski, D. (2016). Reviewing the history of pandemic influenza: Understanding patterns of emergence and transmission. Pathogens, 5(4), 66. doi: 10.3390/pathogens5040066

Segawa, T., Takeuchi, N., Rivera, A., Yamada, A., Yoshimura, Y., Barcaza, G., ... \& Ushida, K. (2013). Distribution of antibiotic resistance genes in glacier environments. Environmental Microbiology Reports, 5, 127-134. doi: 10.1111/17582229.12011

Stella, E., Mari, L., Gabrieli, J., Barbante, C., \& Bertuzzo, E. (2020). Permafrost dynamics and the risk of anthrax transmission: A modelling study. Scientific Reports, 10, 16460.

Vorou, R. M., Papavassiliou, V. G., \& Tsiodras, S. (2007). Emerging zoonoses and vector-borne infections affecting humans in Europe. Epidemiology \& Infection, 135(8), 1231-1247. doi: 10.1017/S0950268807008527

WHO. (2019). Coronavirus disease 2019 (COVID-19) situation report-94. https:// www.who.int/docs/default-source/coronaviruse/situation-reports/2020 0423-sitrep-94-COVID-19.pdf 


\title{
CLIMATE CHANGE AND ITS IMPACT ON HUMAN HEALTH: AN OVERVIEW
}

\author{
Poornima Prabhakaran
}

\begin{abstract}
Introduction
Climate change is recognised today as the biggest public health challenge of the twenty-first century, threatening to undo decades of gains in public health (Costello et al., 2009). Globally, according to the 2018 Lancet Countdown, if temperatures continue to rise, present-day changes in agricultural production, labour capacity and vector-borne disease are indicative of an early warning of compounded and overwhelming impact. Low- and middleincome countries with the most vulnerable populations, weakest health systems and poorest infrastructure are likely to be the worst affected by climate change. This, in turn, translates into further widening of health and economic inequities. Understanding the existential threat of this new public health crisis and its impact on human health is therefore urgent and imperative for healthcare professionals. This chapter aims to outline for the reader:
\end{abstract}

1. The broad implications of climate change for India.

2. The wide-ranging impacts of climate change on human health.

\section{Impacts of climate change for India}

India is undoubtedly one of the most vulnerable countries to the impacts of climate change (Figure 6.1). With its large agricultural economy making up $18 \%$ of the country's GDP and employing nearly half of the population, substantial climate-related impacts on the workforce and economy can occur.

A $2.8 \%$ erosion of the country's GDP by 2050 is predicted, accompanied by a fall in living standards due to changes in temperature, rainfall and precipitation patterns (Mani et al., 2018). There were nearly 10,000 deaths from the floods in Bihar, Odisha, Andhra Pradesh, Tamil Nadu and Kerala, and from cyclones and landslides in other parts of the country during the last decade alone (World Bank, 2019). Additional deaths due to heatwaves will increase the numbers further. While the death burden from climate change needs urgent redressal, we also need to address the huge burden of morbidity from changing disease patterns and reduced quality of life related 


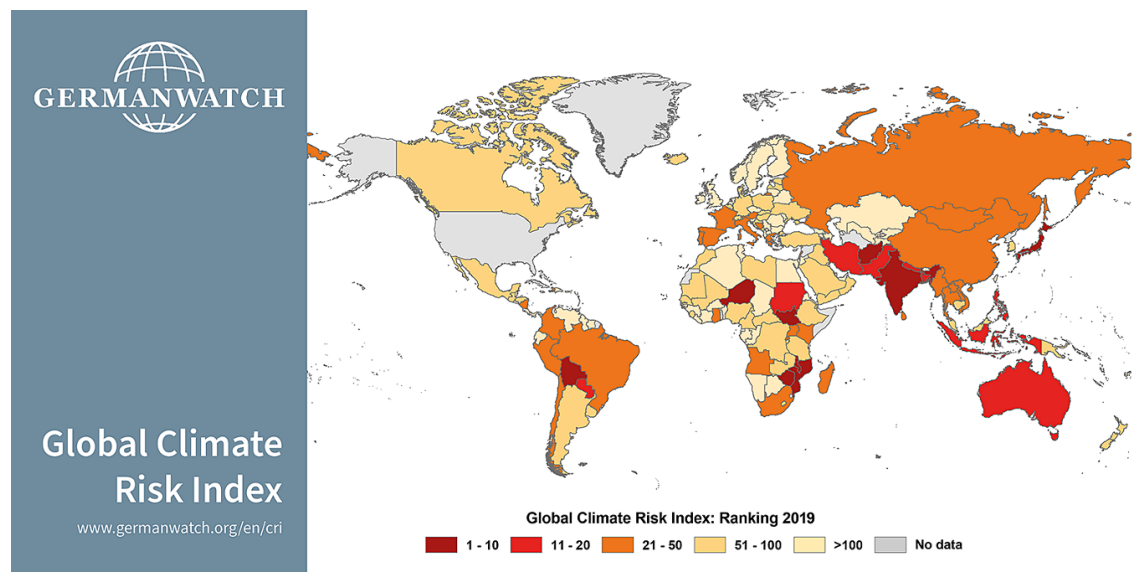

Figure 6.1 World map of the global climate risk index, 2019.

Source: David, E., Marie-Lena, H., \& Maik, W. (Global Climate Risk Index, 2019). Who suffers most from extreme weather events? Weather-related loss events in 2017 and 1998-2017 [Briefing Paper], p. 12. https://germanwatch.org/sites/germanwatch.org/files/Global\%20 Climate\%20Risk\%20Index\%202019_2.pdf .

to climate change. Climate change has huge impacts on health through direct and indirect pathways:

i. Acute changes in climatic conditions exacerbate existing diseases and trigger new patterns of disease dynamics

ii. Acute climatic events resulting in environmental degradation and disruption of ecosystems can cause an impact on human health

iii. Increased disease burden can occur in populations displaced by climate events ("climate refugees")

Figure 6.2 provides an overview of the health impacts of climate change and its pathways.

\section{The impacts of climate change on human health: an overview}

\section{Temperature and bealth}

Extreme temperatures, especially those leading to heatwaves and cold waves of varying duration, frequency and intensity, can impact human health.

Heatwaves - As compared to 2012, there have been an additional 40 million heatwave exposure events in India in 2016, with those above 65 years being the most vulnerable (Watts et al., 2018). This has caused a dangerous surge in the health impacts of heatwaves. Exposure to heatwaves of varying degrees can cause heat exhaustion, heat stress, heat syncope and heat stroke 


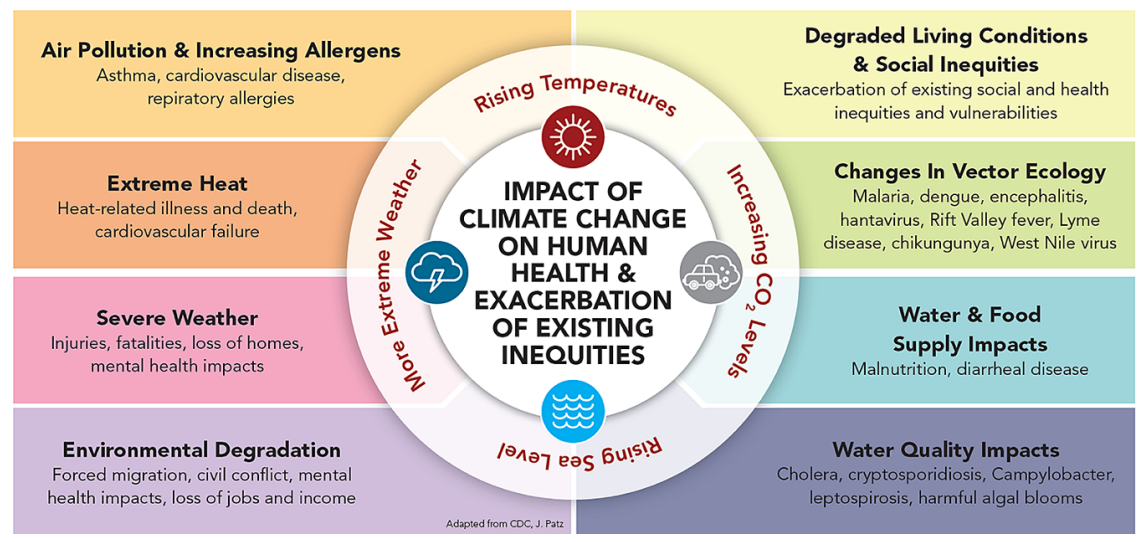

Figure 6.2 The impact of climate change on human health.

Source: California Department of Public Health Website, Climate Change and Health Equity Program. (n.d.). https://www.cdph.ca.gov/Programs/OHE/Pages/CCHEP.aspx

with symptoms ranging from hot, dry skin, heat rashes/eruptions, headaches, nausea, giddiness, excessive sweating, muscle cramps, kidney dysfunction, disturbances in vision, mental impairment and sometimes loss of consciousness. Children, the elderly and those with pre-existing morbidities are particularly vulnerable with the exacerbation of cardiovascular and respiratory illnesses becoming increasingly common. Additionally, severe heatwaves can cause deaths with the most striking example being the nearly 800 excess deaths occurring within one week in the month of May 2010 in Ahmedabad (Azhar et al., 2014). This topic is further discussed in the chapter titled The Status of Heat Health in India.

Cold waves - Exposure to extreme and moderately cold temperatures can also affect health, especially at extremes of age and in populations with preexisting illnesses. Greater incidences of ischemic heart disease, stroke and respiratory illnesses have been recorded in regions vulnerable to extremely cold temperatures, with the highest mortality occurring in those between 30 and 69 years from stroke, and in those above 70 years of age, from respiratory diseases. The impact of extreme temperatures on health are therefore wide-ranging, and any adaptation and mitigation efforts must take into account adequate vulnerability assessments, risk stratification, health system capacity-building and appropriate and adequate management of those affected (Box 6.1).

\section{Vector-borne diseases}

The pattern of vector-borne diseases in India is showing marked changes attributable to warmer temperatures and changing rainfall patterns as a result of climate change (Box 6.2). Changes in these climatic variables in 


\section{Box 6.1 Case study}

\section{Cold waves in Terai region, Nepal}

Nepal has been experiencing a rise in average temperatures due to global warming. However, a trend analysis of two recent periods, 1974-2014 and 2004-2014, showed a decreasing trend in minimum temperatures over the Terai region, which houses over $50 \%$ of Nepal's population. Vulnerable groups comprising children under 5 years of age, pregnant women and elderly citizens account for nearly $17 \%$ of the total population.

The decreasing temperatures during recent years have led to an increase in the number of cold wave days from an average of 8 days to 60 days in the past decade, impacting the poorest and the vulnerable populations the most. About 822 deaths were recorded due to cold waves between 1974-2013, compared to about 45 deaths due to heatwaves in the same period. These were mostly due to poor living conditions, inadequate heating and the consequent increase in illnesses such as acute respiratory infections, influenza, pneumonia, asthma, COPD, cardiovascular conditions, fever and hypothermia at extremes of age. Daily wage workers were also impacted and agricultural production suffered from crop losses due to very cold conditions. Inadequate heating in housing as well as hospitals was a major factor leading to hypothermia and acute respiratory illnesses in neonates and children under five. Cold conditions impacted school and workdays, with poor visibility affecting travel and leading to a greater incidence of trafficrelated injuries besides impacting the aviation industry and tourism.

As part of adaptation measures, locally available firewood and straw was burnt to provide warmth. Government agencies added aid in the form of provision of warm clothes to new-borns and their mothers while distributing firewood in some pockets. However, the increasing trends of cold wave days in this densely populated region, especially during the winter months from November to February, requires a better coordinated response to protect lives and livelihoods.

Source: Pradhan, Sharma and Pradhan, 2019

recent years have impacted vector biology. Both vector growth and development time for the pathogen within the vector's body (extrinsic incubation period) are affected by rising temperatures, with vectorial capacities peaking under these conditions. The geographic spread and transmission windows have also transformed the intensity of the disease burden in previously unaffected areas. Malaria, dengue, chikungunya and Japanese encephalitis are all vector-borne diseases that are projected to increase with changing climatic conditions in India. 


\section{Box 6.2 Case study}

\section{Vector-borne disease trends in India}

The Anopheles mosquito that carries the malarial parasite thrives in hot and humid areas. Altered climatic profiles influencing temperature, rainfall and humidity are affecting adult mosquito densities in large parts of the Indian sub-continent, and the changing transmission windows have caused the spread of disease in hitherto unaffected geographies. In India alone, an estimated 9.6 million cases of malaria were reported, with 16,700 estimated deaths due to the disease (WHO, 2018). The huge disease burden from malaria causes further stress on already burdened healthcare services. Dengue fever, spread by the Aedes Aegypti mosquito, has almost tripled or quadrupled in recent years, with the mosquito's survival, development and reproduction all influenced by warmer temperatures, rainfall and humidity (Lee et al., 2018). Even hilly areas are increasingly prone to dengue with the disease becoming increasingly prevalent in the northeastern states and the southern states of Kerala and Tamil Nadu (Rogers, 2015; Mutheneni et al., 2017). Changing rainfall patterns in recent years, often surpassing decades of previous precipitation levels, has facilitated the ideal conditions for mosquito breeding and the spread of dengue fever across the country. Chikungunya, also transmitted by the Aedes mosquito, has tripled in recent years. Bihar, for example, saw an unprecedented spike in Chikungunya cases in 2017 (CBHI, 2018). The disease, transmitted by a virus, has acute onset of symptoms of fever, joint pains, muscle pains, fatigue and rash. The often debilitating and prolonged symptoms of Chikungunya fever affect worker productivity through increased work absenteeism.

The intricate links between climate change and changing vector-borne disease patterns in India warrants the development of a good framework for prevention, surveillance, diagnosis and management of these conditions, in addition to building the capacity of health and allied services (such as laboratories) for early detection. Linking these efforts with forecasting by the meteorological department will ensure effective handling of the growing burden of vector-borne diseases from climate change in India.

\section{Water-borne diseases}

The combination of warmer temperatures and increasing rainfall are favourable for the spread of temperature-sensitive pathogens through 
water supplies, leading to outbreaks of water-borne diseases. Water-borne pathogens of human and animal faecal origin include several viruses, bacteria and protozoa. Cholera, for example, is climate-sensitive: the climatic suitability in certain geographical areas suitable for vibrio (the choleracausing bacteria) has risen by $3 \%$ since the 1980s (Watts et al., 2019). Floods can cause stormwater overflow with dissolved pathogens, contaminants from industrial and domestic waste, thereby increasing the possibilities of water-borne diseases. Altered concentrations of dissolved minerals and heavy metal contaminants are increasingly common, with high levels of arsenic (which causes severe skin and gastrointestinal conditions) and flourides (which cause dental and skeletal fluorosis) in large parts of floodaffected areas. Cancers have also been implicated through arsenic contamination of groundwater supplies. Gastrointestinal symptoms of nausea, vomiting, diarrhoea, stomach cramps and fever through water-borne diseases can cause school and work absenteeism in affected populations. Acute gastrointestinal diseases often require hospitalisation for rehydration, increasing the burden on health systems. Contaminated water used for bathing and washing purposes can cause skin and ear infections. The extreme situation of water scarcity caused by droughts and famine situations can cause diseases due to re-use and poor treatment of wastewater. The inextricable link between climate variability, access to clean water and sanitation and water-borne diseases is, therefore, an area of growing concern.

\section{Malnutrition}

The climatic impact on nutrition occurs directly and indirectly. Extreme temperatures have a severe impact on agricultural production across India, with allied sectors such as livestock rearing and fisheries also being affected. Staple crops like rice, wheat, maize and soya bean are affected, with the overall reduction in crop production and poor crop maturation patterns impacting food and nutrient availability. With undernutrition and its related impact on vulnerability to infections already existing in India, large sections of our population will suffer from the consequences of food and nutrient insecurity resulting from climate change. Studies have shown that infants show greater vulnerability to stunting and wasting in post-flood situations, with the subsequent unavoidable impact on growth and development (Watts et al., 2019). With the reduction in the availability of staple cereals, fresh fruits and vegetables, coupled with rising prices, the recourse to processed foods sets off an increase in the prevalence of conditions at the other end of the malnutrition spectrum - obesity. This new triad of the link between the three pandemics of climate change, undernutrition and obesity with common drivers has been labelled a global syndemic (Swinburn et al., 2019). 


\section{Air pollution-related diseases}

Air pollution is intricately linked to climate change, with rising temperatures causing a rise in the levels of ozone, an important greenhouse gas. The combustion of fossil fuels (a major source of air pollutants) with other gaseous and particulate pollutants increases greenhouse gases like carbon dioxide and methane, thereby driving climate change. The health impact of air pollution ranges from respiratory and cardiovascular illnesses to outcomes on pregnancy and neurocognitive development of children. Addressing air pollution therefore has co-benefits for climate change. This topic is further discussed in the chapter titled Air Pollution, Climate Change and the Health Sector: Linkages and Solutions.

\section{Mental health}

There is a growing recognition that the overwhelming threats of changing climate manifest in worsening mental health. In the aftermath of acute climatic events such as floods and droughts, post-traumatic stress disorder occurs widely among children and adults alike. Stress, anxiety, poor coping mechanisms and the compounded impacts of conflict for food and shelter signal an urgent need to address the rising burden of mental ill-health. Recent studies have linked increasing rates of suicide to climate change (Burke et al., 2018). A new condition of "eco-anxiety" or "climate anxiety" defined by the American Psychological Association in 2017 refers to the "chronic fear of environmental doom", a fear often experienced by children and adults due to the current and future predicted state of climate change and environmental disasters (Clayton et al., 2017). The trend of increased stress and suicides amongst farmers is also attributed to the influence of extreme temperatures affecting agricultural production and incomes in farmer households. The impacts on mental health of vulnerable populations such as children, women and the elderly must be recognised and an enabling environment for access to care and counselling services must be facilitated. "Solastalgia," a loss of solace due to degradation of the environment of an individual's belonging, is likely to disproportionately affect these vulnerable sections of our population. Enhancing the awareness and capacity of the health sector to deal with this growing burden of mental ill-health is both urgent and critical.

\section{Key takeaways}

- Climate change is an existential threat and can have wide-ranging impacts on human health. The overall impacts of climate change on human health can no longer be ignored; there is a dire need for healthcare professionals around the world to prepare for the growing burden of diseases from climate change. 
- The World Health Organization has designated five areas as major health impacts of climate change - malnutrition, deaths and injuries caused by storms and floods, water contamination and water scarcity related disorders, heatwaves and vector-borne diseases.

- Extreme temperatures (heatwaves and coldwaves) can exacerbate cardiorespiratory illnesses, especially in the elderly, affect labour productivity and cause school and work absenteeism.

- Climate change impacts overall food production, thereby leading to food and nutrition insecurity, with both undernutrition and overnutrition being fuelled by climatic changes

- Acute climatic events such as floods and droughts cause greater burden from water-borne diseases.

- Changing climatic conditions spur the onset of new patterns of vectorborne diseases.

- Climate change triggers onset of a range of mental health disorders.

\section{References}

Azhar, G. S., Mavalankar, D., Nori-Sarma, A., et al., (2014). Heat-related mortality in India: Excess all-cause mortality associated with the 2010 Ahmedabad heat wave [published correction appears]. PLoS One, 9(9), e109457; PLoS One, 9(3), e91831. Published 2014 Mar 14. doi: 10.1371/journal.pone.0091831

Burke, M., Gonzalez, F., Baylis, P., Heft-Neal, S., Baysan, C., Basu, S., \& Hsiang, S. (2018). Higher temperatures increase suicide rates in the United States and Mexico. Nature Climate Change, 8, 723-729.

California Department of Public Health Website, Climate Change and Health Equity Program. (n.d.). https://www.cdph.ca.gov/Programs/OHE/Pages/CCHEP. aspx

CBHI. (2018). National health profile 2018. Central Bureau of Health Intelligence.

Clayton, S., Manning, C. M., Krygsman, K., \& Speiser, M. (2017). Mental health and our changing climate: Impacts, implications, and guidance. American Psychological Association, Climate for Health and eco America. https://www.apa. org/news/press/releases/2017/03/mental-health-climate.pdf

Costello, A., Abbas, M., Allen, A., Ball, S., Bell, S., Bellamy, R., ... \& Patterson, C. (2009). Managing the health effects of climate change: Lancet and University College London Institute for Global Health Commission. Lancet, 373(9676), 1693-1733.

David, E., Marie-Lena, H., \& Maik, W. (Global Climate Risk Index, 2019). Who suffers most from extreme weather events? Weather-related loss events in 2017 and 1998-2017 [Briefing Paper], p. 12. https://germanwatch.org/sites/germanwatch.org/files/Global\%20Climate\%20Risk\%20Index\%202019_2.pdf

Lee, H., Kim, J. E., Lee, S., Lee, C. H. (2018). Potential effects of climate change on dengue transmission dynamics in Korea. PloS One, 13, e0199205.

Mani, M., Bandyopadhyay, S., Chonabayashi, S., Markandya, A., \& Mosier, T. (2018). South Asia's hotspots: Impacts of temperature and precipitation changes on living standards. South Asia development matters. World Bank. https://openknowledge.worldbank.org/handle/10986/28723 
Mutheneni, S. R., Morse, A. P., Caminade, C., \& Upadhyayula, S. M. (2017). Dengue burden in India: Recent trends and importance of climatic parameters. Emerging Microbes \& Infections, 6, 1-10.

Pradhan, B., Sharma, P., \& Pradhan, K. P. (2019, January 17). Impact of cold wave on vulnerable people of Tarai region, Nepal, Climate Change and Global Warming, Ata Amini, IntechOpen. doi: 10.5772/intechopen.82201.

Rogers, D. J. (2015). Dengue: Recent past and future threats. Philosophical Transactions of the Royal Society B: Biological Sciences, 370, 20130562.

Swinburn, B. A., Kraak, V. I., Allender, S., Atkins, V. J., Baker, P. I., Bogard, J. R., ..., \& Dietz, W. H. (2019, February 23). The global syndemic of obesity, undernutrition, and climate change: The Lancet Commission report. The Lancet, 393(10173), 791-846.

Watts, N., Amann, M., \& Arnell, N. W. (2019). The 2019 report of The Lancet Countdown on health and climate change: Ensuring that the health of a child born today is not defined by a changing climate. Lancet, 394, 1836-1878.

Watts, N., Amann, M., Arnell, N., Ayeb-Karlsson, S., Belesova, K., Berry, H., ... \& Costello, A. (2018, November 28). The 2018 report of The Lancet countdown on health and climate change. The Lancet. doi: 10.1016/S0140-6736(18)32594-7

WHO. (2018). World malaria report 2018. World Health Organization.

World Bank. (2019). The climate change knowledge portal [WWW Document]. https://climateknowledgeportal.worldbank.org/country/india/vulnerability 


\title{
AIR POLLUTION, CLIMATE CHANGE AND THE HEALTH SECTOR: LINKAGES AND SOLUTIONS
}

\author{
H. Paramesh, D. J. Christopher and Jyothi S. Menon
}

\section{Introduction}

Prolonged exposure to air pollution can result in numerous health hazards such as cardiovascular diseases, respiratory diseases, hypertension, stroke, cancer and premature births. In the past three decades, non-communicable diseases (NCDs) have emerged as a major cause of death in India, with air pollution as one of the major risk factors. The share of NCDs has increased ( $31 \%$ to $55 \%$ ) while communicable diseases have decreased $(61 \%$ to $33 \%$ ) from 1990 to 2016 (Dandona et al., 2017).

Lungs take the greatest stress from air pollution, from increased inflammation, predisposition to infections of upper and lower airways, and impairment of lung development. A recent study outlined the role of air pollution in triggering asthma as well as changing the genetic pattern in asthma initiation (Paramesh, 2018). Air pollutants can also affect the central nervous system, resulting in dementia, Alzheimer's disease, cognitive impairment, and other neurological problems. Children present "windows of susceptibility" to air pollution threats, where the effects may be cumulative and intergenerational, and its effects evident either early in life, in adulthood, or in the next generation (Paramesh, 2020).

Apart from the health burden, there are significant economic and social costs involved with air pollution, which include burgeoning healthcare and welfare costs, and the subsequent loss of productivity. Air pollution is closely related to climate change since they share common sources; hence, significant co-benefits can be expected from the mitigation of either of these two issues. Air pollution can also increase vulnerability to other diseases, burdening the already overloaded health system. Paradoxically, the health system can itself contribute to emissions, thus resulting in an additional burden of diseases. This chapter examines:

- The role of the health sector in contributing to air pollution.

- The issue of indoor air quality in hospitals and health facilities, and how to ensure safe indoor air quality for patients and healthcare workers. 
- The role of the health sector in combating air pollution and its ill effects on human health.

\section{Air pollution and the health sector}

Studies have estimated the contribution of the health sector to increased greenhouse gas (GHG) emissions along with other air pollutants (particulate matter, ozone, etc.). The emissions could be from direct activities associated with hospitals such as physician services, or indirect activities related to procurement and waste management. There is an urgent need to identify and mitigate emissions associated with healthcare. The various sources of air pollutants related to healthcare facilities are listed in Table 7.1 and discussed below:

- The incineration of medical wastes can emit toxic pollutants such as dioxins, furans, and other criteria air pollutants. It is reported that the burning of medical devices containing polyvinyl chloride (PVC) is a major source of dioxins, and metals in the waste act as a catalyst for its production (Datta et al., 2018). The particulates are released into the atmosphere in the form of fly ash. A major emission from incineration includes heavy metals such as mercury $(\mathrm{Hg})$, lead $(\mathrm{Pb})$, and cadmium (Cd) which are re-distributed in the fly ash and released with exhaust gases. The nitrogen content in the waste can trigger the formation and release of nitrogen oxides.

- The operation of boilers and generators can result in the release of gaseous pollutants such as $\mathrm{NOx}$ and SOx, along with other pollutants such as PM and CO. Other sources include sterilisation units that use volatile organic compounds (VOC) such as ethylene oxide and anaesthetic gas emission.

Table 7.1 Sources of pollutants in the health sector

\begin{tabular}{ll}
\hline Sources & Pollutants \\
\hline Waste Incinerator & $\begin{array}{c}\text { Particulate Matter (PM), Carbon Monoxide (CO), } \\
\text { Hydrogen Chloride (HCl), Sulphur Dioxide, Nitrogen } \\
\text { Oxides, various metals, dioxins/furans, Volatile } \\
\text { Organic Compounds (VOCs), heavy metals such as } \\
\text { Hg, Cd, Pb, etc. }\end{array}$ \\
$\begin{array}{l}\text { BM, SOx, NOx, Hazardous air pollutants (HAPs) } \\
\text { Generator }\end{array}$ & PM, SOx, NOx, Hazardous air pollutants (HAPs) \\
Sterilisation units & VOCs especially ethylene oxide \\
Refrigeration & CFCs \\
Laboratory fume hood & HAPs \\
Anaesthesia & Nitrous Oxide and Waste Anaesthetic Gases \\
& (halogenated anaesthetic agents)
\end{tabular}


- Laboratory operations that handle toxic chemicals can result in the emission of hazardous air pollutants into the atmosphere.

- Transport-related activities for hospital services and procurement can result in vehicular emissions. It is estimated that significant carbon dioxide emissions are contributed by ambulance services. Most ambulances run on diesel engines which produce more emissions as compared to petrol engines.

As per Central Pollution Control Board (CPCB) norms, all biomedical waste incineration facilities should attach a stack to the incinerator with a stack monitoring facility (as per the guidelines) for the regular monitoring of emissions. Air pollution control devices (filters, scrubbers, precipitators, etc.) should also be attached (CPBP Guidelines, 2016). For example, PM, $\mathrm{HCl}$, and $\mathrm{SO}_{2}$ can be controlled using filters, electrostatic precipitators, scrubbers, etc., and nitrogen oxides by process modification. Dioxins and heavy metals such as mercury can be controlled by passing the flue gas through suitable sorbent beds or activated carbon. An advanced technology (rarely practiced in India) is plasma pyrolysis and chemical treatment that contributes to lower emissions. More sustainable options such as electric ambulances or greening the ambulance fleet service will decrease the health facility's vehicular impact on the environment.

\section{Human exposure}

The workers and people living near the incineration facility/healthcare facility are more vulnerable due to direct exposure (inhalation of pollutants through the air) and indirect exposure (through the consumption of water or food contaminated by toxic particles deposited from air to water, soil or vegetation). Pollutants such as heavy metals stay longer in the environment and can be carried to other places. Even though emissions from one facility contributes only to a fraction of total emissions, the cumulative effect of emissions from multiple facilities within an area could be significant. This is important in highly polluted cities such as Delhi. Some studies have indicated that incinerator workers are exposed to higher concentrations of toxic metals, dioxins, and furans (Kumagai et al., 2002). Most of these metals are carcinogenic, causing irreparable damage to the human immune systems. Dioxins can accumulate in fatty tissues and also pass through the food chain. Studies have reported that exposure to dioxins released from incinerators can affect child development and result in cancer (Lundqvist et al., 2006). However, studies on the health impacts of such facilities are limited in India.

\section{Indoor air quality in hospitals}

Indoor air quality (IAQ) within hospitals is compromised due to the number of patients carrying infectious diseases entering the space, as well as 
infiltration of polluted outdoor air into the building. Various factors influence indoor air quality, such as building design and management, ventilation, airflow, and the presence of sources that release particles or toxic gases inside the building. Depending on these factors, the build-up of air pollutants could take place in enclosed spaces such as hospitals, affecting health and facilitating the easy spread of infectious diseases through airborne particle transmission. As a place for healing, hospital buildings/healthcare facilities pose the highest risk due to deterioration in indoor air quality. Patients thus become more vulnerable due to their already compromised immune system.

Indoor air quality (IAQ) is affected by many factors, of which outdoor air quality is a major one. The hospital should be located away from major air pollution sources such as busy roads, major traffic intersections, industries, waste-dumping sites, etc. Most hospitals in cities are located very close to busy roads, which can result in the entry of harmful vehicular emissions into buildings, where it takes a long time to dissipate. Apart from that, the microclimate (temperature, humidity, airflow, pressure, etc.) inside the buildings can also affect IAQ as it has a significant role in the dispersion and transport of pollutants, and can affect the thermal comfort of patients. The microclimate inside the buildings is maintained by air conditioning systems, which itself could be another source of pollutants if not properly managed and maintained. The ventilation and HVAC systems should be adequately designed to facilitate good air distribution inside the building (six air changes per hour).

Chemical compounds (especially VOCs) from substances used for cleaning, disinfecting, and sterilisation can also pollute the indoor air. Excess moisture content in the walls can foster fungal/mould growth and can spread as bio-aerosols. Renovation activities or construction in the hospital could introduce dust and toxic substances such as asbestos into the hospitals. Another major IAQ issue in hospitals is airborne infectious diseases which can easily spread due to poor indoor conditions.

The activities within hospital buildings also have a greater role in determining the IAQ. The patients and hospital staff can act as vectors, carrying air pollutants, especially toxin-laden particles, and aid in spreading them through occupant movement, which can re-suspend the settled particles, or by shedding particles from clothing and bodies (Takahashi et al., 2008). Medical activities such as nebulisation therapy, sterilisation, and use of anaesthetic gases can be a source of harmful pollutants such as VOCs and PAHs. Large microbial concentrations were found to be associated with the nebulisation treatments in the hospitals (Roberts et al., 2006). Studies have shown that pharmacy and medical equipment (blood bags, plastic film, injectors, infusion bags, etc.) can be a source of pollutants, especially phthalates (which are used to make polyvinyl chloride or vinyl more flexible and pliant) (Wang et al., 2015). 


\section{Vulnerable populations in the hospitals}

The groups that are particularly vulnerable to indoor air pollution are the patients (especially infants and the elderly) who spend a considerable amount of time in hospitals, and those with weak immune systems. This may subject them to new infections or aggravate their existing medical conditions. Other major groups potentially at risk are the hospital staff and doctors who are in close contact with the sources. The prolonged exposure to toxic chemicals and pollutants can affect their health. People who visit the facilities are also at risk (although not as much as the aforementioned groups) which include technical staff, inpatient/outpatient users, visitors, etc., depending on their health condition and age.

Hence, unlike other occupational exposure, indoor air pollution in healthcare facilities not only affect the workers, but also the patients and other visitors. Since most of these facilities are enclosed spaces with artificial air conditioning systems in place, this can result in a group of diseases called Sick Hospital Syndrome, which is associated with symptoms such as eye irritation, respiratory problems along with headache, dizziness, fatigue, and nausea (Brandt-Rauf et al., 1991). The presence of endocrine-disrupting chemicals (EDCs) in the indoor air of hospitals can affect the reproductive system, with serious effects on pregnant women and babies in hospitals (Wang et al., 2015).

\section{Hospital-acquired infections (HAI) through airborne transmission}

Microorganisms can be transmitted via three major routes - direct contact, droplet transmission, and airborne transmission. Microorganisms carried by air can be transmitted to longer distances, affecting a higher number of people. The enclosed hospital spaces and healthcare facilities can lead to the spreading of infectious diseases through airborne particle transmission. It is estimated that hospital-acquired infections (HAI) result in costs of \$96-146 billion (direct and indirect costs) in US acute care hospitals (Marchetti and Rossiter, 2013). Some microorganisms such as Aspergillus or Legionella species and fungal spores are aerosolised and can be transmitted via air. If HVAC systems and cooling towers are not properly maintained, they can become breeding grounds for microbes such as Legionella, which is transmitted through the air, causing a respiratory infection called Legionellosis (D’Alessandro et al., 2015).

Studies have also shown that some of these microbes can attach to particulate matter and infect the people who inhale these particles. This is important in highly polluted environments as the particles in the air aid in the transfer of diseases. The activities of staff, patients, and visitors such as coughing, 
sneezing, making of beds (skin scales shed by the infected patient), absence of proper behavioural rules, etc., can all aid in transfer. Coughing and sneezing can form droplet nuclei (of microbes), which can settle on to the particles in the 0.5-12 $\mu \mathrm{m}$ range and become re-suspended in the air (Cole and Cook, 1998). The main routes of transmission of respiratory droplets are by talking (100), coughing (1000), and by sneezing (over 1 lakh). Hence, the recommendation is to keep three feet away from the patient.

The environmental factors contributing to airborne pathogens are design, construction, operation and maintenance of hospital buildings which can lead to an environment that is favourable to the growth of microbes. The burden of disease due to HAI can be reduced if proper care is taken during the design and operation of healthcare facilities, taking into consideration the various environmental transmission routes. Studies have indicated the possibility of several respiratory viruses (SARS-CoV, MERS-CoV, Respiratory Syncytial virus, etc.) of being transmitted via both long-range and short-range airborne transmission.

\section{Ensuring safe indoor air quality}

- Airflow and filtration techniques: Healthcare facilities use heating, ventilation, and air conditioning (HVAC) systems to maintain better indoor air quality and thermal conditions for the safety and comfort of personnel and patients. A critical part of HVAC systems is the filter used to control the airborne contaminants and dust. The use of High-Efficiency Particulate Air (HEPA) filters are generally recommended and internationally recognised; they can filter particles of size up to 0.3 microns with an efficiency as high as $99.99 \%$. Proper ventilation and filtration are crucial to provide a healthy healing environment inside hospitals; proper design and maintenance of HVAC systems can have a positive impact on the health of staff and patients inside the building.

- Use of ultraviolet germicidal irradiation (UVGI) for disinfection: Another common technique used in hospitals to inactivate airborne infectious agents on hospital room surfaces is ultraviolet germicidal irradiation (UVGI). In this method, UV light of wavelength $253.7 \mathrm{~nm}$ is used; this can inactivate airborne bacteria, viruses, fungi and mycoplasma. This system has been in use for a long time and is found to be effective against most airborne pathogens.

\section{Air pollution and COVID-19}

The World Health Organization (WHO) declared the coronavirus disease 2019 (COVID-19) as a global pandemic on 11 March 2020 following its rapid spread across the world. Contact, droplet and airborne transmission are the widely accepted routes for its transfer. WHO acknowledged the possible role of airborne transmission in the spread of COVID-19, especially in 
indoor facilities and crowded areas. It is also hypothesised that particulate matter could carry the virus, triggering the spread of disease in highly polluted areas. A 2020 study has identified airborne transmission as a possible route based on global trend analysis (Zhang et al., 2020). The study reported that the initial outbreak in Wuhan occurred when the ambient $\mathrm{PM}_{2.5}$ levels were also higher. However, authors have mentioned that the effect of $\mathrm{PM}_{2.5}$ on transmission could be highly variable in different urban environments and needs to be studied further. A study in the US reported higher COVID-19 death rates in regions with higher $\mathrm{PM}_{2.5}$ concentrations (Wu et al., 2020). The aerosols bearing the virus can undergo coagulation or grow by attaching to the surface of ambient PM within a few hours. This could also enhance the lifetime of the virus and it may remain active for a much longer time, as indicated in a study from Italy (Setti et al., 2020). The possibility of such spread is higher in highly polluted environments and many Indian cities may fall in this category. However, in enclosed spaces such as hospital environments, aerosol transmission possibility is much higher, and this could result in hospital-acquired COVID-19 infections, affecting healthcare workers, patients and visitors. Healthcare workers worldwide have been affected by the virus. In India, some hospitals had to shut down due to a surge in COVID-19 cases among hospital staff.

\section{The role of the health sector}

As India is struggling to meet the emission standards, the need of the hour is a collaborative effort at a multi-sectoral level, which is required to tackle air pollution-related issues (Box 7.1). Consequently, the health sector's contribution to air pollution cannot be ignored, and appropriate measures should be taken to reduce the emissions from the sector.

Advocacy as Physicians: Physicians can advise patients suffering from diseases related to air pollution to adopt preventive measures when they are exposed to pollutants or during periods of higher pollution. They can provide necessary counselling on how to deal with the pollution problem in their day-to-day life. The doctors can put air pollution into the rational and larger context of a patient's life. Apart from that, all stakeholders, including those in the health sector, should work to reduce air pollution at source, eliminate existing pollutants, protect the health of the affected population and improve the quality of life.

Community Advocacy: Healthcare professionals can bring their expertise with an increased focus on public health to the centre of policymaking and can act as advocates in generating awareness about the ill effects of air pollution.

Research: Health professionals need to be actively involved in health research associated with air pollution in order to generate evidence. They can study the causes, mechanisms, and effects of air pollution 


\section{Box 7.1 Case study}

\section{Role of health professionals in combating the health effects of air pollution}

Healthcare professionals could be the leaders in promoting changes through the active involvement and coordination of all community stakeholders. Concerted actions have already been undertaken in a few cities in India (such as Bengaluru) under the leadership of doctors, such as banning tobacco smoke, banning leaded petrol, improving the health of traffic police by reducing their exposure to air pollution, and restricting the use of firecrackers. Studies for over three decades on airway diseases in the city of Bengaluru indicated that asthma prevalence in children has increased over the years; the results from these studies helped the Bhurelal Committee to formulate guidelines and issue a circular in 2004 to reduce air pollution in Indian megacities and improve the air quality of school environments. When research showed the influence of heavy school bags in adding to the burden of obstructive airway disease from air pollution, the Department of Education, Government of India, passed an order in November 2018 that a student's school bag should not weigh more than $10 \%$ of the bodyweight of the child.

exposure on human beings, focusing on vulnerable groups. Research also needs to be conducted on the quantification of health care emissions and to design strategies to mitigate the quantum of pollution. They should explore traditional systems which are accessible, available and sustainable.

Reducing emissions from the health sector: The health sector should plan and work towards mitigating air pollution and reducing emissions from the sector. Through proper waste segregation strategies, the volume of waste going to incineration facilities can be reduced, thus reducing toxic emissions. Policies should be implemented to reduce the use of dioxin precursors such as PVC, thus achieving reductions in dioxin emission. Proper management and maintenance of sterilisation units, labs, and pharmacies, and promoting the use of solar water heaters, can also reduce emissions. Studies have shown that a good ventilated ward should have six air changes per hour which reduces to 1.5 air changes per hour with windows closed, which can lead to infections four times higher in hospitalised patients (Gilkeson et al., 2013). "Vaastu," the science of structure and design of environments based on Vedic mathematics, recommends good cross-ventilation, natural light and greenery. 
Ensuring safe indoor air: Healthcare facilities should be places for healing and recovery, but this can be compromised with poor indoor air quality. The infiltration of polluted outdoor air can be reduced by strategically planning the design of the building and the area around the building. Green belt development around the building can reduce the pollutant concentration to some extent. Air filtration units and HVAC systems should be maintained properly to ensure proper air ventilation and filtration. The use of VOC emitting disinfectants and use of chemicals should be discouraged. A safer indoor environment would be conducive for the faster recovery and improved well-being of patients and workers.

\section{Key takeaways}

- Air pollution is a public health issue of paramount importance requiring a multi-sectoral collaborative effort, in which the health sector has a great role to play.

- The role of the health sector is crucial in dealing with the increased burden of disease due to air pollution.

- As abodes of healing, healthcare facilities should provide a safe environment for patients, visitors, and healthcare workers. The indoor air quality in hospitals is of utmost importance as the presence of air pollutants can facilitate the spread of infections.

- The health sector should work towards reducing their emissions while ensuring healthy air quality inside their facilities.

- Health voices in air quality-related policy-making are vital, and as thought leaders in a community, health professionals can promote advocacy for policy changes.

- To deal with air pollution and associated health effects one needs to think locally, act locally and propagate the results globally.

\section{References}

Brandt-Rauf, P. W., Andrews, L. R., \& Schwarz-Miller, J. (1991). Sick-hospital syndrome. Journal of Occupational Medicine: Official Publication of the Industrial Medical Association, 33(6), 737-739.

Cole, E. C., \& Cook, C. E. (1998). Characterization of infectious aerosols in health care facilities: An aid to effective engineering controls and preventive strategies. American Journal of Infection Control, 26(4), 453-464.

CPCB. (2016). Guidelines for management of healthcare waste as per biomedical waste management rules (p. 26). https://tspcb.cgg.gov.in/Shared\%20Documents/ Guidelines\%20for \%20Management \%20of\% 20Healthcare \%20Waste $\% 20$ Waste $\% 20$ Management $\% 20$ Rules, $\% 202016 \% 20$ by $\% 20$ Health $\% 20$ Care $\% 20$ Facilities.pdf

D’Alessandro, D., Fabiani, M., Cerquetani, F., \& Orsi, G. B. (2015). Trend of Legionella colonization in hospital water supply. Annali Di Igiene, 27(2), 460-466. 
Dandona, L., Dandona, R., Kumar, G. A., Shukla, D. K., Paul, V. K., Balakrishnan, K., ... \& Thakur, J. S. (2017). Nations within a nation: Variations in epidemiological transition across the states of India, 1990-2016 in the Global Burden of Disease Study. Lancet, 390(10111), 2437-2460. doi: 10.1016/S0140-6736(17) 32804-0

Datta, P., Mohi, G., \& Chander, J. (2018). Biomedical waste management in India: Critical appraisal. Journal of Laboratory Physicians, 10(01), 6-14.

Gilkeson, C.A., Camargo-Valero, M.A., Pickin, L.E., \& Noakes, C.J. (2013). Measurement of ventilation and airborne infection risk in large naturally ventilated hospital wards. Building and Environment. 65, 35-48. http://dx.doi. org/10.1016/j.buildenv.2013.03.0062

Kumagai, S., Koda, S., Miyakita, T., \& Ueno, M. (2002). Polychlorinated dibenzop-dioxin and dibenzofuran concentrations in serum samples of workers at intermittently burning municipal waste incinerators in Japan. Occupational and Environmental Medicine, 59(6), 362-368. doi: 10.1136/oem.59.6.362

Lundqvist, C., Zuurbier, M., Leijs, M., Johansson, C., Ceccatelli, S., Saunders, M., ... \& Koppe, J. G. (2006). The effects of PCBs and dioxins on child health. Acta Paediatrica, 95, 55-64.

Marchetti, A., \& Rossiter, R. (2013). Economic burden of healthcare-associated infection in US acute care hospitals: Societal perspective. Journal of Medical Economics, 16(12), 1399-1404. doi: 10.3111/13696998.2013.842922

Paramesh, H. (2018). Air pollution and allergic airway diseases: Social determinants and sustainability in the control and prevention. Indian Journal of Pediatrics, 85(4), 284-294. doi: 10.1007/s12098-017-2538-3

Paramesh, H. (2020). Air pollution impact on children health knowledge into action, Current Pediatric Research, 23, ISSN: 0971-9032, July 2020.

Roberts, K., Hathway, A., Fletcher, L. A., Beggs, C. B., Elliott, M. W., \& Sleigh, P. A. (2006). Bioaerosol production on a respiratory ward. Indoor and Built Environment, 15(1), 35-40.

Setti, L., Passarini, F., De Gennaro, G., Barbieri, P., Perrone, M. G., Borelli, M., ... \& Miani, A. (2020). SARS-Cov-2RNA found on particulate matter of Bergamo in Northern Italy: First evidence. Environmental Research, 188(May), 109754. doi: 10.1016/j.envres.2020.109754

Takahashi, Y., Takano, K., Suzuki, M., Nagai, S., Yokosuka, M., Takeshita, T., ... \& Enomoto, T. (2008). Two routes for pollen entering indoors: Ventilation and clothes. Journal of Investigational Allergology \& Clinical Immunology, 18(5), 382-388.

Wang, X., Song, M., Guo, M., Chi, C., Mo, F., \& Shen, X. (2015). Pollution levels and characteristics of phthalate esters in indoor air in hospitals. Journal of Environmental Sciences, 37, 67-74.

Wu, X., Nethery, R. C., Sabath, B. M., Braun, D., \& Dominici, F. (2020). Exposure to air pollution and COVID-19 mortality in the United States. Science Advances, 6(45). doi: 110.1126/sciadv.abd4049.

Zhang, R., Li, Y., Zhang, A. L., Wang, Y., \& Molina, M. J. (2020). Identifying airborne transmission as the dominant route for the spread of COVID-19. Proceedings of the National Academy of Sciences, 117(26), 14857-14863. 


\title{
NOURISH OR PERISH: THE EFFECT OF CLIMATE CHANGE ON FOOD, NUTRITION AND HEALTH
}

\author{
Manu Raj Mathur, Ameeka Shereen Lobo, Himanshi \\ Pandey, Anjali Ganpule-Rao and K. Srinath Reddy ${ }^{1}$
}

\section{Introduction}

Food and nutrition form an important dimension of an individual's health and well-being, and by extension, that of the population. Climate change is one among a set of interconnected trends and risks currently facing agriculture and food systems. Other components of global environmental change that are driving the future of food security include rapid changes in biodiversity, land cover, availability of freshwater, oceanic acidification, and nitrogen and phosphorus cycles. The Sustainable Development Goals (SDGs) offer a fresh momentum to affirm support and ensure that current and future diets are nutritionally diverse, accessible and affordable. In this era of rapid change, it is vital that new and updated policies are required to address the needs of nutritionally vulnerable people by making nutritional diets a norm and not an indulgence. A collective commitment is required for a change to occur in the global food systems, for a meaningful contribution towards sustainable human development.

Future food security for all will ultimately depend on management of the interacting trajectories of socioeconomic and environmental changes. Increased variability in climate is considered to be one of the highest challenges to food security, particularly through its effects on the livelihoods of low-income individuals and communities. This chapter will examine the following aspects:

1. The effect of climate change on food systems and vice-versa, along with its influence on health systems.

2. The food systems approach to climate change, and how adaptation and mitigation can determine positive policy changes and support decision making oriented to targeted interventions for environmentally sustainable and healthy food systems. 


\section{The impact of food systems on climate change}

Food systems encompass food chain activities as well as the outcomes of these activities and their governance (Vermeulen et al., 2012). There are multiple procedures involved in the process of getting food from farm to plate. Supply is enhanced through "post-harvest activities" in which continuous refrigeration is used to extend and ensure the shelf life of fresh and processed foods. Several food system undertakings give rise to the production of greenhouse gases (GHGs) and other climate change attributes, such as aerosols and changes in albedo. GHG emissions vary markedly across different food chain activities at the global level. The food system contributes $19-29 \%$ of total global anthropogenic GHG emissions, of which agricultural production contributes $80-86 \%$ at the global level, while the remainder comes from pre-production (predominantly fertiliser manufacture) and post-production activities (Vermeulen et al., 2012).

India emitted 3,202 million metric tons of carbon dioxide equivalent (MtCO2e) in 2014, which constitutes $6.5 \%$ of global GHG emissions. To this, the contribution of the energy sector is the greatest with $69.7 \%$, followed by agriculture $(19.6 \%)$, industrial processes $(6 \%)$, land-use change and forestry $(3.8 \%)$ and waste disposal (1.9\%) (USAID, 2018).

The linkages and drivers between climate change, food security and human health are presented below in Figure 8.1. The framework illustrates the nexus from a food system perspective, highlighting the direct and indirect pathways in which the physical impacts of climate change may work through the food system to influence food security and, subsequently, human health. By identifying the different sectors of the food system, the framework demonstrates that a multi-sectoral approach is necessary for effective adaptation and resilience building in response to climate change (Schnitter and Berry, 2019).

\section{The impact of climate change on food systems}

The impact of global climate change on food systems is expected to be widespread, complex, geographically and temporally variable, and profoundly influenced by pre-existing and emerging social and economic conditions. Weather anomalies and climatic trends on food systems impact plant and animal physiology and the yields, prices, reliability of delivery, food quality and food safety (Vermeulen et al., 2012).

The effect of climate change on growth of crops can be both positive and negative through multiple mechanisms, including changing phenology, heat stress, water stress, waterlogging and increases or reductions in pests and diseases (Vermeulen et al., 2012). Change in temperature has affected cultural crops, thus impacting the productivity and quality of horticulture crops. Due to the increase in temperature, a few areas in North-West India experience a high rate of evaporation and dry conditions (Bhati et al.,2018). 


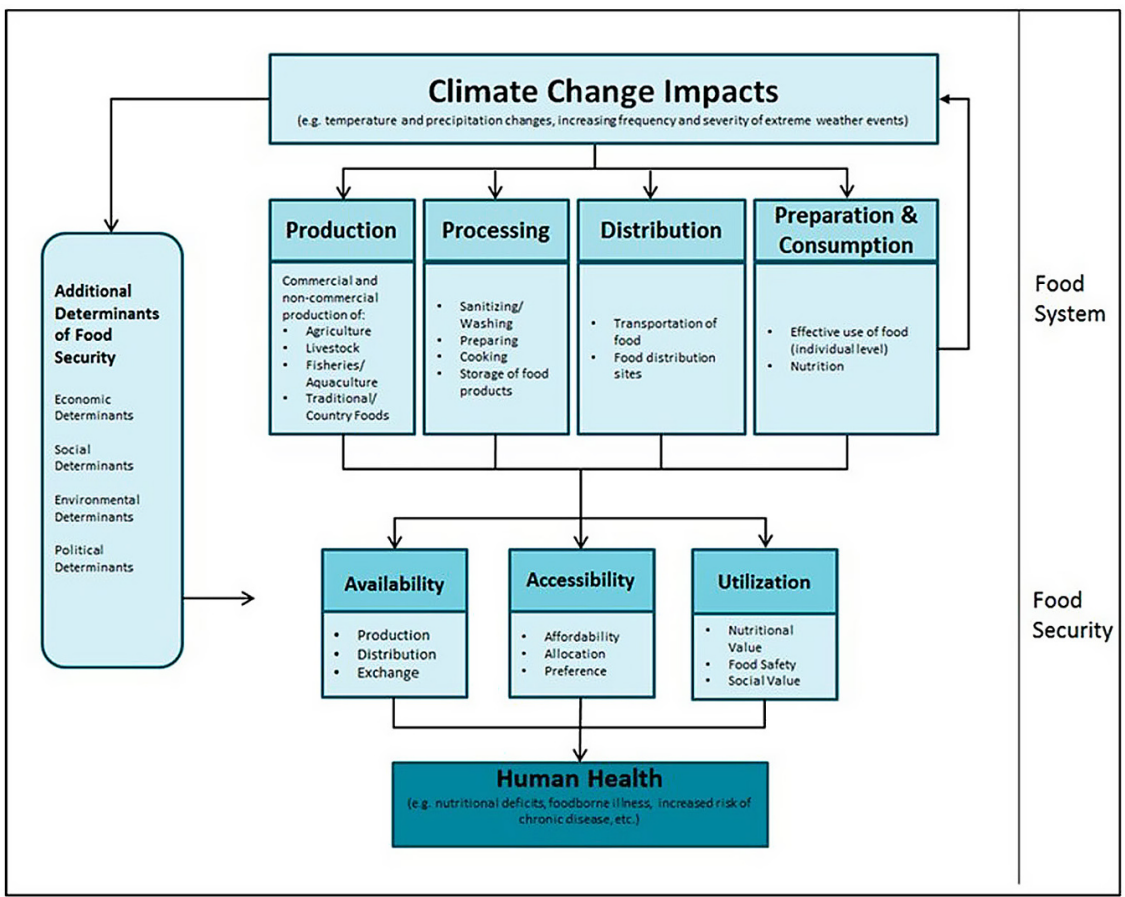

Figure 8.1 Food security, climate change and human health nexus framework.

Source: Reproduced with permission from Schnitter R, Berry P. (2019). The climate change, food security and human health nexus in Canada: A framework to protect population health. International Journal of Environmental Research and Public Health, 16(14), 2531. doi: 10.3390/ijerph16142531.

Rising ambient temperatures are associated with increasing incidence of harmful algal blooms that result in lethal toxins in the fishery industry, particularly in shellfish, which eventually impacts the food availability and safety of human populations (Moore et al., 2008). It is anticipated that climate change could also affect livestock production directly through its impact on water, genetic diversity, diseases, pasture and feed supplies (Vermeulen et al., 2012).

Figure 8.2 describes the impact of climate change on food systems. Decreased water accessibility, uncertain meteorological conditions and depletion of natural resources can increase ambiguity in food production. This reduces food and nutrition availability and increases food price volatility. Climate change also makes individuals susceptible to poor health directly lowering labour productivity. Due to the fluctuation of food prices and decreased food and nutrient availability, food accessibility is diminished, reducing prospective economic growth. The negative effects of climate change can be experienced by people living in coastal areas, poor rural 


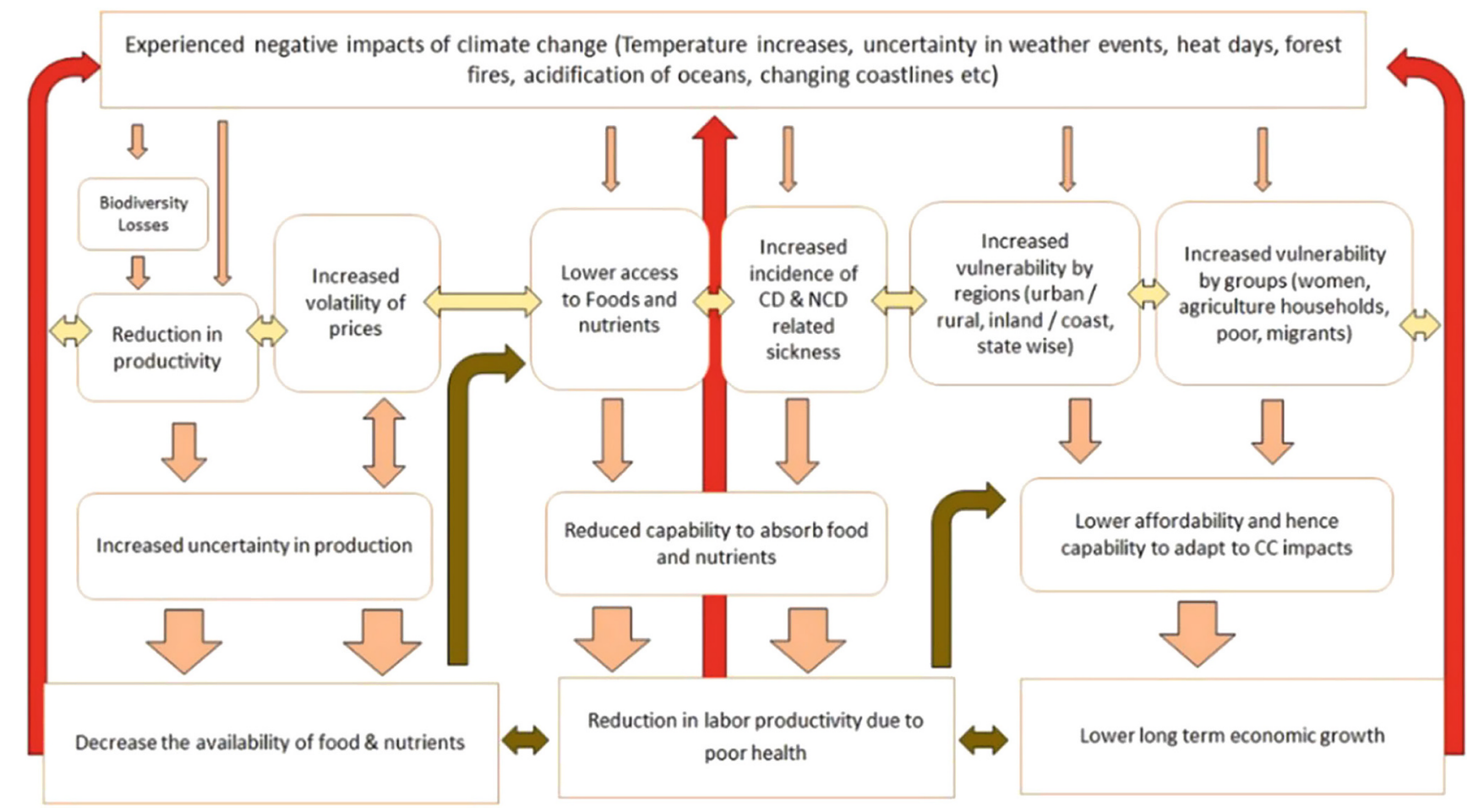

Figure 8.2 Pathways: impact of climate change on food systems.

Reproduced with permission from Pingali P., Aiyar A., Abraham M., Rahman A. (2019) Managing Climate Change Risks in Food Systems. In: Transforming Food Systems for a Rising India. Palgrave Studies in Agricultural Economics and Food Policy. Palgrave Macmillan, Cham. https://doi. org/10.1007/978-3-030-14409-8_10 
agricultural households, women and older individuals. This eventually depresses long-term economic growth prospects for both individuals and food systems. Due to the decrease in food availability, labour productivity and lower long-term economic growth, a vicious cycle is formed, leading to low adaptation capability towards climate change which can worsen its impacts on individuals (Pingali et al., 2019).

\section{Climate change, food systems and health}

Pesticides: Exposure to pesticides is often associated with health and environmental concerns since their residues can be found in food and beverages. The use of pesticides is regulated in export products and not in domestic raw food in India. For export to western countries, the use of good agriculture practices (GAP) and sanitary and phytosanitary (SPS) practices are followed, which are not applicable for Indian use. The presence of pesticides such as organochlorine, organophosphorus and carbamates beyond a regulated limit can lead to neurodevelopmental, endocrine, reproductive, cellular, metabolic, lipid, haematological and hepatic alterations and disorders (Freire et al., 2015; Jahangir et al., 2016).

Antibiotic resistance and hormones: This is one of the biggest threats to global health, food security and development. The use of antibiotics in farming and agriculture is required up to a certain level, but abuse of antibiotics is one of the factors contributing to drug resistance in humans by transferring resistance genes from agriculture into human pathogens (de Kraker et al., 2016).

Organic food: Studies have also suggested that higher levels of vitamin $\mathrm{C}$ and phenolic compounds are present in organic plant products, and higher levels of omega-3 fatty acids and conjugated linoleic acid in milk are found in organically raised animals (Hurtado-Barrasso et al., 2019). Evidence has been put forward that organic food consumption reduces the risk of allergy, overweight and obesity (Mie et al., 2017) along with decreased risk of cardiovascular, neurogenerative diseases and some cancers (Hurtado-Barrasso et al., 2019). Though organic cultivation is good, it is difficult to follow because of the economics: lower yield and issues of cross-pollution of neighbourhood pesticide use. However, large long-term intervention studies as well as economic studies are required to determine the effect of organic food on health and its cost.

Factory farm pollutants: The two primary sources of factory farm pollutants are waste from animal farms and agricultural chemical waste: these drive land, water and air pollution (PACE University, 2020). Untreated animal waste and synthetic fertilisers contain excessive amounts of nitrogen, phosphorous and heavy metals. The residues of the agriculture chemicals are found to be present at every level of 
the food chain. The unabsorbed substance pollutes the environment, degrades water retention and soil fertility, and impairs water resources (Empowered Food Project, 2020). Since India has small farmlands, there is not much of an effect from farm factories in the nation.

Nutrient content of crops: Nutrient acquisition is closely connected with overall biomass and is strongly influenced by root surface area. When there is a change in climate, an alteration in soil factors occurs, which restricts root growth causing nutrient stress (Brouder and Volenec, 2008). The loss in nutrients would lead to nutrition deficiency, especially for those already on the brink of deficiency in Asia, West Asia and North Africa (Smith et al., 2018). Hence, it would be beneficial to either alter the cropping or farming systems, or use climate-resilient crops to accommodate shifts in ecozones (Brouder and Volenec, 2008). Box 8.1 demonstrates the use of technology in agriculture to help increase crop yields.

\section{Box 8.1 Case study}

\section{The use of Artificial Intelligence (AI) to improve farming}

Agriculture is the largest livelihood provider in India; hence, sustainable agriculture practices should be adopted in order to reduce food scarcity. Though agriculture is the least digitised sector, agricultural technologies have recently seen momentum where digital technology can play a transformational role in modernising and optimising India's performance in the sector. It is difficult for farmers to predict weather patterns or crop yields accurately, making it hard for them to make informed financial and operational decisions. Smart farming in India has helped increase crop yield by as much as $30 \%$. Microsoft India, in collaboration with International Crops Research Institute for Semi-Arid Tropics (ICRISAT), has developed a sowing application for farmers combined with a personalised village advisory dashboard for Andhra Pradesh. This application is able to use weather models and data on local crop yields and rainfall to accurately predict and advise local farmers on when they should plant their seeds based on indicators such as weather conditions and soil, among others. It is developed to provide powerful cloud-based predictive analytics to empower farmers with crucial information and insights to help reduce crop failure and increase yield, in turn, reducing stress and generating better income.

Source: Kumar et al., 2020. 
Projected changes in food availability: Rising incomes and growing urbanisation are changing the food basket composition swiftly with a projection of high demand of food in the future. In 2010, Mittal projected India's demand and supply of food up to 2026, stating that there would be an increase in food demand due to the increase in population, while production would be constrained due to low yield growth; and consequently, that it would be difficult for domestic production to meet the food requirement (Mittal, 2010). Figure 8.3 shows the vulnerability of districts in India to climate change in the coming years.

\section{Food safety}

Food safety is a public health priority today. Unsafe food is a threat to everyone, and especially to the vulnerable population. Food can be contaminated at any point in the food chain activity, thus the responsibility for food safety lies in the hands of food producers. Contaminated food can cause numerous diseases. Hence, adequate food systems and infrastructures need to be built and maintained. A multi-sectoral collaboration with sectors such as public health, animal health and agriculture should be developed to successfully integrate food safety into food policies and programmes (Chakrabarty, 2016).

\section{Basic recommendations for a healthy, affordable and sustainable diet}

A healthy and sustainable diet is one that provides all the essential nutrients, including minerals and vitamins while producing a low environmental impact (Dwivedi et al., 2017). In India, there is a co-existence of undernutrition and obesity; however, micronutrient deficiencies are far higher though less visible in lower-income populations in urban and rural India. With the advent of the Green Revolution in the sixties, the government promoted high-yielding, low nutrient-content cereals (rice and wheat) at the expense of more nutritious indigenous varieties of coarse cereals (millet, maize and sorghum). Eating pulses, dark green leafy vegetables, coconut and coarse cereals instead of rice would together alleviate nutritional deficiencies cost-effectively.

India ranks second lowest in meat consumption in the world, and livestock production contributes $10 \%$ of GHG emissions, largely from dairy products. Animal originated foods are typically richer in micronutrients and more bioavailable than vegetarian sources, but also more expensive. The bioavailability of different nutrients alters intake requirements. It varies with health status, processing techniques and food combinations. Nutritional adequacy could be achieved more affordably if meat products were substantially cheaper. Important shifts can be made by offering different food subsidy policies to low-income groups and by extending the scope 


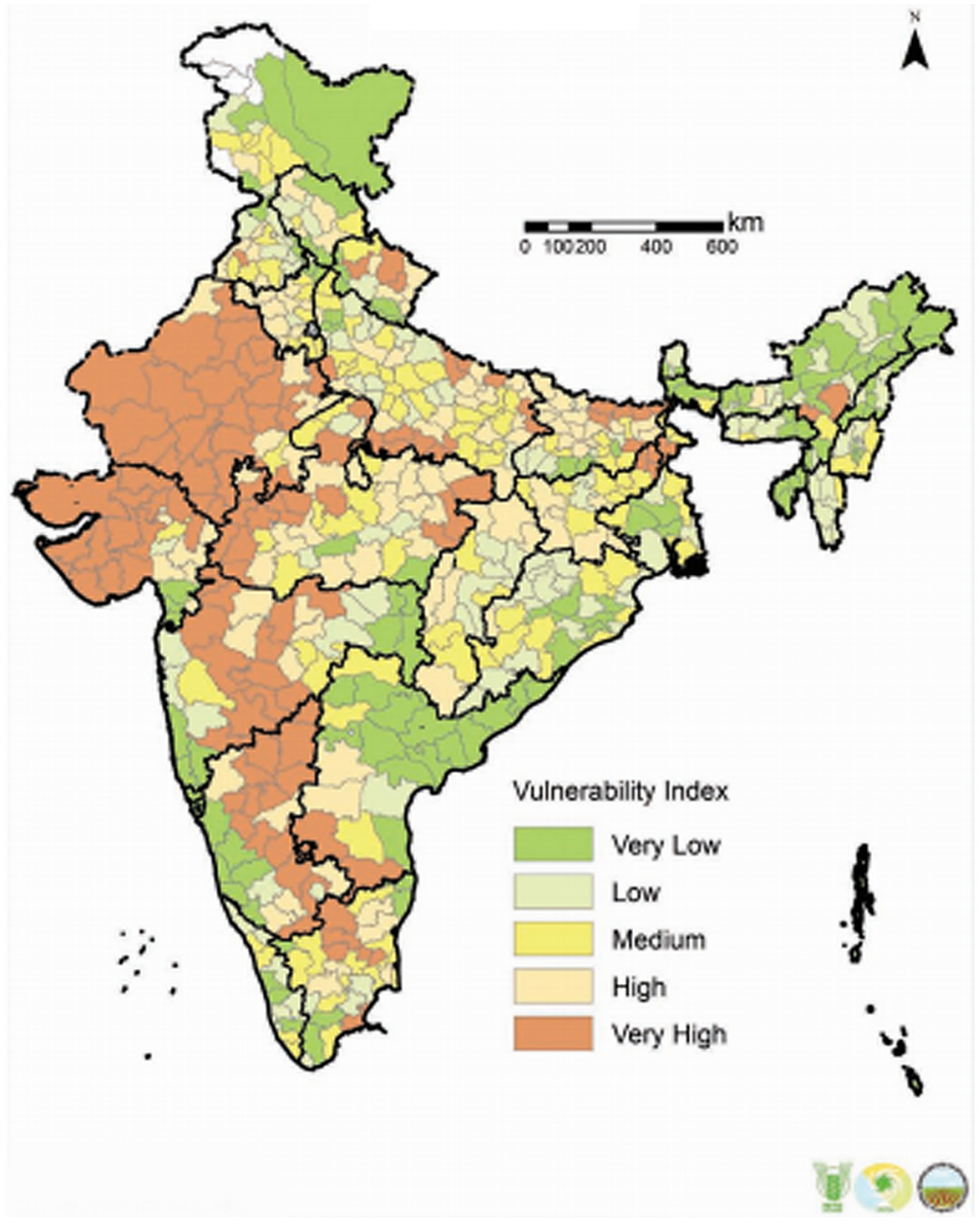

Figure 8.3 Vulnerability of Indian agriculture to climate change (2021-2050).

Source: Reproduced with permission from Rao, C. A. R., Raju, B. M. K., Rao, A. V. M. S., Rao, K. V., Rao, V. U. M., Ramachandran, K., Venkateswarlu, B., \& Sikka, A. K. (2013) Atlas on vulnerability of Indian agriculture to climate change. Central Research Institute for Dryland Agriculture.

of the Public Distribution System to increase the affordability and availability of coarse cereals and dark green vegetables in place of wheat and rice (Rao et al., 2018).

Figure 8.4 describes sustainable healthy diets that promote all dimensions of individuals' health and wellbeing. It aims to achieve optimal growth and development of all individuals and support the functioning of physical, mental and social wellbeing at all life stages for present and future generations. 


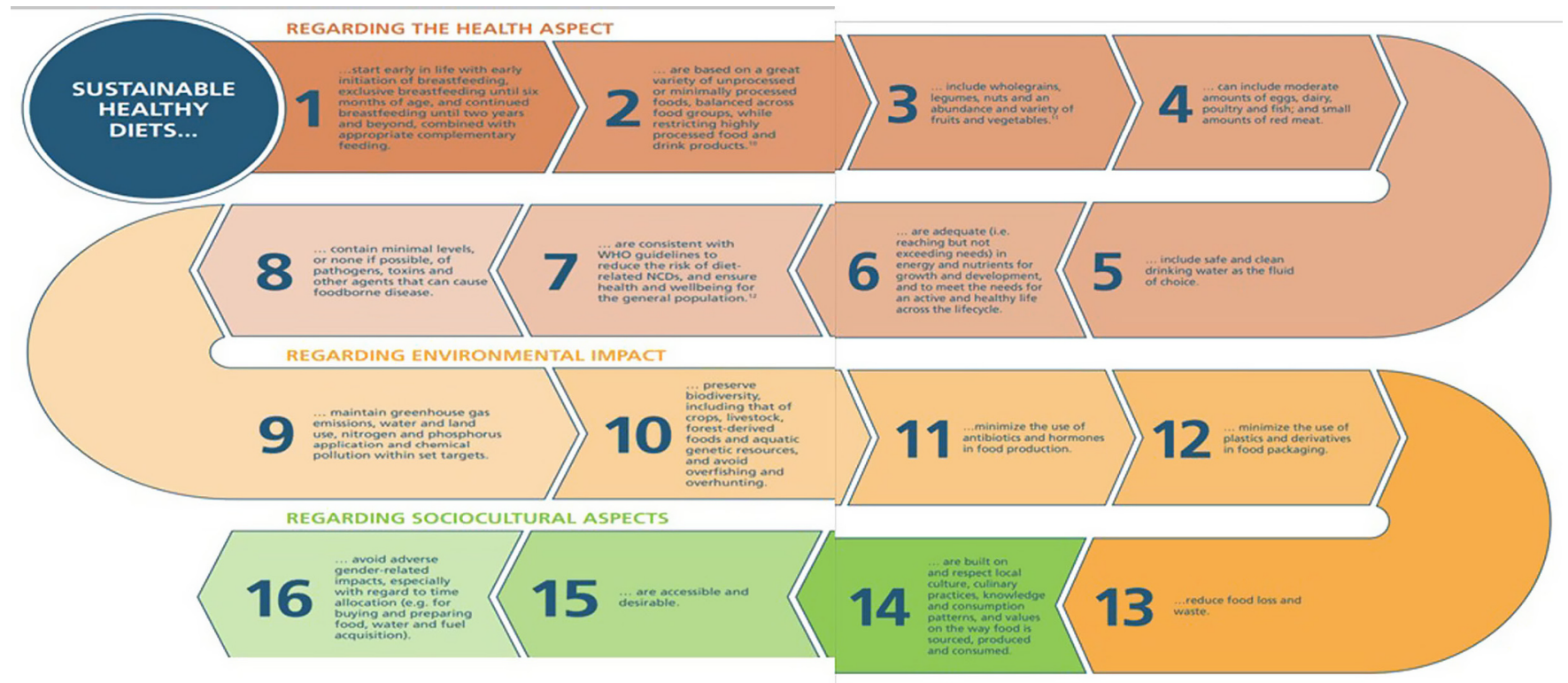

Figure 8.4 Guiding principles for sustainable healthy diets.

Reproduced from FAO and WHO (2019), Sustainable healthy diets: Guiding principles. 


\section{Box 8.2 Case study}

\section{Leaf station farm: A hydroponic growing module}

Hydroponic farms are farms that practice growing plants without soil in a nutrient-rich water solution. This practice of agriculture resolves many of the issues that challenge year-round growing such as availability of fertile soil or clean and surplus water. A leaf station farm is designed to include all the components required for commercial clean food production, and engineered for seamless operation, allowing growers to immediately start growing. This flatbed farm encourages uniform growth, colour, size and appearance with a focus on delivering consistent light to the plants. Its modular and ergonomic design ensures efficient harvesting and easy scalability. It uses a technique called NFT (Nutrient Film Technique) - Flat Bed which occurs by running a thin layer of water through channels to ensure that the plant receives the required amount of water while leaving the roots well aerated. It is low maintenance, uses no pesticides, requires no soil, has more yield per acre, enables re-use of water and requires less labour with ease of harvesting.

Source: Future Farms, 2020.

\section{Risk mitigation strategies}

Risk mitigation strategies require substantial resources, but their application is necessary: the rapid increase in extreme weather events and unprecedented changes to weather and pollution rates require an urgent response. Climate-smart agriculture (CSA) strategies should be adopted to ensure enhanced productivity, increased resilience and limited environmental externalities. This requires a combination of technology, management practices, infrastructure and information systems that can help mitigate, reduce or withstand the effects of climate change (Pingali et al., 2019) (Box 8.2). Cropland mitigation measures, soil carbon sequestration and livestock management can be useful in this regard.

\section{Key takeaways}

- The demand for healthy, affordable and sustainable food is increasing because of population growth, and the pledge to maintain biodiversity and other resources, pose a major challenge to agriculture that is already threatened by climate change. 
- Lack of crop diversity leads to loss of dietary diversity which not only affects the developing world but also the industrialised world. Thus, an integrated system approach is necessary to produce sufficient, safe and nutritionally enhanced food, as not all healthy diets are sustainable, and not all sustainable diets are healthy.

- Plant-derived foods are healthy, diverse and may reduce food-based greenhouse gas emissions, whereas animal-based products have a higher environmental impact. Thus, reducing animal-source foods in human diets can benefit both human and environmental health.

- Climate change impacts human health, economic development, agricultural systems and availability of food and nutrients. The reduction in the quality of natural resources and increased incidence of extreme weather events is expected to impact food systems through multiple channels.

- The environmental impact can be lowered and health enhanced by identifying and adapting the appropriate dietary patterns and crop diversity.

\section{Note}

1 With thanks to Mrs Bhushana Karandikar for her input, and to FAO and SHEFS, Wellcome Trust funded project for their support.

\section{References}

Bhati, A., Kumari, S., \& Ramdeen, K. (2018). Effect of climate changing on horticultural crops in India - A review. Trends in Biosciences. https://www.researchgate. net/publication/331987868_Effect_of_Climate_Changing_on_ Horticultural_Crops_in_India-A_Review

Brouder, S. M., \& Volenec, J. J. (2008). Impact of climate change on crop nutrient and water use efficiencies. Physiologia Plantarum, 705-724.

Chakrabarty, M. (2016). Climate change and food security in India. Observer Research Foundation https://www.orfonline.org/research/climate-change-andfood-security-in-india/

de Kraker, M. E. A., Stewardson, A. J., \& Harbarth, S. (2016, November 29). Will 10 million people die a year due to antimicrobial resistance by 2050? PLOS Medicine, 13(11), e1002184. https://dx.plos.org/10.1371/journal.pmed. 1002184

Dwivedi, S. L., Lammerts van Bueren, E. T., Ceccarelli, S., Grando, S., Upadhyaya, H. D., \& Ortiz, R. (2017). Diversifying food systems in the pursuit of sustainable food production and healthy diets. Trends in Plant Science, 22(10), 842-856.

Empowered Food Project. (2020). Pollution (water, air, chemicals). Food Empowerment Project.https://foodispower.org/environmental-and-global/pollutionwater-air-chemicals/

FAO and WHO. (2019). Sustainable healthy diets: Guiding principles. http://www. fao.org/documents/card/en/c/ca6640en/ 
Future Farms. Leaf Station Farm: FutureFarms: India's leading Commercial Hydroponic Technology Solution Provider|NFT|Dutch BucKet/Vertical Farms|Indoor Farml[Internet]. [cited 2020 Aug 30]. https://www.futurefarms.in/ leaf-station-farm/

Freire, C., Koifman, R. J., \& Koifman, S. (2015). Hematological and hepatic alterations in Brazilian population heavily exposed to organochlorine pesticides. Journal of Toxicology and Environmental Health, Part A, 78(8), 534-548. doi: 10.1080/15287394.2014.999396

Hurtado-Barraso, S., Tresserra-Rimbau, A., Vallverdú-Queralt, A., \& LamuelaRaventós, R. M. (2019). Organic food and the impact on human health. Critical Reviews in Food Science and Nutrition, 59, 704-714.

Jahangir, A. M., Hilbeck, A., Nicolopoulou-Stamati, P., Maipas, S., Kotampasi, C., Stamatis, P., \& Hens, L. (2016). Chemical pesticides and human health: The urgent need for a new concept in agriculture. Frontiers in Public Health. doi: 10.3389/fpubh.2016.00148

Kumar, R., Patel, S. V., Yadav, S., Kumar, M., Kumar, J., \& Kumar, M. (2020). Artificial intelligence: New technology to improve Indian agriculture. International Journal of Chemical Studies, 8(2), 2999-3005.

Mie, A., Andersen, H. R., Gunnarsson, S., Kahl, J., Kesse-Guyot, E., Rembiałkowska, E., Qualigo, G., \& Grandjean, P. (2017). Human health implications of organic food and organic agriculture: A comprehensive review. Environmental Health. doi: 10.1186/s12940-017-0315-4

Mittal, S. (2010). Structural shift in demand for food: Projections for 2020. esocialsciences.com, Working Papers.

Moore, S. K., Trainer, V. L., Mantua, N. J., Parker, M. S., Laws, E. A., Backer, L. C., \& Fleming, L. E. (2008). Impacts of climate variability and future climate change on harmful algal blooms and human health. Environmental Health, 7(S4). doi: 10.1186/1476-069X-7-S2-S4

PACE University. (2020). Research guides: Student project: Factory farming: Environmental impacts. https://libraryguides.law.pace.edu/c.php?g=452979\& $\mathrm{p}=3107602$

Pingali, P., Aiyar, A., Abraham, M., \& Rahman, A. (2019). Managing climate change risks in food systems. In: Transforming food systems for a rising India. Palgrave Studies in Agricultural Economics and Food Policy. Palgrave Macmillan. doi: 10.1007/978-3-030-14409-8_10

Rao, C. A. R., Raju, B. M. K., Rao, A. V. M. S., Rao, K. V., Rao, V. U. M., Ramachandran, K., Venkateswarlu, B., \& Sikka, A. K. (2013). Atlas on vulnerability of Indian agriculture to climate change. Central Research Institute for Dryland Agriculture.

Rao, N. D., Min, J., DeFries, R., Ghosh-Jerath, S., Valin, H., \& Fanzo, J. (2018). Healthy, affordable and climate-friendly diets in India. Global Environment Change, 49(49), 154-165.

Smith, M. R., Thornton, P. K., \& Myers, S. S. (2018). How climate change impacts the concentration of key nutrients in crops. Climate Change, Agriculture and Food Security. https://ccafs.cgiar.org/news/how-climate-change-impacts-concentrationkey-nutrients-crops\#.X0Q3HNwzbIU 
Schnitter, R., \& Berry, P. (2019). The climate change, food security and human health nexus in Canada: A framework to protect population health. International Journal of Environmental Research and Public Health, 16(14), 2531. doi: 10.3390/ijerph16142531

USAID. (2018). Greenhouse gas emissions in India. Climate Links. https://www.climatelinks.org/sites/default/files/asset/document/India \% 20GHG\% 20 Emissions\%20Factsheet\%20FINAL.pdf

Vermeulen, S. J., Campbell, B. M., \& Ingram, J. S. I. (2012). Climate change and food systems. Annual Reviews, 37(1), 195-222. doi: 10.1146/annurev-environ020411-130608 


\title{
GENDERED VULNERABILITIES AND HEALTH INEQUITIES
}

\author{
Vanitha Kommu, Divya Alexander and Lakshmi Lingam
}

\section{Introduction}

Climate change has a profound and increasing impact on human health and well-being, as outlined in the earlier chapters of this book. Given the existing gender-based inequalities, climate change affects the lives of men, women and girls differently (WHO, undated). Understanding the multidimensional aspects of climate change specifically on women and their health is important in order for healthcare workers to build their sensitivity, and to respond pro-actively to ensure health and gender equity. It is useful to understand what causes these differential impacts, which are often referred to as being "gendered."

Gender is defined as the "socially constructed roles, behaviours, activities and attributes that a given society considers appropriate for men and women" (WHO Gender Fact Sheet) and people of other genders. However, gender construction not only leads to differential access to resources (land, property, income, education) but also leads to women and girls being marginalised and having lower access to public and private decision making and autonomy. This structural and systemic gender hierarchy in conjunction with other social stratifiers, such as class, caste, ethnicity, age, ability and citizenship status, produces differential exposure, differential response and differential outcomes to any given situation. Gender differentials in health linked to climate change, therefore, are a combined function of physiological, behavioural and socially constructed differences. The concerns discussed in this chapter cover key aspects linked to the United Nations Sustainable Development Goals that relate to health (Goal 3), gender equality (Goal 5) and climate action (Goal 13). This chapter will:

1. Outline the linkages between climate and gender-specific health impacts and examine the gender-based vulnerabilities that result in differentiated impacts.

2. Explore a gender-sensitive approach in existing healthcare systems, highlighting gaps and providing recommendations. 


\section{Climate change and gender-specific health impacts}

The key impacts of climate change are extreme weather events, altered air quality, favourable weather conditions for degradation and the spread of disease, and contamination of natural resources. Climate change is said to aggravate health risks in humans with gendered differentials, making women and children the most vulnerable (WHO, 2011). In the sections below, we closely study the gender-based vulnerabilities and undesirable impacts of climate-triggered events/alterations on women.

Vulnerability to extreme weather events: Globally, deaths related to natural disasters are higher among women, as they are generally not equipped with the necessary skills (e.g. swimming, running and climbing trees to protect themselves during floods), and also have poor access to climate-related information. Similarly, sociocultural norms, dress codes and women's responsibility for the elderly, children, people with disabilities and homestead livestock restrict women's mobility in general, and at the time of crises in particular (Box 9.1). These disasters may also disturb local security and safety systems, resulting in stress, conflicts and mental health-related issues among children and women (Bartlett, 2008).

Vulnerabilities to temperature variations: The physiological dispensation of women to increasing temperatures is different when compared to men, making them biologically vulnerable. Their heat dissipation through

\section{Box 9.1 Case study \\ The gendered impacts of the tsunami in South-East Asia, 2004}

The 2004 tsunami that decimated South East Asia killed 220,000 people and left 1.6 million homeless. A survey conducted by Oxfam revealed that four times as many women than men were killed in the tsunami-affected areas of Indonesia, Sri Lanka and India (MacDonald, 2005). The reasons were similar across countries: women couldn't swim or climb trees to escape, they stayed behind to look for their children or other relatives, they were at home while the men were out (away from the seafront), they were waiting on shore for the men to bring back the catch, or they were bathing in the sea at the time when the tsunami struck. There are both short-term and long-term consequences, resulting in an imbalance in the male-female survival ratio. Surviving women are far outnumbered by men in crowded relief and resettlement camps, putting them at increased risk for gender-based violence. The shortage of women can also lead to long-term risks including compromised education and reproductive health for women, as they start to get married younger and younger (Oxfam Briefing Note, 2005). 
sweat is less, metabolic rate is high and the subcutaneous fat is thick, which decreases radiative cooling (Duncan, 2006). High ambient temperatures can also lead to complications in pregnancy such as gestational hypertension, preeclampsia (Makhseed et al., 1999) and poor neonatal outcomes (Kakkad et al., 2014).

Vulnerabilities to air pollution: Air pollution contributes to climate change and is also exacerbated by it. According to some experimental studies, women demonstrate a higher burden due to pulmonary deposition of inhaled particles (Chen et al., 2005). Women are reportedly more susceptible to cardiovascular complications according to a study where the intimamedia thickness of arteries in women was significantly correlated with ambient levels of $\mathrm{PM}_{2.5}$, whereas in men it was not (Kunzli et al., 2005). Women have higher rates of anaemia in general, and particularly in India, which makes them more sensitive to airborne pollution than males (Sorensen et al., 2003). Further, women are more exposed to indoor air pollution (especially the particulate matter from fuelwood stoves), resulting in respiratory problems, cardiovascular risks, cataracts and adverse impacts on their reproductive health.

Vulnerabilities to water contamination: Both droughts and floods could result in water contamination. Inorganic contamination due to arsenic and fluoride concentrations seem to have a greater effect on women: women can experience negative pregnancy outcomes, skin hardening, spots and lesions and swelling of limbs due to high arsenic levels, and dental and skeletal deformities due to fluoride levels. Organic contamination also shows detrimental effects, especially in drought-prone regions where women have to rely on unsafe or contaminated sources. This leads to water-borne diseases such as diarrhoea. Hygienic practices are also compromised, resulting in "water-washed diseases" such as trachoma and scabies (WaterAid, 2002).

Vulnerability to food insecurity: Women are the worst affected by disruptions in food production as they are responsible for cooking, feeding, caring and nurturing family members, and collecting fodder for cattle. During times of food insecurity, women resort to extreme steps such as eating less, resorting to poor quality food and quitting meals. This contributes to malnutrition and increases their susceptibility to diseases. In some cultures, the household food hierarchies aggravate this further. Women have special nutritional needs, especially when they are pregnant and breastfeeding, which is unmet in most cases (especially in rural areas and among the urban poor) resulting in health issues. These deficiencies also undermine women's capacity to cope with the impacts of natural disasters (Cannon, 2002). The impact of climate change on food production often results in the migration of men, leaving women to shoulder the burden of agricultural work, cattle rearing, domestic work, care of the elderly and care of young children. Even if women do migrate, the stress related to finding work and the lack of basic facilities such as healthcare and sanitation, etc., affects 
them severely. Periods of food scarcity often also lead to marital stress, spousal violence, sexual abuse and other human rights violations.

Vulnerability to water scarcity: During dry seasons, especially in waterstressed areas, most of a woman's time and energy is spent on collecting water (Box 9.2). The laborious tasks of fetching and carrying water may cause damage to the neck and spine, leading to chronic skeletal pain in the long run.

Travelling long distances for water also increases exhaustion, exposure to heat stress and heat strokes, and threatens their safety by exposing them to violent crimes (Shiva \& Jalees, 2005). The quantity of water collected often does not meet the basic household requirements. The lack of sufficient clean water poses serious health risks to women, especially during menstruation and pregnancy, when the utmost care is required in terms of hygiene (Birch et al., 2012). The availability of freshwater is compromised in coastal areas due to saline water intrusion. This is further aggravated by the rise in sea levels, triggered by climate change.

\section{Box 9.2 Case study}

\section{The gendered impact of water scarcity due to climate change}

Seawater is the major polluter of groundwater in the coastal area of Odisha, according to a 2014 report by of the Ministry of Water Resources, Government of India. Kuntala Rout, 58, spends three, sometimes four, hours to fill enough water for everyone in the family, walking to the only hand pump $500 \mathrm{~m}$ outside her village, Kaliapat, a coastal village in Bhadrak district of Odisha. A single trip can take as much as 20 minutes to an hour, depending on the crowd around the hand pump. The groundwater in this area is five times as saline as fresh drinking water, because of an increase in sea levels, reduction in rainfall and excess drawing of groundwater. When the hand pump outside Kaliapat breaks down every few months, the women have to walk for over an hour to the neighbouring village to fill water. "Our bodies hurt, and we have joint and back pains," said Rout. "To reduce the consumption of water, we try not to drink much water." She is among dozens of women raising their voices through governmentrecognised Self-Help Groups (SHGs), which have formed federations in 11 gram panchayats across Bhadrak, with help from the NGO WaterAid India. Shortage of water, the need for more hand pumps and issues of sanitation in the aftermath of a natural disaster, are issues that women raise, in which the men are not interested.

Source: Shetty, 2019. 
Vulnerabilities of pregnant women: Pregnant women are vulnerable to extreme temperatures that could cause dehydration, releasing labourinducing hormones. Newborns are also sensitive to temperature extremes because of their limited capacity for temperature regulation. Both mothers and infants are more likely to be exposed to indoor air pollution from traditional cookstoves. Exposure to indoor air pollution during pregnancy results in respiratory infections and low birth weight or premature births in newborns. The inhalation of particulate matter results in an increased risk of adverse reproductive, cardiovascular and respiratory outcomes. According to a study on saline water contamination of drinking water in Bangladesh, large numbers of pregnant women in coastal areas are being diagnosed with pre-eclampsia, eclampsia and hypertension (Khan et al., 2014).

\section{A gender-sensitive approach in health services}

Despite the existing knowledge and understanding of the health impacts of climate variations, gendered vulnerabilities and differentiated impacts, current health systems are not sufficiently geared towards incorporating a much-needed gender-sensitive approach. Also lacking is a policy environment conducive to the implementation of gender-sensitive programmes that focus on capacity enhancement, and creating/strengthening facilities.

Public health surveillance needs to track the gender-disaggregated data of human exposure to climatic events or changes in the environment, assess the impact in a gender-sensitive manner, and monitor individuals and communities utilising Human Bio Monitoring (HBM) investigations. Health professionals play a key role in promoting a gender-sensitive understanding of the links between climate change and health, along with mitigation actions and responses. To do this, the first step is for health professionals themselves to be educated on the issue. The case study in the box shows that such sensitisation is an immediate requirement within the healthcare sector (Box 9.3).

\section{Box 9.3 Case study}

\section{Gendered impact among healthcare workers}

Gendered vulnerabilities are strongly brought to the fore during crises: in the following case, not in the general public, but among healthcare workers themselves. Female healthcare workers in China spoke out about their menstruation struggles while battling the coronavirus epidemic. They barely had time to eat or drink, much less change their menstrual materials while working. With a shortage of personal protective equipment, doctors and nurses wore diapers to avoid using the toilet, to conserve their protective suits. Thousands of donations of menstrual hygiene products such as sanitary pads and period-proof underwear were made to these hospitals for the frontline workers, but 
these were rejected by the male hospital managers who didn't consider them "necessities" until a public outcry brought attention to the situation. Photos of female healthcare workers wearing ill-fitting hazmat suits that were designed for men drew further ire from the public for taking women's protective gear less seriously than men's.

Source: Li, 2020.

There is a clear need to integrate gender considerations and linkages to climate change into the health sector right from the beginning: starting with introducing the topic into the curriculum for medical, dental, nursing, allied health and paramedical students, and continuing the integration into daily routines such as grand rounds when they begin their careers in hospitals. This will ensure that the health system has an inflow of people who understand the links between climate change and health, especially among girls and women.

\section{Integration of health and gender concerns into climate change adaptation and mitigation policies}

National-level climate adaptation strategies must address the underlying causes of vulnerability and gender inequity, and bring a gender perspective to policy and programmes in order to develop sustainable and inclusive solutions.

The international response to climate change is governed by the United Nations Framework Convention on Climate Change (UNFCCC). The definition of "adverse impacts" in the framework includes "human health and welfare" along with "natural and managed ecosystems or on the operation of socio-economic systems' (UNFCCC, 1992). However, climate change impacts are largely assessed through environmental and economic perspectives, with limited considerations on health impacts. According to Article 4.f. of the UNFCCC, before the parties propose any new adaptation or mitigation initiatives, they shall assess its health benefits or negative impacts along with environmental and economic considerations. This article also recognises the importance of gender equity. Proper implementation of this provision of UNFCCC will address some of the concerns and open up more opportunities to attain equity (WHO, 2011).

Women play a key role in adaptation and mitigation strategies due to their role in natural resources management and in other productive and reproductive activities at the household and community levels. Women play a prominent role during natural disasters as they carry out the responsibilities of securing food for the family, fodder for livestock, etc., and take charge of children and the elderly. Women tend to actively share information related to community well-being when survival is at stake, and 
communities tend to fare better during natural disasters when women play a leadership role in early warning systems and reconstruction. The disaster response can be made easier and more effective by empowering them with knowledge and information. To achieve SDGs (especially SDG 2) in the context of climate change, women must be supported to become more resilient, and to empower themselves politically, socially and economically. This calls for a better understanding of pathways linking climate, women, agriculture and nutrition, to develop appropriate interventions.

\section{Key takeaways}

- Gendered differentials make women more vulnerable to health risks from climate change, including extreme weather events, temperature variations, air pollution, water contamination, water scarcity and food insecurity, with pregnant women being especially vulnerable.

- Health professionals need to become aware of these gendered differentials and promote a gender-sensitive approach in dealing with the impact of climate change on health.

- Policies and national action plans need to support and empower women to play a key role in adaptation and mitigation strategies.

\section{References}

Bartlett S. (2008), Climate change and urban children: impacts and implications for adaptation in low- and middle-income countries. Environment and Urbanization, 20(2), 501-519. doi: 10.1177/0956247808096125.

Birch, E. L., Meleis, A., \& Wachter, S. (2012). The urban water transition: Why we must address the new reality of urbanization, women, Water, and sanitation in sustainable development. wH2O: The Journal of Gender and Water, 1(1), 1. https://repository.upenn.edu/wh2ojournal/vol1/iss1/1

Cannon, T. (2002). Gender and climate hazards in Bangladesh. Gender and Development, 10, 45-50.

Chen, L. H., Knutsen, S. F., Shavlik, D., Beeson, W. L., Petersen, F., Ghamsary, M., \& Abbey, D. (2005). The association between fatal coronary heart disease and ambient particulate air pollution: Are females at greater risk? Environmental Health Perspectives, 113(12), 1723-1729.

Duncan, K. (2006). Global climate change, air pollution, and women's health. WIT Transactions on Ecology and the Environment, 99. doi: 10.2495/RAV060611

Kakkad, K., Barzaga, M. L., Wallenstein, S., Azhar, G. S., \& Sheffield, P. E. (2014). Neonates in Ahmedabad, India, during the 2010 heat wave: A climate change adaptation study. Journal of Environmental and Public Health, 2014, 946875. doi: 10.1155/2014/946875. Epub 2014 Mar 10. PMID: 24734050; PMCID: PMC3964840.

Khan, A. E., Scheelbeek, P. F. D., Shilpi, A. B., Chan, Q., Mojumder, S. K., Rahman, A., ... \& Vineis, P. (2014). Salinity in drinking water and the risk of (pre) eclampsia and gestational hypertension in coastal Bangladesh: A case-control study. PLoS One, 9(9), e108715. doi: 10.1371/journal.pone.0108715 
Kunzli, N., Jerrett, M., Mack, W. J., Beckerman, B., LaBree, L., Gilliland, F., ... \& Hodis, H. N. (2005). Ambient air pollution and atherosclerosis in Los Angeles. Environmental Health Perspectives, 113(2), 201-206.

Li, J. A. (2020, February 28). How China's coronavirus healthcare workers exposed the taboo on menstruation. South China Morning Post. https:// www.scmp.com/comment/opinion/article/3052524/how-chinas-coronavirushealth-care-workers-exposed-taboo

MacDonald, R. (2005). How women were affected by the Tsunami: A perspective from Oxfam. PLoS Medicine, 2(6), e178. doi: 10.1371/journal.pmed.0020178

Makhseed, M. A., Musini, V. M., Ahmed, M. A., \& Monem, R. A. (1999). Influence of seasonal variation on pregnancy-induced hypertension and/or preeclampsia. Australian and New Zealand Journal of Obstetrics and Gynaecology, 39(2), 196-199.

Oxfam Briefing Note. (2005, March). The tsunami's impact on women. https:// oxfamilibrary.openrepository.com/bitstream/handle/10546/115038/bntsunami-impact-on-women-250305-en.pdf? sequence=1\&isAllowed $=\mathrm{y}$

Shiva, V., \& Jalees, K. (2005). Water \& women: A report by Research Foundation for Science, Technology, and Ecology for National Commission for Women. Research Foundation for Science, Technology, and Ecology (New Delhi, India), \& National Commission for Women (India). Navdanya/RFSTE.

Shetty, D. (2019, 09 Feb). As Climate Changes Grows More Intense, Women in Battered Coastal Orissa Step Up. Bloomberg Quint. https:/www.bloombergquint. com/global-economics/as-climate-change-grows-more-intense-women-inbattered-coastal-odisha-step-up.

Sorensen, M., Daneshvar, B., Hansen, M., Dragsted, L. O., Hertel, O., Knudsen, L., \& Loft, S. (2003). Personal PM2. 5 exposure and markers of oxidative stress in blood. Environmental Health Perspectives, 111(2), 161.

WaterAid. (2002) Diseases related to water and sanitation. WaterAid.

WHO. (n.d.-a). Gender, climate change and health, public health \& environment department. https://www.who.int/globalchange/GenderClimateChangeHealth final.pdf

WHO. (n.d.-b) Gender fact sheet. https://www.who.int/health-topics/gender

World Health Organization. (2011) Gender, climate change and health. https://apps. who.int/iris/bitstream/handle/10665/144781/9789241508186_eng.pdf;jsessionid =B44841E6FD81F00FA5F5DF470EE96082 ?sequence $=1$ 


\title{
10 \\ THE CONSEQUENCES OF CLIMATE CHANGE ON VULNERABLE POPULATIONS
}

\author{
Richa Sharma and R. Srikanth
}

\section{Introduction}

Humankind's heavy dependence on fossil fuels, deforestation, industrialisation, lifestyle changes, etc., have resulted in global warming. While the impact of climate change is felt across all geographies and populations, it is evident that some groups and communities are particularly vulnerable, with these impacts affecting them disproportionately (Islam \& Winkel, 2017). Least developed nations, small island countries, coastal region communities, etc. are more susceptible, as are women, children, elderly, those with low income or vulnerable occupational groups. This chapter gives an overview of the topic by:

1. Introducing the concepts of vulnerability including exposure, sensitivity and adaptivity in terms of climate change health impacts and risks.

2. Describing the importance of understanding and mapping vulnerability with a focus on the most vulnerable populations by age, gender, health condition and socio-economic factors.

3. Discussing the various determinants of vulnerability from the perspectives of policymakers and healthcare professionals.

\section{The concept of vulnerability}

Vulnerability is defined as an exposed system's or subject's internal risk factor corresponding to its intrinsic propensity or predisposition to be adversely affected by the hazard (Cardona, 2004; IPCC, 2014). In a public health context, vulnerability to climate change is defined as the degree to which individuals or communities are prone to the health impacts of climate change.

The Sendai Framework (UNISDR, 2015) defines vulnerability as the conditions determined by "physical, social, economic and environmental factors or processes, which increase the susceptibility of a community to the 
impact of hazards." This definition of vulnerability is in close alignment with the World Health Organization's (WHO) definition of the social determinants of health as the "circumstances in which people are born, grow up, live, work and age, and the systems put in place to deal with illness." These circumstances, in turn, are influenced by the distribution of money, power and resources at international, national and local levels.

Vulnerability is dynamic, varies across temporal and spatial scales, and depends on various determinants such as economic, social, geographic, demographic, cultural, institutional, governance and environmental factors. An essential step for working on adaptation plans is the assessment of vulnerability to climate variability and extremes. Understanding the climate change vulnerabilities, and especially those of the most vulnerable population, is important for policymakers, state/city development authorities, social service providers, etc. who are required to respond to the health impacts of climate change. Their vulnerability assessments should collectively consider how populations of concern experience disproportionate, multiple, and complex risks to their health and well-being in response to climate change.

Vulnerability can be assessed using the Vulnerability framework (Turner, et al., 2003), which is built on three factors, viz. exposure, sensitivity and adaptive capacity. Exposure is determined by the presence of the people in hazard zones and being subject to potential health losses. Higher exposure contributes to increased vulnerability. For instance, construction and agricultural labourers, who work outdoors in the sun, have a higher vulnerability to extreme heat due to their increased exposure. Sensitivity is the degree to which an individual or a system is affected by climate-related stimuli. Sensitivity is often determined by factors including underlying health conditions, medical issues, age, gender, disabilities (physical, mental, cognitive, or sensory), etc. Adaptive capacity is the ability of communities, institutions, or people to adjust to potential hazards or to respond to the consequences of the same.

Vulnerability assessments help in identifying and implementing the appropriate mitigative and adaptive measures for the most vulnerable population. Some of the climate-sensitive health vulnerabilities include extreme temperature, extreme weather, UV radiation, vector-borne diseases, food and water safety, and security, and air quality, to mention a few.

Specific groups of people are at higher risk for distress and other adverse mental health consequences from exposure to climate-related or weatherrelated disasters. These groups include children, the elderly, women (especially pregnant and post-partum women), people with disabilities, people with pre-existing mental illness, the economically disadvantaged, the homeless and first-responders. Communities that rely on the local environment for their livelihood, as well as populations living in areas that are more prone to specific climate change events, are at increased risk for adverse mental health outcomes. 


\section{The health impacts and vulnerabilities of vulnerable populations}

\section{Women}

Women are more vulnerable to the impacts of climate because of their biological sex and the social structures and inequalities, especially in developing and least developed nations. Physical and psychological health risks increase women's health-related vulnerabilities to climate change. This can further impact reproductive outcomes such as early pregnancy loss, stillbirth, premature delivery, perianal rashes and urinary tract infections. These may lead to greater mortality rates in comparison to men, higher rates of malnutrition, and increased exposure to sexual exploitation due to displacement resulting from events of extreme weather. Natural disasters affect the poor disproportionately. This is indicated by the fact that a large number of fatalities during major disasters occur in low- and middle-income countries, where death rates of women and children during a disaster are 14 times higher than that of men (Fatema et al., 2019).

Gender-specific attributes such as socially determined roles and responsibilities, such as women sacrificing their food for other family members, also impact the vulnerability of women. In developing countries, the higher vulnerability of women to the health impacts of climate change are also due to lack of shelter, use of fuel for cooking, and lack of access to food and safe water, resulting in issues with maintaining hygiene. Social inequalities and relatively lower formal education (as compared to men) amongst others, shape women's illness and their options for medical care. Women, especially in many developing and least developed nations, have lower social and economic power. Since they are limited by the lack of education and employment opportunities, they bear the higher burden of unpaid work related to family care and community activities. Such inequalities decrease the adaptive capacities of women while increasing their exposure and sensitivities, making them more vulnerable to the health impacts of climate change. Their vulnerabilities are further discussed in the chapter titled Gendered Vulnerabilities and Health Inequities.

\section{Children}

Children are one of the most vulnerable groups to climate change, owing to their biological modalities (such as high respiratory and metabolic rates, developing physiology, unique exposure pathways, limited adaptive capacities, etc.); they exhibit higher sensitivity to the various climate risks and threats. This is especially true in developing nations where climate change is expected to hit the hardest, and where safety nets are already compromised (King \& Harrington, 2018). Their vulnerability is further increased by their dependency on others (parents or caretakers), which compromises their adaptive capacity. Especially in the context of developing countries like 
India, children belonging to economically poor sections of society have the additional responsibility of taking care of their younger siblings, while parents are away as daily wage workers. Climatic conditions during the inutero stage affect the height and weight of foetuses, indicating that climate change can influence children's health and development even before they are born (Lokshin \& Radyakin, 2012). Climate change has also been found to negatively impact the cognitive performance of children (UNICEF, 2015). A 2019 Lancet report states that a child born today will experience a world that is more than four degrees warmer than the pre-industrial average, and that across the world, children are the worst affected by climate change (Watts et al., 2019). Due to various physiological and biological reasons, children are more vulnerable to impacts of degraded air quality (respiratory diseases like asthma, impacted lung development, etc.,), from floods including water-borne diseases (such as diarrhoea, respiratory, skin and eye diseases) and vector-transmitted diseases (such as dengue, chikungunya, and Zika, and zoonoses such as leptospirosis). It is also seen that exposure to traumatic events can impact children's ability to regulate emotions, impedes their cognitive development and academic performance and can contribute to post-traumatic stress disorder (PTSD) and other psychiatric disorders (such as depression, anxiety, phobia and panic). Children's ability to cope with disasters is affected by factors such as their socioeconomic status, available support systems and timeliness of treatment. Negative mental health effects in children, if untreated, can extend into adulthood.

Flooding-induced prenatal maternal stress influences the cognitive functioning of toddlers (Laplante et al., 2018; McLean et al., 2018; Moss et al., 2018), causing distress, anxiety and disillusionment in children (Mort et al., 2018), results in Post-Traumatic Stress Syndrome (PTSS) (Dogan-Ates, 2010) and also increases risks of pre-term births (Yu et al., 2018) which can cause neonatal morbidity, chronic health conditions and developmental disabilities with lifelong consequences. Extreme weather events like droughts and heat waves which impact crop production can also impact the maintenance of a satisfactory standard of public health in India where there is a high degree $(\sim 47 \%)$ of malnutrition especially among the children (Singh \& Dhiman, 2012).

\section{The elderly}

The decrease in the mobility of the elderly resulting from age, changes in physiology and more restricted access to resources limits the adaptive capacity of older people, putting them at greater risk of bearing the health impacts of climate change. For instance, older people are more vulnerable to temperature extremes and exhibit a significantly higher mortality risk in such extreme weather events. The elderly are also more susceptible to diseases and to the effects of stresses on food and water supply, compounded by the reduced ability to mobilise quickly. This further increases their 
vulnerability to climate change impacts. In addition to biological vulnerabilities, elderly people also experience socio-economic vulnerabilities. They might have been earning members earlier and are now possibly facing the dire consequences of abandonment due to the loss of negotiating power. Thus, the health effects of climate change on older people could be either due to the greater exposure of older people to the threat, those that decrease their adaptive capacity due to a combination of exposure plus greater reactivity as a characteristic of ageing (increased physiological susceptibility) or social factors that vary across individuals (social vulnerability). Therefore, several societal strategies will be required to enable the elderly to cope with the health effects of climate change.

\section{Persons with disabilities}

People with disabilities can experience disproportionate impacts of climate change unless the adaptation and response plans specifically take them into consideration. For example, risk-related communications do not necessarily target communication for individuals who are deaf, visually impaired, and those with low cognitive skills. Furthermore, they are caught in the povertydisability cycle and are vulnerable on several fronts. They are affected further due to inaccessible evacuation, response (including shelters, camps and food distribution), and recovery efforts. Most calamities have shown that that people with disabilities are most likely to be left behind, due to a lack of planning and inaccessible systems. Refugee camps or shelters are, in most cases, are not usually well-equipped to take care of their medical requirements. Therefore, climate change calamities that result in disruption to physical, social, economic and environmental networks and support systems, affect persons with disabilities much more than the general population (Box 10.1).

\section{Box 10.1 Case study}

"A disaster involves steps and procedures - information and warnings, timely evacuations, temporary safe settlements and rehabilitation. In each of these, Persons with Disabilities (PWD) and their needs remain unaddressed. Start with training manuals, camps and alarm systems: they need to be made available in accessible formats. During evacuation, their additional needs and assistive devices need to be picked up because without them, PWDs could become totally immobile. Then the struggle for food and basic amenities: it's not possible for us to stand in line for food. Moreover, rehabilitation for PWD requires a complete restoration of their "spaces". They had adapted 
themselves to a particular system and set-up, making it very difficult for them to adjust to a new one that may not be that considerate of their special needs. And what happens to people with psychological disabilities, those living in institutions, mental asylums or kept tied to beds? They are left behind. It's truly horrific. They are left without food, water or caretakers for days. There isn't much information about what happens to these people."

- Shivani Gupta, founder of cross-disability consultancy AccessAbility

Source: Chadha, 2020.

\section{Outdoor workers}

Climate change is expected to affect the health of outdoor workers due to their increased exposure to extreme weather conditions and low adaptive capacity. The outdoor workers experience adverse health effects of elevated temperature, in combination with changes in precipitation patterns, climate extremes and the effects of air pollution, which have a potential impact on their safety and well-being. Outdoor workers include farmers, agricultural workers, fishermen, construction workers, transportation-related workers, migrants and day wage labourers amongst others. With high heat and humidity, labour productivity for outdoor work drops as workers feel fatigued and need to take longer and more frequent breaks. With extreme heatwave conditions, workers report increased tiredness and exhaustion, dizziness, nausea, loss of appetite, musculoskeletal pain (triggered by the loss of body salts from excessive sweating) and fainting spells. Exposure to direct solar radiation may even blur the vision, impair judgment and make workers light-headed and irritable.

As a developing country with vast inequalities and a growing population that will age as the impacts of climate change become more severe over the next 30 years, India will have to have to be more prepared to take care of the health impacts of climate change through prevention and control measures. The Indian Government has been working with the States in this regard. During the National Review Meeting of the State Plans on Climate Change and Human Health held on December 17, 2019, almost all the States participated in the review meeting of State Plans on Climate Change and Human Health, and a cohort of 16 institutions was established under the initiative to serve as centres of excellence for climate change and health. More details on this topic can be seen in the chapter titled The Climate Change Policy 
Framework and Allied Programs in India. The promises of the developed countries during the Paris Agreement also remain largely unfulfilled since the total amount of pledges to the Green Climate Fund announced till May 12,2020 , is only USD 10.32 billion against the target collection of USD 100 billion every year by 2020 . Therefore, there is an urgent need to take concrete action to identify and mitigate the health impacts of climate change for the vulnerable groups identified in this chapter.

\section{Key takeaways}

- Vulnerability is the extent or degree to which a particular group is prone to the health impacts of climate change

- Vulnerability assessments are extremely beneficial in the context of climate change health impacts and risks.

- Certain groups are disproportionately affected; the vulnerabilities of women, children, the elderly, persons with disabilities and outdoor workers are described.

\section{References}

Cardona, O. (2004). The need for rethinking the concepts of vulnerability and risk from a holistic perspective: A necessary review and criticism for effective risk management. In Mapping vulnerability: Disasters, development and people (3751). Earthscan Publishers.

Chadha, S. (2020 Dec 03). Neglecting the Ones Most Affected: Climate Change and Disability. Bloomberg Quint. https://fit.thequint.com/health-news/why-the-climatemovement-needs-to-be-disability-inclusive

Dogan-Ates, A. (2010). Developmental differences in children's and adolescents'postdisaster reactions. Issues in Mental Health Nursing, 31(7), 470-476. doi: 10.3109/01612840903582528. PMID: 20521917.

Fatema, S., Islam, M., East, L. \& Usher, M. (2019). Women's health-related vulnerabilities in natural disasters: A systematic review protocol. BMJ Open, 9(12), e032079. doi: 10.1136/bmjopen-2019-032079

IPCC. (2014). Climate change 2014: Synthesis report. Contribution of working groups I, II, and III to the fifth assessment report of the intergovernmental panel on climate change, IPCC.

Islam, N. \& Winkel, J. (2017). Climate change and social inequality. UN DESA.

King, A. \& Harrington, L. (2018). The inequality of climate change from 1.5 to $2^{\circ} \mathrm{C}$ of global warming. Geographical Research Letters, 45(10), 5030-5033. doi: 10.1029/2018GL078430

Laplante, D., Hart, K. J., O’Hara, M. W., Brunet, A., \& King, S. (2018). Prenatal maternal stress is associated with toddler cognitive functioning: The Iowa flood study. Early Human Development, 116, 84-92. ISSN 0378-3782. doi: 10.1016/j. earlhumdev.2017.11.012

Lokshin, M., \& Radyakin, S. (2012). Month of birth and children's health in India. The Journal of Human Resources Winter, 47(1), 174-203. doi: 10.3368/jhr.47.1.174 
McLean, M., Cobham, V. E., Simcock, G., Elgbeili, G., Kildea, S., \& King, S. (2018). The role of prenatal maternal stress in the development of childhood anxiety symptomatology: The QF2011 Queensland flood study. Development and Psychopathology, 30(3), 995-1007. doi: 10.1017/S0954579418000408

Mort, M., Walker, M., Williams, A. L., \& Bingley, A. (2018). Displacement: Critical insights from flood-affected children. Health and Place, 52, 148-154. ISSN 13538292, doi: 10.1016/j.healthplace.2018.05.006

Moss, K., Simcock, G., Cobham, V. E., Kildea, S., Laplante, D. P., \& King, S. (2018). Continuous, emerging, and dissipating associations between prenatal maternal stress and child cognitive and motor development: The QF2011 Queensland flood study. Early Human Development, 119, 29-37.

Singh, P. \& Dhiman, R. (2012). Climate change and human health: Indian context. Journal of Vector-Borne Diseases, 49, 55-60.

Turner, B., Kasperson, R. E., Matson, P. A., McCarthy, J. J., Corell, R. W., Christensen, L., ... \& Schiller, A. (2003). A framework for vulnerability analysis in sustainability science. Proceedings of the National Academy of Sciences, 100(14), 80748079. doi: 10.1073/pnas.1231335100

UNICEF. (2015). Unless we act now: The impact of climate change on children. UNICEF.

UNISDR. (2015). Sendai framework for disaster risk reduction 2015-2030. UN.

USGCRP. (2016). The impacts of climate change on buman health in the United States: A scientific assessment. U.S. Global Change Research Program.

Watts, N., Amann, M., Arnell, N., et al. (2019). The 2019 report of the Lancet countdown on health and climate change: Ensuring that the health of a child born today is not defined by a changing climate. The Lancet, 394(10211), 1836-1878. doi: 10.1016/S0140-6736(19)32596-6

Yu, X., Feric, Z., Cordero, J. F., Meeker, J. D., \& Alshawabkeh, A. (2018). Potential influence of temperature and precipitation on preterm birth rate in Puerto Rico. Scientific Reports, 8, 16106. 


\title{
PRIORITISING CLIMATE CHANGE AND HEALTH: THE CURRENT STATUS OF HEAT-HEALTH IN INDIA
}

\author{
Priya Dutta, Mahaveer Golechha and Dileep Mavalankar
}

\section{Introduction}

Climate change is causing an increase in the severity and frequency of extreme weather events and disasters. It is leading to two major changes in weather - an increase in average temperatures and an increase in variability of weather. This leads to the increased possibilities of severe heat and cold waves. In the last twenty years, extreme heat events have become more intense, more frequent and longer-lasting, posing a new global challenge to the health sector worldwide. Extreme heat can lead to dangerous, even deadly, health consequences, including heat stress and heatstroke. As urban populations continue to grow, there is an increasingly urgent need for cities and their residents to adapt to climate change and its impact.

Fortunately, heat-related illnesses are preventable with effective public health interventions. In India, the city of Ahmedabad took the lead in implementing a citywide preparedness plan and developing city-specific heathealth thresholds. The Indian Institute of Public Health, Gandhinagar (IIPHG), in collaboration with other partners, developed and implemented these threshold-based heat action plans. The experience in Ahmedabad provides compelling evidence that heat action plans can meaningfully reduce vulnerability to extreme heat and save lives. This chapter will describe

1. Heat waves and their health impacts from the perspective of public health.

2. Heat Action Plans as public health interventions to reduce heat-related illnesses.

\section{Heat waves}

Extreme temperatures are among the most dangerous natural hazards. Over the past five decades, human activities have released ample greenhouse gases (GHGs), raising the mean global temperature and resulting in an increase in the frequency and intensity of heat waves (Tollefson, 2018). Heat waves are 
anticipated to worsen with climate change, leading to several heat-related health consequences (Gasparrini et al., 2017; Nori-Sarma et al., 2019).

A heat wave is a prolonged period of abnormal high temperature which causes temporary modifications in lifestyle and adverse health effects in the population (Robinson, 2001). In India, heat waves usually occur during the summer months of April to June. In some rare cases, they may start in March and extend till the first or second week of July. The exact definition of a heatwave varies by location, ambient temperature, humidity and physical, social and cultural adaptations (Robinson, 2001). The Indian Meteorological Department (IMD) declares a heat wave when there is an excess of $5^{\circ} \mathrm{C}$ or $6^{\circ} \mathrm{C}$ above a normal maximum temperature less than or equal to $40^{\circ} \mathrm{C}$; or an excess of $4^{\circ} \mathrm{C}$ to $5^{\circ} \mathrm{C}$ above a normal maximum temperature of more than $40^{\circ} \mathrm{C}$ (NDMA, 2019). However, if the actual maximum temperature is $45^{\circ} \mathrm{C}$ or more, a heat wave is declared irrespective of the normal maximum temperature. The normal temperature for that day is derived from a 30-year record of historical temperatures for that area's weather station (NDMA, 2019). The IMD definition does not take into account any health impacts such as morbidity or mortality in determining thresholds for declaring heat waves.

\section{The impact of heat waves on human health}

Several research studies have shown an increased number of deaths during heat waves (D'Ippoliti et al., 2010). In 2003, a heat wave in Europe caused excess mortality estimates varying from 25,000 to 70,000 deaths (Maughan, 2012). Very few studies have been conducted in India to assess the effect of ambient temperature on human health. In India, from 1992 to 2015, heat waves have caused 22,653 officially reported deaths; this number includes over 2,500 deaths in India's deadliest heat wave during the summer of 2015 (NDMA, 2019). Heat-related morbidity and mortality can occur due to direct or indirect effects. Direct effects include heat-related illnesses from heat exhaustion to heat stroke. The indirect effects on physiological systems can cause renal insufficiency and exacerbate cardiovascular diseases, respiratory problems and acute cerebrovascular disease.

According to the latest study by the Indian Meteorological Department (IMD) and the Indian Institute of Tropical Meteorology (IITM), the average heat index of India has increased significantly per decade at the rate of $0.56^{\circ} \mathrm{C}$ and $0.32^{\circ} \mathrm{C}$ in summer and monsoon respectively, which is statistically significant at $95 \%$ level (Jaswal et al., 2017). The heat index is a single number which is calculated based upon a combination of different environmental parameters such as temperature and humidity to posit a humanperceived equivalent temperature.

During heat waves, hospital admissions also increased due to people suffering from heat exhaustion, heat syncope, severe dehydration and 
vomiting. Depletion of salt and electrolytes in the body can cause heat cramps while working under the direct sun could lead to heat exhaustion. The total impact of heat wave events on mortality in India could be even higher, as these figures probably refer to reported deaths from heatstroke only. Morbidities due to heat waves are not even counted.

\section{Populations at risk}

An increase in ambient temperature contributes directly to an increase in mortality, particularly among those who are vulnerable. Pregnant women, elderly people and young children are more vulnerable to extreme heat.

Elderly age group: Ageing can be characterised by a complex process in which progressive age-specific deteriorations of internal physiological systems inevitably impair the body's capacity to respond to extreme heat. In the elderly population, there is also a deterioration in the ability to dissipate heat, a process pivotal to the maintenance of normal core temperature, especially in extreme heat conditions. Further, heatrelated illnesses can also exacerbate existing medical conditions that can make elderly more vulnerable to extreme heat.

Pregnant women: Pregnant and postpartum women and their infants are uniquely vulnerable to the health impacts of heat waves, due to the many physiological changes that occur as a result of pregnancy. Pregnancy increases likelihood for fatigue and dehydration. Dehydration can lead to preterm uterine contractions and even labour.

Infants and children: Due to their anatomical, cognitive, immunological and psychological differences, children and infants are more vulnerable to extreme heat than adults. Because of their small surface-tobody ratio, infants and children are more vulnerable to dehydration and heat stress. During extreme heat events, children are more likely to be affected by respiratory disease, renal disease, electrolyte imbalance and fever.

\section{The urban heat island effect}

Heat waves have a much larger health impact in cities than in surrounding suburban and rural areas. Indian cities are rapidly urbanising with skyrocketing development that converts open space into paved, heat-trapping roofs and roads. These hot surfaces absorb and later re-radiate the sun's thermal energy, worsening city temperatures relative to surrounding rural areas, thereby amplifying the urban heat island effect and increased air pollution (Singh et al., 2020).

There are a number of evidences suggesting that heat-related risks might be reduced through the systemic development of Heat Action Plans which include early warning systems, community awareness strategies and 
capacity building of various stakeholders (Hess et al., 2018; Benmarhnia et al., 2019). Therefore, public health intervention is required to deal with the impact of heat waves on human health in India. The heat action plan should be an essential component of city planning for the management and prevention of heat-related illnesses. In India, several efforts have been made to implement public health strategies to combat the negative effect of heat waves (Box 11.1).

\section{Box 11.1 Case study}

\section{The development and implementation of South Asia's first heat action plan in Ahmedabad, Gujarat, India}

In May 2010, the city of Ahmedabad in Gujarat witnessed a major heat wave with a peak temperature of $47^{\circ} \mathrm{C}$ on 21 May, resulting in over 300 deaths in one day and in excess of 800 deaths in one week (Azhar et al., 2014) (Figure 11.1). Following this, the Indian Institute of Public Health, Gandhinagar (IIPHG), supported by national and international partners, developed and implemented a Heat Action Plan (HAP) in Ahmedabad in 2013. Heat wave early warning systems and adaptation plans have reduced heat wave related mortalities and morbidities in various parts of the world (Knowlton et al., 2014). The Heat Action Plan implemented in Ahmedabad was the first innovative early warning system and preparedness plan for extreme heat

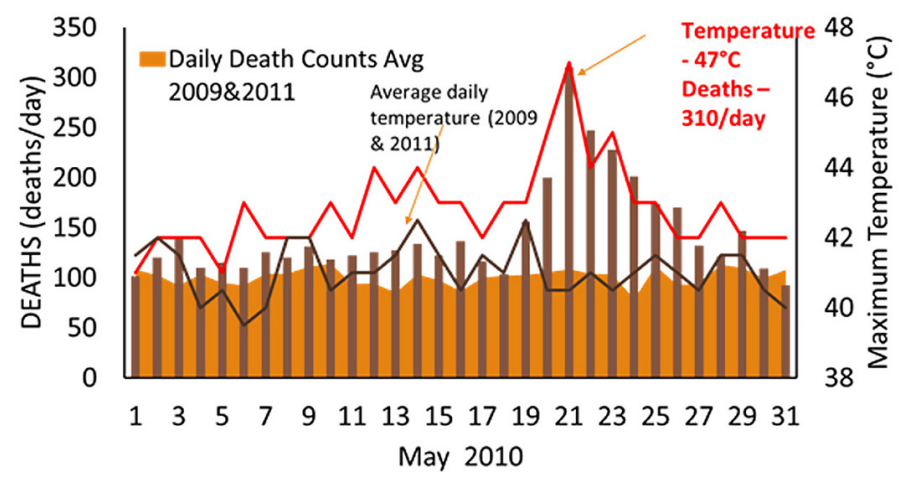

Figure 11.1 Daily temperatures and all-cause mortality correlation graph of Ahmedabad, Gujarat. 


\section{HAP COMPONENTS}

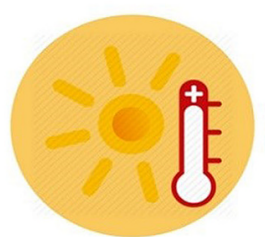

EARLY WARNING SYSTEM \& INTER AGENCY EMERGENCY RESPONSE PLAN

Alert residents of predicted high and extreme temperatures \& formally communication channels to alert governmental agencies

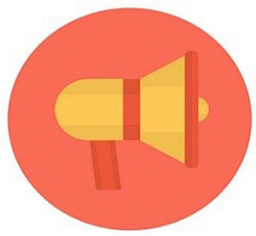

PUBLIC AWARENESS \& COMMUNITY OUTREACH

Communicate the risks of heat waves and implement practices to prevent heat-related deaths and illnesses

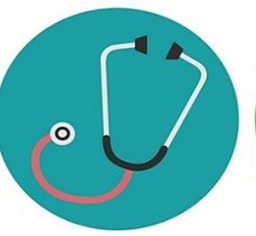

CAPACITY BUILDING OF MEDICAL PROFESSIONALS

Training focus on primary medical officer and other paramedical staff, and community health staff

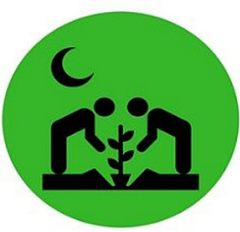

REDUCING HEAT EXPOSURE AND PROMOTING

ADAPTIVE MEASURES Access to potable drinking water and cooling spaces during extreme heat days \& promote adaptive

Figure 11.2 Ahmedabad heat action plan strategies.

events in South Asia, based on learnings from Europe and America (Knowlton et al., 2014).

Heat action plans include early warning systems that alert citizens and organizations in advance of extreme heat, and enable them to respond effectively to save lives. The important strategies of the Ahmedabad Heat Action Plan involved the following components: firstly, building public awareness and community outreach; secondly, an early warning system and inter-agency coordination; thirdly, capacity building of healthcare professionals; and finally, reducing heat exposure and promoting adaptive measures (Figure 11.2). One of the most important components of a Heat Action Plan is the interagency emergency response framework for effective coordination between various departments of municipal administration (Figure 11.3). The administration issues a heat alert based on thresholds determined by the IMD, and uses a colour signal system as an additional means of communication. Depending on the alert that has been issued, different departments will activate their channel and perform pre-defined activities (Table 11.1). 


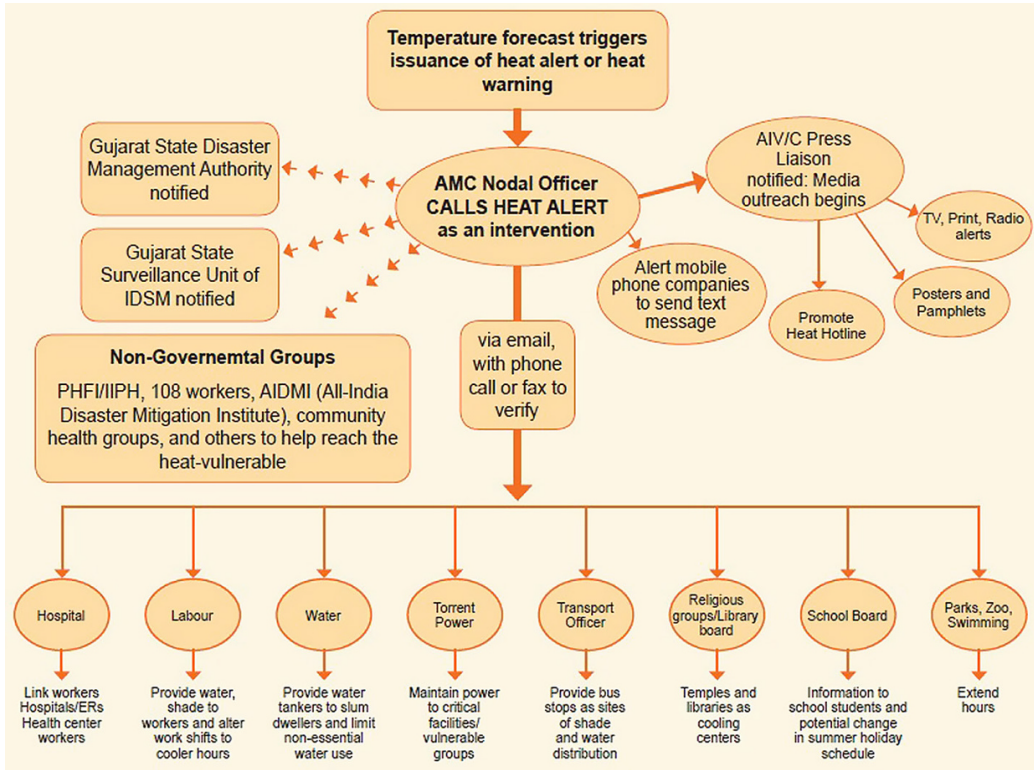

Figure 11.3 The inter-agency emergency communication plan when the Ahmedabad Municipal Corporation (AMC) nodal officer activates a heat alert.

Table 11.1 Colour signals for heat alerts

\begin{tabular}{|c|c|c|}
\hline $\begin{array}{l}\text { Red Alert (Severe } \\
\text { Condition) }\end{array}$ & Extreme Heat Alert Day & $\begin{array}{l}\text { An increase of } 6^{\circ} \mathrm{C} \text { or } \\
\text { more above Normal } \\
\text { Maximum Temperature }\end{array}$ \\
\hline $\begin{array}{l}\text { Orange Alert (Moderate } \\
\text { Condition) }\end{array}$ & Heat Alert Day & $\begin{array}{l}\text { An increase of } 4^{\circ} \mathrm{C} \text { to } 5^{\circ} \mathrm{C} \\
\text { above the Normal } \\
\text { Maximum Temperature }\end{array}$ \\
\hline $\begin{array}{l}\text { Yellow Alert (Heat-wave } \\
\text { Warning) }\end{array}$ & Hot Day Advisory & $\begin{array}{l}\text { Near the Normal } \\
\text { Maximum Temperature }\end{array}$ \\
\hline White (Normal) & Normal Day & $\begin{array}{l}\text { Below the Normal } \\
\text { Maximum Temperature }\end{array}$ \\
\hline
\end{tabular}

\section{The impact of the Ahmedabad heat action plan in reducing mortality due to extreme heat events}

A preliminary health outcome evaluation analysis suggests that there was at least a 25\% decrease from May's excess all-cause mortality in the two years since the HAP was launched (Hess et al., 2018). Hess et al. estimated that 
the Ahmedabad Heat Action Plan (HAP) saves hundreds of lives every summer, and found a decrease in all-cause mortality in the first two years (2014-2015) after the HAP was implemented. The results of this ecological study indicate that the HAP was associated with reduced mortality during the heat season in 2014-2015, especially at higher temperatures (Hess et al., 2018). The Ahmedabad HAP was successful in reducing heat-related illnesses, and the plan has been scaled up in other places across the nation such as Odisha and the Vidarbha region of Maharashtra. The National Disaster Management Authority (NDMA) has developed national guidelines for the prevention and management of heat waves based on the Ahmedabad HAP (Box 11.2).

In subsequent years, cool roof technologies have been added as an additional important strategy under the Heat Action Plan. Cool roofs reflect sunlight and absorb less heat, offering a simple and cost-effective solution to the urban heat island challenge. A study conducted in Ahmedabad slums found that cool roof technologies such as thermocol insulation and solar reflective white paint on the outer surface of the roof can effectively reduce the indoor temperature as compared to non-intervention roofing (Vellingiri et al., 2020).

\section{Limitations to the development and implementation of HAPs}

An important limitation to the effective development and implementation of a heat action plan is the unavailability of health-related data on heatrelated illnesses on a daily or weekly basis. Without health-related data, it is impossible to work out a city-specific temperature threshold and heat stress index. There are several challenges to conducting heat health research in India. Due to the modest registration of deaths, it is very difficult to obtain all-cause mortality data. Furthermore, it is difficult to understand the effects of heat on cause-specific mortality in sufficiently large sample sizes. Another limitation is the lack of India-specific or region-specific Heat Stress Index data. The present early warning system is largely based on epidemiological studies which links temperature and mortality data, i.e. by correlating the daily temperature-mortality relationship.

Due to the efforts of the National Disaster Management Authority, the Indian Meteorological Department and IIPHG, many cities have developed their heat action plans based on the Ahmedabad HAP. However, effective implementation is lacking, as there is no state-level monitoring.

At the national level, the Ministry of Health, the Ministry of the Environment and other line ministries should work jointly under the National Mission on Climate Change and Human Health to implement climate resilience heat action plans. The government should prioritise integrating climate services for health in public health policy and planning. 


\section{Box 11.2 Case study}

\section{The development and implementation of India's first climate resilience heat action plan in rural settings under the Rajasthan climate change project}

More than two-thirds of the population of Rajasthan live in rural areas. There has been an increasing trend of heat waves in Rajasthan over the past several years in which several cities in Rajasthan have been severely affected. The Thar Desert area consists of 12 districts covering $60 \%$ of the area of Rajasthan and is largely affected by extreme heat events. The IIPHG partnered with UNCIEF Rajasthan and the Government of Rajasthan for the development and implementation of a climate resilience heat action plan in rural settings. The aim of this project was to pilot a model for the prevention and management of heat waves in the rural settings of Rajasthan, based on learnings from Ahmedabad. The project districts in the pilot were Jalore, Udaipur and Jaipur. The important activities of the project were:

- To understand the impact of climate change on health

- To develop a Climate Resilience Heat Action Plan for selected blocks of Rajasthan

- To build capacity and generate awareness among healthcare professionals

- To generate awareness of heat-related illness prevention and management among students and teachers.

Various innovative approaches were used, such as organising a Heat Awareness Day and a Mass Awareness Rally; harnessing the potential of children in community awareness; capacity building of frontline health workers and medical officers; and comprehensive Information, Education and Communication (IEC) material made available in local languages. All these activities helped to mainstream climate change within the public health system. The state government then scaled up activities in districts.

\section{Key takeaways}

- The chapter discusses the role of heat action plans and heat health research in improving the resilience of communities against extreme heat events and for the prevention and management of heat-related illnesses. 
- There has been an increasing trend of heat waves in India over the past several years.

- Extreme heat can lead to dangerous, even deadly, health consequences, including heat stress and heatstroke.

- Public health interventions are urgently required to reduce mortality and morbidity due to extreme heat events.

- The city of Ahmedabad implemented South Asia's first Heat Action Plan based on an early warning system.

- The experience in Ahmedabad provides compelling evidence that heat action plans can meaningfully reduce vulnerability to extreme heat and save lives.

\section{References}

Azhar, G. S., Mavalankar, D., Nori-Sarma, A., et al., (2014). Heat-related mortality in India: Excess all-cause mortality associated with the 2010 Ahmedabad heat wave. PLoS One 9(3), e91831.

Benmarhnia, T., Schwarz, L., Nori-Sarma, A., \& Bell, M. L. (2019). Quantifying the impact of changing the threshold of New York City heat emergency plan in reducing heat-related illnesses. Environmental Research Letters, 14(11), 114006.

D’Ippoliti, D., Michelozzi, P., Marino, C., de’ Donato, F., Menne, B., Katsouyanni, K., ... \& Perucci, C. A. (2010). The impact of heat waves on mortality in 9 European cities: Results from the EuroHEAT project. Environmental Health, 9, 37. doi: 10.1186/1476-069X-9-37

Gasparrini, A., Guo, Y., Sera, F., Vicedo-Cabrera, A. M., Huber, V., Tong, S., ... \& Armstrong, B. (2017). Projections of temperature-related excess mortality under climate change scenarios. The Lancet Planetary Health, 1(9), e360-e367.

Hess, J. J., Lm, S., Knowlton, K., Saha, S., Dutta, P., Ganguly, P., ... \& Mavalankar, D. (2018). Building resilience to climate change: Pilot evaluation of the impact of India's first heat action plan on all-cause mortality. Journal of Environmental Public Health, 7973519. doi: 10.1155/2018/7973519

Jaswal, A., Padmakumari, B., Kumar, N., \& Kore, P. A. (2017). Increasing trend in temperature and moisture induced heat index and its effect on human health in climate change scenario over the Indian sub-continent. Journal of Climate Change, 3(1), 11-25.

Knowlton, K., Kulkarni, S. P., Azhar, G. S., Mavalankar, D., Jaiswal, A., Connolly, M., ... \& Hess, J. J. (2014). Development and implementation of South Asia's first heat-health action plan in Ahmedabad (Gujarat, India). International Journal of Environment Research and Public Health, 11(4), 3473-3492. doi: 10.3390/ ijerph110403473

Maughan, R. J. (2012). Hydration, morbidity, and mortality in vulnerable populations. Nutrition Reviews, 70 2, S152-S155. doi: 10.1111/j.1753-4887.2012. 00531

National Disaster Management Authority, Ministry of Home Affairs, Government of India. (2019). National guidelines for preparation of action plan-prevention and management of heat wave. https://ndma.gov.in/images/guidelines/heatwaveguidelines.pdf 
Nori-Sarma, A., Anderson, G. B., Rajiva, A. et al. (2019). The impact of heat waves on mortality in Northwest India. Environmental Research, 176, 108546.

Robinson, P. J. (2001). On the definition of a heat wave. Journal of Applied Meteorology, 40(4), 762-775. doi: 10.1175/1520-0450(2001)040<0762:OTDO $\mathrm{AH}>2.0 . \mathrm{CO} ; 2$

Singh, N., Singh, S., \& Mall, R. K. (2020). Urban ecology and human health: Implications of urban heat island, air pollution and climate change nexus. In Urban Ecology (317-334). Elsevier.

Tollefson, J. (2018). IPCC says limiting global warming to $1.5^{\circ} \mathrm{C}$ will require drastic action. Nature, 562(7726), 172-173. doi: 10.1038/d41586-018-06876-2

Vellingiri, S., Dutta, P., Singh, S., Sathish, L. M., Pingle, S., \& Brahmbhatt, B. (2020). Combating climate change-induced heat stress: Assessing cool roofs and its impact on the indoor ambient temperature of the households in the Urban Slums of Ahmedabad. Indian Journal of Occupational and Environmental Medicine, 24(1), 25-29. doi: 10.4103/ijoem.IJOEM_120_19 
$\Longrightarrow$ Taylor \& Francis

Taylor \& Francis Group

http://taylorandfrancis.com 
Section 3

\section{REDUCING THE CLIMATE FOOTPRINT OF THE HEALTH SECTOR}


$\Longrightarrow$ Taylor \& Francis

Taylor \& Francis Group

http://taylorandfrancis.com 


\title{
CLIMATE-SMART HEALTHCARE: WHAT DOES IT ENTAIL?
}

\author{
Josh Karliner and Shriram Manogaran
}

\begin{abstract}
Introduction
Any health system's primary focus is to improve population health and respond to disease. In order to achieve this, a successful health system must prepare and build resilience to climate and other disruptive events (Karliner et al., 2020). "Climate-smart" is a collective term used for measures that build resilience to climate change while also reducing greenhouse gas emissions. Working on only one of these two measures may yield short-term gains, but will not suffice for a comprehensive healthcare effort to address climate change. The health sector needs to explore opportunities for climate resilience in order to be functional during extreme climate events while adopting low carbon models of care to reduce its own footprint. Hence, a low-carbon and resilient health system can be referred to as climate-smart healthcare (Timothy, Roschnik and Karliner, 2017). This chapter delves into the importance of both these aspects, and provides insight on the following:
\end{abstract}

1. How to build a resilient health system that can adapt to climate threats.

2. What mitigation strategies can be adopted by a health system in order to decarbonise.

\section{Resilient health systems}

Building health-system resilience to climate change is a cumulative process that occurs over the short-, medium- and long term. It entails various tasks such as capacity building, monitoring and evaluation, climate-related communications, responding to and managing uncertainty, and learning from prior experiences.

According to the World Health Organization, a climate-resilient health system is one that is capable of anticipating, responding to, coping with, recovering from and adapting to climate-related shocks and stress, so as to bring sustained improvements in population health despite an unstable climate (WHO, 2008, 2015). This is essential in order to deal with rising 

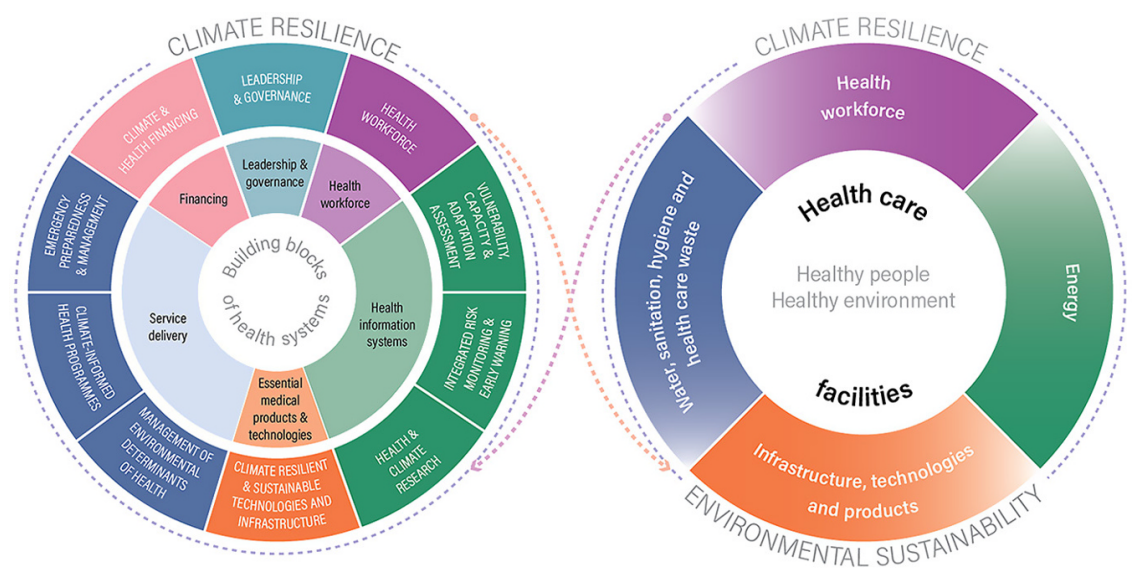

Figure 12.1 Climate resilience and environmental sustainability in healthcare facilities (Reproduced with written permission from WHO (2020), WHO Guidance for Climate Resilience and Environmentally Sustainable Healthcare Facilities, Geneva).

population pressures, environmental degradation and emerging infectious disease outbreaks, such as Ebola and COVID-19, which has highlighted the failures and insufficiency of adaptation measures in health systems around the world.

The WHO operational framework (see Figure 12.1) contains components that elaborate on the building blocks of a resilient health system and its relationship to environmentally sustainable healthcare facilities [WHO, 2020).

Building resilience is the first step in protecting health systems from the complex, unpredictable, and multifaceted ways in which climate change affects healthcare delivery and infrastructure. This is why climate change should be acknowledged as a health issue, and why climate responses should position health as a cross-cutting theme for overall adaptation. Building awareness within the health community on the relationship between climate change and health with both policy and practice will see more well-developed resilience and mitigation systems (WHO 2008, 2015; Costello et al., 2009). The following considerations are essential for integrating climate perspectives into health policy and operations:

\section{Identify and reduce vulnerabilities}

The first step is to identify specific issues within the health system and infrastructure. A generalised risk from extreme climate events is insufficient for planning. This is because not all areas are equally at risk within a state or even within a district. The intensity, frequency and duration of local climate 
events should be assessed and factored into design and execution (Resilient Hospital Dashboard ${ }^{1}$, 2016). A vulnerability assessment should be conducted for the infrastructure and for the community. Potential avenues for collaboration should be initiated with national and local meteorological services with access to local climate vulnerabilities and their assessments (Timothy, Roschnik and Karliner, 2017). Once the local short-term and long-term vulnerabilities of the health system are completely understood, investments should be made available to strengthen weak areas and mitigate the vulnerabilities. Particular importance should be given to human resources and equipment; an adequate workforce and climate-proofed infrastructure at the local level can help control climate-induced disease outbreaks and improve responses to local emergencies such as floods, heat and cold waves. These events not only disrupt health services but also hinder the supply of safe water, sanitation and electricity to health facilities. Thus, possible backup options need to be explored. For instance, installing solar panels or wind turbines and microgrids for energy storage can provide a locally-controlled energy supply that can help ensure the continuity of services during an emergency and would also contribute to reducing a facility's carbon emissions.

\section{Build and diversify capacities}

Awareness generation and capacity building workshops should be held for healthcare practitioners and managers, with progressive steps being made to understand the impact of climate change on health and to evaluate the effectiveness of their interventions (WHO, 2015). The healthcare workforce needs to be sensitised to the global impacts of climate change and what it means locally to their communities (Fox et al., 2019). This will result in public health and climate research capacities attuned to climate realities and projections. Investing in the continued engagement of staff at all levels of healthcare on climate-related issues will aid in developing local (district-level) plans that reflect local priorities for responding to climate change (Walsh, 2013). The impact of climate change on healthcare is a new sub-field of research. Thus, health professionals need to come forward to assist and collaborate in new research studies for a better understanding of trends in the interplay of health and climate change. A nexus of informed health practitioners can also play a key role in policy dialogues, invite new avenues for the financing of climate and health research, and facilitate the transition of the health sector to a climatesmart future (Timothy, Roschnik and Karliner, 2017).

\section{Develop adaptive management approaches}

An adaptive management process is required while handling a complex and uncertain issue like climate change. An iterative process of decision-making 
and implementation is vital in this context. In general, the use of tools, assessments, approaches, feedback and new information for decisionmaking facilitates adaptive management. For example:

- a vulnerability assessment clarifies the scale of local needs

- a staff and partners' survey provides insight on effectiveness

- monitoring identifies any changes in conditions

- the evaluation of performance and failure under different conditions identifies limitations

- pre-testing or piloting small initiatives can improve processes before scaling up

\section{Use community action to strengthen health systems}

Community action is critical in order to achieve climate-resilience. Many countries have outlined community approaches as National Determined Contributions (NDCs) and National Adaptation Plans (NAPs) for implementing the Paris Agreement on climate change (Fransen et al., 2015; PEER, 2009). Several impacts of climate change manifest at the local level. Thus, partnerships between healthcare facilities and systems with local communities and civil society are crucial in order to address local risks and vulnerability. These partnerships can promote both community health and climate resilience. Successful resilient health systems are built through practices that take climate change into consideration while empowering communities (Box 12.1).

\section{Mitigation strategies for the health sector}

While they may differ in scale, all health facilities release greenhouse gases while delivering care and procuring products and technologies from a carbon-intensive supply chain. The health sector contributes to carbon emissions through energy consumption, transport and products manufactured, used and disposed of. These emissions can be understood and divided in accordance with the Greenhouse Gas Protocol framework (GHG Protocol, 2017) into Scope 1 (direct emissions from healthcare facilities), Scope 2 (indirect emissions from purchased energy) and Scope 3 (all indirect emissions, not included in scope 2, that occur in the value chain, including both upstream and downstream emissions) - see Figure 12.2. Although India has the seventh-largest absolute health sector climate footprint in the world, it has low healthcare emissions per capita (Timothy, Roschnik and Karliner, 2017).

As hospitals and health systems explore opportunities to address climate change, they find significant overlap and synergies between mitigation measures and climate change resilience interventions. Many resilience strategies also contribute to climate mitigation and vice 


\section{Box 12.1 Case study}

\section{An analysis of health systems after the 2018 floods in Kerala, India}

An analysis of the hospital site locations and non-structural vulnerabilities resulted in the following recommendations to improve building resilience to flooding from climate change:

- Hospital construction and remodelling should take into account the topography, flood history and climate of the region while planning the building.

- Assessments should be conducted in consultation with the public to map vulnerabilities and diseases, determine the need for specific medicines and plan and provide for these medicines.

- Sufficient power backup, water supply, food and medicines should be provided for within hospitals in case of emergencies.

- Hospital equipment should be relocated to higher floors, either permanently or at least during floods.

- Critical backup power supplies and building infrastructure (electrical power, heating and cooling, drinking water, waste systems) should be located above historical or anticipated flood levels.

- Patient medical records should be stored in a flood safe area.

Source: Sambath, 2019

versa-for example, siting health facilities with access to public transportation, deploying on-site energy generation (including solar and other renewable sources), combined heat and power, buildings with natural ventilation, purchasing energy-efficient medical devices and changes in health delivery (such as telemedicine), contribute to both system resilience and carbon footprint reduction.

Many of these strategies can yield significant operational cost savings as well as facility resilience, such as in the case of short-term grid energy loss. For instance, hospitals are finding that interventions that enable them to reduce their dependence on large power grids and infrastructure also enable them to better withstand situations such as increased storms that disable centralised infrastructure.

Several international institutions have begun to orient themselves in the direction of de-carbonisation. The WHO has called for health systems to "lead by example, advancing models of low-carbon health care" (WHO, 2016). The Lancet Commission on Health and Climate Change has suggested that the health sector can take action in three key areas: mitigation, 


\section{India}

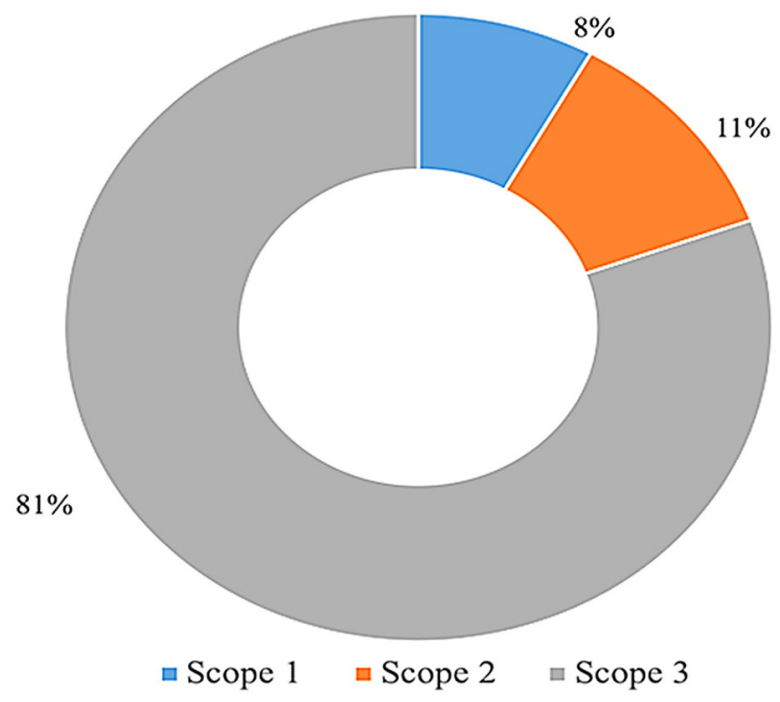

Figure 12.2 India's healthcare footprint split by GHG protocol scopes.

Source: Reproduced with permission from Karliner, J., Slotterback, S., Boyd, R., Ashby, B., \& Steele, K. (2020). Health care's climate footprint: The health sector contribution and opportunities for action. European Journal of Public Health, 30 (Issue Supplement_5), September 2020, ckaa165.843, doi: 10.1093/eurpub/ckaa165.843

resilience and leadership (Watts et al., 2015). The World Bank ClimateSmart Healthcare report lays out a roadmap that says "designing, building, operating, and investing in health systems and facilities that generate minimal amounts of greenhouse gases... aligning health development and delivery with global climate goals... in low-resource, energy-poor settings, powering healthcare with low-carbon solutions can enhance access to care" (Timothy, Roschnik and Karliner, 2017).

Several health systems in multiple countries are already on the road to decarbonisation, serving as models for the sector by implementing a set of actions to reduce their carbon footprint or become carbon-neutral in Scope 1 and 2 emissions, while also building resiliency (GGHH Case Studies, 2015). The transition to low-carbon or de-carbonised healthcare will necessarily include redirecting the health sector's purchasing power toward low-carbon energy sources and technologies to address Scope 3 emissions. In this way, health systems can move their own sector's massive supply chain, thereby also influencing broader markets and policy, and helping accelerate the transition to clean, renewable energy and a low-carbon future (Box 12.2).

Climate-smart healthcare can also foster more equitable access to healthcare and contribute to the development of sustainable, resilient, healthier 


\section{Box 12.2 Case study}

\section{Solar power for public health centres - Chhattisgarh, India}

The Chhattisgarh National Health Mission (NHM), India, was aware of the severe limitations in the delivery of dependable healthcare resulting from the lack of reliable electricity; one-third of the public health centres in Chhattisgarh are either un-electrified or without regular power supply. NHM became aware of the Chhattisgarh Renewable Energy Development Agency (CREDA), which works to provide electrification via solar PV power systems. They fostered a collaboration whereby NHM would identify health centres that would benefit most from the decentralised electricity, and CREDA would be responsible for the full system development, installation, operation and management via local contractors. A pilot programme began in 2008. Its success has led to the installation of more than 900 PV power systems since 2011, all of which are still operational.

Source: Porcaro, Severi and McGregor, 2019

communities. A range of mitigation measures for reducing emissions from healthcare are summarised in Table 12.1.

\section{Key takeaways}

- In order to strengthen its defence, the healthcare community needs to become climate-smart, that is, build resilience to prepare against climate threats while reducing its own carbon footprint.

- To become resilient and adapt to climate threats, health systems should reduce vulnerabilities and build capacities by using adaptive approaches and community action.

- To reduce its carbon footprint and support environmental change in the long run, health systems can adopt mitigation measures during delivery of care, during procurement from a carbon-intensive supply chain, during energy consumption and transport, and through products manufactured, used and disposed of.

- In a climate-smart approach, there can often be overlap and synergy between mitigation and resilience measures.

- A climate-smart approach can also be cost-effective by yielding significant operational cost savings, and can also lead to more equitable access to healthcare. 
Table 12.1 Mitigating strategies applicable to the health sector [Reproduced with permission from B. Timothy, S. Roschnik and J. Karliner (2017), Climate-Smart Healthcare: Low-Carbon and Resilience Strategies for the Health Sector, World Bank Group, Washington DC]

\begin{tabular}{|c|c|c|c|}
\hline Strategy & Actions & GHG impact & Benefits \\
\hline $\begin{array}{l}\text { Improve energy } \\
\text { supply and } \\
\text { distribution } \\
\text { efficiency }\end{array}$ & $\begin{array}{l}\text { - Fuel switching } \\
\text { - Energy recovery } \\
\text { - Distributed generation } \\
\text { - Combined heat and power }\end{array}$ & $\begin{array}{l}\text { - Reduced transmission losses } \\
\text { - Reduced emissions from energy } \\
\text { use, fuel production and } \\
\text { transport }\end{array}$ & $\begin{array}{l}\text { - Immediate energy savings and operational } \\
\text { resilience/ reliability } \\
\text { - Reduced air pollution exposure } \\
\text { - Improved access to reliable healthcare } \\
\text { - Better energy security }\end{array}$ \\
\hline $\begin{array}{l}\text { On-site } \\
\text { renewable } \\
\text { energy sources }\end{array}$ & $\begin{array}{l}\text { - Solar photovoltaics } \\
\text { - Thermal solar energy } \\
\text { - Wind } \\
\text { - Other renewable energy } \\
\text { sources }\end{array}$ & $\begin{array}{l}\text { - Reduced emissions from energy } \\
\text { use, fuel production, and } \\
\text { transport }\end{array}$ & $\begin{array}{l}\text { - Improved operational resilience/reliability } \\
\text { - Long-term energy savings } \\
\text { - Reduced ambient air pollution } \\
\text { - Better energy security }\end{array}$ \\
\hline $\begin{array}{l}\text { Reduced-energy } \\
\text { devices }\end{array}$ & $\begin{array}{l}\text { - Non-electric medical } \\
\text { devices } \\
\text { - Direct-current devices } \\
\text { - Energy efficient appliances }\end{array}$ & $\begin{array}{l}\text { - Reduced emissions from energy } \\
\text { use, fuel production and } \\
\text { transport }\end{array}$ & $\begin{array}{l}\text { - Energy and operations savings and energy } \\
\text { security } \\
\text { - Device reliability and improved } \\
\text { functionality at night } \\
\text { - Improved diagnosis of tuberculosis with } \\
\text { low-energy LED microscopes } \\
\text { - Increased access to healthcare and energy } \\
\text { security }\end{array}$ \\
\hline $\begin{array}{l}\text { Passive cooling, } \\
\text { heating, and } \\
\text { ventilation } \\
\text { strategies }\end{array}$ & $\begin{array}{l}\text { - Natural ventilation in } \\
\text { healthcare settings } \\
\text { - Evaporative cooling } \\
\text { - Desiccant } \\
\text { - dehumidification } \\
\text { - Underground earth-pipe } \\
\text { - Cooling }\end{array}$ & $\begin{array}{l}\text { - Reduced direct } \\
\text { emissions from on-site energy } \\
\text { production; } \\
\text { reduced emissions } \\
\text { from energy use, fuel production, } \\
\text { and transport }\end{array}$ & $\begin{array}{l}\text { - Energy and operations savings and energy } \\
\text { security } \\
\text { - Improved indoor air quality } \\
\text { - Decreased transmission of airborne } \\
\text { infections } \\
\text { - Improved social welfare, productivity and } \\
\text { patient health }\end{array}$ \\
\hline
\end{tabular}


Table 12.1 (Continued)

\begin{tabular}{|c|c|c|c|}
\hline Strategy & Actions & GHG impact & Benefits \\
\hline $\begin{array}{l}\text { Facility } \\
\quad \text { wastewater } \\
\text { and solid } \\
\text { waste } \\
\text { management }\end{array}$ & $\begin{array}{l}\text { - Advanced autoclaving of } \\
\text { infectious healthcare } \\
\text { waste } \\
\text { - On-site wastewater } \\
\text { pre-treatment and } \\
\text { sanitation improvements } \\
\text { - High-heat incineration of } \\
\text { pharmaceuticals with } \\
\text { pollution scrubbers }\end{array}$ & $\begin{array}{l}\text { - Reduced energy emissions for } \\
\text { waste and water treatment } \\
\text { - Reduced greenhouse gas (GHG) } \\
\text { footprint from waste treatment } \\
\text { processes in some settings } \\
\text { - Reduced aquifer and ecosystem } \\
\text { damage }\end{array}$ & $\begin{array}{l}\text { - Savings in waste/water disposal fees } \\
\text { - Reduced waste volumes } \\
\text { - Improved compliance with local air quality } \\
\text { - } \text { regulations/ guidelines } \\
\text { - Rmproved hygiene around facility } \\
\text { - Reduced methane and other emissions } \\
\text { agents and to diarrhoea and other } \\
\text { waterborne diseases }\end{array}$ \\
\hline $\begin{array}{l}\text { Reduced GHG } \\
\text { emissions } \\
\text { from } \\
\text { anaesthesia } \\
\text { gas use and } \\
\text { disposal }\end{array}$ & $\begin{array}{l}\text { - Waste anaesthetic gas } \\
\text { recapture and scavenging }\end{array}$ & $\begin{array}{l}\text { - Reduced direct emissions from } \\
\text { anaesthesia gas waste }\end{array}$ & $\begin{array}{l}\text { - Anaesthesia cost savings with reuse } \\
\text { - Reduced health risks for health workers } \\
\text { - } \text { Imposed to gas } \\
\text { - Improved health worker productivity }\end{array}$ \\
\hline $\begin{array}{l}\text { Reduced } \\
\text { procurement } \\
\text { carbon } \\
\text { footprint }\end{array}$ & $\begin{array}{l}\text { - Better-managed } \\
\text { procurement of } \\
\text { pharmaceuticals, } \\
\text { medical devices, } \\
\text { business products and } \\
\text { services, food/catering, } \\
\text { and other facility inputs }\end{array}$ & $\begin{array}{l}\text { - Reduced energy footprint in } \\
\text { production and transport of } \\
\text { unused pharmaceuticals and } \\
\text { products }\end{array}$ & $\begin{array}{l}\text { - Resource savings on unused/wasted } \\
\text { products } \\
\text { - Reduced risks from use of outdated/expired } \\
\text { products }\end{array}$ \\
\hline $\begin{array}{l}\text { Telehealth/ } \\
\text { Telemedicine }\end{array}$ & $\begin{array}{l}\text { - Home patient tele } \\
\text { monitoring and guidance } \\
\text { - Emergency response } \\
\text { Health worker advice and } \\
\text { collaboration via mobile } \\
\text { phones }\end{array}$ & $\begin{array}{l}\text { - Reduced emissions from } \\
\text { healthcare-related travel }\end{array}$ & $\begin{array}{l}\text { - More cost-effective healthcare } \\
\text { - Reduced risk of travel-related injuries } \\
\text { - Improved management of chronic } \\
\text { conditions, such as diabetes and heart } \\
\text { disease, as well as emergency response } \\
\text { - Better access to healthcare advice in } \\
\text { poorly-resourced remote locations }\end{array}$ \\
\hline
\end{tabular}


Table 12.1 (Continued)

\begin{tabular}{|c|c|c|c|}
\hline Strategy & Actions & GHG impact & Benefits \\
\hline $\begin{array}{l}\text { Health facilities } \\
\text { in proximity } \\
\text { to public } \\
\text { transport and } \\
\text { safe walking/ } \\
\text { cycling }\end{array}$ & $\begin{array}{l}\text { Public transport options } \\
\text { mapped during planning } \\
\text { of buildings to locate new } \\
\text { facilities nearby } \\
\text { - Employee incentives for } \\
\text { public active transport use } \\
\text { \& facilities }\end{array}$ & $\begin{array}{l}\text { Reduced transport-related } \\
\text { emissions from health worker } \\
\text { and hospital visitor travel }\end{array}$ & $\begin{array}{l}\text { - Reduced traffic injury risk for health } \\
\text { workers and hospital/ clinic visitors } \\
\text { travelling to health facilities } \\
\text { - Potential for active transport by healthcare } \\
\text { workers to reduce risks of hypertension, } \\
\text { cardiac disease and diabetes } \\
\text { - Improved facility access for health workers } \\
\text { and visitors who do not have cars }\end{array}$ \\
\hline
\end{tabular}




\section{Note}

1 The Resilient Hospital Dashboard is a USA-focused "interactive platform that enables healthcare networks to identify hotspots, key drivers of risk, and the specific local impacts faced by each of their hospitals. By using climate, socioeconomic, public health and facility specific data, these dashboards analytics help hospitals understand the impact of climate change on their community and patients."

\section{References}

Costello, A., Abbas, M., Allen, A., Ball, S., Bell, S., Bellamy, R., ... \& Patterson, C. (2009). Managing the health effects of climate change. The Lancet, 373, 1693-1733.

Fox, M., Zuidema, C., Bauman, B., Burke, T., \& Sheehan, M. (2019). Integrating public health into climate change policy and planning: State of practice update. International Journal of Environmental Research and Public Health, 16(18), 3232.

Fransen, T., Levin, K., Mogelgaard, K., \& Northrop, E. (2015). National climate plans (INDCs) by the numbers. World Resources Institute. https://www.wri.org/ insights/national-climate-plans-indcs-numbers

GGHH. (2015). Case studies from Global Green and Healthy Hospitals (GGHH) members. https://www.greenhospitals.net/case-studies/\#clima

GHG Protocol. (2017). GHG Protocol Framework. https://ghgprotocol.org/blog/ new-global-framework-measure-greenhouse-gas-emissions-cities

Karliner, J., Slotterback, S., Boyd, R., Ashby, B., \& Steele, K. (2020). Health care's climate footprint: The health sector contribution and opportunities for action. European Journal of Public Health, 30(Issue Supplement_5), September 2020, ckaa165.843, doi: 10.1093/eurpub/ckaa165.843

Partnership for European Environmental Research (PEER). (2009). Europe adapts to climate change: Comparing national adaptation strategies. PEER.

Porcaro, J., Severi, L., \& McGregor, C. (2019). Lasting impact: Sustainable off-grid solar delivery models to power health and education. Research report. UN Foundation and Sustainable Energy for All. https://www.seforall.org/publications/lasting-impact-sustainable-off-grid-solar-delivery-models.

Resilient Hospital Dashboard. (2016). http:/427mt.com/2016/02/resilienthospitals-dashboard/

Sambath, V. (2019). Building climate resilient health systems: Assessment of response of health system to Kerala floods of August 2016. http://www.healthyenergyinitiative.org/wp-content/uploads/2019/03/Kerala-Study_Final-for-web-March2019-.pdf.

Timothy, B., Roschnik, S., \& Karliner, J. (2017). Climate-smart healthcare: Lowcarbon and resilience strategies for the health sector. World Bank Group.

Walsh, M. (2013). Capacity building strategy on climate change and health related risks - Final technical report. UNDP, GEF and Ministry of Health, Ghana.

Watts, N., Adger, W. N., Agnolucci, P., Blackstock, J., Byass, P., Cai, W., ... \& Costello, A. (2015). Health and climate change: Policy responses to protect public health. The Lancet, 386(10006), 1861-1914.

WHO. (2008). 61st world health assembly: Climate and health. http://www.who. int/globalchange/health_policy/wha_eb_documentation/en/ 
WHO. (2015). Operational framework for building climate resilient health systems. WHO. http://www.who.int/globalchange/publications/building-climate-resilienthealth-systems/en/

WHO. (2020). WHO guidance for climate resilient and environmentally sustainable healthcare facilities. WHO.

WHO (World Health Organization). (2016). Conference Conclusions and Action Agenda (Final Version). Second Global Conference, Health and Climate, 7-8 July. 


\title{
GREEN AND RESILIENT HEALTH INFRASTRUCTURE
}

\author{
Yatin Choudhary and Hari Kumar
}

\section{Introduction}

A green building is a structure that is environmentally responsible in its design, construction and operation, consequently improving the quality of both its indoor and outdoor environments. In healthcare, green infrastructure deals mainly with reducing the carbon footprint and thereby mitigating the impact on climate change. When implemented effectively, it can also provide the aesthetic component and improve the well-being of people using healthcare facilities, both patients and professionals. Health facilities have an environmental impact on the natural resources they consume, starting with the construction materials and the generated waste. Green infrastructure improves environmental sustainability with the usage of environment-friendly resources and practices, and by releasing well-treated and less harmful waste to its surroundings.

Resilient healthcare infrastructure, on the other hand, is that which can withstand extreme weather events (such as heavy precipitation, heatwaves, coldwaves, flooding, etc.) and cope with the consequent health impacts. These extreme weather events disrupt either the infrastructure or the function of the healthcare facilities completely or in varying degrees, right when they are needed the most, causing adverse psychosocial outcomes, injuries and deaths. A resilient hospital building can resist the impact of natural hazards, thereby allowing health facilities to remain functional during a calamity and in its immediate aftermath.

The concept of green buildings is not unique to healthcare, but hospitals do face unique challenges in terms of sustainability and disaster resilience, chiefly because they are resource- and energy-intensive. Similar to the medical doctrine of do no harm, it is important to follow green building principles and do the least harm to the environment. It is often thought that green designs and disaster-resilient designs are mutually exclusive, and that one aspect has to be compromised in order to cater to the other, but this is 
untrue. In fact, considering the multi-hazard prone nature of our country, it is vital for environmental sustainability that healthcare infrastructure be both green and resilient. Sometimes, making a building disaster-resilient may increase the environmental impact, and it can become challenging to balance the needs for resilience and optimum design requirements for resource efficiency in green buildings. This chapter will explore the means to achieve convergence between these needs, providing readers with an understanding of the following:

1. How to design and develop health facilities that are both green and resilient to disasters.

2. How to make existing buildings adapt to changing environmental conditions because of extreme weather events that are mainly attributable to climate change.

\section{Green infrastructure}

Green buildings are, by definition, resource-efficient and therefore have smaller environmental footprints. They are designed to optimise the onsite available resources such as sunlight, ventilation, water and energy. They are built of environmentally friendly materials, use energy-efficient devices and appliances, use water conservation strategies such as rainwater harvesting, and generate energy from clean and renewable sources (solar, wind or biogas). An important aspect of green hospital buildings is that they provide better indoor environment conditions for their occupants.

Green buildings are designed according to the functional requirements defined in standards and codes. In 2016, sustainable building design was incorporated into the National Building Codes. For energy efficiency, Energy Conservation Building Codes were introduced in 2007 (and updated in 2017). Sustainability was included in the Model Building Byelaws, 2016. There are several frameworks available in India for the design of green buildings including the AHPI Standard for Green and Clean Hospitals. The prominent rating systems that assess and certify the buildings on the basis of nationally acceptable benchmarks include a) Green Rating for Integrated Habitat Assessment (GRIHA), developed by the GRIHA Council, b) Indian Green Building Council (IGBC) rating systems, c) Leadership in Energy and Environment Design (LEED) developed by the US Green Building Council, and d) Excellence in Design for Greater Efficiencies (EDGE) by International Finance Corporation (IFC). In all of these, common green building principles utilise considerations such as land use, siting, low water and energy usage, utilisation of locally available materials, adoption of better standards of ventilation, day lighting and environment-friendly materials. These considerations are demonstrated in the case study of a green healthcare facility in Kurla, Mumbai (Box 13.1). 


\section{Box 13.1 Case study}

\section{Kohinoor Hospital in Kurla, Mumbai - the first LEED platinum-rated hospital in Asia}

Kohinoor Hospital was built using an environmentally sensitive design that not only conserves water and electricity, but also positively impacts the hospital's clinical environment by improving air quality, utilising natural sunlight and reducing a wide range of pollutants. During construction, the hospital used more than $29 \%$ of recycled material and $72 \%$ of regional material manufactured within a radius of $800 \mathrm{~km}$; appropriate construction waste management practices were followed to ensure that waste was recycled where possible and not diverted to landfills; and scrap steel was sourced and used for the overhead tank foundation.

Water efficiency was achieved by using urinal sensors, fixtures with low flow rates, and efficient grey water management. The landscaping requires no irrigation and the hospital's sewage treatment plant of 130 KLD treats $100 \%$ of the waste water.

The windmill installed by the hospital generates power offsite equivalent to $90 \%$ of the hospital's total requirement, hugely reducing its carbon footprint. The hospital conducted a detailed study of the solar path of the sun before finalising the orientation of the building, and its façade was designed with double glazed units of high-performance reflective glass to ensure that solar heat does not enter the building, whilst simultaneously ensuring that it is well-lit during the day. Solar panels on the roof are used for heating $84 \%$ of the water used by the hospital. Low wattage CFLs and LEDs were used in the lighting design and light fixtures, adding to the energy savings.

With respect to indoor air quality, the building has a no smoking policy; and the use of MERV-13 filters and $\mathrm{CO}_{2}$ sensors has increased the delivery of fresh air by 30\%. Mr. Unmesh Joshi, CMD of the Kohinoor Group, says, "Being green has a profound effect on the healing process, and what's good for the environment will be good for our patients.”

Source: https:/www.mgsarchitecture.in/building-materials-products/technologyautomation/273-kohinoor-hospital-1st-leed-platinum-rated-project-in-asia2nd-in-the-world.html

\section{Functionality of health facilities in emergencies}

As stated above, health facilities in our country should be resilient to every hazard that can affect their functionality. Staying safe during and after disastrous events poses a unique challenge for every medical care facility in 
terms of infrastructure, capacity and preparedness. However, for hospital buildings with a post-disaster role, it is not enough to only ensure the safety of the occupants of the building; the hospital building must be functional in all respects even during disasters, as it is expected to take in a surge of affected patients (Box 13.2). For a hospital to be functional during emergencies, the structure should remain largely undamaged and the facility should function as normal. For instance, a hospital emergency department where back-up electricity and water supply have been lost will not be able to serve a meaningful purpose in saving lives after the occurrence of a disaster.

\section{Box 13.2}

When hospitals are affected by disasters, there are health-related, social and economic repercussions. The health impact of hospitals being affected by disasters include the lapses in medical care being provided to victims of a disaster, lapses in preventive medicine and lapses in public health response. The social impact of hospitals being affected by disasters includes a loss of morale in the affected community which can affect the long-term recovery and sense of well-being of the community. The economic impact of hospitals being affected by disasters is enormous, given the huge investments required to be made to construct hospitals and the expensive equipment that is lost when disasters strike hospitals. Even the use of temporary field hospitals as a contingency measure is economically unviable. It is an attested fact that the costs involved to mitigate and prepare hospitals for disasters are far less than those required for re-building hospitals after they have been damaged by disasters. - National Disaster Management Guidelines, page 2.

A hospital needs to fulfil certain criteria for continued functionality in the aftermath of a natural disaster. We will examine the resilience and environmental challenges of each of these aspects after understanding the hazards the location is prone to.

\section{a) Safe and functional green buildings}

One of the earliest decisions to take in the lifespan of any health facility is the selection of the hospital site. A facility close to public facilities and even within communities reduces long-term costs and the environmental effects of transportation. Depending on the location, hospitals might be prone to different natural hazards such as earthquakes, landslides, cyclones, storm surges, or heavy rainfall. It should be borne in mind that during disastrous events and emergency situations, unlike in other buildings, evacuating 
patients from a healthcare facility will be extremely complex even with detailed evacuation plans. The site selection should take these aspects into consideration. Sandy soils with high water tables will amplify the effects of earthquakes and could undergo liquefaction, which can be dangerous for buildings. Other important factors that must be ensured during siting is to keep health facilities away from flood plains, landslide-/rock fall-prone areas, storm surges, tsunami inundation areas and so on. In the Indian context, the design of the building should consider all hazards that can affect the location using the Vulnerability Atlas of India (Building Materials and Technology Promotion Council, Ministry of Housing and Urban Affairs, Govt. of India, 2019).

Designers should take special care to follow all provisions as per the building code to ensure the safety of the roofs and external facades during earthquakes and high winds. In fact, the National Disaster Management Authority Guidelines on Hospital Safety (National Disaster Management Authority, Government of India, 2016) stipulate that hospital buildings with critical functions should be designed beyond the building codes, as these must remain functional in the events of crisis.

Gandhiji once said, "The ideal house in an ideal village would be built with materials found within a five-mile radius from the house." This holds true even for the construction of health infrastructure, and the selected materials should be locally available as possible without compromising on quality. The same principle applies for all procurement, which is another reason that the location of the health facility's location should be such that most or all procurement can take place from within a reasonable distance.

On top of this, the health facility should be green and resource-efficient with a minimal environmental footprint. Making sustainability an integral part of the building design will bring about a reduction in the hospital's energy requirement. Ensuring the right building façade will not only reduce the cooling and lighting requirements, but also aid in improved occupant comfort. In a tropical country like India, extensive glazing material should be avoided for buildings. The designs should optimise the use of onsite resources like sunlight, water and energy for functional requirements and aim to operate efficiently with minimal external dependence.

\section{b) Retrofitting of existing health facilities}

In the case of existing buildings, hospitals can initiate "retrofit" projects, to incorporate these changes. The energy savings from these projects, through reduced cooling or lighting requirements, can pay for the cost of the projects in most cases. However, it should also be clear that many structural retrofits will involve some level of disruption of normal functioning of the building and the hospital administration should work closely with the engineering team to work out a disruption plan for the retrofitting work.

The task of retrofitting existing hospital buildings into more resilient buildings and at the same time reducing its environmental impact is 
challenging, and requires detailed planning and coordination between the structural engineers and the green building specialists. Energy-efficiency upgrades can be carried out during a structural retrofit that utilises natural daylight better, provides improved ventilation, brings in higher efficiency in lighting/heating/cooling needs and utilises renewable energy and green roofs. These can help existing health facilities remain safe in disaster situations and reduce their environmental footprint. Such retrofits offer high returns in terms of reduced utility costs, lower dependency on external power and water sources, and better indoor environment conditions, leading to a healthier, safer and much more comfortable setting for the patients and staff.

\section{c) Safe and functional utility systems}

The functionality of a hospital depends largely on the availability of its utility services such as electricity, water supply and medical gas supply. It is important for health facilities to minimise their dependence on external suppliers and be self-sufficient to the maximum possible extent, as the external supplies are likely to be affected by hazards such as earthquakes, floods, or cyclones.

According to the Hospital Safety Index (WHO, 2015b), hospitals should have back-up electricity sources to power the facility for at least three days before the restoration of external sources. Solar passive architecture and planned ventilation can help in achieving this and effectively reduce the power requirements for heating and cooling purposes. Improving energy efficiency and reducing dependency on fossil fuel energy by using renewable energy such as solar rooftop panels as backup, could make a hospital selfreliant during these periods. The maintenance department of hospitals should develop a disaster power supply plan to estimate the departmentwise needs for electricity and identify alternate sources for supply in advance.

The HSI also recommends provision for in-hospital storage of enough water to run the hospital for the three-day emergency period. The reduced dependence on external sources of water must be achieved by the adoption of planned measures in the form of water conservation, recycling and treatment. The maintenance department of hospitals should develop a disaster water supply plan to estimate both quantity and quality of water required to continue operation of the critical functions and to meet emergency needs.

\section{d) Safe and functional medical equipment}

The safety and functionality of a medical facility can be affected not just by the loss of utility supply, but also due to the occurrence of flooding or earthquakes. To overcome this, it is important that critical equipment needed in emergency responses are as protected as possible from natural calamities (Rodgers et al., 2009). For example, in the 2015 Nepal earthquake, solar panels that had not been anchored properly in many hospitals either fell down or collided against each other and were damaged. In 
another instance during the 2015 Chennai floods, a hospital situated on the banks of the Adyar River lost several patients who were on ventilators, as the back-up electricity equipment was kept in the basement, which flooded.

\section{e) Safe and appropriate medical supplies}

Post-disaster emergency treatment requires medical supplies, and this largely depends on the nature of the disaster that occurred. Medical supplies required for earthquakes, floods and fires are different, and disaster medical supplies kits should be available within the stores for any emergency as per the Hospital Disaster Management Plan (HDMP). However, in order to reduce wastage and pharmaceutical pollution, hospital pharmacies should have a clear plan to utilise the medicines including emergency medicines much before expiry dates with strict stock controls, ensuring that these are sent out either as donations to other health facilities, or via manufacturer take-backs.

\section{f) Safe and prepared staff members}

The functionality of a health care institution in a post-emergency situation also depends on the level of preparedness of the staff members. A robust HDMP, staff training and preparedness drills/table-top exercises to test the plan will play a crucial role in ensuring that staff are prepared to take up their roles as detailed in the plan. In the field of disaster resilience and in aspects of green hospitals, leadership support for staff members will play a pivotal role in creating long-term organization cultural change towards safer, greener hospitals.

Healthcare leadership can also look at international guidelines such as the SMART Hospitals Toolkit (PAHO, 2017), the WHO HSI and the existing Framework for Climate-resilient Health Care Systems (WHO, 2015) on how to achieve resilience in preparation for disaster occurrences.

\section{Key takeaways}

- A green and resilient health sector plays a critical role in mitigating natural hazard risks and the effects of climate change through the adoption of eco-friendly strategies.

- It is imperative that the health facilities bring together resilience and minimal environmental impact in their design, construction and operations.

- India is a vast country where different regions of the country are prone to different hazards, and these should be assessed at the local level in the form of a situational analysis before embarking on the design of new healthcare facilities or before retrofitting an existing building.

- A hospital can decrease its carbon footprint and demonstrate continued functionality in the aftermath of a natural disaster with safe and 
functional green buildings, retrofitted existing buildings for efficient operations, safe and functional utility systems, safe and functional medical equipment, safe and appropriate medical supplies, and safe and prepared staff members.

- Codes, frameworks and standards for green buildings and resilient infrastructure have been provided for reference.

\section{References}

Building Materials and Technology Promotion Council, Ministry of Housing and Urban Affairs, Govt. of India. (2019). Vulnerability atlas of India (3rd ed.) BMTPC. https://bmtpc.org/DataFiles/CMS/file/VAI2019/Index.html

National Disaster Management Authority, Government of India. (2016). National disaster management guidelines: Hospital safety. A publication of the National Disaster Management Authority, Government of India. ISBN: 978-93-84792-03-9

Pan American Health Organization. (2017). Smart hospitals toolkit. https://www.

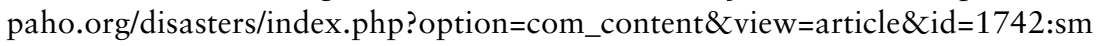
art-hospitals-toolkit\&Itemid=1248\&lang=en

Rodgers, J., Cedillos, V., Kumar, H., Tobin, L. T., \& Yawitz, K. (2009). Reducing earthquake risk in hospitals from equipment, contents, architectural elements and building utility systems. Geohazards International and Geohazards Society.

World Health Organization. (2015a). Operational framework for building climate resilient health systems. https://www.who.int/globalchange/publications/buildingclimate-resilient-health-systems/en/

World Health Organization \& Pan American Health Organization. (2015b). Hospital safety index: Guide for evaluators ( 2 nd ed.) World Health Organization. https://apps.who.int/iris/handle/10665/258966 


\title{
SUSTAINABLE ENERGY MANAGEMENT IN THE HEALTH SECTOR
}

\author{
Huda Jaffer and Harish Hande
}

\section{Introduction}

Over half of the health sector's carbon footprint comes from its energy use. Hospitals and healthcare facilities function 24 hours a day, 365 days a year, necessitating continuous energy usage patterns. There are many fuel options for the health sector to choose from, ranging from fossil fuel-based grids to diesel generators, but there are consequences to opting for these choices. The health sector today bears all of the operational costs, including the significant cost of energy, offloading the cost into the public health arena, making it expensive to run many critical care devices and contributing a significant amount towards the greenhouse gas emissions that cause climate change. There are huge opportunities for the health sector to lower its carbon footprint, and consequently make healthcare more affordable, by introducing energy efficiency combined with decentralised reliable renewable energy.

The combination of sustainable energy combined with efficiencies of medical technologies and greener built environments can be one of the most critical components to decrease the health sector's climate footprint. Expensive and unsustainable solutions hinder the replication and scale of sustainable delivery models. A primary assumption being made in healthcare facilities is that existing infrastructure cannot be changed, leading to inefficient solutions that cannot be replicated in other contexts. As in the case of the electricity sector, decentralised energies like solar power have disrupted delivery models, making it available in a more modular form, and consequently more affordable. The availability of sustainable energies, especially for healthcare, in a decentralised mode also pushes innovations in healthcare technologies, increases the efficiencies of medical devices, introduces savings and thermal comforts in health centres through active and passive methods and gives rise to newer delivery models if implemented in a holistic manner. This chapter will examine:

1. Energy usage in the health industry, and how lack of reliable energy sources prevents access to healthcare, especially in rural areas. 
2. An ecosystem-driven approach towards implementing sustainable energy for the health sector.

\section{Energy consumption in the health sector}

Access to reliable energy is a critical barrier to providing accessible sustainable healthcare to all. Effective and optimum utilisation of energy will only take place when the appliances and equipment in the medical profession are designed to be energy efficient while remaining uncompromising on the quality of output. The current inefficiencies in equipment offload the cost of energy onto the public health sector. The health sector today bears all of the operational costs, making it expensive to run many critical care devices, especially in energy-deficient areas. This results in the marginalisation of many populations from availing of reliable health services.

Today, more than half of the world's population lacks access to health services (World Bank and WHO, 2017). Most of the unreached populations reside in the poorest countries, their governments left with no choice but to rely on fossil fuels to power the last-mile health facilities.

A typical medical centre runs continuously all day, every day; internal temperatures need to be carefully controlled for patient safety, human comfort and medical procedures, with energy being consumed by systems for cooling, heating, lighting, ventilation and thermal insulation systems, along with standby generators to ensure an uninterrupted supply of electricity. Autoclave, sterilisation facilities, laundry and catering facilities also require huge amounts of energy for steam, hot water and other thermal applications. These large amounts of energy inputs are not available in remote locations, with the consequence that healthcare facilities in rural remote locations do not have either heating or cooling systems nor critical machines like autoclaves and refrigerators, etc.

\section{Energy efficiency and selected sectors}

While designing medical products, a basic assumption made is that there will be no dearth of reliable energy access to power it. There are two problems that arise from such an assumption: the operational costs of centres with access to energy are not trivial, and centres with unreliable electricity must depend on expensive diesel generators for operation. Inefficient appliances also make decentralised energies such as solar energy seem more expensive than they actually are. Availability of medical devices that are designed for low-resource settings can help the health sector not only to mitigate its carbon footprint, but also to reach the underserved communities.

There is a strong case to be made for a nexus between the efficiency of medical appliances, reliable health services and access to sustainable energy. Low power usage equipment encourages health services to opt for solar energy as a primary source of electricity for reasons of economy and 
reliability. There are some areas in the health sector where energy efficiency methodologies can be adopted immediately, leading to considerable financial savings and environmental impact (Alexander \& Manogaran, forthcoming 2022):

- Maximising the use of natural light in healthcare facilities will help reduce stress levels, and energise employees and patients, as sunlight is beneficial to human health. However, artificial lighting should not be compromised on in sensitive areas such as operation theatres, medical dispensaries, etc.

- Optimising energy efficiency within healthcare facilities simply by turning off energy equipment such as lights, exhausts, air-conditioners, etc. when they are not being used. This can be done through automatic sensors, but it is more economical to sensitise the hospital employees about the issue. Climate-resilient options for lighting, cooling, heating can be easily implemented in the short run, as the technology for this already exists.

- Identifying materials and equipment in the market that have lower environmental impacts. For instance, procuring electronic devices that have been rated as five-star or four-star by the Bureau of Energy Efficiency (BEE) will translate to better savings on energy. Compact Fluorescent Lamps (CFL) can be replaced with light-emitting diodes (LED) lights for more energy savings. Energy metering can identify the facility's energy consumption and indicate opportunities for better efficiency. This option can be used for HVAC systems, and internal and external lighting.

- Investing in renewable energy. This is affordable, safe, economically beneficial in the long run, and provides an opportunity for healthcare facilities to reduce dependency on the grid and be self-sufficient during extreme climate events. A renewable energy backup will decrease the greenhouse gas (GHG) emissions from the facility and enable it to be functional during power cuts.

\section{Lighting}

Lighting is a critical requirement of the health sector for various applications, from patient waiting areas to the operation theatre. Unfortunately, in many primary health centres and sub-centres, the design of the building mandates the requirement of lighting throughout the day. Inefficient bulbs, poor placement of lights and a mismatch of intensity required leads to inefficient usage. Lighting requirements should be customised according to the type of space utilisation and hours of usage. Sensors should be installed in areas of sporadic utilisation, such as rest rooms and corridors. Low intensity LED lighting in waiting areas and high intensity LED with shadow-less fixtures are suitable for operation theatres. A simple and appropriate lighting mapping exercise will save enormous financial resources for individual 
centres without any compromise in quality. Replacing tube lights and incandescent lights with LED can save any centre up to $50 \%$ in lighting costs (Lorenzi, 2019).

\section{Fans}

Fans usage is a major energy expense in the health sector. Again, poor building design and rooms with inappropriate ventilation leads to the unnecessary over-usage of fans. Well-designed buildings with the appropriate placement (wall mounted versus ceiling) of high-efficiency fans can reduce electricity requirements. The benchmark for efficient fans across the world is between 30 and 40 watts, but the ones normally used in India are between 60 and 75 watts, $50 \%$ more than world standards (Sarang, 2015). Solar power is a very viable power source for fans and lights.

\section{Heating}

In a health centre, heating is a crucial requirement for the sterilisation of various instruments, hot water during deliveries, for bathing purposes in patient wards, space heating in colder geographical areas, etc. It is critical to work on the efficiencies of the various appliances used for thermal applications. Inefficient boilers in autoclaves could be directly responsible for increased electricity bills. There are solutions to increase the efficiencies. For example, in-patient needs for hot water can be provided by solar water heaters. Solar water heaters can also supply preheated water to boilers, thus reducing the consumption of other fuels. Autoclaves should be customised for increased efficiency, as it depends on the type and length of usage.

\section{Cooling}

Space cooling is a need that has been underestimated, especially in the health centres of the developing world. The increase in daytime temperatures is being felt by every vertical in the health sector. Take the example of maternal delivery areas and post-delivery rest areas: high day-time temperatures take an enormous toll on mothers and newborn babies. Cooling can no longer be considered a luxury service, but a necessity. Unreliable power and high rates of electricity can be a challenge for many health providers to ensure that the premises maintain temperatures comfortable to human bodies. Fortunately, there are options that can address the challenges of high costs and inefficiencies. Direct current solar-powered air conditioners and other cooling technologies that run on renewables do exist and need to be scaled up. The need for cooling will increase in the future, and health services will have enormous opportunities to show that the alternatives are climate-friendly. Another segment that requires the need for lower temperatures is the storage of medicines and vaccines. The absence or unreliability 
of existing power sources leads to enormous loss of medication and critical vaccines. Again, decentralised solar-powered vaccine refrigerators have proven to be efficient and financially viable for numerous institutions across the world.

The following two case studies capture how the decentralisation of energy generation and access is especially useful in remote areas which are often otherwise unreachable in terms of sustainable healthcare. They showcase the improved reach and increase in impact when health services, energy efficiency and decentralised renewable energy are brought together (Figures 14.1 to 14.3) (Boxes 14.1 and 14.2).

Both the cases studies prove that efficient lighting and appliances powered by solar power can drastically increase the reliability of health services and make it accessible even in the most difficult conditions. Success depends on stakeholders in both the energy and health sectors.

While both these particular cases focused on solar power, other forms of renewable energies can also be explored, for example, using biogas systems for heating or wind turbines for electricity. The chapter titled Green and Resilient Health Infrastructure enumerates the case study of Kohinoor Hospital in Mumbai, which generates $90 \%$ of its energy requirements from a windmill installed offsite. In India however, solar energy is currently one of the easiest options to choose when considering supply chains and aftersales services. Solar systems have proven to be effective in remote areas and even with heavy cloud cover.

There should be a compulsory energy-health assessment at every level of health service. These assessments can help in the identification and procurement of energy-efficient medical appliances and equipment, optimal building and load designs (including utilisation patterns) according to the need of the locality. Climate-resilient options for lighting, cooling, heating can be easily implemented in the short run, as the technology for this already exists. One way to increase the efficiency and lower the costs for the health sector is by the bulk purchasing of equipment by State governments. This was pioneered in a project by the Energy Efficiency Services Limited (EESL), financed by the World Bank for the India Energy Efficiency Scale-up Program (World Bank, 2018) while procuring LED lights.

The health sector, led by critical stakeholders, can set up equivalent standards for efficiency, for both energy and health, along the lines of LEED and GRIHA. These standards can be used as a benchmark not just in India but also in countries in Africa and Latin America.

By making solar and Distributed Renewal Energy (DRE) into an essential component of health networks at the designing stage, the health sector can pave the way for similar approaches for housing and rural development, thus making the scaling of solar power in the country more pragmatic and use-centric.

The Prime Minister's Council on Climate Change, Govt. of India, developed the National Action Plan on Climate Change, under which there are 


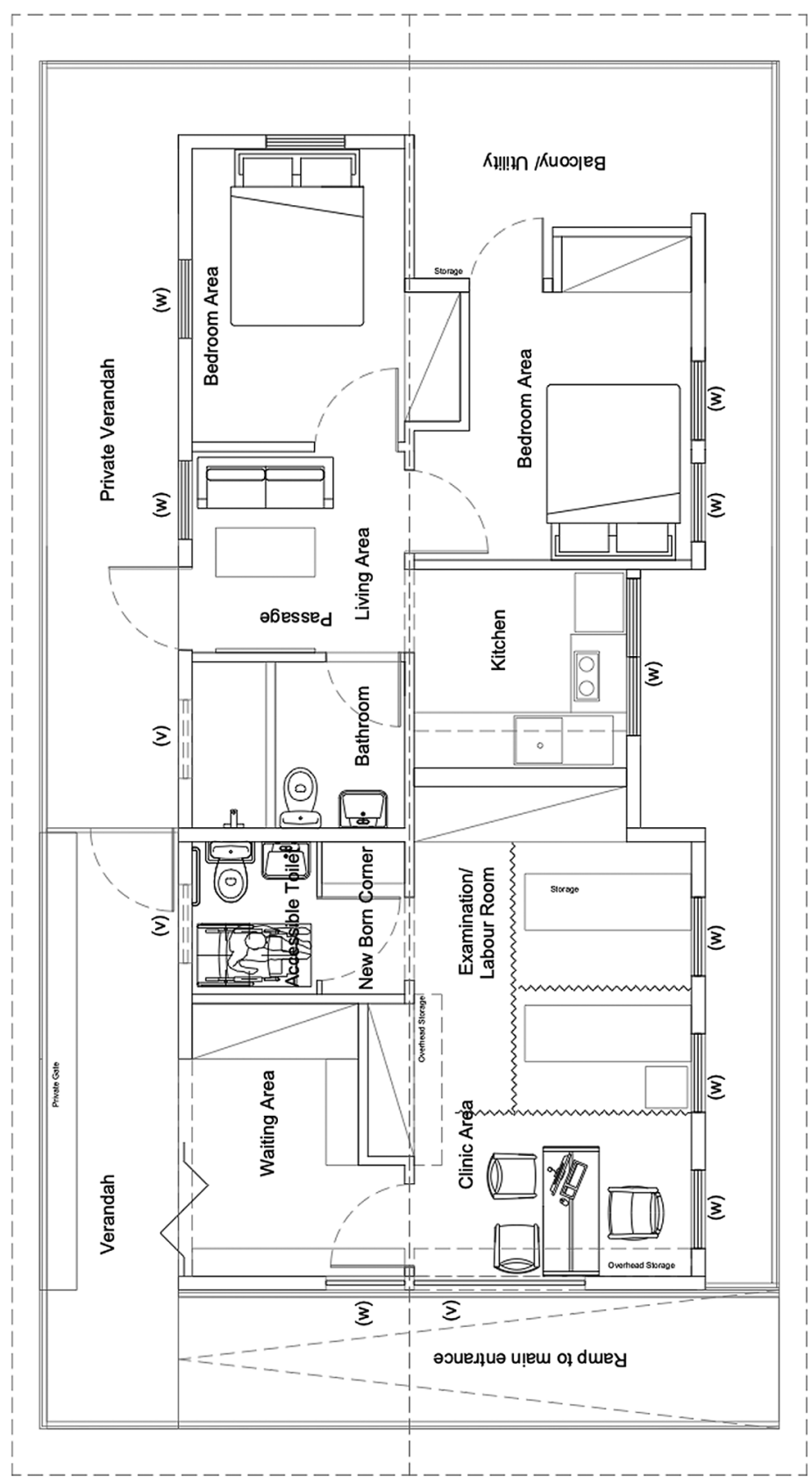

Figure 14.1 The modified KEBA sub-centre layout for maximising thermal comfort through passive build techniques, including efficient health equipment, green building and optimised solar design guidelines.

Source: KEBA Sub-Centre run by Karuna Trust through a PPP Model with the Arunachal Pradesh Health and Family Welfare Department. 


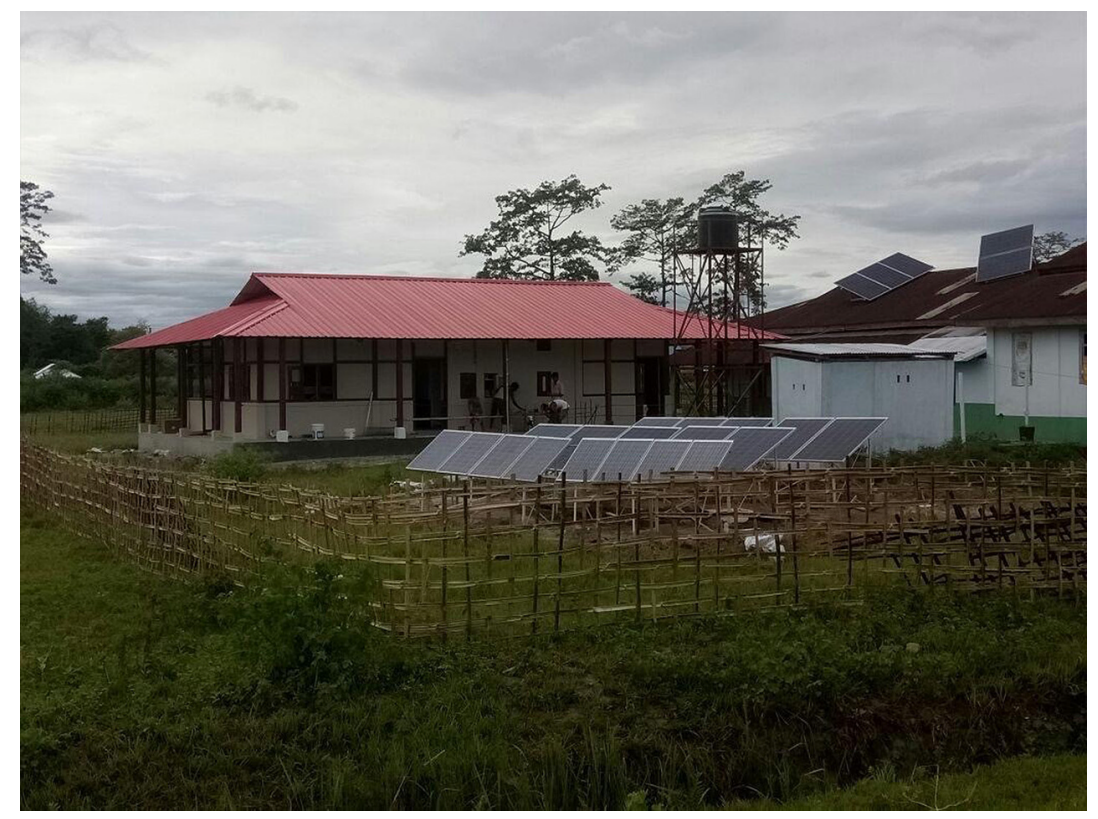

Figure 14.2 The modified KEBA sub-centre.

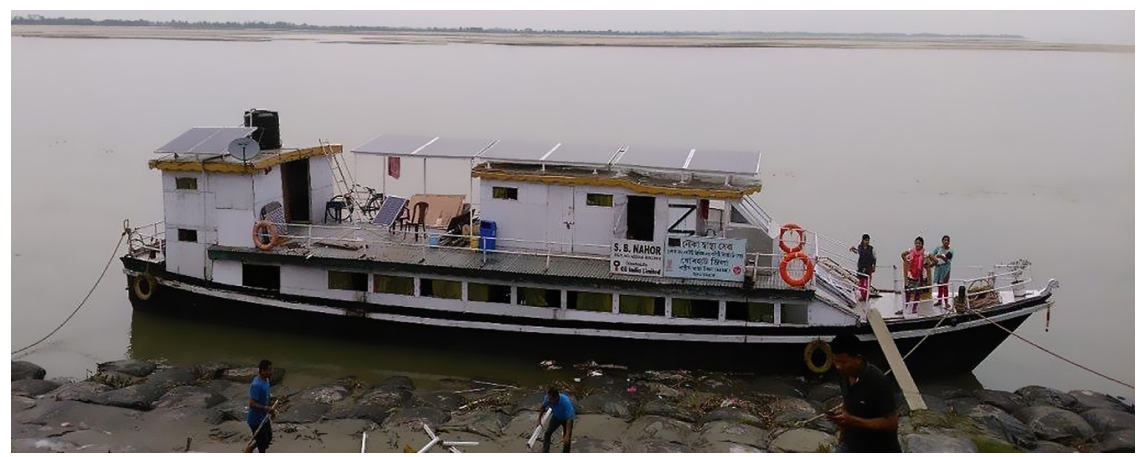

Figure 14.3 The boat clinics within which all health and general appliances are energy-efficient and solar powered.

Source: C-NES Boat Clinics run through the PPP Model with the Assam Health and Family Welfare Department.

twelve missions to address the impact of climate change in our country. Two missions are particularly important in relation to energy: The National Mission for Enhanced Energy Efficiency (NMEEE) and the Jawaharlal Nehru National Solar Mission. 


\section{Box 14.1 Case study}

\section{KEBA health sub-centre in Arunachal Pradesh, India}

Most rural health centres in India have poor natural lighting, lack cross ventilation and are thermally uncomfortable. KEBA, a health sub-centre in Arunachal Pradesh, like many others, was heavily dependent on electricity for basic needs such as lights and fans, with their unreliability and expenses taking a toll on the operations of these centres. The solutions for the problems in KEBA were designed taking into consideration its warm and humid tropical conditions. The centre is located in a remote location with sparse human and financial resources.

To begin with, the centre was physically modified for improved thermal comfort, better ventilation and utilisation of natural light. Locally available construction materials were chosen for modification of the building. The construction technology took into account the low thermal conductivity, the geography and local climatic conditions. The position and size of the windows were redesigned around the path of the sun to reduce solar heat gains. The spatial design of the building was also modified to enhance the ease of use of the space and to improve productivity.

For other lighting needs, including during night-time, energyefficient LED lights providing thermal comfort were designed and installed. The design also took into consideration dry bulb temperature, relative humidity and lux value. Customised lighting was provided in different spaces according to the need and utilisation. The procured medical appliances were energy-efficient. A decentralised solar system was designed to power all the requirements of the KEBA centre. The solar system was designed with extra battery storage backup after accounting for sunshine hours in the region. A solar-powered vaccine storage unit was also designed as per the local climate parameters. In KEBA, there was a reduction in energy consumption for lighting by $80 \%$ and a reduction in energy for fans of over $85 \%$, when compared to sub-centres of similar type and in similar climatic zones. Overall, the KEBA sub-centre consumes $60 \%$ less energy than a comparable sub-centre. The solar powering of the centre therefore led to an overall reduction in electricity bills.

Source: SELCO Foundation 


\section{Box 14.2 Case study Mobile boat clinics on the Brahmaputra River}

The Centre for North East Studies and Policy Research (C-NES) in partnership with the National Health Mission, Government of Assam, has been operating Boat Clinics providing primary health care to the remote island populations in the Brahmaputra and across it since 2005.

The boat clinics provided doorstep health services to people who otherwise had to travel hours to access even basic care. The length of trips of these boat clinics would vary from one day to several days. One of the biggest challenges faced by these mobile clinics was the lack of continuous access to energy to power basic health and communication equipment on the boat. Previously, all these loads were powered by a diesel generator. Diesel is hard to procure on the islands, and the intense noise from the generator makes it difficult to work and stay on the boat.

The Jorhat boat clinic reaches out to approximately 17,000 people and conducts between 18 and 22 camps per month across 34 villages (CNESPR data, 2017). First, all the specific energy needs and hours of utilisation for mobile health unit was mapped. The critical equipment included lights, fans, laboratory instruments, audio-visual devices, vaccine storage, autoclave and dental chair. A solar system was designed keeping in mind the hours of usage, the criticality of the medical appliances, and the space available on the boat for the panels. The solar-powered boat health clinic has led to reliable delivery of health services. It has also led to an increase in staff well-being and a decrease in cost-per-patient for healthcare while avoiding the costs of diesel.

The Bureau of Energy Efficiency (BEE), Govt. of India, operates the NMEEE, which consists of four main initiatives - to improve efficiency in energy-intensive sectors, provide an energy efficiency financing platform, accelerate the shift towards energy-efficient appliances and develop fiscal instruments to promote energy efficiency.

The National Solar Mission aims to promote the consumption of solar energy and establish India as a global leader in solar energy by setting up an enabling environment for penetration of solar technology at the centralised and decentralised level, one example of which was to reduce risks for solar power producers. A renewable energy corridor was launched to develop a dedicated transmission grid for areas with an abundance of sunlight or wind to create solar and wind energy. Solar radiation monitoring stations were also set up across India. The government revised the original target of establishing grid-connected solar power under the NSM from 20 GW by 
2022 to $100 \mathrm{GW}$ by 2022 . This was part of the overall renewable energy target of $175 \mathrm{GW}$, which also includes $60 \mathrm{GW}$ of wind energy, $10 \mathrm{GW}$ of bio-energy, and $5 \mathrm{GW}$ of small hydro-power plants. This five-fold jump in the NSM target has created a huge demand for solar energy projects and equipment. The health sector can also benefit from this initiative by serving the population's health needs while being environmentally sustainable by bringing energy-efficient mechanisms through various stakeholders (both government and private sectors) to all levels of healthcare facilities.

\section{Key takeaways}

- The health sector can lead essential sectors in decreasing their carbon footprint by showcasing the use of energy-efficient equipment and decentralised renewable energy.

- By filling the gaps in providing reliable health services to all, the health sector has a huge opportunity to be climate resilient while being able to democratise its services in a holistic manner.

- The case studies demonstrate how renewable energy sources can greatly increase the reliability of health services and make them accessible even under difficult conditions

- Energy-efficient appliances combined with decentralised solar power can increase the impact of existing health services multifold.

\section{References}

Alexander, D., \& Manogaran, S. (2022, forthcoming). Healthcare and climate change: Implementing green facilities in hospitals. In Dr. Girdhar Gyani \& Dr. Alexander Thomas (Eds.) The handbook of healthcare quality and patient safety ( $3 r d$ ed.). Jaypee.

Centre for North East Studies and Policy Research. (2017). Solar energy to Jorhat Boat Clinic. https://www.c-nes.org/4046/solar-energy-to-jorhat-boat-clinic/

Lorenzi, N. (2019, May 16). Versatility and efficiency drive health care lighting. Health Facilities Management. https://www.hfmmagazine.com/articles/3636versatility-and-efficiency-drive-health-care-lighting

Sarang, B. (2015, March 2). Five ways to keep your power bills low. Economic Times. https://economictimes.indiatimes.com/industry/energy/power/five-waysto-keep-your-power-bills-low/articleshow/46418945.cms?from=mdr

World Bank. (2018). India energy efficiency scale up program. http://documents1. worldbank.org/curated/en/532521527391818294/pdf/India-Energy-EfficiencyScale-up-Program-Project.pdf

World Bank and WHO. (2017). Half the world lacks access to essential health services, 100 million still pushed into extreme poverty because of health expenses. WHO News Release. https://www.who.int/news-room/detail/13-12-2017-worldbank-and-who-half-the-world-lacks-access-to-essential-health-services-100million-still-pushed-into-extreme-poverty-because-of-health-expenses 


\title{
WATER STRESS AND THE EFFECTIVE MANAGEMENT OF WATER IN THE HEALTHCARE SECTOR
}

\author{
Shyamala Mani, Samayita Ghosh and R. Srinivasan
}

\section{Introduction}

The impacts of climate change can be manifested through changing patterns of water availability. Given that water and weather are closely linked through evaporation and precipitation, any alteration in the balance between the two can cause an erratic rise in droughts, floods, humidity, glacial melt and rise in sea level. Increased flood discharge of surface water, as well as frequent droughts, are not congenial for the groundwater recharge that supports the maintenance of the water table, which sustains base flow in rivers. Increasing demand for water, including groundwater exploitation, exacerbates the water crisis and seasonal irregularities in the availability patterns (Payus et al., 2020). This chapter examines:

1. The aspect of water stress, especially in the health sector, as a function of availability of safe water in terms of quantity and quality, a key constituent to healthcare operations in various healthcare establishments.

2. The urgent need for efficient management to ensure continuity in access, reduction in wastage and overconsumption.

\section{Understanding water quantity and quality in the Indian context}

In terms of water quantity, India has about $4 \%$ of global water resources with a per capita availability of 1086 cubic meters annually, which is projected to go down to 760 cubic meters by 2050 , indicating surmounting deficits over the years. India supports $16 \%$ of the world's population and $15 \%$ of livestock with $66 \%$ of its 1.38 billion population being rural. There is also a considerable gap in the development and management of water resources between urban and rural areas. Going by per capita availability, India has been ranked among the countries which are extremely water stressed, with the intensity varying regionally and seasonally (Hofste et al., 2019).

Currently, the total utilizable water resources in the county is about 1123 billion cubic meters ( $\mathrm{bcm}$ ) with $690 \mathrm{bcm}$ of surface and $433 \mathrm{bcm}$ of groundwater resources, replenished and recharged by total rainfall of about 
$4000 \mathrm{bcm}$. Almost $90 \%$ of the groundwater is utilised for irrigation needs; the remaining $10 \%$ supplies about $85 \%$ of the country's drinking water. As against a requirement of $70 \mathrm{~L}$ per capita per day (lpcd) of water, the current provision is only about $40 \mathrm{lpcd}$, even though the coverage of population with access to improved sources of drinking water has increased manifold since independence (CWC, 2019). While the National Rural Water Supply Mission is committed to providing safe water to even the remotest of villages, Jal Shakti Abhiyan has taken up addressing the problem of water shortage in 255 water stressed districts of the country.

Water quality refers to the physical, chemical, biological and radiological characteristics of water with the usability of freshwater being assessed against standardised parameters. ${ }^{1}$ Almost $70 \%$ of the country's surface water and an increasing quantum of its groundwater are contaminated with toxic elements that are bio-accumulative and carcinogenic, rendering serious health hazards on humans, flora and fauna. The toxicity of water, measured against acceptable and permissible levels of various constituent elements point at several geogenic and anthropogenic factors. Co-occurrence of contaminants is usually characterised by a combination of these factors, although in some cases anthropogenic activities, such as infiltration of organic and nitrate-rich water, may contribute to the persistence and enhanced mobilisation of geogenic contaminants (Coyte et al., 2018).

Poor waste management, disposal and discharge wastewater emanating from domestic and industrial settings are some of the anthropogenic factors or human activities that contribute to water pollution. Wastewater emanating from water-intensive chemical, distillery, food, dairy and beverage, pulp and paper, sugar, textile, bleaching and dying, tannery and other industries produce 501 million litres of wastewater per day, while there are treatment facilities only for 193 million litres (National Green Tribunal Status Report, 2019). The lack of sewage disposal facilities, especially in the rural context, has led to anthropogenic surface water pollution. Open defecation, infiltration of pollutants from industrial discharge, non-compliance with standards by stakeholders, and indiscriminate use of pesticides are some of the main causes for groundwater contamination.

Naturally occurring or geogenic contaminants manifest by elevated levels of arsenic, fluoride, nitrate, total dissolved solids, chloride and iron often seen in groundwater. Arsenic contamination is predominant in the Ganga and Brahmaputra valleys in West Bengal, Assam, Chhattisgarh, Bihar and Uttar Pradesh. Fluoride contamination is more widespread in the country, especially in the arid and semi-arid belts. Total dissolved solids as indicated by electrical conductivity, contribute to hardness of water and salinity, which is dominant in the coastal and arid belts. Of late, higher concentrations of uranium have been reported from groundwater in Punjab, Gujarat, Rajasthan, Andhra Pradesh, Tamil Nadu, and a few eastern districts of Karnataka (Coyte et al., 2018). 


\section{Disease burden}

Extreme events such as floods and droughts are associated with outbreaks of communicable diseases and some chronic conditions. During periods of heavy rainfall and flooding, the capacity of water treatment plants may prove inadequate, and there may be contamination of drinking water with sewage; especially where water supply infrastructure is old, sewage can overflow and contaminate local waterways. Droughts or extended dry periods are known to reduce the volume of river flow and reduce the dilution of concentration of effluents (Cann et al., 2013).

The concentration of dissolved chemicals in water is controlled by soilwater and rock-water interaction, both of which are controlled by climatic conditions which influence the $\mathrm{E}_{\mathrm{h}}$ (redox potential) and $\mathrm{pH}$ (potential of hydrogen ion) of water passing through the pores and cracks in soil and rocks. Droughts are also associated with food insufficiency, reduced nutrition and calorific intake, as well as compromised sanitation and hygiene, leading to low nutritional uptake as consequences of poor gastrointestinal performance. Diseases from water can arise because of chemical and biological contamination, both being climate sensitive.

Moreover, there is an increased risk of infection of water-borne diseases contracted through direct contact with polluted waters, such as wound infections, dermatitis, conjunctivitis, and ear, nose and throat infections. The epidemic infection which can be transmitted directly from contaminated water is leptospirosis, a zoonotic bacterial disease. Transmission occurs through contact with water, damp soil or vegetation (such as sugarcane) or mud contaminated with rodent urine on the skin and/or mucous membranes. The occurrence of flooding after heavy rainfall facilitates the spread of the organism due to the proliferation of rodents which shed large amounts of leptospirosis in their urine. Similarly, in the case of vector-borne diseases, flooding may initially flush out mosquito breeding, but it comes back when the floodwaters recede. The lag time in such cases is usually around 6-8 weeks before the onset of malaria epidemic (National Health Portal, Govt. of India, 2018). Annually, about 37.7 million Indians are affected by waterborne diseases, 1.5 million children die of diarrhoea and 73 million working days are lost leading to an economic burden of $\$ 600$ million a year. Waterborne diseases such as cholera, acute diarrhoeal diseases, typhoid and viral hepatitis continue to be prevalent in India and have caused 10,738 deaths over the last five years. Of this, acute diarrhoeal diseases caused maximum deaths followed by viral hepatitis, typhoid and cholera (Kelkar, 2019).

Moreover, exposure to contaminated water from surface and sub-surface sources is mediated through various primary and secondary activities that involve direct and indirect ingestion or dermal contact. The adverse health effects due to exposure to elevated levels of chemicals and heavy metals in water varying regionally are tabulated in Table 15.1. 
Table 15.1 Toxin standards and associated health effects

\begin{tabular}{|c|c|c|c|}
\hline $\begin{array}{l}\text { Chemical } \\
\text { constituent }\end{array}$ & $\begin{array}{l}\text { Drinking } \\
\text { water standard } \\
\text { set by BIS } \\
10500(2012) \\
\text { in } m g / L\end{array}$ & $\begin{array}{l}\text { Drinking } \\
\text { water } \\
\text { standard set } \\
\text { by WHO } \\
\text { (2011) } m g / L\end{array}$ & $\begin{array}{l}\text { Health effects when } \\
\text { concentrations exceed the } \\
\text { permissible limit }\end{array}$ \\
\hline Arsenic & 0.05 & 0.01 & $\begin{array}{l}\text { Skin lesions, keratosis, backfoot } \\
\text { disease, basal cell carcinoma, } \\
\text { squamous cell carcinoma } \\
\text { Hepatotoxicity or liver diseases } \\
\text { hypertension, cardiomyopathy }\end{array}$ \\
\hline Chromium & 0.05 & 0.05 & $\begin{array}{l}\text { Hexavalent chromium causes } \\
\text { dermatitis, ulcers and cancer }\end{array}$ \\
\hline Fluoride & 1.5 & 1.5 & $\begin{array}{l}\text { Below } 0.5 \mathrm{mg} / \mathrm{L} \text { causes dental } \\
\text { caries; } 0.5-1.5 \mathrm{mg} / \mathrm{L} \text { desirable; } \\
1.5-3 \mathrm{mg} / \mathrm{L} \text { causes dental } \\
\text { fluorosis; } 3.1-6 \mathrm{mg} / \mathrm{L} \\
\text { osteoporosis; } 20 \text { to } 80 \mathrm{mg} \text { per } \\
\text { day through air and water } \\
\text { - crippling skeletal fluorosis; } \\
50 \mathrm{mg} / \mathrm{L} / \text { per day causes thyroid } \\
\text { changes; } 100 \mathrm{mg} / \mathrm{L} / \text { day retards } \\
\text { growth; more than } 125 \mathrm{mg} / \mathrm{L} \\
\text { causes kidney damage. }\end{array}$ \\
\hline Iron & 0.3 & & $\begin{array}{l}\text { At low levels good for health; } \\
\text { beyond } 0.3 \text { undesirable as it can } \\
\text { lead to haematochromatosis. } \\
\text { Total iron and manganese } \\
\text { should not exceed } 0.3 \mathrm{mg} / \mathrm{L} . \\
\text { Water also tastes bad when Fe, } \\
\text { Mn are high }\end{array}$ \\
\hline Selenium & 0.01 & 0.01 & $\begin{array}{l}\text { Selenium deficiency in human } \\
\text { body can cause gastrointestinal } \\
\text { disturbances, discoloration of } \\
\text { the skin and decay of teeth; it } \\
\text { can also cause Keshan disease } \\
\text { (multifocal myocarditis) or } \\
\text { chondrodystrophy (also called } \\
\text { Kaschin-Beck disease). Higher } \\
\text { selenium concentrations can } \\
\text { lead to higher risk of coronary } \\
\text { heart disease }\end{array}$ \\
\hline Uranium & & 0.015 & Liver damage and cancer \\
\hline $\begin{array}{l}\text { Nitrate } \\
\text { especially } \\
\text { nitrite }\end{array}$ & 45 & 50 & $\begin{array}{l}\text { At levels higher than threshold } \\
\text { gives rise to } \\
\text { methaemoglobinamia }\end{array}$ \\
\hline
\end{tabular}




\section{Water consumption patterns in the health sector}

(a) Consumption: Water consumption can be mapped in terms of utilisation and wastage within a sector. According to the Bureau of Indian Standards, hospitals with more than 100 beds need on an average, 450 $\mathrm{L} /$ head/day (equating to $164,250 \mathrm{~L}$ of water/head/year); those hospitals which have less than 100 beds require 340 Litres per head/day (see Table 15.2). However, according to an audit conducted by the Comptroller and Auditor General, $36 \%$ of the primary healthcare facilities forming an important constituent of rural health infrastructure have no access to this quantity of clean water.

(b) Uses: Water is an important resource for the healthcare sector to meet its daily operational needs that pertain to infection prevention and control activities and engineering functions. Any disruption in water supply may result in seriously compromising hand-washing and hygiene, drinking, food preparation, flushing of toilets and bathing the patients, laundry, cleaning and sterilisation of surgical instruments, reprocessing of medical equipment, patient care (haemodialysis, hemofiltration, extracorporeal membrane oxygenation, hydrotherapy), fire suppression sprinkler systems, water-cooled medical gas and suction compressors, HVAC and decontamination.

(c) Implications of water insufficiency: Unhygienic environment with inadequate supply of running water, hand washing facilities and poorly maintained or dysfunctional toilets, may lead to several adverse hospital outcomes. For instance, women may avoid or delay seeking care and are likely to leave such facilities sooner than they should after

Table 15.2 Water requirements for buildings in the health sector

\begin{tabular}{llcc}
\hline & $\begin{array}{l}\text { Domestic } \\
\text { Litres per } \\
\text { head/day }\end{array}$ & $\begin{array}{l}\text { Flushing } \\
\text { Litres per } \\
\text { head/day }\end{array}$ & $\begin{array}{l}\text { Total Consumption } \\
\text { Litres per head/day }\end{array}$ \\
\hline $1 \quad \begin{array}{l}\text { Hospital (excluding } \\
\text { laundry and kitchen): } \\
\text { a) Number of beds not } \\
\text { exceeding 100 }\end{array}$ & 230 & 110 & 340 \\
$\begin{array}{l}\text { b) Number of beds } \\
\text { exceeding 100 } \\
\text { c) Out Patient } \\
\text { Department (OPD) }\end{array}$ & 300 & 150 & 450 \\
$\begin{array}{c}\text { Nurses' homes and } \\
\text { medical quarters }\end{array}$ & 10 & 5 & 135 \\
\hline
\end{tabular}

Bureau of India Standards, 2012 
delivery, resulting in inadequacies in maternal and child health care. Sepsis, a hospital borne infection, accounts for $11 \%$ of maternal deaths in India, with the highest rate in Southern Asia (13.7\%). In places with high mortality such as India, up to $50 \%$ of neonatal deaths are due to infections, with $30-40 \%$ of infections that result in fatal neonatal sepsis transmitted at the time of birth (Water Aid India, 2005). SARS CoV $1 \& 2$, MERS and several other diseases such as diarrhoea and acute respiratory tract infections (ARIs) can be prevented and their transmission effectively reduced through frequent handwashing practices.

(d) Implications of elemental presence: Use of iron-rich water in hospital laundries turns the bed linen yellow or yellow brown after a couple of washes. Groundwater with high concentrations of total dissolved solids (TDS) and salinity is hard and is also not suitable for hospital laundry. It is not uncommon to see stained toilet bowls and bathroom floors and scaling on taps and flush tanks in public health facilities, which are a result of the use of such iron $(\mathrm{Fe})$ rich hard water. The hard water can clog the pipes and or corrode them. They can deposit the salts and corrode sterilisation units. It is not known as to how many health care centres are provided with ultraviolet lamp fitted reverse osmosis units (UV-ROs) to generate adequate amounts of water free of biological and metal contaminants and safe for drinking required in patient care and the maintenance of hospital equipment (Box 15.1).

\section{Wastewater in the health sector}

Healthcare organizations generate high strength sewage ${ }^{2}$ and wastewater, and are prone to variable flows and loads due to changing patient and visitor rates. High loads can also be expected due to large amounts of laundry and maintenance activities (Box 15.2). Hospital wastewater consists of harmful pathogens, metabolites of pharmaceuticals, pesticides, disinfectants and radioactive elements if it is from facilities conducting cancer treatment. According to AERB, India, most radioisotopes used in medical facilities have very short half-lives; therefore, keeping the effluents from such sources in the healthcare facilities in lead coated underground tanks for ten half-lives before discharging them into municipal wastewater mains is required to reduce radioactivity and toxic chemicals. In developing countries like India, the improper disposal of effluents both from hospitals and bulk drug manufacturing units is the major pathway for antibiotics to enter the aquatic environment, one of the primary causes for development of antimicrobial resistance (AMR) (McClellan and Halden 2010).

In India, antibiotic-resistant bacteria and their genes as well as persistent, non-biodegradable hydrophilic chemicals in water bodies, have been reported from different water sources, resulting in the spread of diseases. The major sources are the pharmaceutical wastewaters and hospital effluents that are released into the nearby water bodies without 


\section{Box 15.1 Case study}

\section{The Spinal Injury Centre, New Delhi}

Concerned with falling water levels, and with growing dependence on groundwater, the authorities at the Indian Spinal Injury Centre decided to adopt rainwater harvesting on the hospital premises. Before the system was implemented, the water level in the hospital borewell stood at $32.2 \mathrm{~m}$ below ground level (bgl) in April 2003. The Spinal Injury Centre deployed a rainwater harvesting system that is able to harvest 27,317 cubic metre $\left(\mathrm{m}^{3}\right)$ or $273,17,000$ litres. The rooftop rainwater and the surface runoff from the western part of the building are drained into a storm-water drain that runs to the west side of the building. This water is diverted into a recharge well located at the northwest corner of the campus near an existing borewell. A part of the rooftop rainwater from the east side of the hospital building and runoff from the paved area are diverted through a network of pipes and collection chambers to another stormwater drain that runs to the north of the premises. This runoff is also diverted to the same recharge well located near the borewell. The recharge well is $2.75 \mathrm{~m}$ in length, $2.13 \mathrm{~m}$ in breadth and $1.82 \mathrm{~m}$ deep, with a recharge bore of $100 \mathrm{~mm}$ diameter that led the water table to rise to $20 \mathrm{~m}$ from its previous depth of $36.6 \mathrm{~m}$. The recharge well has two compartments, and the runoff water undergoes two stages of filtering before it enters the recharge borewell. Layers of brickbats and sand ensure the quality of water used for recharging purposes. This project confirmed that it is possible to arrest declining water levels through rainwater harvesting.

Source: CSE, Centre for Environmental Health, 2016

\section{Box 15.2 Case study Aravind Eye Care Hospital, Pondicherry}

Aravind Eye Care Hospital in Pondicherry pumps out $120 \mathrm{~m}^{3}$ of water from a bore well every year, of which $100 \mathrm{~m}^{3}$ of water is recycled using the DEWATS (Decentralized Wastewater Treatment System). The treated water is used in toilets, gardens, for vegetable cultivation and for irrigating the paddy field. The treatment facility receives 270-300 KLD from the hospital building that includes only domestic sewage. As seen in Figure 15.1, the greywater and the black water generated in the hospital premises first enter separate two-chambered settlers. The settlers for black water treatment are 
integrated with the anaerobic baffled reactors. The partially treated black water then undergoes secondary anaerobic treatment. The black water and grey water are collectively passed through anaerobic filters and then to the series of horizontal gravel filters planted with Canna indica. The final treatment is done through polishing ponds where the water is stored for further reuse (Figure 15.2).

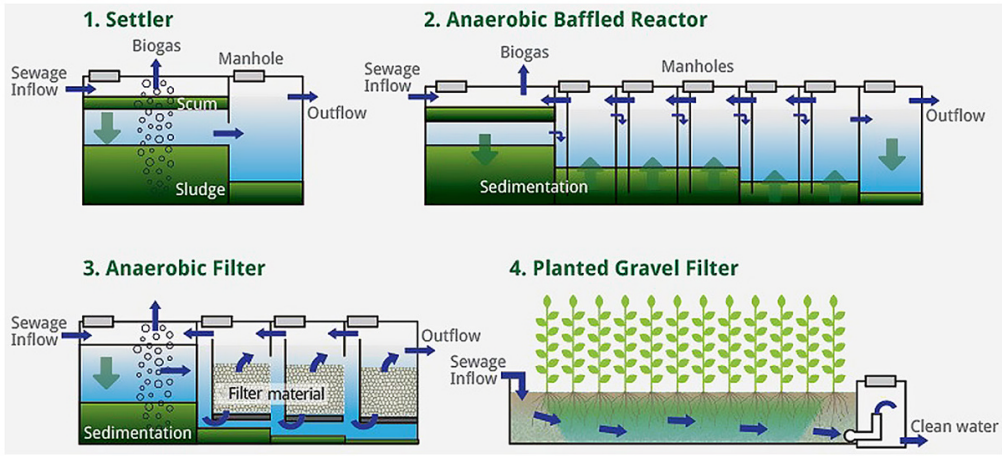

Figure 15.1 Treatment of wastewater at Aravind Eye Hospital.

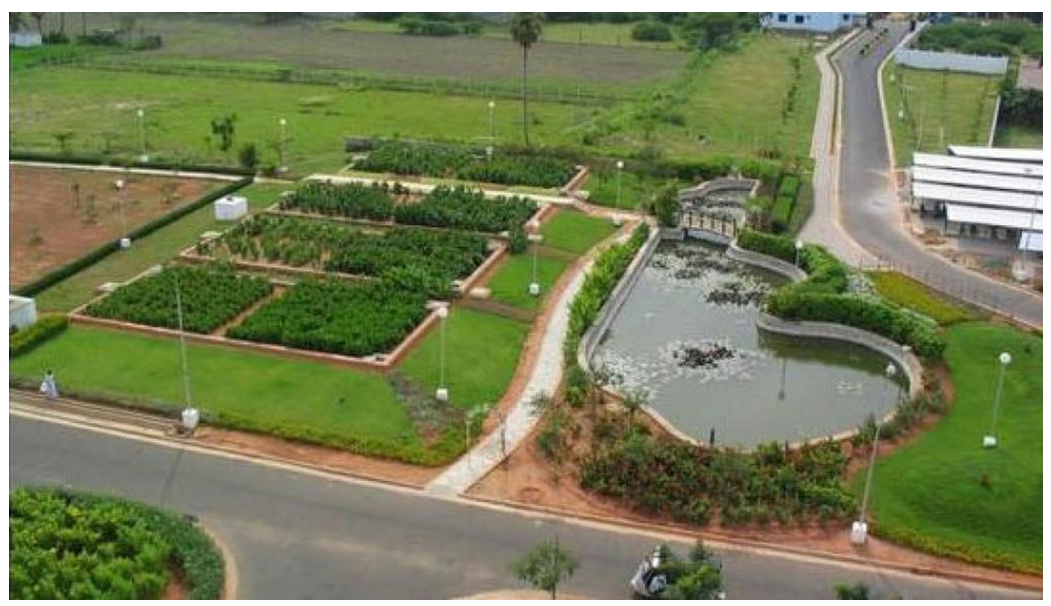

Figure 15.2 A bird's-eye view of the facility.

adequate treatment. The two largest rivers of India - Ganga and Yamuna, receive varying concentrations of drug-resistant bacteria from multiple sources. 


\section{The role of the health sector}

Responses in combating climate adversities, efficient management of water resources and management of emerging disease patterns and conditions are some of the perceived roles of the healthcare sector. Some of these features are described below:

a. Water conservation and effective management in healthcare facilities: Any beneficial reduction in water loss, water use and water wastage can be classified as water conservation. An important component of water conservation involves minimising water losses, prevention of water wastage and increasing efficiency in water use. The Kayakalp scheme outlines the measures that include ensuring adequate quantity of supply of quality water by estimating and providing storage facilities, in-situ treatment and prevention against identified parameters of contaminants, maintenance of supply systems, inspection of wastage through water audits, rainwater harvesting and recycling of wastewater through effluent treatment plants (ETPs), sewage treatment plants (STPs) and hardness removal if required. Various treatment technologies can be installed to decisively remove elemental presence based on regional contaminant profiles.

b. Wastewater recycling and use: Wastewater can be minimised by enhancing water-use efficiency such as installation of automatic turn-off systems in water faucets, preventing and stopping leakages, using efficient flush models in toilets, use of cold loop systems in heating, ventilating, air conditioning (HVAC), on-site wastewater treatment system wherever feasible, recycling wastewater for cooling, toilets and irrigation. Hospital wastewater can be of three types - black water, grey water and storm water. Black water may have faecal matter and urine of patients with or without infectious diseases. Grey water contains residues from washing, bathing, laboratory processes, laundry, kitchen and other technical processes such as cooling water or the rinsing of X-ray films, potentially loaded with genotoxic or cytotoxic agents. Storm water is from rain. This last category consists of water collected from roofs, grounds, yards and paved surfaces, which can be used for irrigating hospital grounds, toilet flushing and other general washing purposes. It may be lost to drains and watercourses, but it is sometimes used for groundwater recharging. The first two categories are the ones that need proper treatment before disposal. Hospitals must explore the usage of suitable wastewater treatment technologies for chemicals and pathogens to reduce pollution and maximise reuse.

c. Preparedness for managing emerging diseases related to water stress and water pollution: Poor water quality and management leading to infectious as well as non-communicable diseases require surveillance; timely detection and early warning of outbreaks. These present a complex challenge to health authorities in India. Water stagnation leading 
to vector-borne diseases like Malaria, Dengue, Chikungunya, Nipah can be prevented through proper utilisation of stormwater and wastewater management. Cleanliness and hygiene using simple soap and water cleaning methods can prevent the spread of debilitating emerging diseases.

\section{Key takeaways}

- While the healthcare system in India is faced with adversities related to erratic climate events, it serves as a key player in managing and mitigating risks to human health. Both events of flood and drought pose a critical threat to the healthcare infrastructure by reducing its ability to function at optimal capacity. Yet it must be resilient to respond to rapid health impacts caused as a result of such events.

- The health sector must optimise its current functions in water-deficient systems by improvising and harnessing currently available technologies while maintaining regular checks and balances as well as reduce its water footprint.

- The healthcare sector is also a major contributor to water-related pollution and this can be neutralised if systems are in place to regularise the in situ management of various contaminants and reuse/sell some of the treated water for non-potable purposes and in sensitive areas.

\section{Notes}

1 Water suitable for drinking belongs to Class A or C. Class A water can be consumed after disinfection and does not require conventional treatment, whereas class $\mathrm{C}$ requires conventional treatment and disinfection before drinking. In Class A water, most probable number (MPN) of coliform bacteria per hundred millilitres of water is 50 or less, $\mathrm{pH}$ is 6.5 to 8.5 and bacterial oxygen demand after 5 days at $20^{\circ} \mathrm{C}$ is $2 \mathrm{mg} / \mathrm{L}$ or less. In Class $\mathrm{C}$ water MPN of coliform bacteria could be up to $5000, \mathrm{pH}$ is between 6 and 9 and $\mathrm{BOD}$ after 5 days is $3 \mathrm{mg} / \mathrm{L}$ or less.

2 High-strength sewage contains greater amounts of fats, oils, and greases (FOG) or other organic components than residential wastewater. It can also refer to effluent containing large quantities of suspended solids or high amounts of certain chemicals, such as disinfectants. Any or all of these components can interfere with the normal biological processes that most onsite systems use.

\section{References}

Bureau of Indian Standards IS 10500. (2012), with Amendment No. 1, June 2015, 11 p. Cann, K. F., Thomas, D. R., Salmon, R. L., Wyn-Jones, A. P., \& Kay, D. (2013). Extreme water-related weather events and waterborne disease. Epidemiology and Infection, 141(4), 671-686. 
Central Groundwater Board, Ministry of Water Resources, Govt. of India. (2018). Groundwater quality in shallow aquifers of India. CGWB. http://cgwb.gov.in/ documents/Waterquality/GW_Quality_in_shallow_aquifers.pdf.

Central Water Commission. (2019). Status of trace and toxic metals in Indian rivers Ministry of Jalshakti, Govt. of India.

Chokshi, M., Patil, B., Khanna, R., Neogi, S. B. Sharma, J. Paul, V. K., \& Zodpey, S. (2016). Health systems in India. Journal of Perinatology, 36. doi: 10.1038/jp.2016.184

Coyte, R. M., Jain, R. C., Srivastava, S. K., Sharma, K. C., Khalil, A., Ma, L., \& Vengosh, A. (2018). Large-scale uranium contamination of groundwater resources in India. Environmental Science \& Technology Letters, 5-6, 341-347.

Dhara, V. R., Schramm, P. J., \& Luber, G. (2013). Climate change \& infectious diseases in India: Implications for health care providers. Indian Journal of Medical Research, 138(6), 847-852.

ENVIS Centre and MOEF. (2019). National status of Wastewater Generation and Treatment. ENVIS Centre and the Ministry of Environment, Forest and Climate Change, Govt. of India. http://www.sulabhenvis.nic.in/database/stst_wastewater_2090.aspx

Govt. of India and Govt. of Netherlands. (2003). Volume 6: Water quality sampling - design manual. http://nhp.mowr.gov.in/Docs/HP-2/Manuals/ManualSWVolume6DesignManualW.pdf.

Hofste, R. W., Reig, P., \& Schleifer, L. (2019). 17 Countries, home to one-quarter of the world's population, face extremely high water stress. World Resources Institute. https:/www.wri.org/insights/17-countries-home-one-quarter-worldspopulation-face-extremely-high-water-stress, World Resources Institute Blog.

Kelkar, S. (2019, September 01). When water kills, India Water Portal, https:// www.indiawaterportal.org/faqs/waterborne.

Kumari, A., Maurya, N. S., \& Tiwari, B. (2020). Hospital wastewater treatment scenario around the globe. Current Developments in Biotechnology and Bioengineering 549-570, doi: 10.1016/B978-0-12-819722-6.00015-8.

McClellan, K., \& Halden, R. U. (2010). Pharmaceuticals and personal care products in archived U.S. Biosolids from the 2001 EPA national sewage sludge survey. Water Research, 44, 658-668.

National Health Portal, Govt. of India. (2018). Health impacts of flooding and risk management. NHP. https://www.nhp.gov.in/health-impacts-of-flooding-and-riskmanagement_pg

Payus, C., Huey, L. A., Adnan, F., Rimba, A. B., Mohan, G., Chapagain, S. K., \& Fukushi, K. (2020). Impact of extreme drought climate on water security in North Borneo: Case study of Sabah. Water, 12(4), 1135, doi: 10.3390/w12041135.

Water Aid India. (2005). Drinking water and sanitation status in India. Water Aid India. WHO. (2011). Guidelines for Drinking Water Quality (4th Ed.). World Health Organisation. https://www.who.int/water_sanitation_health/publications/2011/ 9789241548151_ch10.pdf

WHO. (2014). Safe Management of Wastes from Healthcare Activities (2nd Ed.). WHO. https://www.who.int/water_sanitation_health/publications/2011/ 9789241548151_ch10.pdf. 


\title{
16
}

\section{SUSTAINABLE WAYS TO MANAGE WASTE IN HEALTHCARE FACILITIES}

\author{
Ananya Tewari and Shyamala Mani
}

\section{Introduction}

The healthcare sector plays a vital role in protecting the health of individuals. However, it contributes to the climate crisis through its energy-intensive operations, manufacturing of various healthcare products, transportation and waste management. The World Bank has estimated GHG emissions for the Indian healthcare sector to be between 8 million and 14 million metric tonnes of carbon dioxide equivalent $\left(\mathrm{mtCO}_{2} \mathrm{e}\right)$. A 2020 study suggests that according to the emission reduction experience of some developed countries, waste is the second-largest research area for emission reduction after energy (Xin et al., 2020).

The health sector significantly contributes to the total waste load of a country. It generates large quantities of infectious, non-infectious, general and hazardous chemical waste. An enormous amount of energy is spent in treatment and disposal of this waste. This chapter looks at:

1. Practices in waste management and disposal, including future sustainable strategies, that will help to reduce greenhouse gas emissions and increase the potential for climate change mitigation from healthcare establishments.

2. The management of biomedical waste originating from healthcare facilities, including the characterisation, quantification, segregation, storage, transport, treatment and disposal of biomedical waste.

3. Climate-smart and clean waste disposal mechanisms that will not only promote the development and supply of sustainable products but will also prepare the health sector for climate-related health hazards.

\section{Waste management and disposal}

Every department within a healthcare facility generates waste. These can be broadly divided into three categories: healthcare waste, general waste and other waste. Healthcare waste mostly includes infectious waste, chemicals, expired pharmaceuticals and sharps. General waste consists of discarded 


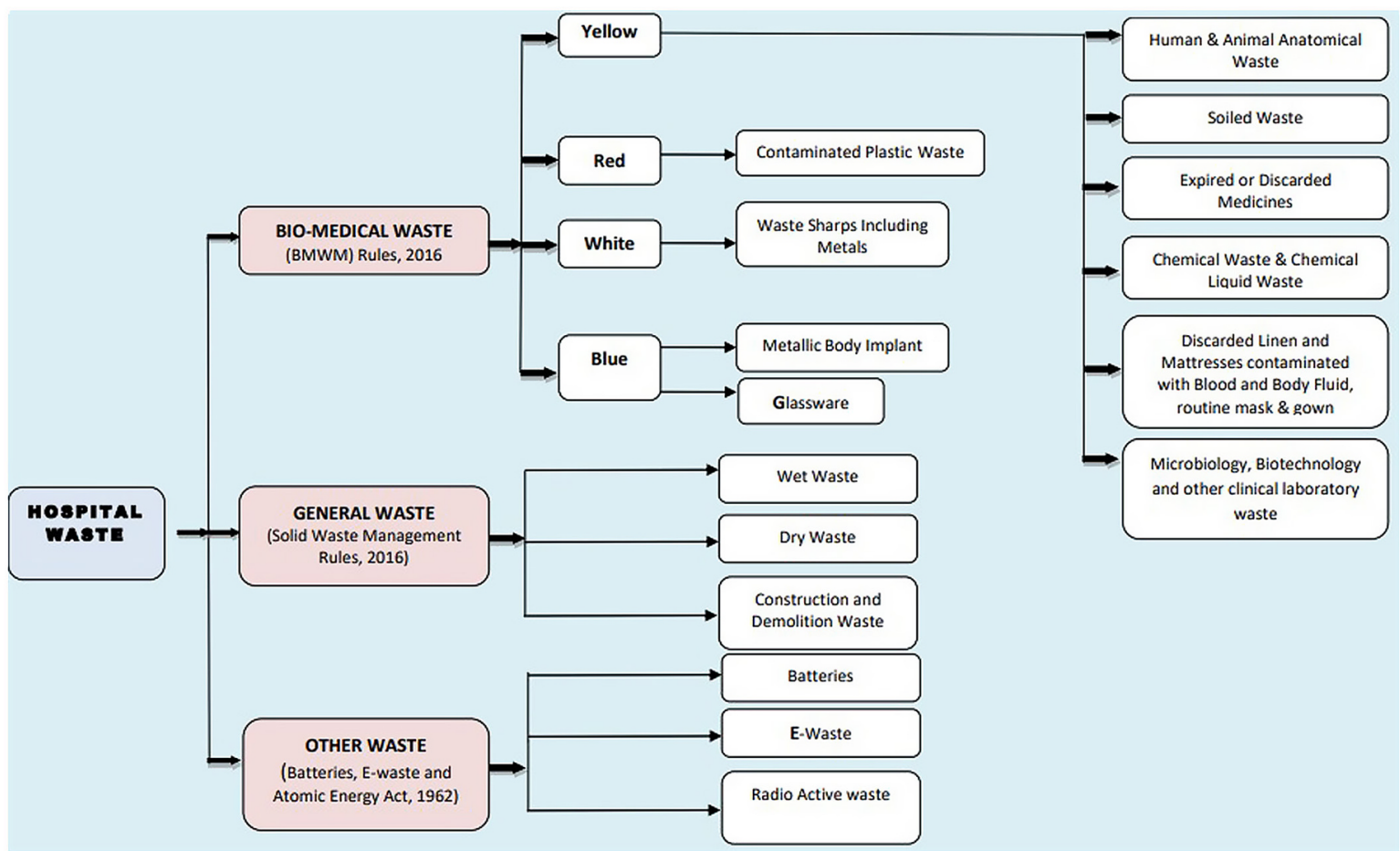

Figure 16.1 Different categories and classification of waste generated from healthcare facilities. Note: According to the Solid Waste Management Rules, 2016 "Domestic Hazardous Waste" is a separate category under the "General Waste" that includes sanitary waste. However, this waste is collected as part of dry waste under the general waste category.

Source: Ministry of Health, Family and Welfare and Central Pollution Control Board. 
packaging of medical items, food waste and waste from offices (Aljabre, 2002). Other wastes include e-waste, hazardous waste, plastic waste, etc.

Various regulations are in place to manage each waste category. Hospitals fall under the category of Bulk Waste Generator i.e. an establishment that generates more than $100 \mathrm{~kg}$ of waste per day (of all waste streams put together) (BSWGC, 2016). Therefore, specifications prescribed in listed regulations are applicable to healthcare facilities for managing and segregating each of their waste categories. Solid waste generated from hospitals consists of bandages, linen and other infectious waste (30-35\%), plastics $(7-10 \%)$, disposable syringes $(0.3-0.5 \%)$, glass $(3-5 \%)$ and other general wastes including food (40-45\%) (Patil \& Shekdar, 2001). Given the nature and risks associated with biomedical waste, its management requires increased attention and diligence in order to avoid adverse health outcomes associated with exposure to infectious agents and toxic substances. Healthcare waste, also referred to as biomedical waste (BMW) in this chapter, is any waste produced during the diagnosis, treatment or immunisation of humans or related animal research activities or in the production or testing of biologicals or in health camps (Biomedical Waste Management Rules, 2016) (Figure 16.1 and Table 16.1).

Table 16.1 Policy framework for managing various types of waste generated in India

\begin{tabular}{|c|c|c|c|c|}
\hline $\begin{array}{l}\text { S. } \\
\text { No. }\end{array}$ & $\begin{array}{l}\text { Different } \\
\text { Waste }\end{array}$ & Regulations & $\begin{array}{l}\text { Concerned } \\
\text { Authorities }\end{array}$ & Stakebolders \\
\hline 1. & Solid Waste & $\begin{array}{l}\text { Solid Waste } \\
\text { Management } \\
\text { Rules, } 2016\end{array}$ & $\begin{array}{l}\text { Ministry of } \\
\text { Environment, } \\
\text { Forests and } \\
\text { Climate } \\
\text { Change, and } \\
\text { Ministry of } \\
\text { Housing and } \\
\text { Urban Affairs }\end{array}$ & $\begin{array}{l}\text { Municipal areas, urban } \\
\text { agglomerations, } \\
\text { census towns, notified } \\
\text { industrial townships, } \\
\text { Indian Railways, } \\
\text { airports, special } \\
\text { economic zones, } \\
\text { religious and historical } \\
\text { places, State and } \\
\text { Central Government } \\
\text { organizations }\end{array}$ \\
\hline 2. & $\begin{array}{l}\text { Plastic } \\
\text { Waste }\end{array}$ & $\begin{array}{l}\text { The Plastic } \\
\text { Waste } \\
\text { (Management } \\
\text { and Handling) } \\
\text { Rules, 2016 }\end{array}$ & $\begin{array}{l}\text { Ministry of } \\
\text { Environment, } \\
\text { Forests and } \\
\text { Climate } \\
\text { Change, and } \\
\text { Ministry of } \\
\text { Housing and } \\
\text { Urban Affairs }\end{array}$ & $\begin{array}{l}\text { Manufacturers of plastic } \\
\text { items, packaging } \\
\text { industry, food and } \\
\text { catering services, } \\
\text { FMCG industries, } \\
\text { event organisers, } \\
\text { households, urban } \\
\text { shopping areas, } \\
\text { offices, automobile } \\
\text { industries and } \\
\text { manufacturers of } \\
\text { electronic items. }\end{array}$ \\
\hline
\end{tabular}

(Continued) 
Table 16.1 (Continued)

\begin{tabular}{|c|c|c|c|c|}
\hline $\begin{array}{l}S . \\
\text { No. }\end{array}$ & $\begin{array}{l}\text { Different } \\
\text { Waste }\end{array}$ & Regulations & $\begin{array}{l}\text { Concerned } \\
\text { Authorities }\end{array}$ & Stakeholders \\
\hline 3. & $\begin{array}{l}\text { Biomedical } \\
\text { Waste }\end{array}$ & $\begin{array}{l}\text { Biomedical } \\
\text { Waste } \\
\text { Management } \\
\text { Rules, } 2016\end{array}$ & $\begin{array}{l}\text { Ministry of } \\
\text { Environment, } \\
\text { Forests and } \\
\text { Climate } \\
\text { Change }\end{array}$ & $\begin{array}{l}\text { Healthcare } \\
\text { establishments, } \\
\text { CBWTF and TSDF }\end{array}$ \\
\hline 4. & $\begin{array}{l}\text { Hazardous } \\
\text { Waste }\end{array}$ & $\begin{array}{l}\text { Hazardous } \\
\text { Waste } \\
\text { Management } \\
\text { Rules, } 2016\end{array}$ & $\begin{array}{l}\text { Ministry of } \\
\text { Environment, } \\
\text { Forests and } \\
\text { Climate } \\
\text { Change }\end{array}$ & $\begin{array}{l}\text { TSDF, petrochemicals, } \\
\text { pharmaceuticals, } \\
\text { chemicals, fertilisers } \\
\text { and general } \\
\text { engineering industries }\end{array}$ \\
\hline 5. & E- Waste & $\begin{array}{l}\text { E-waste } \\
\text { (Management) } \\
\text { Rules, } 2016\end{array}$ & $\begin{array}{l}\text { Ministry of } \\
\text { Environment, } \\
\text { Forests and } \\
\text { Climate } \\
\text { Change }\end{array}$ & $\begin{array}{l}\text { Equipment } \\
\text { manufacturers and } \\
\text { end users }\end{array}$ \\
\hline
\end{tabular}

Source: Created by CCDC-PHFI

\section{Waste management in the Indian health sector: process flow}

India generates 614 tonnes of biomedical waste on a daily basis (BMWM Annural Report 2018). It is estimated to reach 775.5 tonnes by 2022, says a study conducted by ASSOCHAM and Velocity. Management of biomedical waste originating from healthcare facilities follows the cradle-to-grave approach which includes characterisation, quantification, segregation, storage, transport, treatment and disposal of biomedical waste (Datta et al., 2018). Healthcare facilities are required to segregate their biomedical waste into four colour-coded categories - yellow, red, white and blue - at its point of segregation, before handing it over to the common biomedical waste treatment and disposal facility (CBWTF) operators to avoid environmental and occupational health risks (Table 16.2).

All the four waste categories are collected by the authorised collector or CBWTF operator for final treatment and disposal. The purpose of treatment is to reduce the potential hazards posed by the biomedical waste (WHO, 2014). The choice of a waste treatment system involves consideration of waste characteristics, technology capabilities, requirements, environmental and safety factors and costs (WHO, 2014). Hazardous components of biomedical waste particularly sharps, infectious and pathological waste are treated by thermal, chemical, irradiation, biological and mechanical processes (WHO, 2014). The diagram below describes the process flow of biomedical waste management (Figure 16.2).

Waste in Yellow bags is the only category that needs to be incinerated, after which the ash is disposed of at a Treatment, Storage and Disposal Facility (TSDF). Some of the yellow category wastes such as used blood 
Table 16.2 Colour-coded BMW categories along with their treatment and disposal methods

\begin{tabular}{|c|c|c|c|}
\hline Category & Type of Bag/Container Used & Type of Waste & Treatment/Disposal Option \\
\hline Yellow & $\begin{array}{l}\text { Non- chlorinated plastic bags } \\
\text { Separate collection system leading to } \\
\text { an effluent treatment system for } \\
\text { chemical liquid waste }\end{array}$ & $\begin{array}{l}\text { - Human anatomical waste } \\
\text { - Animal anatomical waste } \\
\text { - Soiled Waste } \\
\text { - Expired of discarded medicines } \\
\text { - Chemical waste } \\
\text { - Microbiological, biotechnological } \\
\text { - Chd other clinical lab waste } \\
\text { - Chemical liquid waste }\end{array}$ & $\begin{array}{l}\text { Incineration or plasma pyrolysis or } \\
\text { deep burial }\end{array}$ \\
\hline Red & $\begin{array}{l}\text { Non- chlorinated plastic bags or } \\
\text { containers }\end{array}$ & $\begin{array}{l}\text { Contaminated waste (Recyclable) } \\
\text { tubing, bottles, intravenous tubes } \\
\text { and sets, catheters, urine bags, } \\
\text { syringes (without needles) and } \\
\text { gloves }\end{array}$ & $\begin{array}{l}\text { Autoclaving/Microwaving/ } \\
\text { Hydroclaving and then sent for } \\
\text { recycling. Not be sent to landfill. }\end{array}$ \\
\hline White & $\begin{array}{l}\text { Puncture, leak and tamper proof } \\
\text { containers }\end{array}$ & Waste sharps including metals & $\begin{array}{l}\text { Autoclaving or dry heat sterilisation } \\
\text { followed by shredding or mutilation } \\
\text { or encapsulation }\end{array}$ \\
\hline Blue & $\begin{array}{l}\text { Puncture proof and leak proof boxes } \\
\text { or containers with blue coloured } \\
\text { marking }\end{array}$ & Glassware & $\begin{array}{l}\text { Disinfection/autoclaving/microwaving/ } \\
\text { hydroclaving and then sent for } \\
\text { recycling }\end{array}$ \\
\hline
\end{tabular}




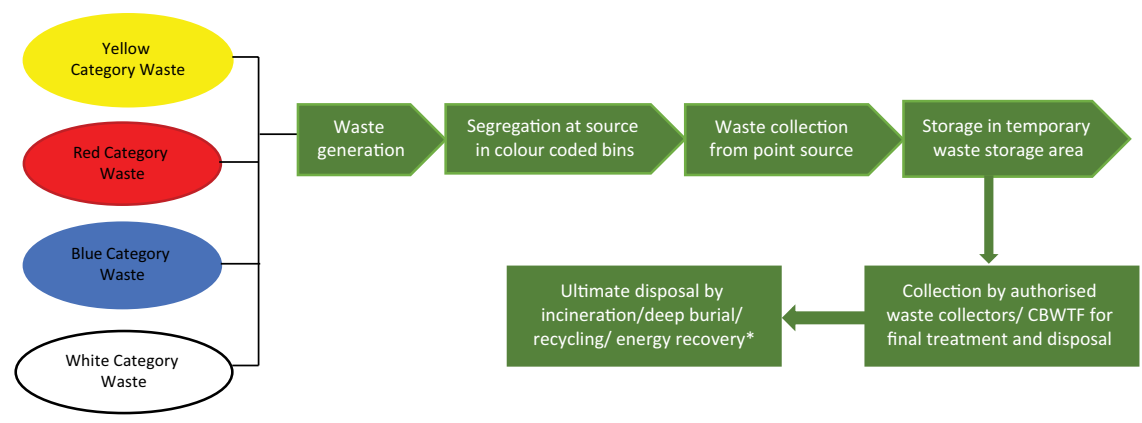

Figure 16.2 Methods prescribed in the BMWM rules for different waste categories.

Source: CCDC-PHFI

bags, vacutainers and other microbiological waste are to be pre-treated by autoclaving at the Health Care Facility (HCF) level before handing over to Captive Biomedical Waste Treatment Facilities (CBWTFs). All other waste is to be treated and disposed at CTFs or Captive Treatment Facilities only (in case of non-availability of CBWTFs).

\section{Why is waste segregation important?}

Segregation at source and waste reduction is the basic principle of biomedical waste management (BMWM) (Datta et al., 2018). It is the first and most essential step in BMWM (Sengodan, 2014). Segregation of each category at its source not only decreases the waste volume of each waste stream and its ease of processing and disposal (and consequently, the burden on waste management systems), but also prevents occupational health risks to the sanitation and waste-handling sector. Waste segregation is an effective procedure for reducing risks associated with and minimising the cost of waste disposal (Khobragade, 2019). Waste segregation can help in ensuring that incinerators are not overwhelmed with unwanted waste items.

According to the United Nations Environment Programme (UNEP), about $25 \%$ of biomedical waste is hazardous in nature. Part of this waste requires special treatment. The cost of its treatment and disposal can be greatly reduced if it is appropriately segregated (WHO Data Sheet). The remaining $75 \%$ of waste is of a non-hazardous nature that is generated from offices, kitchen and housekeeping areas. If the non-hazardous waste is mixed with potentially infectious and hazardous waste, it can lead to an increased volume of hazardous waste. In order to achieve adequate segregation, clear protocols for identifying different waste categories and separate disposal methods are essential. 


\section{Challenges on the ground}

The Indian policy for the management of biomedical waste has been in place since 1998. The regulations of 1998 were later modified in the years 2000, 2003 and 2011. In 2016, new rules for BMWM were notified by the Ministry of Environment, Forests and Climate Change (MoEFCC) and these were subsequently amended in 2018 and 2019. In spite of all the amendments that were intended to address practical constraints, several studies suggest inadequate enforcement of BMWM regulations. As early as 2001, i.e. after the first amendment made to the 1998 rules, a study conducted by the Centre for Environment Education indicated discrepancies in the implementation of rules (Verma et al., 2008). In 2008, another study revealed inadequacies across Delhi nursing homes and smaller hospital establishments in waste segregation, storage and disposal. The study highlighted the malpractice of collecting sharps waste in plastic bags instead of puncture-proof containers, lack of dedicated space for waste storage and the practice of handing over laboratory waste to the external service provider without disinfecting the waste (Verma et al., 2008).

Later in 2016, a report by the Comptroller and Auditor General (CAG) of India highlighted the gaps in waste segregation across different facilities in Mumbai and Nashik. Some of the evaluated facilities were found to have used plastic bags instead of puncture-proof containers for glass and metal sharps waste. In Mumbai, the CAG found two facilities to have mixed sharp wastes with incinerable waste and some BMW was also found to be stored near a patient's bed (Kakodkar, 2017). As per the Central Pollution Control Board's Annual Report on Biomedical Waste Management of 2018, out of the total 2,70,416 healthcare facilities (HCFs) in India, 27,301 ( $10 \%)$ violated the biomedical waste management rules. About 16,956 showcause notices/directions were issued to defaulter HCFs. A total of 12,326 HCFs have captive treatment facilities for BMW treatment and disposal (BMWM Annual Report, 2018).

Another CAG report of 2018 that evaluated the performance audit of Solid Waste Management in Karnataka stated that healthcare institutions were functioning without authorisation and the facilities had resorted to unauthorised disposal of biomedical waste (CAG, Govt. of India, 2018). A recent study conducted by Toxics Link in 2019 across HCFs of Delhi showed that practices in larger establishments were more or less compliant with the new rules, but that smaller establishments were found to be lacking in several aspects such as absence of ETP/STPs, lack of personal protective equipment, waste storage in the open, manual waste transportation within the facilities, improper waste quantum records and lack of accident reporting (Mahesh and Syed, 2019). 


\section{Environmental concerns}

Yellow category waste has eight sub-categories that cumulatively contribute to a large proportion of the total biomedical waste generated from HCFs. Due to its infectious and hazardous nature, most of this waste is subject to high heat thermal processes such as incineration. If not incinerated, many of the waste items can end up in regular landfill sites or garbage dumps (Fullerton, 2017). Incineration is a high-temperature, dry oxidation process that reduces organic and combustible waste to inorganic, incombustible matter and theoretically results in a significant reduction of waste volume and weight (WHO, 2014). Even though incineration is considered to be the most preferred method to dispose of yellow category waste as it can efficiently kill pathogens while reducing the volume of waste, there are several environmental concerns associated with the process.

Incineration is highly dependent on the use of fossil fuel, adding to the issues of climate change along with increasing particulate matter (PM) pollution. Many respiratory diseases are closely associated with increased levels of $\mathrm{PM}_{10}$ and $\mathrm{PM}_{2.5}$, and the increase in PM is known to exacerbate such conditions. Further, the incineration of biomedical waste releases combustion by-products into the atmosphere and generates residual ash which can contain heavy metals, requiring disposal in hazardous waste treatment facilities. The combustion produces gaseous emissions such as steam, carbon dioxide, nitrogen oxides, a range of volatile substances (e.g. metal compounds, halogenic acids, products of incomplete combustion), particulate matter and solid residues in form of ashes (WHO, 2014). These gaseous emissions are directly released into the atmosphere and contribute to the greenhouse effect. In waste incineration plants, $\mathrm{CO}_{2}$ constitutes the chief climate-relevant emission that is considerably higher than other climaterelevant emissions (Johnke et al., 2003). The climate-relevant $\mathrm{CO}_{2}$ emissions from waste incineration are determined by the proportion of waste whose carbon compounds are assumed to be of fossil origin (Johnke et al., 2003). The level of fossil $\mathrm{CO}_{2}$ emitted by burning 1 tonne of waste depends on what is burned (Zero Waste Europe, 2019).

According to the Stockholm Convention: "If medical waste is incinerated in conditions that do not constitute best available techniques or best environmental practices, there is potential for the release of polychlorinated dibenzodioxins and polychlorinated dibenzofurans in relatively high concentrations" (Secretariat of the Stockholm Convention, 2006). Dioxins are considered to have cancer-causing potential and are human carcinogens as per the International Agency for Research on Cancer, an arm of WHO (Gautam et al., 2010).

In order to prevent environmental damage, current regulations for BMWM have standards for incineration along with other treatment technologies 
such as microwaving and autoclaving. However, segregation at source and volume reduction of biomedical waste fractions can reduce disposal costs, the amount of raw materials required for the process, and energy use. A reduction in GHG emissions from waste disposal methods and waste volume can also be achieved through better purchasing, minimising the packaging, opting for recycling and composting or biodigestion of non-healthcare biodegradable waste $(\mathrm{HCWH}, 2020)$. Reducing the distance of waste transportation for treatment and disposal can also contribute to a decrease in GHG emissions (HCWH, 2020). This can be done by operationalising adequate numbers of CBWTFs in all regions of the country, which currently is the biggest challenge in the area of BMWM. Currently, there are only 200 CBWTFs that are operational and an additional 28 are under construction (BMWM Annual Report, 2018). Furthermore, there are seven states where there are no CBWTFs.

\section{Climate-smart waste practices for the Indian healthcare sector}

Best practices for managing healthcare waste are primarily based on the appropriate segregation of waste at source based on its hazardousness, infectiousness and the type of material of the waste. Segregation is most effective when done at the waste generation source (Khobragade, 2019). For instance, segregation of uninfected and infectious waste is a must as this is a major factor determining the facilities and energy requirements during the entire process of waste collection, storage and its treatment and disposal. The Solid Waste Management Rules (2016) have provisions for colour coding different categories of waste such as green for biodegradable food waste with the recycling symbol, light blue for non-biodegradable (non-infected) general waste with the recycling symbol, black for the collection of domestic hazardous waste such as residual paints, pesticides, CFLs, tube lights, batteries and disinfectant containers, etc. Similarly, as per the BMWM Rules (2016), BMW is to be segregated into four colour-coded categories that have been discussed in the previous sections.

Once these categories are colour coded and segregated, it is easy to assign sustainable technologies without having to incinerate the entire amount of waste in case of mixing. For instance, the biodegradable waste category, especially food waste, can be processed by biomethanation and composting. Red category waste can be autoclaved, blue category waste can either be chemically disinfected or autoclaved or microwaved, and white category waste can be treated by dry heat sterilisation and steam sterilisation. All three categories, namely red, blue and white, can then be given to authorised recyclers for recycling and manufacture of different materials after the treatment (but not used for food or medical purposes). Recyclable wastes can be recycled, domestic hazardous chemical waste can be neutralised and treated and disposed in TSDF. If this is successfully achieved, only $25-30 \%$, that is, the biomedical waste (yellow category) would be the only category 
requiring incineration. This can greatly reduce the volume of incinerable waste and improve the performance efficiency of incinerators.

\section{Benefits of biomethanation and composting}

Adoption of biomethanation or composting for onsite treatment of biodegradable waste can be sustainable ways to treat biodegradable waste (Anand, 2019). The benefits of biomethanation composting of the biodegradable fraction of cooked and uncooked food waste are that these processes speed up the degradation. Another advantage of biomethanation is that even possibly infected food waste is processed in a covered predigester (for stabilising $\mathrm{pH}$ ) or in the main digester, and is exposed to a retention time between 15 to 21 days at a steady temperature of $35-40^{\circ} \mathrm{C}$. The process develops conditions that could be sufficient to kill pathogenic bacteria and viruses. The process of biomethanation produces biogas, which is a combination of methane, carbon dioxide, hydrogen sulphide, etc., with efficient biodigesters producing at least $70-72 \%$ methane. This biogas has been tested as a clean fuel for cooking, heating and other purposes. Biogas is most easily produced from gobar gas digesters and food waste digesters.

Direct composting of kitchen waste, food leftovers and soft garden waste under aerobic conditions in pits, piles or in-vessel composters shows that

\section{Box 16.1 Case study}

\section{Composting for the on-site treatment of biodegradable waste in the Indian healthcare sector}

There are several case studies in India where food waste from healthcare establishments is being composted either in in-vessel composters or the traditional pits of appropriate capacities. Lokmanya Tilak Municipal General Hospital, commonly known as "Sion Hospital," a public sector hospital situated in Mumbai has adopted on-site treatment of their food waste through aerobic bacterial composting. Thirteen brick-walled compost pits measuring $9 \mathrm{ft}$. long, $4.5 \mathrm{ft}$. wide and $3.5 \mathrm{ft}$. high have been constructed for the treatment of wet food waste in the hospital campus. The manure generated after this treatment is collected and used in the campus plantations maintained at the hospital. A similar initiative has been taken up by HBT Medical College and Dr. R. N. Cooper Hospital, a municipal general hospital in Mumbai. The hospital management has taken up vermi-composting to treat their food waste and soft garden waste.

Source: HELP Case Studies, 2018 
temperatures inside the composting piles reach $55-65^{\circ} \mathrm{C}$. When the waste, along with bulk matter such as garden waste, moisture and inoculum, remains inside the pile for nearly seven days between turnings, these temperatures are sufficient to kill pathogenic microorganisms, including the SARS-CoV-2 virus. It also helps in decomposition and mineralisation of food waste into compost and humus, which are necessary ingredients for the growth of plants, trees, etc. (Box 16.1).

\section{Key takeaways}

- Biomedical waste is hazardous but all the other types of waste generated in healthcare establishments are not necessarily infectious or hazardous.

- Non-compliance with segregation, storage and treatment policies and subjecting the entire waste from healthcare establishments to incineration is highly unsustainable.

- Practices as outlined above would help in reducing greenhouse gases and increase the climate change mitigation potential of a healthcare establishment and make it climate resilient.

- Mobilising the health systems towards adopting such practices for safe handling and disposal of healthcare waste are essential in order to bring overall health, economic and environmental benefits.

\section{References}

Aljabre, S. H. M. (2002). Hospital generated waste: A plan for its proper management. Journal of Family \& Community Medicine, 9(2), 61-65. https://www.ncbi. nlm.nih.gov/pmc/articles/PMC3430187/\#: :text=Hospitals\%20are\%20important $\% 20$ sites $\% 20$ for $\% 20$ the $\% 20$ generation $\% 20$ of $\% 20$ waste., and $\% 20$ radioactive $\% 20$ items $\% 20$ and $\% 20$ sharps.

Anand, Kisslay (2019). Solid waste management initiatives in Urban India: A Compendium. Ministry of Housing and Urban Affairs, National Institute of Urban Affairs. 88-90. NIUA. https://niua.org/intranet/sites/default/files/745.pdf.

BMWM Annual Report. (2018). Annual report on biomedical waste management as per biomedical waste management rules, 2016 for the year 2018. CPCB: https://cpcb.nic.in/uploads/Projects/Bio-Medical-Waste/AR_BMWM_2018.pdf

CAG, Govt. of India. (2018). Performance audit of solid waste management in urban local bodies, Government of Karnataka. Comptroller and Auditor General of India. https://cag.gov.in/sites/default/files/audit_report_files/Report_No_4_ of_2018_Performance_Audit_of_Solid_Waste_Management_in_Urban_Local_ Bodies_Government_of_Karnataka.pdf

Datta, P., Mohi, G., \& Chander, J. (2018). Biomedical waste management in India: Critical appraisal. Journal of Laboratory Physicians, 10(1), 6-14. https://www. ncbi.nlm.nih.gov/pmc/articles/PMC5784295/

Fullerton, K. (2017). The Environmental Hazards of Medical Waste. Sense and Sustainability. https://www.senseandsustainability.net/2017/09/29/dumpedmedical-waste-hazardous-to-the-environment/ 
Gautam, V., Thapar, R., \& Sharma, M. (2010). Biomedical waste management: Incineration vs. environmental safety. Indian Journal of Medical Microbiology, 28(3), 191-192. doi: 10.4103/0255-0857.66465.

HELP. (2018). HELP case studies: On site food waste management to reduce the waste load on municipal dump site. Health and Environment Leadership Platform (HELP) https://www.ceh.org.in/wp-content/uploads/2018/10/CaseStudy_Waste_Sion.pdf

Health Care Without Harm. (2020). Healthcare waste: Our vision. HCWH. https://noharm-global.org/issues/global/our-vision.

Johnke, B., Robert, H., Eugene, L., Bill, I., Martinsen, T., \& Mareckova, K. (2003). Emissions from waste incineration. Good practice guidance and uncertainty management in national greenhouse gas inventories. https://www.ipcc-nggip.iges. or.jp/public/gp/bgp/5_3_Waste_Incineration.pdf

Kakodkar, P. (2017). Inadequate management of bio-medical waste in Maharastra: CAG. The Times of India, 17, 52. https://timesofindia.indiatimes.com/city/mumbai/inadequate-management-of-bio-medical-waste-in-maharashtra-cag/articleshow/60209901.cms

Khobragade, S. D. (2019). Health care waste: Avoiding hazards to living and non living environment by efficient management. Fortune Journal of Health Sciences, $2(2), \quad 014-029$. http://www.fortunejournals.com/articles/health-care-wasteavoiding-hazards-to-living-and-non-livingnbspenvironment-by-efficientmanagementp.pdf

Mahesh, P. B., \& Syed, S. (2019). Spreading infection? Healthcare facilities in Delhi. Toxics Link. http://toxicslink.org/docs/Spreading\%20infection.pdf

Ministry of Housing and Urban Affairs, Govt. of India. (2017). Bulk solid waste generators: A step by step guidance for urban local bodies to implement the solid waste management rules, 2016. MoHUA. http://164.100.228.143:8080/sbm/content/writereaddata/Bulk\%20Waste\%20Generator\%20Book.pdf

Patil, A. D., \& Shekdar, A. V. (2001). Health-care waste management in India. Journal of Environmental Management, 63, 211-220. doi:10.1006/ jema.2001.0453.

Sengodan, V. C. (2014). Segregation of biomedical waste in an South Indian tertiary care hospital. Journal of Natural Science, Biology and Medicine, 5(2), 378-382. doi: 10.4103/0976-9668.136194

SSC - Secretariat of the Stockholm Convention. (2006). Revised draft guidelines on best available techniques and provisional guidance on best environmental practices relevant to Article 5 and Annex $C$ of the Stockholm Convention on Persistent Organic Pollutants. Secretariat of the Stockholm Convention.

UNEP and WHO. (2014). National health-care waste management plan, guidance manual. WHO. https://www.who.int/water_sanitation_health/medicalwaste/en/ guidancemanual1.pdf

Verma, L. K., Mani, S., Sinha, N., \& Rana, S. (2008). Biomedical waste management in nursing homes and smaller hospitals in Delhi. Waste Management, 28(12), 2723-2734. doi: 10.1016/j.wasman.2007.12.013

WHO. (2014). Safe Management of Wastes from Healthcare Activities (2nd Ed.). https://www.who.int/water_sanitation_health/publications/2011/ 9789241548151_ch10.pdf 
Xin, C., Tingting, Z., Sang-Bing, T., Yu-Ming, Z., \& Jiangtao, W. (2020). An empirical study on greenhouse gas emission calculations under different municipal solid waste management strategies. Applied Science, 2020(10), 1673. doi: 10.1016/j. wasman.2007.12.013

Zero Waste Europe. (2019). The impact of waste-to-energy incineration on climate, 2019. https://zerowasteeurope.eu/wp-content/uploads/edd/2019/09/ZWE_Policybriefing_The-impact-of-Waste-to-Energy-incineration-on-Climate.pdf 


\title{
SUSTAINABLE TRANSPORT SOLUTIONS IN THE HEALTH SECTOR
}

\author{
Shailendra P. Singh and Sundeep Singh Chauhan
}

\section{Introduction}

Greenhouse gas emissions from transportation primarily originate from burning fossil fuels to run cars, trucks, ships, trains and planes. Globally, the transportation sector generates $23 \%$ of all greenhouse gas emissions (Kahn et al., 2007), making it a major contributor towards climate change. In the United States, the sector accounted for $28.2 \%$ of all GHG emissions in 2018 (USEPA, 2018). In India, the transport sector is the third-largest contributor amongst GHG emitting sectors, where the majority comes from road transport $(90.1 \%)$, with rail $(3.1 \%)$, civil aviation $(5.6 \%)$ and domestic water-borne navigation (1.2\%) making up the remainder in 2014.

Diesel transport is one of the world's major sources of black carbon, a short-lived climate pollutant (SLCP) that is the second-highest contributor to global warming after $\mathrm{CO}_{2}$. Black carbon has a significant warming effect, but it is also a major component of particulate matter, the air pollutant most closely associated with increased air-pollution related mortality and morbidity. This chapter will provide:

1. An overview of the health risks associated with transport-related pollutants.

2. Adaptation and mitigation measures to deal with transportationrelated GHG emissions in the health sector.

\section{Health risks from transport-related pollutants}

The transport sector releases gases such as $\mathrm{NO} 2$, causes ozone-layer depletion and increases the amount of UVB exposure responsible for nonmelanoma skin cancer, as well as playing a major role in malignant melanoma development. Carbon dioxide persists in the atmosphere for over a century, with long-term warming effects (IPCC, 2014). Black carbon particulate matter is responsible for premature deaths due to heart or lung disease, 
Table 17.1 Health risks associated with transport related pollutants

\begin{tabular}{|c|c|}
\hline Health Risk & Associated Transport Related Pollutants \\
\hline Mortality & Black smoke, ozone, $\mathrm{PM}_{2.5}$ \\
\hline Respiratory disease (non-allergic) & $\begin{array}{l}\text { Black smoke, smoke, ozone, nitrogen } \\
\text { dioxide, VOCs, CAPs, diesel exhaust }\end{array}$ \\
\hline Respiratory disease (allergic) & $\begin{array}{l}\text { Ozone, nitrogen dioxide, PM, VOCs, CAPs, } \\
\text { diesel exhaust }\end{array}$ \\
\hline Cardiovascular diseases & Black smoke, CAPs \\
\hline Cancer & $\mathrm{NO}_{2}$, diesel exhaust \\
\hline Adverse reproductive outcomes & $\begin{array}{l}\text { Diesel exhaust, also equivocal evidence for } \\
\mathrm{NO}_{2}, \mathrm{CO}, \mathrm{SO}_{2}, \mathrm{TSP}\end{array}$ \\
\hline
\end{tabular}

non-fatal heart attacks, irregular heartbeat or arrhythmia, aggravated asthma attacks, decreased or restricted lung function, increased respiratory symptoms, such as coughing, irritation of the airways, and other breathing problems (USEPA, 2018).

Transport-related health risks are considered a major cause of the deaths of millions of people annually. For example, the World Health Organization estimates that around 1.3 million people are killed annually due to urban air pollution, much of it transport-generated (WHO, 2011). Traffic injuries are the cause of death for another 1.3 million people each year, primarily in low- and middle-income countries (WHO, 2011). Some 3.2 million deaths are annually attributed to physical inactivity in the transport sector (WHO, 2011). The health risks associated with transport-related air pollutants are summarised in Table 17.1.

Outdoor air pollution kills more than three million people across the world every year and causes health problems ranging from asthma to heart disease. This costs around USD 3.5 trillion considering just OECD countries, India and China. It is estimated that road transport contributes to approximately half the cost in the OECD region.

Low- and middle-income cities may have the most to gain in health terms from low-carbon transport. These cities are experiencing the most rapid urban population growth as well as traffic congestion, air pollution and risks of traffic injury. The same cities face growing risks of noncommunicable disease from more sedentary lifestyles. Healthier transport strategies and the judicious use of effective measures for road transport in the value chain of the health sector, such as the transportation of medical goods and equipment and the travel footprints of patient and medical staff, will go a long way in addressing these risks (WHO, 2011).

The two-pronged strategy to combat the climate change caused by transportation involves (a) mitigation measures and (b) adaptation measures. The key measures under each are described in the following sections. 


\section{Mitigation measures applicable to transportation in the health sector}

\section{- Modified vehicles and fuel}

The strategies under this are mandatory fuel economy $/ \mathrm{CO}_{2}$ standards for road transport; shifting to lower-carbon fossil fuels, biofuels, CNG and hybrid/electric vehicles; other vehicle design modifications. The IPCC estimates that these strategies could reduce global emissions from light-duty vehicles (LDVs) in 2030 by about $800 \mathrm{MtCO} 2$ (about 21\%) compared with business-as-usual scenarios. IPCC estimates that 718-766 MtCO2 could be achieved at a cost less than US\$ $100 / \mathrm{tCO} 2$ and up to $697 \mathrm{MtCO} 2$ at costs less than US\$ 0/tCO2 (i.e. using cost-saving measures). IPCC also cites estimates of the mitigation potential of shifts to biofuels in the transport sector, reflecting a possible mitigation potential of between 600 and $1500 \mathrm{MtCO} 2$ in 2030 at a relatively low cost of less than US\$25/tCO2.

Electric vehicles also can potentially offer substantial local air pollution reductions and fewer health impacts when compared with conventionally fuelled vehicles, particularly in heavily trafficked urban areas (Kahn et al., 2007). The IPCC also notes that vehicles powered by CNG can provide relatively low greenhouse gas emissions for fossil-fuel-powered vehicles. As noted, CNG vehicles are already widely used in many low- and middleincome countries partly due to lower fuel costs (Sharma et al., 2014 and WHO COP24 Report). But CNG for buses or taxis has also been promoted and, in some cases, required explicitly as a means of reducing urban pollution emissions (e.g. all public buses in New Delhi, India; auto-rickshaws in Dhaka, Bangladesh). Battery electric vehicles (BEVs) emit no tailpipe emissions and have potentially very low fuel-production emissions (when using low-carbon electricity generation) (Kromer and Heywood, 2007). BEVs operate at a drive-train efficiency of around $80 \%$ compared with about 20-35\% for conventional ICE LDVs. The Government of India has targeted $30 \%$ electric vehicle adoption by 2030 . In the Indian electric vehicle ecosystem market, the EV market is anticipated to grow at a robust CAGR of $43.13 \%$ during the forecast period from 2019 to 2030.

\section{- Modified price of vehicles, fuel and infrastructure}

Under this, the strategies are higher taxes on vehicle purchase, registration, use of higher taxes on motor fuels; road and parking fee; congestion/area pricing, etc. As described by the IPCC: "transport pricing refers to the collection of measures used to alter market prices by influencing the purchase or use of a vehicle. Typically, the measures applied to road transport are fuel pricing and taxation, vehicle license/registration fees, annual circulation taxes, tolls and road charges and parking charges." The operating cost of an electric vehicle may be low, but the capital cost may be high. A tax reduction for the electric vehicle in least developed countries could be options. The Government of India's policy think tank is considering 
tapping into the green cess in place of taxing electric vehicles, and additional road taxes imposed on certain types of vehicles to incentivise the sale of electric vehicles (EVs).

Similarly, the cost of solar and renewable fuel is decreasing, but is yet to be made at par with other cheaper fuels. Therefore, economic incentives for renewable energy and low GHG emission fuels are better options in India and developing countries. As traffic congestion grows and freeway infrastructure reaches the physical, political and economic limits, the modal share of public transit has also increased. In addition to improved access in developing countries, a substantial number of people are employed in the formal and informal public transport sector. A shift to public transport modes is likely to generate additional employment opportunities in this sector (Santos et al., 2010). One of the oldest examples of congestion pricing is the area licensing scheme introduced in Singapore in 1975, involving a fee to enter a restricted zone during the morning commuting period. It reduced car traffic by $75 \%$ (Seik, 1997).

\section{- Land-use strategy/land-use changes and mode shifts from private to public transit and non-motorised modes}

Influencing mobility needs through land-use design/regulations and infrastructure planning; prioritisation of, and investment in public transportation systems such as city buses, metro and non-motorised transport infrastructure and amenities such as cycling lanes. Barías et al., (2005) found that a hypothetical "optimal land use" reallocation in the existing urban form of Santiago in Chile could achieve a $67 \%$ reduction in transport emissions in the city over a 20-year period, although costs were prohibitively high. However, more moderate measures to relocate residential and commercial facilities closer together reduced emissions by $21 \%$ and were cost-effective in carbon mitigation terms (US\$ 91/tCO2 reduction over 20 years). Very low-cost measures to relocate schools and hospitals closer to residences could potentially achieve a $12 \%$ reduction in transport emissions in the same period for only US $\$ 2$ per tonne of $\mathrm{CO}_{2}$ reduction (Barias et al., 2005). The IPCC cites a study by Wright and Fulton (2005) estimating that increases in the mode share of walking in Bogotá, Colombia from $20 \%$ to $25 \%$ of travel could reduce transport emissions by $6.9 \%$ at a cost of US\$ $17 / \mathrm{tCO} 2$ (Table 17.2 to 17.4 ).

Thus, shifting from diesel to gasoline vehicles could reduce emissions of health-damaging small particulates $\left(\mathrm{PM}_{10} \& \mathrm{PM}_{2.5}\right)$, while a shift to the use of active transport, such as walking and cycling besides rapid transit/public transport, combined with improved land use can lead to much greater and instantaneous health co-benefits. The adoption and promotion of economic incentives have also proven to be effective, as seen in Table 17.5. Some of these measures were adopted in developed and developing countries, and their impacts on health were measured. The outcomes of selected climate change mitigation activities of transport sector presented at COP24 are summarised in Table 17.5 (Box 17.1). 
Table 17.2 Summary of case studies of climate change related measures on health

\begin{tabular}{|c|c|c|c|}
\hline Area (study) & $\begin{array}{l}\text { Description of } \\
\text { case study }\end{array}$ & $\begin{array}{l}\text { Scale and/or } \\
\text { parameters }\end{array}$ & Outcomes \\
\hline $\begin{array}{l}\text { Europe emissions } \\
\text { impacts } \\
\text { (Watkiss et al., } \\
\text { 2005) }\end{array}$ & $\begin{array}{l}\text { Ozone and PM } \\
\text { health impact } \\
\text { analysis at } \\
\text { national and } \\
\text { continental } \\
\text { level }\end{array}$ & $\begin{array}{l}\text { Continental } \\
\text { (EU25) and } \\
\text { national. } \\
\text { Whole } \\
\text { population, } \\
\text { approx. } \\
450 \text { million }\end{array}$ & $\begin{array}{l}\text { Found that ozone } \\
\text { generates large } \\
\text { numbers of morbidity } \\
\text { effects, with tens of } \\
\text { millions of minor } \\
\text { restricted activity days } \\
\text { and respiratory } \\
\text { medication use days } \\
\text { each year. PM } \\
\text { exposure annual } \\
\text { impacts across the EU } \\
25 \text { total an estimated } \\
3.7 \text { million years of life } \\
\text { lost each year. The } \\
\text { morbidity effects of } \\
\text { PM estimated } 100,000 \\
\text { cases of respiratory or } \\
\text { cardiac hospital } \\
\text { admissions in } 2008 \text {. }\end{array}$ \\
\hline $\begin{array}{l}\text { Delhi emission } \\
\text { reduction }\end{array}$ & $\begin{array}{l}\text { Emission } \\
\text { Reduction } \\
\text { from MRTS } \\
\text { Projects - A } \\
\text { Case Study of } \\
\text { Delhi Metro } \\
\text { Rail }\end{array}$ & $\begin{array}{l}\text { CO, HC, } \\
\text { NOX, PM } \\
\text { emission } \\
\text { estimate at } \\
\text { Delhi level }\end{array}$ & $\begin{array}{l}\text { Delhi Metro Rail } \\
\text { Corporation carried } \\
\text { out a similar study and } \\
\text { reported emissions } \\
\text { savings of } 1453 \mathrm{t} \text { per } \\
\text { day for } 2011 \text { of } \mathrm{CO}_{2} \\
\text { emissions using } \\
\text { fuel-based emissions } \\
\text { factor (Sharma et al., } \\
\text { 2014). }\end{array}$ \\
\hline
\end{tabular}

Table 17.3 Benefits of core measures - land use strategy

\begin{tabular}{lcc}
\hline Land use strategy & $\begin{array}{c}\text { Reduction in } \\
\text { transport emission }\end{array}$ & $\begin{array}{c}\text { Cost (US\$/tCo2) } \\
\text { over 20 years }\end{array}$ \\
\hline $\begin{array}{l}\text { Relocating educational and hospital } \\
\text { facilities in proportion to residential } \\
\text { locations }\end{array}$ & $12 \%$ & 2 \\
$\begin{array}{c}\text { Relocating non-residential land uses in } \\
\text { proportion to residential locations }\end{array}$ & $21 \%$ & 91 \\
$\begin{array}{c}\text { Concentrating a high proportion of } \\
\text { residential and non-residential land } \\
\text { uses into subcentres on urban edges }\end{array}$ & $40 \%$ & 538 \\
$\begin{array}{l}\text { Hypothetical optimum land use } \\
\text { re-allocation }\end{array}$ & $67 \%$ & 2014 \\
\hline
\end{tabular}


Table 17.4 Impact of transport-related mitigation activities on climate and health

\begin{tabular}{|c|c|c|c|c|}
\hline Mitigation activity & $\begin{array}{l}\text { Certainty of major } \\
\text { effect on shortlived } \\
\text { climate pollutants }\end{array}$ & $\begin{array}{l}\text { Aggregate level of } \\
\text { potential health } \\
\text { benefit }\end{array}$ & $\begin{array}{l}\text { Main health benefits; direct benefits; } \\
\text { indirect benefits; } \\
\text { ancillary benefits for bealth }\end{array}$ & $\begin{array}{l}\text { Potential level } \\
\text { of reduction in } \\
\mathrm{CO}_{2}\end{array}$ \\
\hline $\begin{array}{l}\text { Support for active (and } \\
\text { rapid mass transport) }\end{array}$ & High & High & $\begin{array}{l}\text { Improved air quality } \\
\text { Less crop damage and extreme weather } \\
\text { Increased physical activity } \\
\text { Reduced noise } \\
\text { Fewer road traffic injuries }\end{array}$ & High \\
\hline $\begin{array}{l}\text { Support for active (and } \\
\text { rapid mass) transport }\end{array}$ & High & High & $\begin{array}{l}\text { Improved air quality } \\
\text { Less crop damage and extreme weather } \\
\text { Increased physical activity } \\
\text { Reduced noise } \\
\text { Fewer road traffic injuries }\end{array}$ & None \\
\hline $\begin{array}{l}\text { Ultra-low-sulphur diesel } \\
\text { with diesel particle } \\
\text { filters }\end{array}$ & Medium-High & Medium & $\begin{array}{l}\text { Improved air quality } \\
\text { Less crop damage and extreme weather }\end{array}$ & None \\
\hline $\begin{array}{l}\text { Higher standards for } \\
\text { vehicle emissions and } \\
\text { efficiency }\end{array}$ & High & Medium-High & $\begin{array}{l}\text { Improved air quality } \\
\text { Less crop damage and extreme weather }\end{array}$ & High \\
\hline
\end{tabular}


Table 17.5 Impact of economic incentive measures on GHG savings in different countries

\begin{tabular}{lc}
$\begin{array}{l}\text { Economic inventive } \\
\text { measures }\end{array}$ & Impact on GHG savings \\
\hline $\begin{array}{l}\text { Optimal road pricing based } \\
\text { on congestion charging } \\
\text { (London, UK) }\end{array}$ & $\begin{array}{c}20 \% \text { reduction in } \mathrm{CO}_{2} \text { emissions because of } 18 \% \\
\text { reduction in traffic }\end{array}$ \\
Congestion pricing of the & $\begin{array}{l}34 \% \text { reduction of peak passenger traffic volume. } \\
\text { Namsan Tunnels (Seoul, }\end{array}$ \\
South Korea) & Traffic flow from 20 to $30 \mathrm{~km} / \mathrm{hr}$. \\
Fuel pricing and taxation & $15-20 \%$ for vehicle operators \\
Area Licensing Scheme & $1.043 \mathrm{GJ} /$ day energy savings. Vehicular traffic \\
(Singapore) & reduced by $50 \%$ Private traffic reduced by \\
& $75 \%$. Travel speed increased 20 to $33 \mathrm{~km} / \mathrm{hr}$ \\
Urban gasoline tax (Canada) & 4 million ton by 2010 and 2.6 million ton by \\
& 2020 \\
Congestion charge trial in & $13 \%$ reduction of $\mathrm{CO}_{2}$ \\
Stockholm (2005-2006) &
\end{tabular}

Source: IPCC Fourth Assessment Report: Climate Change 2007. Working Group III. Mitigation of Climate Change. https://archive.ipcc.ch/publications_and_data/ar4/wg3/en/ch5s5-5-1-2. html

\section{Box 17.1 Case Studies}

\section{Mitigation measures in hospitals around the world}

The "Go Well” Travel Plan in Hawke's Bay District Health Board, New Zealand, aimed to change the way staff travelled to the hospital once a fortnight. The annual travel survey results showed the following travel behaviour from 2015 to 2018: driving alone (-18\%), arriving by car $(-16 \%)$, travelling by bus $(+7 \%)$, travelling by bicycle $(+6 \%)$, walking/running $(+3 \%)$ and in patients; driving alone $(-8 \%)$, arriving by bus $(+11 \%)$, walking $(+2 \%)$. Parking complaints reduced from a high of 88 in 2015 to zero in 2018.

Sunnybrook Health Sciences Centre in Toronto, Canada, has a shuttle bus running to and from the site; this has been fitted with a low-emission and eco-friendly dual-fuel system.

Martha's Vineyard Hospital in Massachusetts, USA, provides special parking amenities for low-emission vehicles, car-poolers, and cyclists to promote more environmentally-friendly forms of transportation.

Narayana Health City in Bengaluru, India, uses electric vehicles for their daily operations; Table 17.6 lists out their energy consumption and cost savings. 
Table 17.6 Energy consumption and cost savings of Narayana Health City, Bengaluru, India

\begin{tabular}{|c|c|c|c|c|c|c|c|c|c|}
\hline $\begin{array}{l}\text { Vebicle } \\
\text { No. }\end{array}$ & $\begin{array}{l}\text { Capacity } \\
K W\end{array}$ & $\begin{array}{l}\text { Operating } \\
\text { Trip in } \\
\text { Total KM }\end{array}$ & $\begin{array}{l}\text { Year of } \\
\text { Commissioning }\end{array}$ & $\begin{array}{l}\text { Electricity } \\
\text { Consumption } \\
\text { per Month in } \\
\text { KWH }\end{array}$ & $\begin{array}{l}\text { Electricity } \\
\text { Consumption } \\
\text { per Month } \\
\text { INR }\end{array}$ & $\begin{array}{l}\text { Total } \\
\text { Electricity } \\
\text { Consumption } \\
\text { to Date INR }\end{array}$ & $\begin{array}{l}\text { Diesel Vehicle } \\
\text { Consumption } \\
\text { for the Same } \\
\text { Operation/ } \\
\text { Month INR }\end{array}$ & $\begin{array}{l}\text { Total Diesel } \\
\text { Consumption } \\
\text { INR }\end{array}$ & $\begin{array}{l}\text { Total Savings } \\
\text { from } \\
\text { Commissioning } \\
\text { INR }\end{array}$ \\
\hline Buggy \# 1 & 2.6 & 80 & 11-08-2008 & 312 & 2028 & 292032 & 6000 & 864000 & 571968 \\
\hline Buggy \# 2 & 2.6 & 80 & 14-05-2009 & 312 & 2028 & 281892 & 6000 & 834000 & 552108 \\
\hline Buggy \# 3 & 2.6 & 80 & 11-07-2009 & 312 & 2028 & 277836 & 6000 & 822000 & 544164 \\
\hline Buggy \# 4 & 2.6 & 80 & 11-07-2009 & 312 & 2028 & 277836 & 6000 & 822000 & 544164 \\
\hline
\end{tabular}




\section{Adaptation measures to reduce climate change vulnerability in the transport sector}

Mapping out the impact of climate change on the transport sector reveals that sea-level rise, storm surge, and flooding; strong wind and storms; increasing precipitation intensity; change in (average) precipitation; extreme heat; change in (average) temperature; freezing cold; increased freeze-thaw cycles; and permafrost degradation can damage the physical infrastructure and create inconvenience in the associated transportation services and create foundational change.

The impact can be minimised with the appropriate adaptation measures in the transport sector through innovative programme formulation and implementation at all levels: design, construction and O\&M. Some successful practices could be used in road infrastructure for generating and using solar energy; provision of rainwater harvesting and groundwater recharge component in transport projects; and the adaptation of green design, construction best practices and associated training.

\section{Key takeaways}

- Transportation is a major contributor to GHG emissions.

- There are numerous health risks associated with transport-related pollutants.

- The mitigation measures discussed modified vehicles and fuel, modified pricing of vehicles, fuel and infrastructure, changes in land-use strategies, shifts to active transport and economic incentives.

- The adaptation measures outlined how to minimise the impact of climate change on the transport sector through green design and sustainable strategies.

\section{References}

Barías, J. L., Sanhueza, E., Silsbe, E., Winkelman, S., \& Zegras, C. (2005). Getting on track: Finding a path for transportation in the CDM. International Institute for Sustainable Development.

IPCC. (2014). Climate change 2014: Synthesis report. Contribution of working groups I, II and III to the fifth assessment report of the intergovernmental panel on climate change. IPCC, 151.

Kahn, R. S., Kobayashi, S., Beuthe, M., Gasca, J., Greene, D., Lee, D. S., Muromachi, Y., Newton, P. J., Plotkin, S., Sperling, D., Wit, R., Zhou, P. J. (2007). Transport and its infrastructure. In Contribution of working group III to the fourth assessment report of the intergovernmental panel on climate change [B. Metz, O. R. Davidson, P. R. Bosch, R. Dave, \& L. A. Meyer (Eds.)]. Cambridge University Press.

Kromer, M., \& Heywood, J. (2007). Thesis (S.M.)--Massachusetts institute of technology, engineering systems division, technology and policy program, MIT. 
Santos, G., Behrendt, H., Maconi, L., Shirvani, T., \& Teytelboym, A. (2010). Part I: Externalities and economic policies in road transport. Research in Transportation Economics, 28(1): 2-45, ISSN 0739-8859, doi: 10.1016/j.retrec.2009.11.002

Seik, F. T. (1997). An effective demand management instrument in urban transport: The Area Licensing Scheme in Singapore. Cities, 14(3), 155-164.

Sharma, N., Singh, A., Dhyani, R., \& Gaur, S. (2014). Emission reduction from MRTS projects - A case study of Delhi Metro. Atmospheric Pollution Research, 5(4), 721-728, ISSN 1309-1042, doi: 10.5094/APR.2014.081

USEPA. (2018). Total US greenhouse gas emissions by economic sector in 2018. https://www.epa.gov/ghgemissions/sources-greenhouse-gas-emissions

Watkiss, P., Pye, S., \& Holland, M. (2005). CAFE CBA: Baseline analysis 2000 to 2020. Baseline scenarios for service contract for carrying out cost-benefit analysis of air quality related issues, in particular in the clean air for Europe (CAFE) programme. European Commission.

WHO. (2018). WHO's COP24 special report - health and climate change. World Health Organization.

World Health Organization. (2011). Health co-benefits of climate change mitigation Transport sector: Health in the green economy. World Health Organization.

Wright, L., \& Fulton, L. (2005). Climate change mitigation and transport in developing nations. Transport Reviews, 25(6), 691-717. 


\title{
SUSTAINABLE PROCUREMENT IN HEALTHCARE
}

\author{
Susan Wilburn, Ishika Jharia and Poornima Prabhakaran
}

\section{Introduction}

Sustainable and climate-friendly healthcare encompasses activities and services across the entire lifecycle of healthcare delivery. This includes the upstream health sector supply chain which represents the largest proportion of a health system's greenhouse gas emissions. Greenhouse gas emissions are divided into scopes 1,2 and 3, as outlined in the chapter titled The Role of Health Systems in the Global and Indian Context. Supply chain emissions mostly fall under scope 3 which include: purchases, products and services (including transportation and the distribution of products), patient transportation and employee commuting and waste management (WRI, 2020). In India, scope 3 emissions represent $81 \%$ of the total health sector emissions (Karliner et al., 2019). India serves as a critical component of the global supply chain as the largest supplier of goods provided to the UN. It is, therefore, important for the Indian health sector to measure, monitor and act to reduce greenhouse gas emissions from throughout the health supply chain.

Sustainable health systems are those that deliver healthcare based on not just the economic sustainability of their own operations but also on the impacts of those services on the environment. Sustainable Procurement stands on the three principles of environmental, social and economic sustainability as described in Goal 12 of the United Nations' Sustainable Development Goals: sustainable production and consumption (UN, 2015). In sustainable procurement, organizations meet their needs for goods and services while generating benefits for the organization, society and the economy while minimising damage to health and the environment. Sustainable procurement looks at how to achieve value on a whole-life basis. This chapter will:

1. Review the greenhouse gas emissions of the health supply chain and provide an overview of the guiding principles for fostering environmental sustainability by promoting sustainable procurement in the healthcare sector. 
2. Describe how the sustainable procurement principles and methods identified will guide contributions by health sector actors to achieving transition to sustainable alternatives for health sector procurement.

3. Provide case studies from India and England as examples of sustainable procurement in the health sector.

\section{The climate footprint of the health sector in India}

The health sector emissions in India are equivalent to the emissions of 10 coal-fired power plants or 5,16,286 tanker trucks worth of gasoline or 8,280,255 passenger vehicles for a year (HCWH and Arup, 2019, p. 26). Taking emissions from various sectors into account, India's healthcare sector's contribution to total carbon emissions is $1.5 \%$ as compared to the global average of $4.4 \%$.

If the global health sector were a country, it would be the fifth-largest greenhouse gas emitter on the planet. More than half of the sector's carbon footprint comes from its supply chain. Fossil fuel consumption is at the heart of healthcare's emissions through its energy consumption across the life cycle of its operations. The lion's share of emissions (71\%) is primarily derived from the healthcare supply chain through the production, transport, packaging, transport and disposal of medical devices, pharmaceuticals and other products. Emissions emanating directly from healthcare facilities and healthcare owned vehicles make up $17 \%$ of the sector's worldwide footprint (HCWH and Arup, 2019, p. 5).

\section{Principles guiding sustainable health systems}

As outlined above, healthcare including hospitals, health systems and the health products' supply chain can paradoxically contribute to emissions from the entire lifecycle of their operations. The sector therefore has a responsibility to adopt sustainable, low-carbon solutions to mitigate and reduce their own climate footprint while incorporating the principles of environmental, economic and social responsibility to forge parallel and related paths towards net zero carbon emissions. The following section outlines some key principles guiding this action:

\section{A. Environmental sustainability}

Key steps towards environmental sustainability can be based on the Greenhouse Gas Protocol and should include:

SCOPE 1 - Taking immediate action to reduce healthcare facility emissions (Box 18.1).

SCOPE 2 - Investing in and advocating for the decarbonisation of local and national energy systems and the implementation of clean, renewable energy. 
SCOPE 3 - Setting and implementing criteria for low-carbon or zeroemissions procurement so as to begin to decarbonise the supply chain.

\section{Box 18.1 Case study}

Potential sustainable options: Health Care Without Harm, a global organization working to help health systems around the world move to sustainable healthcare practices has identified the following five high impact, low carbon interventions for health sector action:

- Transition to renewable forms of energy

- Energy-efficient low hydro-fluorocarbon (HFC) air conditioners and cooling technologies

- Intravenous anaesthetic agents, closed anaesthetic systems, elimination of desflurane and minimisation of nitrous oxide

- Energy-efficient lighting (LEDs) and optimisation of the use of natural light

- Low/zero-emission transportation and fleet vehicles

The adoption of a framework to implement these interventions as short-term goals across health systems will provide a starting point for decarbonising healthcare facilities.

\section{B. Economic principles: the significance of whole life/lifecycle costing in sustainable procurement}

Whole-life costing takes account of the total cost of a product or service over its lifetime, from determining the need for it, through to its eventual disposal and replacement. For example, for equipment, it would include the cost of maintaining and operating the product as well as outright purchase, hire or lease price; the cost of consumables, utilities, training; and the cost of disposal or potential sale value at the end of its life (Figure 18.1).

\section{Social criteria in sustainable procurement}

In addition to principles of environmental sustainability, social criteria must also be addressed for a holistic approach to procurement. Social sustainability consists of stakeholder engagement, community cooperation, a people-centred approach to organizational procurement impacts and inclusive social development in terms of health and safety standards, local production and ethically sourced goods and services. 


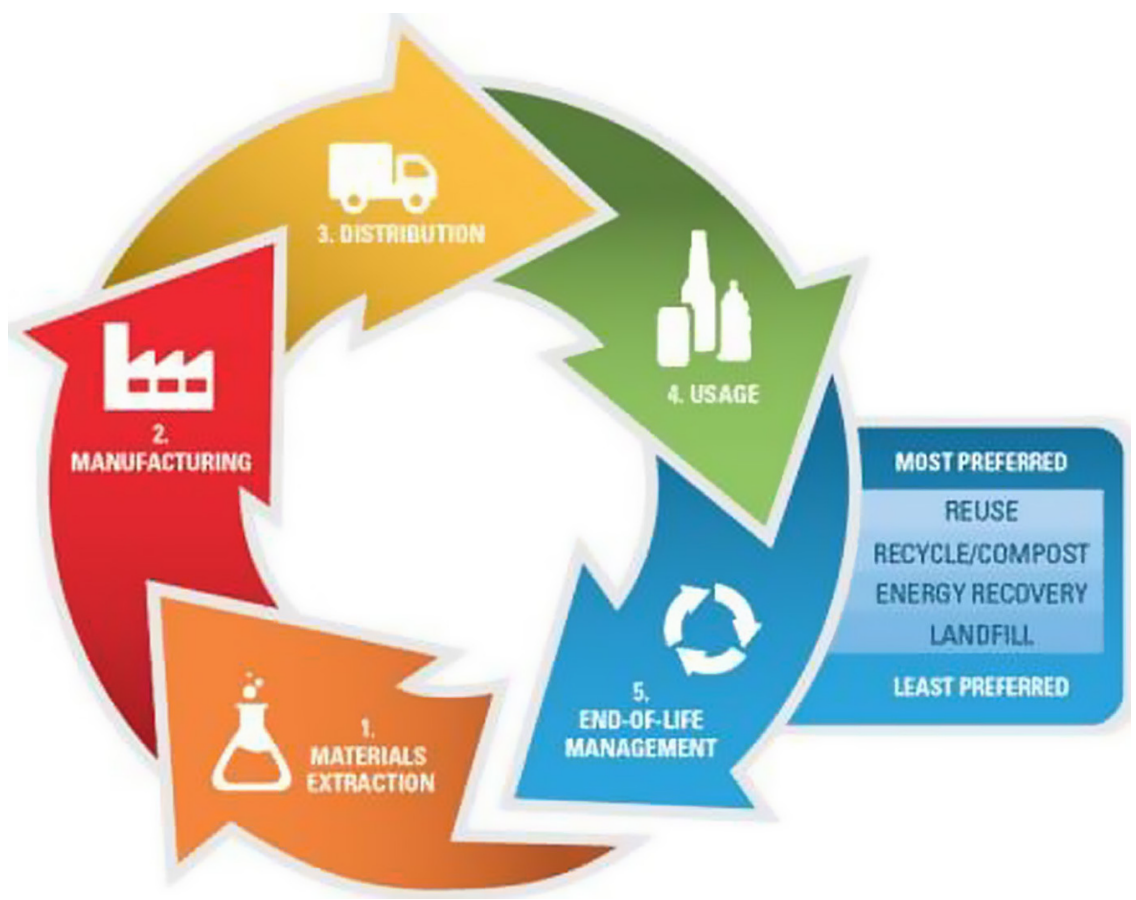

Figure 18.1 Lifecycle of materials and products from material extraction, manufacturing, distribution and use till end-of-life.

Source: USEPA, 2017

\section{Examples of sustainable procurement practices in India}

The application of the above principles of reducing sectoral emissions, lifecycle costing and social principles enables the right sustainable purchasing practices. The incorporation of various criteria in procurement of general goods has been practiced in India in the past. For example, principles of star rating appliances are established by the Bureau of Energy Efficiency (BEE). The procurement of LED bulbs, solar panels and certain star rated appliances is mandated in some government agencies. The Central Public Works Department (CPWD) in its tender conditions state that buildings constructed shall follow the Green Rating for Integrated Habitat Assessment (GRIHA) principles. Many state governments have taken initiatives to install off-grid solar photovoltaic systems in their respective state rural health centres, funded by either a mix of state (usually health department) and central government support, or entirely through the state budget; and in certain cases, through partnership between government ministries and international organizations. For example, the Chhattisgarh State Health Department collaborated with the Chhattisgarh State Renewable Energy 
Development Agency (CREDA) on a programme to provide solar power at all the primary health centres (Ramji et al., 2017).

These principles do ensure environmental sustainability; however, with the above initiatives already in place, there is also the need to bring the focus on procuring sustainable alternatives for goods and consumables in healthcare. Two examples are the procurement of digital thermometers and sphygmomanometers in place of mercury thermometers and sphygmomanometers, and nitrile gloves in place of Polyvinyl Chloride (PVC) gloves. These changes were made in order to replace polluting and potentially toxic materials with sustainable alternatives.

Such transitions to sustainable alternatives can also be practiced in the case of sterilants and disinfectants. The most common high-level disinfectants are glutaraldehyde and formaldehyde, and cold sterilant ethylene oxide. Formaldehyde and glutaraldehyde cause breathing discomfort to the users, and ethylene oxide and formaldehyde are known human carcinogens (IARC data, 2020). Safer alternatives that exist include: peracetic acid, hydrogen peroxide, steam sterilisation, UV radiation, etc. Similarly, a conscious move to better-managed procurement of pharmaceuticals, medical devices, business products and services, food/catering, and other health facility inputs are key to the efficient and sustainable functioning of healthcare facilities.

In order to facilitate a global practice within the Indian healthcare system of sustainable procurement, guidelines to sustainable procurement are being incorporated within national and sub-national programmes including the Indian Public Health Standards (IPHS) and the National Program for Climate Change and Human Health. The current advocacy for developing all levels of Indian healthcare into green and resilient facilities incorporates an entire vertical of sustainable procurement.

The following section provides two case studies where sustainable practices were adopted in healthcare (Boxes 18.2 and 18.3).

\section{Recommendations}

Sustainable procurement of goods and services for healthcare must address the entire lifecycle of healthcare delivery, spanning the manufacture and supply of goods such as pharmaceutical products and medical devices, the actual delivery of healthcare with efficient and sustainable procurement of services for resources like water and energy, and appropriate disposal of used products at the end of life, including waste, packaging materials, food waste, etc. The incorporation of appropriate technical specifications in tender documents for the sustainable procurement of goods is a strategic way to create demand for the production of such goods. Sustainable Procurement in Health Care Guide, a useful resource recently released by Health Care Without Harm, provides a step-by-step guide to sustainable procurement in healthcare (HCWH and GGHH, 2020). 


\section{Box 18.2 Case study}

\section{NHS England procurement for carbon reduction}

The Sustainable Development Unit (SDU) of the National Health Service (NHS) in England has conducted the most extensive analysis of the carbon footprint of their supply chain, identified the hot spots in their supply chain and analysed the interventions that are the most cost-effective in order to reduce carbon and save money.

Figure 18.2 shows the detailed break-down of the products and services that represent the top carbon emissions of the NHS (NHS, 2012). In acute (hospital) care, the top 3 carbon emissions are biomedical instruments/equipment and building energy use (gas and electricity). The procurement of pharmaceutical agents represents the highest emissions from primary care settings in England. The NHS SDU worked with their largest suppliers of pharmaceuticals to develop and build consensus around measuring carbon emissions within the drug supply chain. Within pharmaceuticals, waste anaesthetic gas represented $5 \%$ of the NHS acute care emissions, and metered-dose inhalers for the treatment of asthma represented 3.5\% of the total carbon footprint of the NHS (Public Health England and NHS SDU, 2018). The NHS Procurement for Carbon Reduction (P4CR) programme includes a hierarchy of four interventions to reduce the emission of the health system:

1) Reducing the demand for products and services

2) Reducing the in-use emissions such as reduced energy use and improved energy efficiency (for example, the procurement of LED energy efficient lightbulbs)

3) Innovation and substitution

4) Supply chain management

The NHS has also identified the most cost-effective and cost-saving GHG reduction interventions in a Marginal Abatement Curve (MAC). Changes in the heating and ventilation system to become more efficient, and the substitution of dry powdered inhaler asthma medicine to replace the potent greenhouse gas emissions from metered-dose inhalers, are among the interventions that save money and reduce carbon emissions. 


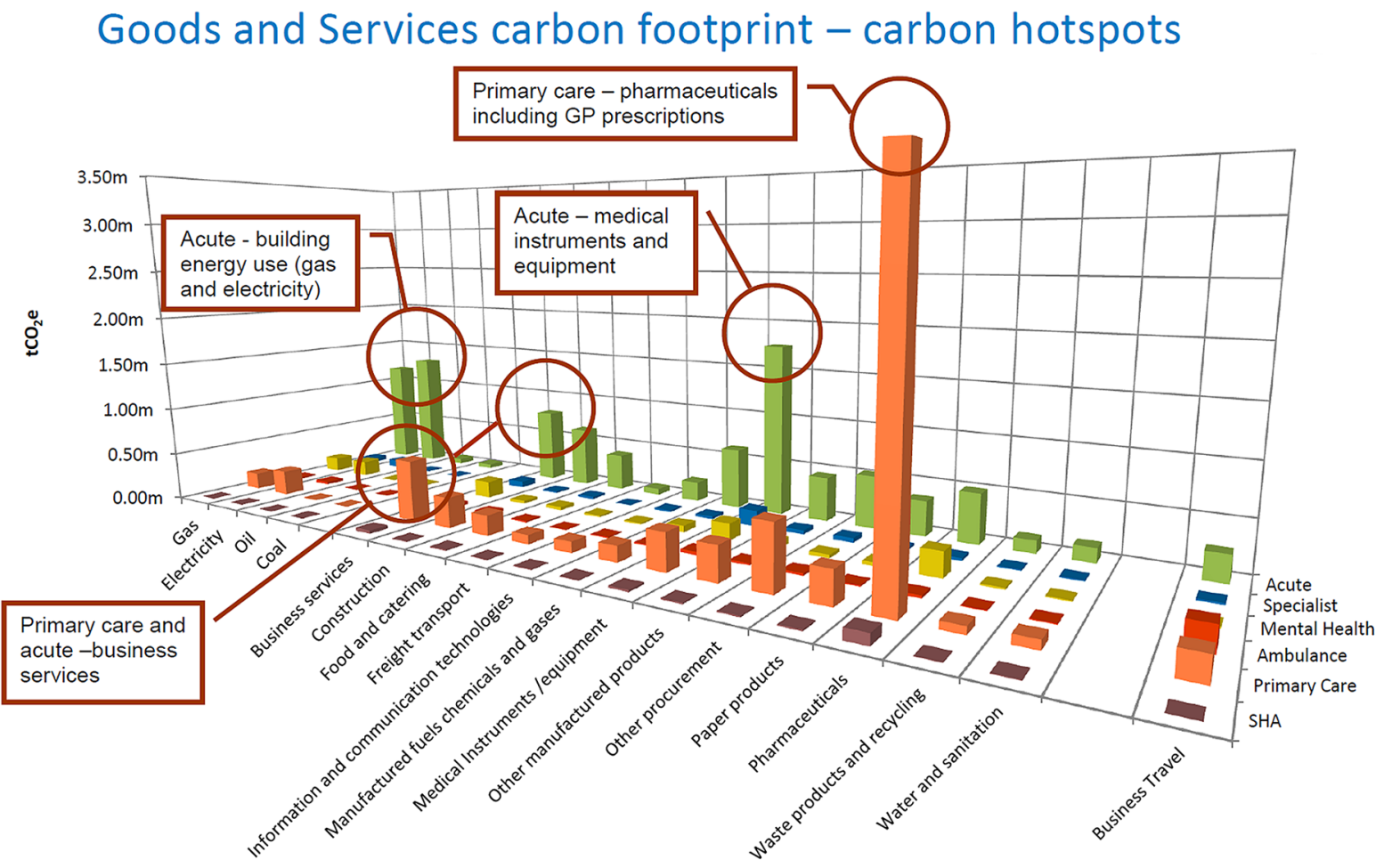

Figure 18.2 NHS and social care England goods and services' carbon footprint - carbon hotspots.

Source: National Health Service, England: Sustainable Development Unit 


\section{Box 18.3 Case study}

\section{A solar energy initiative at Dr. R. N. Cooper Municipal General Hospital, Mumbai}

HBT Medical College and Dr. R. N. Cooper Hospital is a 636-bedded secondary care municipal hospital with all general specialties, located in the western suburbs of Mumbai. Large in size and capacity, the hospital addresses diverse needs that require round-the-clock use. This means inevitable energy use which often results in high and overlooked consumption. Motivated to reduce operating costs and support sustainability goals, the management team at the municipal general hospital decided to install passive solar thermal water heating systems with a capacity of $3000 \mathrm{~L}$ per day (each) on six buildings within the hospital campus.

The total installation cost of the solar thermal water heating systems was $4,230,000$ INR $(\$ 58,570)$. The time for the return on investment of this system was calculated at 19 months. 100L of water per day, heated from this system, saves up to 1500 electricity units annually as per the efficiency capacity installed. Therefore, an 18,000 L per day system saves 27,0000 electricity units per year. The cost of one unit of electricity is $10 \mathrm{INR}$, resulting in a savings of 2,700,000 INR $(\$ 37,500)$ net savings per year. In terms of carbon savings and environmental benefits, an 18,000 L per day system saves 27,000 electricity units per year, which in turn reduces 270 tonnes of $\mathrm{CO} 2$ emission into the atmosphere; whereas to generate 1500 units of electricity per year from a coal-based power plant, 1.5 tonne of $\mathrm{CO}_{2}$ is released into the atmosphere.

Dr. RN Cooper hospital aims for more energy efficiency to follow; however, it is recommended to focus first on efficiency before procuring anything new. There are many easy low and no-cost options to help save on energy expenses and improve energy performance. Simple measures such as switching off all non-essential lights, turning off unused electrical and office equipment, putting x-rays on standby, and using natural ventilation methods for cooling, can have considerable financial, environmental and strategic benefits.

Source: Global Green and Healthy Hospitals, 2018

\section{Key takeaways}

- Health systems that aspire to carbon neutrality must analyse their supply chain, identify carbon hot spots and engage with suppliers to establish targets for the reduction of greenhouse gas emissions throughout 
the life cycle of the products from manufacturing to distribution to end of use/reuse.

- Procurement policies that integrate sustainability criteria for a lowcarbon health supply chain are needed to achieve the goal of climatesmart, resilient health systems.

\section{References}

Global Green and Healthy Hospitals. (2018). A solar energy initiative to reduce cost. https:/www.ceh.org.in/wp-content/uploads/2019/01/GGHH-Case-StudyEnergy_RN-Cooper_AT_SM.pdf.

HCWH and Arup. (2019). Healthcare's climate footprint: How the health sector contributes to the global climate crisis and opportunities for action. HCWH and Arup. https://noharm-global.org/sites/default/files/documents-files/5961/ HealthCaresClimateFootprint_092319.pdf.

HCWH and GGHH. (2020). Sustainable procurement in health care guide. Practice Greenhealth.

International Agency for Research on Cancer (IARC). (2020). Monographs on the identification of carcinogenic hazards to bumans. https://monographs.iarc.fr/ agents-classified-by-the-iarc/ 26 July 2020.

Karliner, J., Slotterback, S., Boyd, R., Ashby, B., \& Steele, K. (2019). Health care's climate footprint: How the health sector contributes to the global climate crisis and opportunities for action. Health Care Without Harm and ARUP.

National Health Service (NHS - England) Sustainable Development Unit (SDU). (2012). Goods and services carbon hotspots. https://www.sduhealth.org.uk/ policy-strategy/reporting/natural-resource-footprint-2018/carbonhotspots.aspx.

Public Health England and NHS SDU. (2018). Natural resource footprint: Reducing the use of natural resources in health and social care. https://www.sduhealth.org. uk/policy-strategy/reporting/naturalresource-footprint-2018.aspx.

Ramji, A., Patnaik, S., Mani, S., \& Dholakia, H. H. (2017). Powering primary healthcare through solar in India: Lessons from Chhattisgarh. Council on Energy, Environment and Water. https://www.ceew.in/publications/powering-primaryhealthcare-through-solar-india

United Nations. (2015). UN sustainable development goals. www.un.org/sustainabledevelopment/sustainable-development-goals/.

USEPA. (2017). Sustainable materials management basics. https://www.epa.gov/ $\mathrm{smm} /$ sustainable-materials-management-basics\#lifecycle.

World Resources Institute. (2020). Greenhouse gas protocol. www.ghgprotocol.org. 
$\Longrightarrow$ Taylor \& Francis

Taylor \& Francis Group

http://taylorandfrancis.com 
Section 4

CLIMATE ACTION BY ALLIED

SECTORS 
$\Longrightarrow$ Taylor \& Francis

Taylor \& Francis Group

http://taylorandfrancis.com 


\title{
ENVIRONMENTAL SUSTAINABILITY IN THE PHARMACEUTICAL INDUSTRY
}

\author{
Suman Sharma and Alba Tiley ${ }^{1}$
}

\section{Introduction}

In the context of climate change as the biggest human health hazard of the twenty-first century (Costello et al., 2009), the pharmaceutical industry needs to ensure that the impact of climate change on health is better understood, and to evaluate its role and responsibilities towards the mitigation of risks associated with climate change. It is important to note that climate change alleviation and public health improvement are mutually reinforcing. This chapter will:

1. Highlight the impact of climate change on the pharmaceutical industry and the role played by the industry in mitigating risks of climate change by adopting responsible measures of production.

2. Use a case study on Centrient Pharmaceuticals to demonstrate the proven benefits of climate-friendly processes on the environment.

3. Explore the connections between irresponsible manufacturing practices and Antimicrobial Resistance (AMR), and the burden on climate change due to AMR.

4. Offer policy recommendations to pave the way for ethical practices aimed at establishing climate resilience.

\section{The effect of climate change on the pharmaceutical industry}

With climate change high on the global agenda, industries across sectors are setting clear environmental sustainability goals and are linking it to a vision for long-term business viability. The pharmaceutical sector has a significant role to play in achieving the Sustainable Development Goal 13 of tackling climate change by reducing greenhouse gas emissions, including reductions in energy use, and overall increased use of renewable energy. A few companies have already pledged to achieve carbon neutrality by investing in renewable energy and through internal energy management programmes. Others in the sector have begun to explore innovative models that qualify 
as climate compliant with an aim to improve water and energy efficiency, reduce waste footprints and limit the lifecycle impacts of products by focusing on materials, packaging and design.

The total global emissions of the pharma sector amounted to about 52 megatons of $\mathrm{CO}_{2}$ in 2015 (Belkhir and Elmeligi, 2019). The pharmaceutical industry's carbon emissions might not match those of heavy manufacturing industries and the energy sector, but various global studies have demonstrated the strong need for the pharma sector to step up and make concerted efforts to reduce carbon emission and to manage effluent discharge systems that pollute water and land resources, causing a huge threat to public health.

The need to reduce emissions and provide long-term reduction by global pharma companies are linked to legally binding international treaties on climate change mitigation such as the 2016 Paris Climate Change agreement. One study deduced that by 2025 , the overall pharma sector would need to reduce its emissions intensity by about 59\% from 2015 levels to adhere to the commitments as per the Paris Agreement (Belkhir, 2019).

For the pharma sector, the impact of climate change is twofold - firstly, responding to the increased risk of emerging diseases and health concerns as a result of environmental damage and secondly, decarbonising its own manufacturing and operational processes to prevent worsening impact.

The global disease burden due to climate change is difficult to determine; consequently, research and development for the pharmaceutical sector remains a challenge. In addition, while changing weather patterns are not expected to lead to occurrences of a new disease, they are very likely to lead to disease proliferation in new geographical areas (Thissen, 2011).

Some pharmaceutical companies have been looking at the issue of climate change and environment impact holistically. One stated goal is water neutrality, which can be attained by assuming a multi-pronged strategy with the aim of reducing freshwater consumption within a manufacturing plant by following the principle of reduce, reuse and recycle; additionally, rainwater is harvested within the plant to counterbalance the outside freshwater use; and the consumption of freshwater is compensated for by investing in watershed projects beyond the boundary for sustainable water management.

\section{The importance of responsible production}

The indispensability of medicines has allowed pharma companies to go unquestioned when it comes to the environmental impact they cause. Although reducing greenhouse gas emissions is an important aspect of responsible production, there are additional aspects that are also equally crucial. Two examples are the emissions of pharmaceuticals substances into the environment and product stewardship.

According to a literature review in Environmental Toxicology and Chemistry, it was found that 631 different pharmaceutical substances have 
been detected in the environment of 71 countries spread over each and every continent (aus der Beek et al., 2016). The review cited the example of the anti-inflammatory drug diclofenac, which has been detected in environmental matrices in 50 countries, and concentrations found in several locations exceeded predicted no-effect concentrations.

Hence, aspects like Extended Producer Responsibility (EPR), also known as Product Stewardship, should be adopted by pharma companies in addition to the quality aspects; sustainability should be woven in at all stages of production, procurement, and consumption (Box 19.1). It should also include the aspects of sustainable packaging and disposal.

\section{Box 19.1 Case study}

\section{Centrient Pharmaceuticals: Developing climate-friendly processes}

Sustainability and climate change is an area where the private sector can develop innovative solutions to global challenges by using their core competencies.

In 2012, Centrient Pharmaceuticals developed an enzymatic process known as PureActives ${ }^{\circledR}$ technology which reduces the number of production process steps - by more than $50 \%$ in some cases - thereby reducing the use of energy, water and raw materials. Traditional betalactam antibiotic manufacturing methods consist of 13 steps, with each step having a considerable impact on the environment.

The enzymatic technology allows the customers to significantly reduce their environmental footprint while also removing the use of aggressive solvents. During the PureActives ${ }^{\circledR}$ process, Centrient uses its own enzymes to alter the molecules and couple the side chain to make 6-APA or 7-ADCA molecules. In contrast with traditional chemical production processes, all of this takes place at ambient temperatures which require less energy, and moreover, it is done without the use of toxic solvents. Therefore, the impact of production on human health, as well as on the broader environment, is substantially lower.

These natural processes adopted by Centrient Pharmaceuticals have proven benefits when it comes to reducing the burden on the environment. The in-house Life Cycle Assessment (LCA) which evaluates environmental impacts throughout the entire life cycle of a product (production, use and discarding phases) demonstrates that the PureActives ${ }^{\circledR}$ technology results in a $63 \%$ reduction in the carbon footprint as compared to the traditional chemical method.

Source: Centrient, 2017 


\section{The linkage between irresponsible manufacturing of pharmaceuticals and antimicrobial resistance (AMR)}

A critical aspect that needs to be called out is the spread of antimicrobial resistance from the untreated effluent of pharma companies. Antimicrobial resistance (AMR) is essentially the ability of a microbe (bacteria, fungi, etc.) to resist the effects of medication that could once successfully treat the disease; AMR arises when bacteria become resistant to the antibiotic due to unnecessary exposure, rendering the antibiotic useless. In such cases, the illness caused by the bacteria becomes difficult or even impossible to treat. Drug resistance has the potential to endanger both developed and developing countries alike (IACG, 2019). Based on broad estimates, in addition to the costs associated with the loss of human lives, AMR has the potential to bring about a loss of $2-3.5 \%$ of global GDP, which could amount to USD 100 trillion by 2050 (Jonas et al., 2017).

AMR is emerging as one of the largest challenges to public health. In fact, in January 2020, the World Health Organization identified AMR as one of the top health priorities for the next decade (WHO, 2020). Lifesaving medical procedures which use antibiotics (such as joint replacement, cancer chemotherapy and organ transplantation) are becoming riskier to perform, and common diseases are turning unresponsive to treatment due to alarming levels of resistance reported in countries of all income levels. AMR-induced drug-resistant diseases claim the lives of over 700,000 people globally each year; without effective action, this number is set to reach 10 million by 2050, with almost a fifth of fatalities occurring in India (Jonas et al., 2017).

Countries such as India and China are at immediate higher risk as $80 \%$ of the antibiotics sold by multinational pharmaceutical companies globally are manufactured in these two countries. A June 2016 on-the-ground study by British investigative media agency Ecostorm and the subsequent analysis of water samples by Dr. Mark Holmes of the University of Cambridge found high levels of drug-resistant bacteria at sites in three Indian cities: Hyderabad, New Delhi and Chennai. In total, out of 34 sites tested, 16 were found to be harbouring bacteria resistant to antibiotics.

Box 19.2 discusses the formation of the AMR Industry Alliance.

\section{Box 19.2 Case study}

\section{AMR Industry Alliance: Industry initiative solving the environmental challenge}

In 2016, the United Nations called for a collaborative initiative from governments and various sectors to tackle the effects of antimicrobial resistance in a comprehensive manner and to implement strategies at the national level. The AMR Industry Alliance is the pharmaceutical 
industry's response to the appeal by the United Nations (Changing Markets and Ecostorm, 2016).

Accordingly, the AMR Industry Alliance's member companies made commitments to decrease the environmental impact resulting from the production of antibiotics. The Alliance aims to help eliminate or substantially reduce antibiotic residues in manufacturing discharges. The focus is particularly on ensuring better management of waste as well ensuring rigorous processes to minimise accidental spills and releases.

In early 2018, the AMR Alliance published the Common Manufacturing Framework which specified a set of minimum environmental expectations for antibiotic manufacturers. It also established science-driven, risk-based quantitative effluent discharge targets which apply to all types of factories that make antibiotics. The Framework is currently being implemented at all member companies across their supply chains (AMRIA, 2018).

This case study emphasises how responsible pharmaceutical/life science companies try to voluntarily opt for greener methods, keeping in mind the environmental aspect.

\section{The linkage between climate change and AMR}

A 2018 study explored the role of climate (temperature) and additional factors on the distribution of antibiotic resistance across the United States. The findings indicated that an increase in temperature of $10^{\circ} \mathrm{C}$ across regions was associated with an increase in antibiotic resistance of $4.2 \%, 2.2 \%$, and 2.7\% for the common pathogens Escherichia coli, Klebsiella pneumonia, and Staphylococcus aureus. The associations between temperature and antibiotic resistance within the ecological study were consistent across most classes of antibiotics and pathogens and may be strengthening over time (MacFadden et al., 2018). These findings suggest that current forecasts of the burden of antibiotic resistance might be significant underestimates within the face of a growing population and global climate change (O'Neill, 2016).

Another study investigated whether the explanatory strength of climate variables holds true in a region with diverse healthcare systems and societies and whether a global climate change dimension is identified, using Europe as a case region. The researchers conducted a 30-country observational study across Europe. The six-year prevalence of carbapenem-resistant Pseudomonas aeruginosa (CRPA), Klebsiella pneumonia (CRKP), multiresistant Escherichia coli (MREC), and Methicillin-resistant Staphylococcus aureus (MRSA) was determined based on data published by the European Centre for Disease Prevention and Control (ECDC). The authors cited that findings reveal a novel association between AMR and climatic factors in Europe. These results reveal two aspects: climatic factors significantly 
contribute to the prediction of AMR in several sorts of healthcare systems and societies, while global climate change might increase AMR transmission and carbapenem resistance (Kaba et al., 2020).

In May 2019, the World Health Organization (WHO) released a draft document on the environmental aspects of good manufacturing practices (GMP) to aid inspectors and manufacturers of antimicrobials in the prevention of antimicrobial resistance (AMR). The draft proposes ways to control and reduce the contamination of the environment with antimicrobials and chemicals from production processes, as part of WHO's response to the growing threat of AMR (WHO, 2019).

Hence, it is imperative for pharma companies to adhere to responsible manufacturing to lower the rate of spread of drug resistance.

\section{Reporting}

As per a study done in 2018 , more than 200 companies represent the global pharmaceutical market, yet only 25 consistently reported their direct and indirect greenhouse gas emissions in the past five years. Of those, only 15 reported their emissions since 2012 (Lotfi and Elmeligi, 2019). This further reiterates that not all pharma firms are transparent about their environmental practices; however, there are at least a few who are setting practical examples for others to follow. The pharma industry needs to follow the example of other industries to become more transparent regarding the protection of the environment.

\section{Recommendations}

Looking at the urgency with which the issue should be tackled, the following initiatives are recommended:

1. Setting science-based targets: To start with, it will be useful to link environmental targets to the Paris Agreement goals. For example, this can be done by aligning with the Science-Based Targets Initiative - a platform that encourages companies to commit to staying within a safe range for carbon emissions. This can be made stronger by encouraging companies to report carbon emissions in a more transparent manner.

2. Allocating responsibility across the value chain: Buyers of pharmaceutical products including government agencies can use their purchasing power to influence the industry by valuing sustainability factors (e.g. climate impact and AMR impact) when making procurement decisions. 
3. Assign Accountability: The prevailing production, distribution and marketing practices of pharmaceutical companies need to be periodically reviewed. Governments may award economic incentives to entities that follow sustainable measures and carry out appropriate waste management, including effluent discharge. In the same vein, existing incentives should be withdrawn from those who are found to be non-compliant.

4. Higher investments: Serious efforts should be made to implement the One Health approach by exploring innovative means and alternatives and increasing funding for promotion, affordable access and research on antimicrobials, diagnostics, vaccines, waste management tools, and safe and effective alternatives to antimicrobials.

5. Greater collaborative efforts: Multisectoral efforts involving civil society groups is essential in order to respond to AMR challenges. Closer engagement with stakeholders such as professional societies (medical and veterinary), NGOs, farmers' associations, research networks and academia, will be helpful in advocacy efforts, generating awareness and ensuring transparency of governance and monitoring.

\section{Key takeaways}

- The pharmaceutical industry must adopt responsible measures of production to mitigate their role in causing climate change.

- Irresponsible manufacturing practices and Antimicrobial Resistance (AMR) have increased the burden of climate change from the pharma industry.

- There is a need for government as well as pharmaceutical companies to understand the interface between people, health, environment, and their own operations.

- The full value chain - from manufacturer and distributor to user - must be involved in order to ensure sustainable buying and procurement

- It is crucial for the pharmaceutical industry to learn from best practices in other industries and work collaboratively with governments and other relevant stakeholders to create a conducive ecosystem that contributes positively to public health.

\section{Note}

1 With thanks to Chase India for research support provided.

\section{References}

AMR Industry Alliance Secretariat. (2018). Making antibiotics responsibly: A common antibiotic manufacturing framework to tackle AMR. AMRIA. https://www. amrindustryalliance.org/wp-content/uploads/2019/11/Making-antibioticsresponsibly_A-common-manufacturing-framework-to-tackle-AMR.pdf 
aus der Beek, T., Weber, F. A., Bergmann, A., Hickmann, S., Ebert, I., Hein, A., \& Küster, A. (2016). Pharmaceuticals in the environment. Global occurrences and perspectives. Environmental Toxicology and Chemistry, 35(4), 823-835. doi: 10.1002/etc.3339

Belkhir, L. (2019, May 28). Big pharma emits more greenhouse gases than the automotive industry. McMaster University. https://brighterworld.mcmaster.ca/articles/ big-pharma-emits-more-greenhouse-gases-than-the-automotive-industry/

Belkhir, L., \& Elmeligi, A. (2019). Carbon footprint of the global pharmaceutical industry and relative impact of its major players. Journal of Cleaner Production, 214. doi: 10.1016/j.jclepro.2018.11.204.

Centrient. (2017). Centrient pharmaceuticals sustainability report 2017. Centrient Pharmaceuticals Global Communications. https://Centrient_SustainabilityReport _2017_web.pdf

Changing Markets and Ecostorm. (2016). Superbugs in the supply chain: How pollution from antibiotics factories in India and China is fueling the global rise of drug-resistant infections. Changing Markets. https:/epha.org/wp-content/ uploads/2016/10/Superbugsinthesupplychain_CMreport.pdf

Costello, A., Abbas, M., Allen, A., Ball, S., Bell, S., Bellamy, R., Friel, S., Groce, N., Johnson, A., Kett, M., Lee, M., Levy, C., Maslin, M., McCoy, D., McGuire, B., Montgomery, H., Napier, D., Pagel, C., Patel, J., de Oliveira, J. A., Redclift, N., Rees, H., Rogger, D., Scott, J., Stephenson, J., Twigg, J., Wolff, J., \& Patterson, C. (2009). Managing the health effects of climate change: Lancet and University College London Institute for Global Health Commission. Lancet, 373(9676), 1693-1733. doi: 10.1016/S0140-6736(09)60935-1. Erratum in: (2009, June 27). Lancet, 373(9682), 2200. PMID: 19447250.

IACG. (2019, April). No time to wait: Securing the future from drug-resistant infections Report to the Secretary-General of the United Nations by the Interagency Coordination Group on Antimicrobial Resistance. https://cdn.who.int/media/ docs/default-source/documents/no-time-to-wait-securing-the-future-from-drugresistant-infections-en.pdf?sfvrsn=5b424d7_6\&download=true

Jonas, O. B., Irwin, A., Berthe, F. C. J., Le, G., Francois, G., \& Marquez, P. V. (2017). Drug-resistant infections: A threat to our economic future (Vol. 2): Final report (English). HNP/Agriculture Global Antimicrobial Resistance Initiative. World Bank Group.http://documents.worldbank.org/curated/en/323311493396993758/ final-report

Kaba, H. E. J., Kuhlmann, E., \& Scheithauer, S. (2020). Thinking outside the box: Association of antimicrobial resistance with climate warming in Europe - A 30 country observational study. International Journal of Hygiene and Environmental Health, 223(1), 151-158. doi: 10.1016/j.ijheh.2019.09.008

MacFadden, D. R., McGough, S. F., Fisman, D., Santillana, M., \& Brownstein, J. S. (2018). Antibiotic resistance increases with local temperature. Nature Climate Change, 8, 510-514. doi: 10.1038/s41558-018-0161-6

O’Neill, J. (2016). Tackling drug-resistant infections globally: Final report and recommendations. HM Government and Wellcome Trust.

Thissen, E. (2011). Climate change and global health: The role for business. Sustainability Issue Brief, 3. 
WHO. (2019). Environmental aspects of good manufacturing practices: Points to consider for manufacturers and inspectors in the prevention of antimicrobial resistance. WHO Draft Working Document QAS/19-802. https://www.who.int/ medicines/areas/quality_safety/quality_assurance/qas19_802_environmental_ aspects_of_GMP.pdf?ua $=1$

WHO. (2020). Antimicrobial resistance. WHO factsheet. https://www.who.int/ news-room/fact-sheets/detail/antimicrobial-resistance 


\title{
20 \\ CHEMICALS AND CLIMATE: CHALLENGES FOR THE HEALTH SECTOR
}

\author{
Tracey Easthope and Megha Rathi
}

\section{Introduction}

All natural and human-made systems are being impacted by the climate crisis. The scale of those impacts will be determined by the extent of the climate disruption, but ample evidence exists that disruptions are significant in nearly every respect, and will accelerate. The health sector is a major contributor to the climate crisis. As noted in the Introduction to this book, the healthcare sector's climate footprint is equivalent to $4.4 \%$ of global net emissions (HCWH, 2019). Seventy-one per cent of the healthcare sector's greenhouse gas emissions are the result of the healthcare supply chain (HCWH, 2019).

Chemicals are the fundamental building blocks of products and materials used in healthcare. The widespread manufacture, use and disposal of hazardous chemicals has created a second crisis that poses a global threat to human rights (UN, 2019), contaminates air, water and soil, poisons food chains and people, and threatens human and ecosystem health. For example, three million people are hospitalised with acute pesticide poisoning each year. The health sector contributes to this crisis, which takes a toll not only on the environment and communities, but also on healthcare workers. According to the US Center for Disease Control and Prevention, healthcare workers have the highest prevalence of asthma of all professions - higher than workers in manufacturing, agriculture and mining (Mazurek \& Syamlal, 2018).

Chemical contamination can act in concert with climate change to exacerbate and accelerate ecosystem and human health impacts that threaten the basis of all life. Healthcare is also at the centre of the humanitarian response to many challenges as the climate and chemical crises accelerate. The health sector will be required to do more under difficult circumstances, as public health is increasingly threatened by extreme weather, population dislocation and pandemics (Box 20.1). This chapter will help readers to:

1. Recognise the breadth and severity of human and ecosystem threats from the interconnected crises of chemical pollution and climate change. 


\section{Box 20.1 Case study}

\section{Coronavirus, chemicals and climate}

The coronavirus pandemic highlighted the interconnected crises of climate and hazardous chemicals in healthcare. The frequency of pandemics is expected to increase as changes in climate collide with changes in people's settlement patterns. Areas with high rates of particulate air pollution have been shown to have higher death rates from COVID-19 (Wu et al., 2020). Healthcare organizations are at the centre of the response to pandemics, being required to serve all who are sick, while protecting healthcare workers. With a novel infectious agent, personal protective equipment and disinfection chemicals were reportedly used in enormous quantities in an attempt to provide safe care. The increased volume of disinfectants resulted in a significant increase in calls to poison control centres (Chang et al., 2020). Impacts include risks to wildlife (Nabi et al., 2020), during both manufacture and disposal. In addition, every month, the world used 89 million medical masks, 76 million gloves and 1.6 million goggles (WHO, 2020a). This level of production means an increased volume of chemicals used in production.

The COVID-19 pandemic led to an "abrupt collapse of waste management chains... Wuhan, the COVID-19 epicentre of China, experienced a massive increase of medical waste from between 40 and 50 tons/day before the outbreak to about 247 tons on 1 March.... With fewer options available, traditional waste management practices such as landfills and incineration are replacing more sustainable measures such as recycling, with adverse effects on the environment" (Siming et al., 2020). Cities across the world experienced similar challenges, including those in India. The increased incineration of PPE releases chemicals and particulate air pollutants that both exacerbate climate change and threaten public health including impairing lung capacity. Methane gas and $\mathrm{CO}_{2}$ are generated by waste decomposition in landfills, contributing to climate impacts.

2. Realise the unique challenges faced by the health sector when confronting the climate and chemical crises.

3. Understand how the manufacture, use and disposal of the large volume of chemicals and materials used in healthcare can impact both the climate and human health.

4. Identify the products used in healthcare that have a significant impact on the climate.

5. Learn about solutions that reduce the need for health services, the use of chemicals of concern and the release of GHGs. 


\section{The chemical industry in the healthcare supply chain}

Seventy one per cent of the healthcare sector's greenhouse gas emissions are the result of the healthcare supply chain including the production, transport and disposal of goods and services, such as pharmaceuticals, cleaners and disinfectants, disposables and plastics, food and agricultural products, packaging, medical devices, hospital equipment and instruments (HCWH and Arup, 2019). Manufacturing all of these products also results in the release of chemicals of concern.

The size of the global chemical industry was $\$ 5$ trillion in 2017 and is projected to double by 2030 , and approximately 62 per cent of the 345 million tons of chemicals consumed in the EU in 2016 were hazardous to health (UNEP, 2019). $35 \%$ of the volume of chemicals used in the EU are reported to be toxic to ecosystems, according to the report. This chemical pollution threatens the critical systems that contribute to ecosystem stability and support ecosystem services including biodiversity. In addition, the WHO estimated the global burden of disease from selected chemicals to be 1.6 million lives in 2016. This is likely to be an underestimate (UNEP, 2019).

The global healthcare market is expected to grow at a compound annual growth rate of $8.9 \%$ to nearly $\$ 11,908.9$ billion by 2022 (BusinessWire, 2019), increasing the chemical and climate footprint of the sector. In addition, climate change is adding to the conditions that make health-related social conditions worse, increasing the demands on, and threatening the stability of, the health sector. Those increased demands for services in turn increase the chemical and GHG footprint of the sector.

In the last several decades, the health sector's reliance on single-use plastics has increased dramatically resulting in significant climate and chemical impacts. $25 \%$ of the waste generated by a hospital is plastic. A single surgery can produce up to 20 pounds of waste, most of which is plastic. Polymers and plastics, especially polyethylene, polypropylene, polyvinyl chloride, polyethylene terephthalate, polystyrene and polycarbonate comprise about $80 \%$ of the industry's output worldwide. Building materials and packaging make up a significant percentage of this output. Plastics manufacturing and its associated energy consumption account for $7-8 \%$ of total oil and gas consumption globally. In 2019 alone, the production and incineration of all plastic added more than 850 million metric tons of greenhouse gases to the atmosphere-equal to the pollution from 189 new 500-megawatt coal-fired power plants, according to a report (CIEL, 2019). Half of all plastics ever manufactured have been made in the last 15 years, overwhelming the world's ability to manage them. Possibly the largest contributor of any material to the toxic chemical economy, five of the most commonly used polymers use chemicals of high concern at every step of manufacturing. Most plastic also contains toxic chemicals, which can be released to the environment as they degrade (CPA 2014). Workers are 
particularly vulnerable to toxic exposures during plastic manufacturing. Plastics, particularly PVC, can also leach toxic chemicals like plasticisers into vulnerable patients, which can threaten health (Schettler, 2020). The subject of plastics in healthcare is dealt with in greater detail in the chapter titled The Paradox of Plastics in Healthcare and Health.

Pharmaceuticals make up a significant fraction of products manufactured by the chemical sector, and pharmaceuticals generate a high percentage of waste per product. In 2019, patients received an estimated 1.8 trillion days of therapy, an average of 234 per person globally. By 2024, the global pharmaceuticals market should reach USD 1,550 billion and grow at a pace of $4.4 \%$ per year, $1.8 \%$ above the forecast worldwide economic growth. The U.K's National Health Service found that medical equipment and pharmaceuticals alone generated 30\% of their system's GHG emissions (NHS 2020).

Pharmaceuticals are also biologically active and can threaten health during manufacture, use and disposal. More than six hundred pharmaceuticals or their transformation products including antibiotics, analgesics, lipid-lowering drugs and oestrogens have been detected in the environment of 71 countries, threatening aquatic life, contributing to antimicrobial resistance and threatening human health (aus der Beek et al., 2016). The Swedish Government has classified pharmaceuticals based on their environmental impact.

Many healthcare institutions have large foodservice operations. Agriculture contributes an estimated $21-37 \%$ of total net anthropogenic GHG emissions mainly due to the use of chemical fertilisers, pesticides and animal wastes (IPCC, 2019). This will increase with food demand. Agriculture is also contributing to the chemical contamination crisis. A 2020 study estimated that 385 million cases of unintentional, acute pesticide poisoning occur annually world-wide including around 11,000 fatalities (BMC, 2020).

All of the disposable plastics, PPE, IV bags, gloves and other materials generated by the healthcare sector must go somewhere. The disposal of healthcare waste contributes significantly to the climate and chemical crises. High levels of methane gas and $\mathrm{CO}_{2}$ are generated by waste decomposition typical of landfills. Leachate from landfills contaminates water sources. As noted above, the incineration of plastic will add significantly to GHG emissions.

The vast scale of the chemical and climate crises require solutions on the same scale. These solutions should increase resilience and promote health for all, and address the disproportionate public health and safety risks to vulnerable populations. Solutions must address the following:

\section{Focus on prevention}

A health promotion model that addresses the social determinants of health such as economic and housing security, and access to food, safe water and other basic necessities, and that emphasises public health interventions is the most important way to reduce healthcare demand. Preventive approaches that address population health such as vaccination and screening are 
cost-effective and can help build resilience and promote healthy behaviours (WHO, 2014). They can also contribute to wider sustainability, with economic, social and environmental benefits.

\section{Eliminate unnecessary care}

Eliminating unnecessary care and avoiding the use of products where they are not needed is an effective way to reduce the release of GHGs and chemicals of concern. Evidence of widespread overuse is accumulating from many countries including low- and middle-income countries (LMICs), although the problem predominates in high-income countries (Brownlee et al., 2017). Overuse can coexist with unmet health needs. Avoiding re-hospitalisation by adhering to strict infection control is also critical to reducing the need for care, and consequently, the release of GHG's and chemicals of concern (WHO, 2016).

\section{Detoxify and decarbonise the supply chain}

A comprehensive global framework is needed, with ambitious goals and indicators to address the chemical sector. The energy intensity of the chemical sector could be reduced by up to $25 \%$ compared to the current level through wide-scale upgrading, replacement and deployment of best available technologies, particularly in countries and industries where this has not yet happened. The sector could also dramatically reduce the toxicity of its output by a major investment in green chemistry innovations. Demand from the healthcare sector must help drive this change. Healthcare can take steps to detoxify and decarbonise its supply chain (HCWH, 2019) by: ending the purchase and use of single-use, disposable plastic where possible; fostering the transition to zero-waste healthcare; requiring extended producer responsibility as a critical component of circular economies; adopting and enforcing targets to eliminate chemicals of concern in products where possible; reducing pharmaceutical waste through regulations; instituting take-back programmes; adopting and enforcing ambitious targets to reduce GHGs emissions from all supply chain sectors; driving innovation in biobased feedstocks and advances in green chemistry, among other solutions. Several papers have detailed these opportunities including a report from Health Care Without Harm: Health Care's Climate Footprint: How the health sector contributes to the global climate crisis and opportunities for action (HCWH, 2019).

\section{Integrate product design, recycling and waste management}

Products must be designed with life cycle management in mind in order to address the full range of chemical and climate threats. Designing products for end-of-life reusability and recyclability, reduction of GHG's and 
elimination of waste is critical. Designing products without hazardous chemicals will also facilitate reuse and recycling in a circular economy.

The sector already has years of experience in evaluating and making purchasing decisions based on the toxicity of products and services throughout their life cycle. Critical work is still needed to understand the energy intensity of products, and to make the chemical and climate impacts of products more transparent in order to allow demand to drive change through the supply chain. It is essential to expand advocacy to accelerate this work and to drive markets toward less toxic, less climate threatening and less wasteproducing products. The UNDP- HCWH Sustainable Health in Procurement project offers a model of detoxifying and decarbonising the supply chain.

\section{The impact of chemicals on climate change}

Some products used in healthcare can have direct climate impacts. These agents have high global warming potential (GWP). They include the use of climate-altering chemicals like anaesthetic gases, air conditioning and cooling agents and fumigants.

Anaesthesia gases are potent greenhouse gases. Commonly used anaesthetics include nitrous oxide and the fluorinated gases sevoflurane, isoflurane and desflurane. At present, the majority of these gases are not captured, and enter the atmosphere. Research by the National Health Service (NHS) Sustainable Development Unit indicates that the United Kingdom's anaesthetic gas footprint is $1.7 \%$ of the total and the majority can be attributed to nitrous oxide use (CSH, 2019). Medical nitrous oxide use for UNFCCC Annex 1 nations contributed an additional $0.4 \%$ to the global healthcare footprint, and an additional $2.5 \%$ to the global Scope 1 footprint $\mathrm{HCWH}$, 2019). Together, UNFCCC nations accounted for $57 \%$ of the global GDP, and $73 \%$ of global health expenditure in 2014 , so the full impact of nitrous oxide use in anaesthesia can be expected to be substantially greater than the figures for Annex 1 nations alone (HCWH, 2019). For fluorinated gases used in anaesthesia, global emissions to the atmosphere in 2014 were estimated to be an additional $0.2 \%$ of the global healthcare footprint $(\mathrm{HCWH}$, 2019). Due to increasing uptake of fluorinated gases, increasingly preferred to nitrous oxide, the footprint from anaesthetic gases can be expected to increase. Anaesthetic gases currently contribute at least $0.6 \%$ of healthcare's global climate impact (HCWH, 2019). Wider adoption of waste anaesthetic capture systems has the potential to be a high impact healthcarespecific climate mitigation measure (Box 20.2).

Air conditioning and cooling agents have a direct impact on the climate. There have been various multilateral environmental agreements such as the Montreal Protocol and Kigali Amendment that are adapting better standards and safer chemicals to minimise these impacts within the health sector. WHO's Project Optimize introduced solar direct drive refrigerators for the vaccine supply chain, and introduced the requirement of procuring 


\section{Box 20.2 Case study}

\section{Nitrous oxide}

For many individual health facilities and systems, the proportion of the contribution of both nitrous oxide and fluorinated anaesthetic gases to their climate footprint can be very high. For instance, Albert Einstein Hospital in Sao Paulo, Brazil found that GHG emissions from nitrous oxide contributed $75 \%$ of their Scope 1 GHG emissions and nearly $35 \%$ of their total reported GHG emissions in 2013. Meanwhile, a study of operating theatres in three health systems in the United States, United Kingdom and Canada found that preferential use of desflurane resulted in a ten-fold higher quantity of anaesthetic-related GHG emissions across hospitals in the study (Bouley et al., 2017).

chlorofluorocarbon (CFC) free refrigerators within the pre-qualification standard for refrigerators procured by the WHO (2013).

Fumigants are among the most hazardous and greenhouse gas-producing pesticides. Fumigant use has been shown to contribute to nitrous oxide, a greenhouse gas 300 times more potent than carbon dioxide.

Sustainable procurement criteria to avoid these products is the most important intervention to reduce Scope 1 emissions from the sector.

\section{The interlinkages between chemicals and climate change}

Global climate change is already directly responsible for 150,000 deaths annually (WHO, 2020b). From 2030 to 2050 it is expected to cause 250,000 additional deaths per year, from malnutrition, malaria, diarrhoea and heat stress. Toxic pollution is already conservatively estimated to be the single largest source of premature death in the world (UN, 2019). The interaction of these two crises will multiply the risks to humans and ecosystems.

1. Extreme weather events associated with climate change will increase exposure to toxic chemicals

Drought can threaten water quality because of toxic chemical loading in the environment. Regions subject to decreases in precipitation may experience enhanced volatilisation of POPs and pesticides to the atmosphere (Noyes et al., 2009). Regions subject to increased precipitation will experience enhanced surface deposition of airborne POPs and increased run-off of pesticides and other contaminants to water sources. Hurricanes and extreme rainfall often result in flooding and costly damage to facilities or homes that store, make or use toxic chemicals (Reible et al., 2006). Healthcare can become a source of chemical 
contamination because of the volatile and toxic substances on site. All of these releases can further threaten health and lead to greater demands on the healthcare system.

2. Warmer temperatures will worsen air pollution

Reduced precipitation will increase air pollution in urbanised regions. 4.2 million premature deaths annually are already due to the effects of outdoor air pollution (WHO Factsheet n.d.). Stagnation events when warm air traps pollution in the lower atmosphere are becoming more prevalent leading to increased ground-level ozone formation. Ozone is particularly dangerous for children, the elderly, people with cardiovascular or lung diseases and for those who work outside. Low levels of ozone exposure can be hazardous for anyone spending time outdoors. Air pollution can lead to more hospital and emergency room visits and long-term health risks. Climate change may also increase particulate pollution, which can travel deep into the lungs and cause or aggravate heart and lung diseases (Hong et al., 2019). Healthcare contributes to air pollution both directly through energy consumption and indirectly through the supply chain.

3. Climate change will likely increase the vulnerability of biological systems to the effects of chemicals

Scientists expect warmer weather to increase the amount of chemicals that organisms take in, store, break down and eliminate. Warmer temperatures weaken the ability of humans and animals to cope with chemical toxicity (Noyes et al., 2009). Suppressed immune systems as a result of chemical exposures are less capable of withstanding climate change threats (Erickson, 2019). Climate change can also make organisms more sensitive to chemical stressors (Hooper et al., 2013).

These are just a few examples that underline an urgent need to reduce the volume and toxicity of chemicals used in order to reduce the threats posed by the converging threats of climate and chemical contamination.

\section{Key takeaways}

- The health sector is a major contributor to both the crises of climate change and widespread chemical contamination, and is at the centre of our humanitarian response to these crises.

- The breadth and severity of human and ecosystem threats from the interlocking crises of chemical pollution and climate change cannot be overstated.

- These threats are in large part the result of the healthcare supply chain including the manufacture, use and disposal of chemicals and materials used in the sector, and the energy required to produce them.

- The healthcare sector is uniquely vulnerable to climate and chemical challenges, and that vulnerability can threaten the stability of the sector. 
- Healthcare must urgently redesign, decarbonise and detoxify the supply chain.

- Healthcare must support broader systemic changes that address prevention in order to reduce demand for healthcare services.

- There are solutions that can be implemented now to help reduce the sector's carbon footprint and dramatically reduce the toxicity and volume of chemicals and materials used in healthcare.

\section{References}

aus der Beek, T., Weber, F., Bergmann, A., Grüttner, G., \& Carius, A. (2016). Pharmaceuticals in the environment: Global occurrence and potential cooperative action under the Strategic Approach to International Chemicals Management (SAICM). Umweltbundesamt.

BMC. (2020). The global distribution of acute unintentional pesticide poisoning: Estimations based on a systematic review. https://bmcpublichealth.biomedcentral.com/articles/10.1186/s12889-020-09939-0.

Bouley, T., Roschnik, S., Karliner, J., Wilburn, S., Slotterback, S., Guenther, R., Orris, P. Kasper, T., Platzer, B. L., \& Torgeson, K. (2017). Climate-smart healthcare: Lowcarbon and resilience strategies for the health sector (English). Investing in climate change and health series. World Bank Group. https://documents.worldbank. org/en/publication/documents-reports/documentdetail/322251495434571418/ climate-smart-healthcare-low-carbon-and-resilience-strategies-for-the-health-sector Brownlee, S., Chalkidou, K., Doust, J., Elshaug, A. G., Glasziou, P., Heath, I., Nagpal, S., Saini, V., Srivastava, D., Chalmers, K., \& Korenstein, D. (2017). Evidence for overuse of medical services around the world. The Lancet, 390(10090), 156-168. doi: 10.1016/S0140-6736(16)32585-5

BusinessWire. (2019). The \$11.9 trillion global healthcare market: Key opportunities o strategies (2014-2022). https://www.businesswire.com/news/home/ 20190625005862/en/The-11.9-Trillion-Global-Healthcare-Market-KeyOpportunities-Strategies-2014-2022---ResearchAndMarkets.com

Center for International Environmental Law. (2019). Plastic and climate: The hidden costs of a plastic planet. CIEL. www.ciel.org/plasticandclimate

Chang, A., Schnall, A. H., Law, R. et al., (2020). Cleaning and disinfectant chemical exposures and temporal associations with COVID-19 - National Poison Data System, United States. January 1, 2020 -March 31, 2020. Morbidity and Mortality Weekly Report. 69, 496 -498. doi: 10.15585/mmwr.mm6916e1

CSH. 2019. Anaesthetics. Centre for Sustainable Healthcare. https://sustainablehealthcare.org.uk/what-we-do/sustainable-specialties/anaesthetics

Erickson, B. E. (2019). Linking pollution and infectious disease: Chemicals and pathogens interact to weaken the immune system, reduce vaccine efficacy, and increase pathogen virulence. Chemical and Engineering News, March 18, appeared in 97(11). https://cen.acs.org/environment/persistent-pollutants/Linkingpollution-infectious-disease/97/i11

Health Care Without Harm. (2019). Health care's climate footprint: How the health sector contributes to the global climate crisis and opportunities for action. HWCH. https://noharm-global.org/sites/default/files/documents-files/5961/ HealthCaresClimateFootprint_092319.pdf 
Hong, C., Zhang, Q., Zhang, Y., Davis, S. J., Tong, D., Zheng, Y., Liu, Z., Guan, D., He, K., \& Schellnhuber, H. J. (2019). Impacts of climate change on future air quality and human health in China. Proceedings of the National Academy of Sciences,116(35), 17193-17200. doi:10.1073/pnas.1812881116.

Hooper, M. J., Ankley, G. T., Cristol, D. A., Maryoung, L. A., Noyes, P. D., \& Pinkerton, K. E. (2013). Interactions between chemical and climate stressors: A role for mechanistic toxicology in assessing climate change risks. Environmental Toxicology and Chemistry, 32(1), 32-48. https://doi.org/10.1002/etc.2043

IPCC. (2019. Land: An IPCC Special Report on climate change, desertification, land degradation, sustainable land management, food security, and greenhouse gas fluxes in terrestrial ecosystem. IPCC.

Mazurek, J. M., \& Syamlal, G. (2018). Prevalence of asthma, Asthma attacks, and emergency department visits for asthma among working adults - National Health Interview Survey, 2011-2016. Morbidity and Mortality Weekly Report, 67, 377-386. doi: 10.15585/mmwr.mm6713a1

Nabi, G., Wang, Y., Hao, Y., Khan, S., Wu, Y., \& Li, D. (2020). Massive use of disinfectants against COVID-19 poses potential risks to urban wildlife. Environmental Research, 188, 109916. doi: 10.1016/j.envres.2020.109916

NHS. (2020). Delivering a net zero national health service. https://www.england. nhs.uk/greenernhs/wp-content/uploads/sites/51/2020/10/delivering-a-net-zeronational-health-service.pdf

Noyes, P., McElwee, M., Miller, H. K., Clark, B. W., Van T., Lindsey, A., Walcott, K. C., Erwin, K. N., \& Levin, E. D. (2009). The toxicology of climate change: Environmental contaminants in a warming world. Environment International, 35(6), 971-986. https://www.sciencedirect.com/science/article/ pii/S0160412009000543

Reible, D. D., Haas, C. N., Pardue, J. H., \& Walsh, W. J. (2006). Toxic and contaminant concerns generated by Hurricane Katrina. National Academy of Engineering, 36, (1), The Aftermath of Katrina, March 1, 2006. https://www.nae.edu/7623/Toxi candContaminantConcernsGeneratedbyHurricaneKatrina\#: : text= When $\% 20$ Hurricane $\% 20$ Katrina $\% 20$ flooded $\% 20$ the,in $\% 20$ its $\% 20$ wake $\% 20$ was $\% 20$ contamination. \& text $=$ Adding $\% 20$ to $\% 20$ the $\% 20$ potential $\% 20$ sources,creosote $\% 2 \mathrm{C} \% 20$ pentachlorophenol $\% 2 \mathrm{C} \% 20$ and $\% 20$ arsenic.

Rossi, M., \& Blake, A. (2014). Plastics scorecard: Evaluating the chemical footprint of plastics. Clean Production Action. https://www.bizngo.org/images/ee_images/ uploads/resources/plastics_scorecard_2015_2_25e.pdf

Schettler, T. (2020). Polyvinyl chloride in health care: A rationale for choosing alternatives. Health Care Without Harm. https://noharmuscanada.org/sites/default/ files/documents-files/6222/Polyvinyl $\% 20$ chloride $\% 20$ in $\% 20$ health $\% 20$ care $\% 20$ - \%20A\%20rationale \%20for \% 20choosing \%20alternatives \% 20-\%201-31-2020.pdf

Siming, Y., Christian, S., \& Yong, S. O. (2020). COVID-19's unsustainable waste management. Science, 368(6498), 1438. doi: 10.1126/science.abc7778. https:// science.sciencemag.org/content/368/6498/1438.1

United Nations Environment Programme. (2019). Global chemicals outlook II: From legacies to innovative solutions, implementing the 2030 Agenda for sustainable development. UNEP. https://wedocs.unep.org/bitstream/handle/20.500.11822/28187/ GCO-II_Intro.pdf?sequence=1\&isAllowed=y 
United Nations Human Rights Office of the High Commissioner. (2019, October 24). Toxic pollution: Another extinction crisis looms, warns UN expert [press release]. https://www.ohchr.org/EN/NewsEvents/Pages/DisplayNews.aspx?News $\mathrm{ID}=25201 \&$ LangID $=\mathrm{E}$

WHO Factsheet. Air pollution. https://www.who.int/health-topics/air-pollution\# tab=tab_2

World Health Organization. (2013). Stimulating innovation in the vaccine cold chain equipment industry. WHO and PATH. https:/www.who.int/immunization/ programmes_systems/supply_chain/optimize/TS_opt_stim_innovation_overview. pdf?ua=1)

World Health Organization. (2014). The Case for Investing in Public Health: The strengthening public health services and capacity. A public health summary report for EPHO 8. WHO. https://www.euro.who.int/_data/assets/pdf_file/0009/ 278073/Case-Investing-Public-Health.pdf

World Health Organization. (2016). Health care without avoidable infections: The critical role of infection prevention and control. Infection Prevention and Control Global Unit Service Delivery and Safety. https://apps.who.int/iris/bitstream/handle/10665/246235/WHO-HIS-SDS-2016.10-eng.pdf;jsessionid=73F5807D1FC2 9A2309ADF77F4F12F327? sequence $=1$

World Health Organization. (2020a, March). Shortage of personal protective equipment endangering healthcare workers worldwide. WHO News Release. https:/www.who.int/news/item/03-03-2020-shortage-of-personal-protectiveequipment-endangering-health-workers-worldwide

World Health Organization. (2020b, August). Climate change. The Health and Environment Linkages Program. https://www.who.int/heli/risks/climate/climatechange/en/

Wu, X., Nethery, R. C., Sabath, B. M., Braun, D., \& Dominici, F. (2020). Exposure to air pollution and COVID-19 mortality in the United States. medRxiv April 05 20054502. doi: 10.1101/2020.04.05.20054502 


\title{
THE PARADOX OF PLASTICS IN HEALTHCARE AND HEALTH
}

\author{
Swaminathan Sivaram, Aditi Roy and Swapan K. Ray
}

\section{Introduction}

Plastics have emerged as one of the miracles of man-made materials, growing exponentially over the last seventy years. Plastics are high molecular mass polymers comprising mostly of carbon, hydrogen, nitrogen and oxygen, and often incorporate other lower molecular mass substances as additives to improve their functional properties. The use of plastics has brought deep-seated changes into the field of medicine by making healthcare safer and simpler, and are used in every phase of human healthcare: preventive, diagnostic, therapeutic, prosthetic and palliative (Maitz, 2015). Yet, paradoxically, the same material has been at the receiving end of civil society's wrath for contributing to environmental as well as public health hazards. This chapter will:

1. Examine the science-based evidence on the paradox of plastics.

2. Seek out solutions to exploit the beneficial use of plastics in healthcare while minimising their adverse impact on health and the environment.

3. Lay out the challenges in finding these solutions, including safe end-oflife solutions for plastics used in healthcare, safety of chemicals used and sustainable alternatives for plastic products in healthcare.

4. Re-examine the legacy application of plastics in healthcare and explore how to create new solutions which can resolve the paradox of plastics effectively.

\section{An introduction to plastics}

Plastics are a class of organic materials, synthetic or semi-synthetic, malleable in nature and can be shaped into objects by the application of heat and pressure. They are primarily comprised of polymers which are longchain organic molecules with high molecular mass (macromolecules) built from smaller repeating units called monomers. Monomers are commonly derived from petrochemicals. The organised plastic manufacturing industry began in 1950 and grew rapidly, fuelled by increasing consumer acceptance. 
The global manufacturing capacity for plastics is about 360 million tons today, exceeding that of steel by volume. Plastics are pervasive in our everyday life in a wide range of applications to such an extent that life on earth today cannot be imagined without the use of plastics.

Most plastics are durable and degrade very slowly, as their chemical structure renders them resistant to many natural processes of degradation. By one estimate, the cumulative human production of plastics is 8.3 billion tons, of which 6.3 billion tons have ended up as waste. It is estimated that $50-80 \%$ of debris in marine environments are of plastic origin (Geyer, Jambeck and Law, 2017).

Plastics have a potential effect on greenhouse gas emissions, climate change and health (Azoulay et al., 2019; Kumar, 2018). The production, management and incineration of plastics added 860 million tons of $\mathrm{CO}_{2}$ (or equivalent greenhouse gases) to the atmosphere in 2019, equal to the emissions from almost 200 typical coal-fired power stations. For comparison, global $\mathrm{CO}_{2}$ emissions exceeded 36 billion tons in 2019. The carbon footprint of plastics is expected to triple in size by 2050 . Plastics are generally made from petroleum and natural gas, which are non-renewable fossil fuels. However, it must be noted that the manufacturing of plastics leaves a relatively smaller carbon footprint as compared to other industrial sectors, such as the generation of power from coal or natural gas, manufacture of glass, steel, paper, aluminium or cement. Additionally, plastics are far lighter in weight and hence more efficient to transport in terms of fuel consumed. These two benefits taken together results in a lower carbon footprint for plastics when compared to equivalent products made from glass, paper or aluminium during the life-cycle of their application (Amienyo et al., 2013; Brandt and Pilz, 2011).

\section{The role of plastics in healthcare}

\section{Materials, applications and desirable functional properties}

Plastics bring many benefits to medicine and public health because they are low-cost, efficient, unbreakable, easy to transport, can be sterilised, and can be processed into intricate shapes and forms. A representative list of plastics used in medical applications is shown in Table 21.1. Irrespective of the chemical composition of the plastic, there are a few properties that are critical to medical applications, these being (a) mechanical strength (b) flexibility and softness (c) chemical inertness (d) moisture barrier (e) transparency (f) weathering resistance (g) ability to use accepted sterilisation techniques without loss of physical properties and (h) ability to process the plastics into intricate shapes. For polymers that come into contact with body parts and fluids, there are additional functionalities such as (a) biocompatibility (no adverse reactions to body tissues) (b) non-cytotoxicity (is not carcinogenic), and (c) antithrombogenicity (incapable of clotting blood) if the 
material is likely to come into contact with blood and (d) non-allergenic, if skin contact is required.

\section{Common additives used in plastics for healthcare}

Plastics products used in healthcare invariably require the use of additives to enhance their useful functional properties. Examples are the use of plasticisers to render polyvinyl chloride (PVC) soft and flexible, the use of antioxidants and anti-UV additives to make polyethylene $(\mathrm{PE})$ and polypropylene (PP) able to withstand oxidative and light-induced ageing, additives used to make plastics capable of being sterilised using $\gamma$-ray radiation, to make them more transparent for better visibility (clarifiers and nucleating agents), to make them opaque to X-ray as well as to render them anti-microbial and increase the lubricity. Additives are added either prior to or during the processing and shaping of the plastic, under the influence of temperature and shear forces. Additives tend to leach out into fluids that come in contact with the plastic. The safety of chemicals used as additives has come under intense scrutiny in recent times, thanks to a better understanding of how trace organic chemicals interact with living biological systems, and how chemicals alter human cells down to the genetic, genomic and DNA level.

\section{Life cycle analysis and end-of-life solutions}

The increasing penetration of plastics into healthcare and medical devices applications is also generating substantial quantities of disposed wastes. By their very nature, in such applications, plastics qualify as "single-use" materials. Since such products may have come into contact with pathogens and other biological hazards, they are classified as "hazardous wastes." Thus, while plastics play an invaluable role in healthcare, they are also often reviled for the negative consequences they have on the environment as well as on human health.

The Biomedical Waste Management Rules 2016 and subsequent modifications thereof mandate incineration of discarded medicines, body parts, and disposable plastics contaminated with blood or body fluids. These are put in yellow-coloured bags/bins for incineration. Other waste plastics packed in red-coloured bags/bins are categorised as recyclables. When it comes to disposal of medical waste, incineration has a number of benefits, such as the prevention of disease transmission and a large reduction in the volume and weight of the waste. However, incineration increases the $\mathrm{CO}_{2}$ load on the environment, as discussed in the chapter titled Sustainable Ways to Manage Waste in Healthcare Facilities.

The incineration of chlorinated plastics (e.g. PVC) is known to result in hazardous emissions unless they are incinerated with special care. Significant human health hazards, particularly from the release of carcinogenic air toxins such as dioxins and polychlorinated dibenzo-dioxins/polychlorinated 
Table 21.1 Representative list of plastics used in medical applications

\begin{tabular}{|c|c|c|}
\hline S. No & Plastic Type & Application Area \\
\hline 1 & $\begin{array}{l}\text { Low-density polyethylene, very } \\
\text { low-density polyethylene }\end{array}$ & Flexible clear tubing, packaging films \\
\hline 2 & Polyvinyl chloride & $\begin{array}{l}\text { Flexible clear tubing, blood bag, } \\
\text { blood tubing, flexible pouches for } \\
\text { intravenous fluids }\end{array}$ \\
\hline 3 & $\begin{array}{l}\text { Polyvinyl chloride, cyclic olefin } \\
\text { copolymers }\end{array}$ & $\begin{array}{l}\text { Blister packaging for } \\
\text { pharmaceuticals (tablets and } \\
\text { capsules) }\end{array}$ \\
\hline 4 & $\begin{array}{l}\text { Polypropylene, high-density } \\
\text { polyethylene, cyclic olefin } \\
\text { copolymers }\end{array}$ & $\begin{array}{l}\text { Syringe housings, pre-filled syringes, } \\
\text { inner lining of catheters, graft for } \\
\text { craniofacial contour } \\
\text { augmentation, ocular surgical aids }\end{array}$ \\
\hline 5 & Polyethene terephthalate & $\begin{array}{l}\text { Rigid transparent tubes for blood } \\
\text { collection, vascular graft, surgical } \\
\text { meshes }\end{array}$ \\
\hline 6 & $\begin{array}{l}\text { Polymethyl methacrylate, } \\
\text { Polycarbonate, polyesters } \\
\text { containing cycloaliphatic diols, } \\
\text { glycol modified polyethylene } \\
\text { terephthalate, polysulfone }\end{array}$ & $\begin{array}{l}\text { Transparent components of medical } \\
\text { devices and instruments, clamps, } \\
\text { face shields, IV connectors, blood } \\
\text { filters, renal dialysis equipment, } \\
\text { containers }\end{array}$ \\
\hline 7 & Polycarbonate-ABS blends & $\begin{array}{l}\text { Ventilators, anaesthesia machines, IV } \\
\text { tube connectors, thermometers }\end{array}$ \\
\hline 8 & Polytetrafluoroethylene & $\begin{array}{l}\text { Catheter linings and multi-lumen } \\
\text { tubing, soft tissue generation } \\
\text { patches, vascular grafts, surgical } \\
\text { meshes, tendon repair materials }\end{array}$ \\
\hline 9 & Polyether sulfone & $\begin{array}{l}\text { Single and multi-lumen tubing, } \\
\text { catheters }\end{array}$ \\
\hline 10 & $\begin{array}{l}\text { Sulfonated polyacrylonitrile, } \\
\text { polysulfone, } \\
\text { polyarylethersulfone }\end{array}$ & Dialysis membranes \\
\hline 11 & Poly (4-methyl pentene-1) & $\begin{array}{l}\text { Membranes for extracorporeal } \\
\text { "protective ventilators" for } \\
\text { oxygen-carbon dioxide exchange } \\
\text { in blood }\end{array}$ \\
\hline 12 & $\begin{array}{l}\text { Ultra-high molecular weight } \\
\text { polyethylene, Polyether ether } \\
\text { ketone }\end{array}$ & $\begin{array}{l}\text { Heart valve, artificial tendons, } \\
\text { low-friction orthopaedic surgical } \\
\text { implants, hip replacements }\end{array}$ \\
\hline 13 & Polyurethanes & Breathable wound dressings \\
\hline 14 & $\begin{array}{l}\text { Polyethylene and polypropylene } \\
\text { nonwovens (melt blown and } \\
\text { spun bonded) }\end{array}$ & $\begin{array}{l}\text { Disposable gowns, face masks, head } \\
\text { and shoe covers, blue wraps for } \\
\text { wrapping sterilised hospital tools }\end{array}$ \\
\hline 15 & Natural rubber, nitrile rubber & Surgical gloves, condoms \\
\hline 16 & Thermosetting polycarbonates & Prescription eye lenses \\
\hline 17 & $\begin{array}{l}\text { Polystyrene, cyclic olefin } \\
\text { copolymers }\end{array}$ & $\begin{array}{l}\text { Medical diagnostics, Elisa well and } \\
\text { microtiter plates }\end{array}$ \\
\hline 18 & Variety of clear plastic films & $\begin{array}{l}\text { Pharmaceutical packaging, shrink } \\
\text { wraps, child safe closures }\end{array}$ \\
\hline
\end{tabular}


Table 21.1 (Continued)

\begin{tabular}{|c|c|c|}
\hline S. No & Plastic Type & Application Area \\
\hline 19 & $\begin{array}{l}\text { Polystyrene-b-polyisobutylene- } \\
\text { polystyrene block copolymers }\end{array}$ & Coating on drug-eluting stents \\
\hline 20 & $\begin{array}{l}\text { Ethylene copolymers, } \\
\text { polyurethanes silicones, } \\
\text { natural polymers }\end{array}$ & $\begin{array}{l}\text { Wound healing gauzes, fluid } \\
\text { adsorbent gauzes }\end{array}$ \\
\hline 21 & $\begin{array}{l}\text { Polyethylene glycols, } \\
\text { polyvinylpyrrolidone, } \\
\text { polyvinyl alcohol }\end{array}$ & Anti-fouling coatings on catheters \\
\hline 22 & $\begin{array}{l}\text { Polyamide, polypropylene, } \\
\text { polyethylene terephthalate, } \\
\text { polyglycolic acid, } \\
\text { polydioxanone }\end{array}$ & $\begin{array}{l}\text { Non absorbable and absorbable } \\
\text { surgical sutures }\end{array}$ \\
\hline 23 & $\begin{array}{l}\text { Polydimethylsiloxane, poly } \\
\text { hydroxyethyl methyl acrylate }\end{array}$ & Intraocular lenses \\
\hline 24 & Polyamides & $\begin{array}{l}\text { Balloon of catheters, ligament and } \\
\text { tendon repair materials }\end{array}$ \\
\hline 25 & Polylactic acid & $\begin{array}{l}\text { Bio-absorbable orthopaedic implant } \\
\text { materials for knee and hip } \\
\text { reconstructive surgery }\end{array}$ \\
\hline
\end{tabular}

dibenzofurans (PCDD/PCDF) have been reported. Incineration also produces ashes containing toxic metals which can find their way into groundwater aquifers. Although there have been great benefits from using plastics in the healthcare sector, there is a need to undertake rigorous life-cycle studies which are factored into the production and disposal decisions for plastics in this sector.

This creates a sad juxtaposition; on one hand, plastics deliver life-saving care to patients, but once used, their disposal contributes negatively to health and the environment. This indeed is the paradox of plastics in healthcare and health. The real challenge is to manage the good, bad and ugly faces of plastic in a rational and informed manner (North and Halden, 2013).

\section{The impact of plastics on human health}

While plastics, in general, are considered safe for human health, some of them are reported to cause adverse effects when used in specific applications. They result from two factors: degradation and leaching. The health risks are further compounded by indiscriminate use and improper disposal. Attributing direct cause-and-effect links or indirect risks of plastic use on human health and diseases are challenging. Great progress has been made in recent years, through animal models and epidemiological studies, in understanding the risks posed by plastics to environment, biological systems and human health (Halden, 2010; Rodrigues et al., 2019). Health risk assessments are critical not only for informing policy and regulations but 
also for developing alternatives that are functionally effective, yet safe for the environment and public health.

Bisphenol-A (BPA), which can be formed during degradation of aromatic polycarbonates, has been implicated in a host of adverse health effects, including reductions in fertility and birth weight, male genital abnormalities, altered behavioural development, diabetes, heart disease and obesity. Although underlying mechanisms through which individual chemicals interact with biological systems vary, it is recognised that BPA is an endocrine disrupting chemical (EDC). The human biological system has many endocrine glands that produce hormones essential for a wide range of bodily functions such as reproduction, growth, development, immunity, and functioning of brain and nervous system. Therefore, by their actions, many EDCs have been confirmed or suspected in their roles in development of reproductive, immunological, genetic and neurological toxicities (Rochester, 2013).

Establishing a clear connection between a chemical compound such as BPA, and human health, is not easy. Most studies are restricted to various cell- or animal-based models. The question of whether constant long-term exposure, albeit in small quantities, has any adverse effect on human health invariably goes unanswered (Glausiusz, 2014). Nevertheless, many countries have, as a matter of abundant caution, prohibited the use of PC in specific applications such as reusable water bottles, feeding bottles and food containers used by infants.

Another chemical that has come under significant scrutiny by the regulators is di-(2-ethylexyl) phthalate (DEHP or DOP) which is used as a plasticiser in PVC. Since in this application, PVC comes in contact with blood or liquids that are ingested, safety issues associated with DOP assumes importance (Tickner et al., 2001). DEHP has been characterised as a "possible human carcinogen" by the International Agency for Research on Cancer (IARC) with most evidence pointing towards a possible link with breast cancer. Other health outcomes that are frequently studied are childhood asthma, adult cardio-metabolic diseases such as type- 2 diabetes, heart disease, hypertension, cholesterol levels, liver function, childhood and adult obesity, thyroid-related disorders and compromised immune function. These toxic effects were observed upon oral uptake, but not upon parenteral administration, because lipid bi-layers appear necessary for the dissolution and release of DOP.

The process of identifying an alternative and establishing its safety, de novo, in application is expensive and time-consuming. In the meantime, use of phthalate-based PVC continues to be used in medical applications, especially blood bags and tubing, since there are no seemingly effective and affordable alternatives. This is a case where the benefits seem to outweigh the risks. 


\section{Resolving the paradox of plastics in healthcare and health}

Resolving the paradox of plastics in healthcare and health requires a multipronged intervention:

(a) material substitution strategy, especially where the life cycle of the material in use is short

(b) better product design for safety in use as well as disposal

(c) better understanding of the mammalian response to chemicals and their mixtures

(d) technology to reuse plastics in medical applications after de-contamination.

Every plastic currently being used in medical applications must be subjected to careful analysis in terms of its strengths and weaknesses and alternatives sought for substitution, where possible. Technology is available today to replace PVC containing plasticisers with high co-monomer content polyethylene elastomers. This eliminates the need for plasticiser and, thereby, the hazards of PVC. Several safer substitutes for DOP are also now available. Biodegradable and biocompatible plastics can be disposed of under controlled composting conditions. Some of these are suitable for replacing the currently used fossil fuel-derived plastics in medical applications. Predictive heuristics to understand mammalian responses to chemicals, based on big data and AI-based tools are emerging which may make future choice of materials for medical applications more rational and evidence based (Wambaugh et al., 2014). Chemistry and chemical engineering, which form the foundations of the plastic industry, by its very nature, have been largely reductionist. While reductionism has resulted in tremendous advances in material science, it has also caused unintended consequences on human health and environment. To resolve the paradox, it is necessary to combine our present knowledge and understanding with integrative systems thinking leading to product design for inherency, life-cycle and function (Anastas, 2019).

The problem is not limited to simply avoiding plastics that have been linked with health hazards and substituting them with safer alternatives. More fundamental changes in the design, application, re-use and disposal of plastics are necessary. Issues that need to be considered when evaluating use of plastics in health care are choosing materials based on a careful understanding of risks and benefits, in the short and long-term, using hard scientific data. Rigorous cradle-to-grave life cycle studies should be undertaken as alternatives to conventional petroleum-based plastics emerge, as well as risk assessments before adopting them in practice. This will ensure that the alternatives truly serve to reduce adverse effects without any 


\section{Box 21.1 Case study}

\section{Plastics in healthcare in the time of COVID-19}

In the fight against SARS-CoV-2, plastics played an indispensable role in protecting both the patient and the medical service professional. The sample collection vials and container, the swabs and the petridishes are derived from plastics. Surgical face masks are made with non-woven fabrics, which has better pathogen filtration capabilities and air permeability. Body overalls, gowns, caps and linens are made from non-woven PE and PP fabric. Goggles and visors are made from polycarbonates (PC) or polymethyl methacrylate (PMMA). Every country of the world rapidly scaled up their production of PPEs. The WHO requested a $50 \%$ escalation of disposable PPE production (Tullo, 2020).

The resulting plastic wastes were also a cause for concern. Hospitals generated much more waste as compared to normal times and rapidly ran out of space to store waste PPEs. It is reported that the city of Wuhan in China produced more than 240 tons of single-use plastics waste per day at the peak of the pandemic (Adyel, 2020). Incinerator capacities were woefully inadequate to cope with the increasing load of wastes. This extra pressure also led to inappropriate and unacceptable waste disposal methods. The prioritisation of human health over environmental health in these unprecedented times has likely set back public policies to minimise the use of single-use plastics and is a stark illustration of the paradox of plastics in healthcare.

unintended consequences. There is a clear case for developing degradable or compostable plastics for single-use applications with a programmed, short lifespan. Finally, in order to reduce plastic use to the bare minimum that cannot be achieved by non-plastic substances, healthcare professionals, like everyone else, should review and modify their use of plastic in their personal and professional lives (Box 21.1).

\section{Key takeaways}

- The healthcare sector provides an opportunity to develop strategies for more sustainable consumption and disposal of plastic materials.

- Examples of reducing single-use plastics in hospital environments, reprocessing medical equipment for multiple uses and switching to alternative plastics which have no negative environmental impact are already emerging. 
- These interventions could help realise the full potential of plastics in healthcare and public health and eventually lead to sustainable manufacturing and consumption of plastics in healthcare with a minimum impact on health.

\section{References}

Adyel, T. M. (2020). Accumulation of plastic waste during COVID-19. Science, 369, (11), September, 1314.

Amienyo, D., Gujba, H., Stichnothe, H., \& Azapagic, A. (2013). Life cycle environmental impacts of carbonated soft drinks. International Journal of Life Cycle Assessment, 18, 77-92.

Anastas, P. T. (2019). Beyond reductionist thinking in chemistry for sustainability. Trends in Chemistry, 1, 145-148. doi:10.1016/j.trechm.2019.03.007

Azoulay, D., Villa, P., Arellano, Y., Gordon, M., Moon, D., Miller, K., \& Thompson, K. (2019). Plastic and health: The hidden costs of a plastic planet (1-74). https:// www.ciel.org/plasticandhealth/

Brandt, B., \& Pilz, H. (2011). The impact of plastic packaging on life cycle energy consumption and greenhouse gas emissions in Europe (1-7). Denkstatt GmbH.

Geyer, R., Jambeck, J. R., \& Law, K.L. (2017). Production, use, and fate of all plastics ever made. Science Advances, 3(7), e1700782. https://www.science.org/doi/ full/10.1126/sciadv.1700782

Glausiusz, J. (2014). The plastics puzzle. Nature, 508, 306-308.

Halden, R. U. (2010). Plastics and health risks. Annual Review of Public Health, 31, 79-194.

Kumar, P. (2018). Role of plastics on human health. Indian Journal of Pediatrics, 85, 384-389.

Maitz, M. F. (2015). Applications of synthetic polymers in clinical medicine. Biosurface and Biotribology, 1, 161-176. doi: 10.1016/j.bsbt.2015.08.002.

North, E. J., \& Halden, R. U. (2013). Plastics and environmental health: The road ahead. Reviews on Environmental Health, 28, 1-8.

Rochester, J. R. (2013). Bisphenol A and human health: a review of the literature. Reproductive Toxicology, 42, 132-155.

Rodrigues, M. O., Abrantes, N., Gonçalves, F. J. M., Nogueira, H., Marques, J. C., \& Gonçalves, A. M. M. (2019). Impacts of plastic products used in daily life on the environment and human health: What is known? Environmental Toxicology and Pharmacology, 72, 103239-103273.

Tickner, J. A., Schettler, T., Guidotti, T., McCally, M., Rossi, M. (2001). Health risks posed by use of di-2-ethylhexyl phthalate (DEHP) in PVC medical devices. American Journal of Industrial Medicine, 39, 100-111.

Tullo, A. H. (2020). Plastics during the pandemic. C\&EN, 98.

Wambaugh, J. F., Wang, A., Dionisio, K. L., Frame, A., Egeghy, P., Judson, R., \& Woodrow Setzer, R. W. (2014). High throughput heuristics for prioritizing human exposure to environmental chemicals. Environmental Science \& Technology, 48, 12760-12767. 


\title{
Conclusion
}

\section{CAUSATIVE AND CURATIVE: THE HEALTH SECTOR'S IMPACT ON CLIMATE CHANGE}

\author{
Divya Alexander
}

Climate change is a looming threat that risks unravelling decades of development in human health. In the last ten years, the incidence of heat stress, water scarcity, malnutrition and outbreaks of vector-borne and water-borne diseases have become more frequent. However, the interlinkages between climate change and healthcare represent a unique opportunity for the health sector to take a leadership role in slowing down anthropogenic climate change, while combating its effects. The chapters in this book have presented ways for the health sector to seize the opportunity, and a summary is provided below.

The health sector can be an example to other sectors by aggressively embracing climate-smart strategies, and using its collective voice for leadership at the policy level. Most health systems have a high health carbon footprint, but can be made resilient and more effective by using efficient technologies and techniques. If hospitals and healthcare centres can bring in clean, renewable energy and invest in conservation strategies, health systems can lead by example and become a model of leadership for the rest of the community. Improvement in energy infrastructure to better serve health facilities can strengthen health systems' responses to large-scale health needs while achieving developmental co-benefits. For example, the solarisation of health centres can significantly reduce COVID-19 fatalities and ease the patient load on provincial health centres. These responses can be strengthened through policy action.

Globally, the threat of climate change is being addressed by the IPCC and the UNFCCC, a Convention to which India is a signatory. The National Program on Climate Change and Human Health (NPCCHH) under the nodal Ministry of Health and Family Welfare and nodal technical agency National Centre for Disease Control, was started in order to fulfil India's commitments in the international and national climate change policy frameworks and to build a climate-resilient health sector. These have led to the development of state and district-level climate activities.

The section on climate change and health affirms that human wellness is inextricably linked to planetary health. Individually and collectively, humans have contributed to creating ecological conditions for zoonotic 
diseases to emerge and spread, while also being responsible for loss of biodiversity and consumption of fossil fuels, leading to climate change. Raging zoonotic disease, such as the pandemic Influenza of 1918 or COVID-19, are wake-up calls to the global community on the ultimate cost of inaction on the rapidly unfolding climate crisis. Additionally, there is a dire need for healthcare professionals around the world to prepare for the growing burden of disease from climate change. The World Health Organization has designated five areas as major health impacts of climate change - malnutrition, deaths and injuries caused by storms and floods, water contamination and water scarcity related disorders, heatwaves and vector-borne diseases. Heat action plans and heat health research are important factors in improving the resilience of communities against extreme heat events and for the prevention and management of heat-related illnesses.

Air pollution is a public health issue of paramount importance requiring a multi-sectoral collaborative effort, and the role of the health sector is crucial in dealing with the increased burden of disease due to air pollution. As abodes of healing, healthcare facilities should provide a safe environment for patients, visitors and healthcare workers. Health voices in air qualityrelated policy-making are vital, and as thought leaders in a community, health professionals can promote advocacy for policy changes.

Climate change impacts human health, economic development, agricultural systems and the availability of food and nutrients. The reduction in the quality of natural resources and increased incidence of extreme weather events is expected to impact food systems through multiple channels. An integrated system approach is necessary to produce sufficient, safe and nutritionally enhanced food, as not all healthy diets are sustainable, and not all sustainable diets are healthy.

Certain groups are disproportionately affected by climate change; the vulnerabilities of women, children, the elderly, persons with disabilities and outdoor workers are described. Gendered differentials make women more vulnerable to health risks from climate change, including extreme weather events, temperature variations, air pollution, water contamination water scarcity and food insecurity, with pregnant women being especially vulnerable. Health professionals need to become aware of these vulnerabilities.

In order to strengthen its defence, the healthcare community needs to become climate-smart, that is, build resilience to prepare against climate threats while reducing its own carbon footprint. To become resilient and adapt to climate threats, health systems should reduce vulnerabilities and build capacities by using adaptive approaches and community action.

Operationally, the health sector can lead essential sectors in decreasing their carbon footprint by showcasing the use of energy-efficient equipment and decentralised renewable energy. The combination of sustainable energy combined with efficiencies of medical technologies and green buildings can be the most critical component to decrease the health sector climate footprint. A hospital can decrease its carbon footprint and demonstrate 
continued functionality in the aftermath of a natural disaster with safe and functional green buildings. The sector must also optimise its current functions in water-deficient systems by improvising and harnessing currently available technologies to reduce its water footprint. Biomedical waste is hazardous but all the other types of waste generated in healthcare establishments are not necessarily infectious or hazardous. Non-compliance with segregation, storage and treatment policies and subjecting all waste from healthcare establishments to incineration is highly unsustainable. It is essential to mobilise health systems towards adopting practices for the safe handling and disposal of healthcare waste. Transportation activities relating to the health sector such as through the supply chain delivery of health sector goods and equipment, the travel footprint of patients and healthcare personnel and waste disposal methods from healthcare facilities, can all be reduced using the adaptation measures outlined in this book.

Health systems that aspire to carbon neutrality must analyse their supply chain, identify carbon hot spots and engage with suppliers to establish targets for the reduction of greenhouse gas emissions throughout the life cycle of the products from manufacturing to distribution to end of use/reuse. Sustainable procurement policies that integrate sustainability criteria for a low-carbon health supply chain are needed to achieve the goal of climatesmart, resilient health systems. These extend to related industries such as the pharmaceutical industry, who must adopt responsible measures of production to mitigate their role in causing climate change due to irresponsible manufacturing practices and Antimicrobial Resistance (AMR). The entire value chain - from manufacturer and distributor to user - must be involved in order to ensure sustainable buying and procurement. It is crucial for the pharmaceutical industry to learn from best practices in other industries and work collaboratively with governments and other relevant stakeholders to create a conducive ecosystem that contributes positively to public health.

The altered global climate will bring about myriad human health consequences with particular implications for the manufacture and use of chemicals and plastics used in healthcare. The chemical products used in healthcare have high global warming potential (GWP), while the reputation of plastics, especially single-use plastics in healthcare, are widely written about. The interventions laid out in this book could help realise the full potential of plastics in healthcare and public health, and eventually lead to sustainable manufacturing and consumption of chemicals and of plastics in healthcare with a minimum impact on health.

It is heartening to note that the response from the health profession is gaining momentum. In 2019, spending on health system adaptation increased by $12.7 \%$ to $\$ 18.4$ billion, original research on health and climate change has increased by a factor of eight in the last ten years, and, in half that time, health institutions with total assets of $\$ 42$ billion have divested their holdings from fossil fuel industries (Watts et al., 2020). Led by lowincome countries, more governments are linking health and climate change 
in their annual speeches at the UN General Debate and their NDCs under the Paris Agreement. In the efforts to heal the world and mitigate climate change, which has largely been brought about by human civilisation through the process of modernisation, the healthcare community must continue to work collectively, assertively and decisively towards a sustainable future.

\section{References}

Watts, N., Amann, M., Arnell, N., Ayeb-Karlsson, S., Beagley, J., Belesova, K., ... \& Campbell-Lendrum, D. (2020). The 2020 report of The Lancet Countdown on health and climate change: Responding to converging crises. The Lancet. doi:10.1016/s0140-6736(20)32290-x 


\section{EDITORS}

Alexander Thomas is the President of AHPI, President of the Association of National Board Accredited Institutions (ANBAI), Founder-President (20122017) and Patron of the Consortium of Accredited Healthcare Organizations (CAHO). He has effected far-reaching policy changes within the healthcare landscape, including incorporating healthcare communication among the $\mathrm{NABH}$ accreditation standards and in the Indian medical curricula, rolling back the service tax for the health sector, making assaults on doctors a nonbailable offence, leading the expert group on medical education for the National Education Policy 2019 headed by Dr. Kasturirangan, creating national coalitions (with the IMA), a think tank on health (with NLSUI), and liaising between government and health stakeholders during the COVID-19 pandemic. He has developed major initiatives at the State level, especially in Karnataka, and served on committees of the Union Health Ministry, NABH, HSSC, CII, FICCI, UNESCO, PHFI, and NBE. He is an NBE Examiner and Inspector, Former Professor of Orthopaedics at the MSU in Malaysia, Visiting Faculty at IIM-B and NLSIU, pioneering several healthcare training initiatives. His recent publications include books on healthcare communication and healthcare quality, and white papers submitted to the Government of India. He was awarded the Emeritus Teacher Award by NBE (2014), the National Distinguished Services Award by the IMA (2016), and the Lifetime Achievement Award by CAHO (2018).

K. Srinath Reddy, a Padma Bhushan awardee, is the President of the Public Health Foundation of India (PHFI), and formerly headed the Department of Cardiology at the All India Institute of Medical Sciences (AIIMS), New Delhi. Under his leadership, PHFI has established five Indian Institutes of Public Health (IIPHs) to advance multi-disciplinary public health education, research, health technologies and implementation support to strengthen health systems. He was appointed as the first Bernard Lown Visiting Professor of Cardiovascular Health at the Harvard School of Public Health (2009-2013), and presently serves as Adjunct Professor of Epidemiology at Harvard (2014-2023). He is also Adjunct Professor at Emory University and Sydney University. He is the first Indian to be elected to the National 
Academy of Medicine, USA. He is an advisor to the Governments of Odisha and Andhra Pradesh on Health. His recent publications include Make Health in India: Reaching a Billion Plus (2019). He holds advisory positions in numerous national and international bodies, including the position of former President of the World Heart Federation (2013-2015), and has been awarded several prestigious national and international doctorates and fellowships.

Divya Alexander read for her Master's degree at the University of Oxford as a Commonwealth Scholar and is a gold medallist from Bangalore University (Mount Carmel College), India. With over a decade of expertise in gender, health and public policy research, she has drawn up policy recommendations and drafted healthcare legislation in India and abroad, through her work with AHPI, the United Nations Population Fund (UNFPA), and Amnesty International USA. She provided technical expertise for the development of the Karnataka State Public Health Policy, the Committee for SDG Goal 3 (Health) to the Govt. of Karnataka, and the AHPI group to sensitise healthcare professionals on climate change and healthcare communication. She has worked with the World Bank, UNDP, UN Women, and NGOs on the outcomes of quality accreditation, the reformation of higher medical education, and the impact of climate change on the health sector. Her recent publications include Communicate. Care. Cure. A Guide to Healthcare Communication ( $3^{\text {rd }}$ Edition 2019), Anmol Ashayein (2015), an adolescent health education manual that has reached more than 250,000 students in India, and several papers on healthcare communication, public policy and climate change.

Poornima Prabhakaran is Additional Professor and Head of Environmental Health; Deputy Director at the Centre for Environmental Health, Public Health Foundation of India; and Senior Research Scientist at the Centre for Chronic Disease Control. She leads work engaging the Indian health sector on environmental issues, including a strong advocacy and movement towards climate-resilient and sustainable health care systems in India. She is a member of technical expert groups providing the health perspective to various national programs related to climate change, air pollution and urban resilience. She is Chair and Member of the Board of Directors of the research sub-group in the World Health Organization (Geneva) - Global Climate and Health Alliance (GCHA), Member of the inaugural Steering Group of the Health and Climate Network hosted by the Welcome Trust, and works closely with other UN organizations including UNDP and UNEP. She currently leads the Centre of Excellence in PHFI for green and climateresilient healthcare facilities under the National Program for Climate Change and Human Health, Ministry of Health and Family Welfare, Government of India. 


\section{ABOUT THE CONTRIBUTORS}

Sundeep Singh Chauhan is the Director of CEG India and CEO of CEGTH, a Geotechnical/ Environment/Food/Pharma NABL-accredited testing and research company, with 33 years of leadership experience in diverse industries and business functions. He has a B.E (Hons.) Degree in Chemical Engineering from BITS, Pilani, and a PGDM from the Indian Institute of Management - Bangalore (IIMB), India.

Yatin Choudhary is a Fellow at The Energy and Resources Institute (TERI), with over 16 years' experience in the field of sustainable building design. An architect by training, he has guided several hospital projects certified by green building rating agencies for sustainability and resource efficiency. With a Master's degree in Urban and Rural Planning from IIT-Roorkee, he has accreditations from LEED-USGBC, GRIHA, and GEM-ASSOCHAM as a green building professional.

Devasahayam Jesudas Christopher [DNB, FRCP (Glasgow), FCCP (USA), FAPSR, FICS] is a Professor of Pulmonary Medicine at the Christian Medical College, Vellore and a Fellow of the Royal College of Physicians \& Surgeons, the American College of Chest Physicians and the Asia Pacific Society of Respirology. He is the former President of the Indian Chest Society and the Indian Association of Respiratory Care. He has received several prestigious fellowships and research awards, and authored over 190 research publications.

Priya Dutta is an environmental health consultant at the Indian Institute of Public Health, Gandhinagar, who addresses environmental health challenges with a focus on the public health burden of air pollution and extreme heat events. She holds a Ph.D. from the Indian Council of Medical Research (ICMR), was trained in Environmental Health from the Harvard School of Public Health and has published many articles in professional journals and books.

Tracey Easthope is a founding member and Senior Strategist for Health Care Without Harm. She has 30 years of experience in chemicals 
management, chemicals policy and market-based campaigning in the healthcare sector. She has a Master's degree in Public Health from the University of Michigan.

Anjali Ganpule-Rao holds a Ph.D. in Nutrition with a strong research interest in food systems research, maternal child nutrition and public health. As a trained nutrition and health researcher, she was the recipient of the Asian Research Fellowship at NIHN, Tokyo, and a post-doctoral research fellowship for Innovative Methods and Metrics for Agriculture and Nutrition Actions (IMMANA).

Samayita Ghosh is a Senior Research Associate at the Centre for Environmental Health, PHFI, and works at the intersection of social and behavioural determinants of water, sanitation, and hygiene, mediation of exposures through ingestion of contaminated water, and impact assessments. Her sectoral experience spans WASH, education, livelihoods, and gender with an emphasis on participatory techniques and community mobilisation for sustainable change.

Mahaveer Golechha is the Associate Professor and Project Lead for Climate Change and Health at the Indian Institute of Public Health, Gandhinagar. He has a Master's degree in Health Policy Planning and Financing from the London School of Economics, U.K., and holds a Master's degree and Ph.D. from the All India Institute of Medical Sciences, New Delhi, and Delhi University, India.

Girdhar Gyani is the Director General of the Association of Healthcare Providers - India (AHPI) and former Secretary-General of the Quality Council of India (2003-2012). He works to build capacity in Indian health systems, is a strong advocate for Universal Health Coverage, and pioneered quality accreditation frameworks in healthcare, school education, environment, food safety, and public services, among others.

Harish Hande is the Founder and CEO of SELCO Foundation. He is a renewable energy entrepreneur with over 25 years of grassroots experience in meeting the energy needs of underserved populations. He is a graduate from the Indian Institute of Technology, Kharagpur, and holds a Master's degree and Ph.D. from the University of Massachusetts Lowell. He became an Ashoka Fellow in 2008 and was awarded the Ramon Magsaysay award in 2011.

Gifty Immanuel [MD, Ph.D, MPH\&TM] is the Director, Center for AIDS \& Antiviral Research, Tuticorin, and the Medical Division, Synergia Foundation, Bangalore. He is a specialist in Human Virology and Global Health, with a Master's from Cambridge University and trained in Global 
Infectious Diseases at Harvard University. He is a Fellow of the Royal College of Physicians, U.K., and a Member of the New York Academy of Medicine and National Academy of Medical Sciences, India.

Huda Jaffer is the Director of SELCO Foundation. She is a product-service systems designer with an undergraduate degree in design from the Srishti School of Art, Design and Technology, Bangalore, and a Master of Science degree in Engineering and Business (Integrated Design and Management) from the Massachusetts Institute of Technology, Cambridge.

Ishika Jharia is a Project Officer and Senior Research Associate for the Sustainable Health in Procurement Project in India, working with the Indian health sector to reduce harm to people and the environment caused by the delivery of healthcare services and manufacture, procurement, use and disposal of medical products. She is a Dental Surgeon with a Master's degree in Health and Hospital Management from the Indian Institute of Health Management Research, Jaipur.

Lalit Kant [MBBS, MD and MSc. (Communicable Diseases Epidemiology)] is an infectious disease epidemiologist. He is presently an independent consultant and formerly headed the Division of Epidemiology and Communicable Diseases at the Indian Council of Medical Research (ICMR), New Delhi, India. He was also a Senior Adviser on Infectious Diseases at the Public Health Foundation of India.

Josh Karliner is the International Director of Program and Strategy for the NGO Health Care Without Harm, where he directs the International Climate Program. He has over 30 years' experience working on international environmental, health and social justice issues. He has authored numerous papers for a wide range of publications.

Vanitha Kommu is a research scholar pursuing a Ph.D. with the Tata Institute of Social Sciences. She has previously worked with the Centre for Environment Education. She currently works with the World Bank as a consultant (Environmental Specialist) providing support to projects in areas of rural development, livelihoods and agriculture.

Hari Kumar is a civil engineer with 34 years of experience, specialising in Disaster Risk Mitigation, with a focus on earthquake risk mitigation and the safety of educational and health facilities. He is the South Asia Regional Coordinator of Geohazards International and heads the GeoHazards Society, India. He has been involved in hospital retrofitting, assessment of hospitals and non-structural risk reduction projects across the country. $\mathrm{He}$ has a Ph.D. from IIEST, Shibpur, West Bengal, India. 
Lakshmi Lingam is a Dean and Professor at the School of Media and Cultural Studies, Tata Institute of Social Sciences, Mumbai, India. She is a well-known expert in the field of gender studies, with several research publications on women's health, public policy, and reproductive and sexual rights.

Ameeka Shereen Lobo is a Senior Research Assistant at the Public Health Foundation of India, currently working on a food systems project. She is a qualified public health professional with a degree from the Indian Institute of Public Health - Delhi, India and a Master's degree in Child Health Nursing from MAHE. With her experience in public health, academia, administration, clinical and critical care, she has authored many publications.

Shyamala Mani is a Senior Advisor, WASH and Waste Management, at the Centre for Environmental Health, Public Health Foundation of India. She holds a Ph.D. in Environmental Science from Jawaharlal Nehru University, and an MPH from the School of Public Health, University of California, Berkeley. A recipient of the UNCHS Global 100 award, ICAR Fellowship in Agricultural Microbiology and Fogarty International Fellowship in Environmental Health, she has authored several publications.

Shriram Manogaran is a Technical Program Coordinator at the Centre for Chronic Disease Control. He works on research activities and other campaigns pertaining to clean air and climate-smart healthcare. He holds a master's in environmental management from the University of Malta and has eight years of work experience in climate change.

Manu Raj Mathur is the Head of Health Policy and Additional Professor at the Public Health Foundation of India. He is a public health practitioner with a Ph.D. in Epidemiology and Population Health from University College London and an MPH from the University of Glasgow. He has received several prestigious scholarships and awards, and has published over 100 papers on health systems and policy research.

Dileep Mavalankar [MPH, MD, Dr. PH] is the Director of the Indian Institute of Public Health - Gandhinagar, and Vice President of the Western Region, Public Health Foundation of India. He has worked as a post-doctoral fellow at the National Institute of Health (NIH), USA and as Faculty at the Indian Institute of Management - Ahmedabad. He has published numerous papers in professional journals and books, and has been a consultant to many national and international organizations.

Jyothi S. Menon is a Senior Research Associate at the Center for Environmental Health, Public Foundation of India (PHFI), where her 
primary research focus is on air pollution and health. She holds a Ph.D. in Environmental Engineering from the Indian Institute of Technology Madras. Her research interests are urban air quality monitoring, modelling, personal exposure, characterisation of atmospheric particles and human health risk assessment.

Jai Prakash Narain received his MBBS and MD degrees from the All India Institute of Medical Sciences, and his MPH and MS degrees from the Harvard School of Public Health, Boston. He is Senior Visiting Fellow, University of New South Wales, Sydney, and former Regional Advisor and Director at the World Health Organization, SEARO.

Zerin Osho is an international climate law and policy expert. She is currently the Project Lead at the International Solar Alliance where her focus is on developing sustainable cold chains. She previously served as an advisor to the Executive Director of UN Environment on sustainable cooling. She holds a Master's degree in Law and Diplomacy from the Fletcher School and was awarded the prestigious LAMP fellowship in 2015.

Himanshi Pandey is a Senior Research Assistant at the Public Health Foundation of India (PHFI), New Delhi, India. She has previously worked as a research assistant at the Gokhale Institute of Politics and Economics, Pune. She holds a Master's degree in Applied Nutrition from the National Institute of Nutrition, Hyderabad, India.

Manish Pant [MBBS, MD] heads the Health and Governance Unit at UNDP India where he has led the digitisation of India's vaccine supply chain and leads on a program portfolio that focuses on system strengthening, maternal \& child health, and NCDs, among others. A medical doctor by training, he has over 20 years of work experience in the humanitarian and development sector across Asia, Pacific, Africa and Europe, working for the International Federation of Red Cross and Red Crescent Societies, International Diabetes Federation and PHFI.

H. Paramesh [MD, FAAP (USA), FIAP, FIAMS, FIAA, FICAAI, FPAI] is a pediatric pulmonologist and environmentalist, Distinguished Visiting Professor at the Divecha Center for Climate Change, Indian Institute of Science (IISc), President of the COMHAD India Chapter (2021-2022), Chair of the Lakeside Education Trust, Member of the WHO Climate and Health Working Group, Geneva, Lead of the Future Earth Health Sensitization in South Asia, and Member of the Editorial Board of Current Science.

Megha Rathi is Project Co-ordinator at SHIPP, Health Care Without Harm, and a Consultant to the World Health Organization. With a Ph.D. in 
Environmental Sciences, she has over 20 years of experience in integrating environmental best practices within health systems, focusing on procurement, chemicals and waste management, working with international and governmental bodies, NGOs and health facilities to drive the agenda of sustainability in the health sector.

Swapan K. Ray is a Mechanical Engineer with a PGGM from the Indian Institute of Management - Bangalore, India and has over 45 years of experience in the petrochemical and plastics industry. At present, he is mentoring the Sustainability Initiative at Reliance Industries Limited. He serves as the Honorary Secretary of the Indian Center for Plastics in the Environment (ICPE), Mumbai, an organization focused on the sustainable use of plastics.

Aditi Roy is a research scientist at the Center for Environmental Health, and an Adjunct Faculty at the Public Health Foundation of India. She completed her Ph.D. from Pennsylvania State University and a post-doctoral fellowship from Vanderbilt University, USA. She conducts research and awareness programs on waste management, children's environmental health, and sustainability.

Jagjeet Sareen is the Assistant Director-General at the International Solar Alliance, on secondment from the World Bank. He has been working on global economic governance issues for over 16 years at MDBs, UN agencies, think tanks, and in the private sector. He was awarded a Chevening Gurukul Fellowship for Leadership and Excellence by the UK Government, hosted by the University of Oxford. He is a member of Chatham House and the International Institute for Strategic Studies.

Richa Sharma is a Research Scientist at the Centre for Environmental Health, at the Public Health Foundation of India. With a MSc. and Ph.D. in Environmental Studies from TERI University and a post-doc from VITO (Belgium), she conducts research at the intersection of environment, climate change and health. She also worked at NIUA, where she focused on climate change impacts, vulnerabilities and adaptation for Indian cities,

Suman Sharma is the Director of Marketing (Sustainability) at Centrient Pharmaceuticals for the APAC Region. She works on issues related to sustainability and health such as antimicrobial resistance, access to medicine and climate change. She has a Master's degree in Microbiology and a General Management degree from INSEAD Business School.

Aakash Shrivastava is the Additional Director and Head, Centre for Environmental Health and Occupational Health, Climate Change and Health, National Centre for Disease Control, and the national lead for the 
National Programme on Climate Change and Human Health, Ministry of Health and Family Welfare, Government of India. He holds an MD, MPH and Ph.D. from the National University of Ireland.

Shailendra P. Singh is a NABET-certified consultant and Environmental Impact Assessment co-ordinator for road, river, construction and waste facilities. With a double Master's in Agriculture Economics as well as Ecology and Environment, and a Ph.D. in Agriculture Economics, he has 25 years of experience working on climate change issues. He has worked with UN agencies in Central Asian and Eastern European countries.

Swaminathan Sivaram [Ph.D. (1972) and D.Sc. (2010), Purdue University] is the former director of CSIR - National Chemical Laboratory, Pune. Currently, he is an Honorary Professor and INSA Senior Scientist of the Indian Institute of Science Education and Research, Pune. He has authored over 245 papers and over 100 patents. He was conferred the Padma Shri award by the President of India in 2006.

Preeti Soni is Head of the Asian and Pacific Centre for Transfer of Technology, UNESCAP, with over 25 years of programme and research experience in climate change, environment and sustainable development. She has a Master's degree from Delhi University, India, and a Ph.D. from Virje University, Amsterdam.

Rameshwar Sorokhaibam is the Deputy Director at the Centre for Environmental and Occupational Health, Climate Change and Health, National Centre for Disease Control (NCDC), Delhi, under the Ministry of Health and Family Welfare. With an MD in Community Health Administration (MD CHA) from the National Institute of Health and Family Welfare, and a DNB in Health Administration including Hospital Administration, he is involved in the implementation of the program related-activities for the National Program on Climate Change and Human Health.

R. Srikanth is the Dean, School of Natural Sciences and Engineering at the National Institute of Advanced Studies (NIAS), and heads the Energy, Environment and Climate Change Program. He has a dual Ph.D. in Mining Engineering and Operations Research from the Pennsylvania State University and joined NIAS after serving industry for 20 years.

R. Srinivasan is a reputed geoscientist who has worked on the Precambrian hard rock terrain of India. He is steering the activities of the Water Quality Laboratory at the Divecha Centre for Climate Change, Indian Institute of Science, Bengaluru, to holistically address the problems arising from 
geogenic and anthropogenic contaminants of groundwater resources of India. He is an elected Fellow of all the three National Science Academies of the Country.

Ananya Tewari is a Senior Research Associate at the Centre for Environmental Health, Public Health Foundation of India, and Centre for Chronic Disease Control. With an undergraduate degree in Biotechnology and a Master's in Environmental Science and Technology, she focuses on the areas of sustainable food systems and waste management in the Indian health sector, and has worked on several aspects of environmental contamination and the associated impacts on public health.

Alba Tiley is the Sustainable Antibiotics Director at Centrient Pharmaceuticals (Global) where she works on issues at the intersection of sustainability and health such as antimicrobial resistance, access to medicine and climate change. She has a Master's degree in Strategic Management from the Rotterdam School of Management.

Shikha Vardhan [MBBS, MD, PGDHHM] is the Joint Director, National Centre for Disease Control, Ministry of Health and Family Welfare, Government of India. She has coordinated and contributed to India's National Action Plan for Climate Change and Human Health and represented India's view on environmental health, climate change and air pollution at international forums such as the Conference of Parties for Climate Change at Paris, Marrakesh, Bonn, and Kathmandu.

Susan Wilburn [BSc. Nursing, MPH] is the International Sustainable Director, Health Care Without Harm. An occupational and environmental health specialist, she leads HCWH's work with the UNDP, WHO and UN Environment on sustainable procurement. She is the health sector civil society representative to the Bureau of the International Conference on Chemicals Management, co-authored Climate Smart Health Care and has written multiple articles on the environmental health impact of healthcare activities. 


\section{INDEX}

Page numbers in bold indicate tables and boxes, page numbers in italics indicate figures and page numbers followed by $\mathrm{n}$ indicate notes.

absorption refrigerators $30-32$

acute respiratory infections (ARIs) 40, $43,61,154$

adaptive capacity 99

adaptive management process $121-122$, 123

AERB see Atomic Energy Regulatory Board (AERB)

Ahmedabad heat action plan 110, 111-112, 113

AHPI see Association of Healthcare Providers - India (AHPI)

airborne transmission 70-73, 126 air pollution 211, 225; and COVID-

19 72-73; ensuring safe indoor air quality 72 ; gendered vulnerabilities to 92 ; and the health sector 68 , 68-69; health sector's contribution to 73-75, 74; hospital-acquired infections 71-72; human exposure 69; indoor air quality 69-70; overview of 67-68; vulnerable populations, in hospitals 71 air pollution-related diseases 64 American Psychological Association 64 AMR see antimicrobial resistance (AMR)

AMR Industry Alliance 198, 198-199 anaesthetic gases 68, 70, 209 animal originated foods 83

antibiotics in farming and agriculture 81

antimicrobial resistance (AMR) 154, 226; climate change and 199-200; initiatives 200-201; pharmaceuticals vs. 198, 198-199; reporting 200
ARIs see acute respiratory infections (ARIs)

arsenic contamination 92, 150, 152

Association of Healthcare Providers India (AHPI) 9-10

Atomic Energy Regulatory Board (AERB) 154

Aureobasidium pullulans 50

Bacillus anthracis 48, 50

bacterial threats 49, 49-50, 50

BEE see Bureau of Energy Efficiency (BEE)

biogas 169; biological systems, vulnerability of 211

biomedical waste (BMW) 160, 162, $163,164,167-168$

biomedical waste management (BMWM) 165, 165, 166

biomedical waste management rules (2016) 217

biomethanation/composting 168-170, 169

BIS see Bureau of Indian Standards (BIS)

bisphenol-A (BPA) 220

black carbon 173

BMW see biomedical waste (BMW)

BMWM see biomedical waste management (BMWM)

BPA see bisphenol-A (BPA)

bulk waste generator 162

Bureau of Energy Efficiency (BEE) 141, 147,186

Bureau of Indian Standards (BIS) 152, 153 
Call to Action on Climate and Health (2018) 8

Candida auris 50

captive biomedical waste treatment facilities (CBWTFs) 165, 168

captive treatment facilities (CTFs) 165

carbapenem-resistant Klebsiella pneumoniae (CRKP) 199

carbapenem-resistant Pseudomonas aeruginosa (CRPA) 199

carbon dioxide 167, 169, 173, 210

carbon footprint $8,14,18-20,21,36$, $42,123,131,133,139-140,188,189$, 216, 225

Central Pollution Control Board (CPCB) 69, 164

Central Public Works Department (CPWD) 186

Centre for Environment Education (CEE) 166

Centre for North East Studies and Policy Research (C-NES) 147

Centres of Excellence (CoE) 39

chemicals 226; and climate change 210-211; detoxify and decarbonise supply chain 208; eliminating unnecessary care 208; in healthcare supply chain 206-207; impact, on climate change 209-210, 210; integrate product design 208-209; overview of 204-205, 205; preventive approaches 207-208; recycling and waste management 208-209

Chhattisgarh State Health Department 186-187

Chhattisgarh State Renewable Energy Development Agency (CREDA) 186-187

chlorinated plastics, incineration of 217,219

chlorofluorocarbon (CFC) 68, 210

cholera 49, 49, 50, 63, 151

chromium 152

climate anxiety 64

climate change, definition of 1

climate-resilient healthcare facilities 8 , 42,131

climate sensitive diseases (CSDs) 39, 42

climate-smart agriculture (CSA) strategies 86

climate-smart healthcare 3, 225; adaptive management process 121-122, 123; build and diversify capacities 121; definition of 119 ; identify and reduce vulnerabilities 120-121; mitigation strategies, for the health sector 122-125, 124, 125-128; resilient health systems 119-120,120

climate-smart waste practices, for the Indian health sector 168-169

CNG vehicles 175

CoE see Centres of Excellence (CoE) cold waves $60,61,121$

common biomedical waste treatment and disposal facility (CBWTF) 163, 165,168

community: healthcare $3-4,10,11$; leadership in 10-11, 11; action, to strengthen health systems 122,123 ; advocacy 73

compact fluorescent lamps (CFL) 141

Comptroller and Auditor General (CAG) 166

cooling technologies 142-148, 144145, 146-147

coronavirus disease 2019 (COVID-

19) $72,120,225$; advent of 1 ; air pollution and 72-73; chemicals and climate 205; healthcare professional's role during 54-55; pandemics and climate change during 52, 52-53; plastics during 222; solar energy and 31-33, 32-33

COVID-19 see coronavirus disease 2019 (COVID-19)

cradle-to-grave approach 163

CREDA see Chhattisgarh State Renewable Energy Development Agency (CREDA)

Cryptococcus 50

CSDs see climate sensitive diseases (CSDs)

DAPCCHH see District Action Plan on Climate Change and Human Health (DAPCCHH)

di-(2-ethylexyl) phthalate (DEHP/DOP) 220

diarrhoea $63,92,101,127,151,154$, 210

diclofenac 197

diesel transport 173

dioxins 68, 68, 69, 167, 217, 219

distributed renewal energy (DRE) 143

District Action Plan on Climate Change and Human Health (DAPCCHH), $38,41-42$

drug resistance 198 
early warning system $27,41,43-44$, 49, 53, 96, 108, 109, 112

Ebola 51, 120

eco-anxiety 64

effluent treatment plants (ETPs) 157, 166

elderly age group 101-102, 108

electric vehicles (EVs) 175-176, 179

endocrine-disrupting chemicals (EDCs) 71,220

energy conservation building codes 132

energy consumption, in the health sector 19-20, 122, 140-141

energy efficiency, in the health sector 20-23, 132, 139-141, 188, 190

Energy Efficiency Services Limited (EESL) 143

energy-health assessment 143

environmental sustainability 184-185, $185,187,195$; in the pharmaceutical industry see pharmaceutical industry environment-friendly construction 12 epidemic infection 151

Escherichia coli 49, 199

European Centre for Disease Prevention and Control (ECDC) 199 e-waste 8, 162, 163

extended producer responsibility (EPR) 197

factory farm pollutants $81-82$

fluoride contamination 92, 150, 152

food insecurity, gendered vulnerabilities to $92-93$

food security/systems 77, 225; climate change impact on $78-81,80$; farming and agriculture 81-83, 82, 82; healthy, affordable and sustainable diet $82,83,85$; impact on climate change 77,79 ; risk mitigation strategies 84,84 ; safety 83

fossil fuel consumption 7,184

fumigant 210

fungal threats 50-52, 51-52

gender, definition of 90

gendered differentials 225

gendered vulnerabilities and health inequities: adaptation and mitigation strategies 95-96; air pollution 92; extreme weather events 91, 91; food insecurity 92-93; gender-sensitive approach 94-95, 94-95; overview of 90; pregnant women 94; temperature variations 91-92; water contamination 92; water scarcity 93, 93

gender-sensitive approach 94-95, 94-95

gender-specific attributes 100

general waste 160-162, 168

GHG emissions 168; see also greenhouse gas (GHG) emissions

Global Climate Observing System 53

Global Climate Risk Index (2019) 59

Global Early Warning System (GLEWS) 53

Global Outbreak Alert and Response

Network (GOARN) 53

global syndemic, of climate change, undernutrition and obesity 63

global warming potential (GWP) 209, 226

good agriculture practices (GAP) 81 good manufacturing practices (GMP) 200

green and resilient health infrastructure 131-132, 133; medical equipment 136-137; medical supplies 137; retrofitting existing hospital buildings 135-136; safe and functional 133-135, 134; utility systems 136 green buildings 131-137, 226

green healthcare facilities $11,15,42$, 132

greenhouse gas (GHG) emissions 7, 12, 68, 106; chemicals 208; direct and indirect 20,21; economic incentive measures on 179; energy efficiency 141; environmental sustainability 184-185; food system 78; local pollution and financial strain 22; from transportation 173

Greenhouse Gas (GHG) Protocol 21, $122,124,184$

Green Rating for Integrated Habitat Assessment (GRIHA) principles 143, 186

GWP see global warming potential (GWP)

HAP see heat action plan (HAP) hazardous wastes 163, 217

HCF see health carbon footprint (HCF)

HCFs see healthcare facilities (HCFs)

Health and Environmental Leadership Platform (HELP) 10, 15, 169

health carbon footprint (HCF) 19, 19; determinants of 20-21, 21 
healthcare community $3-4,10,11$

healthcare facilities (HCFs) 165-167; leadership in 11-15, 11, 12

healthcare infrastructure, across lowincome countries 30-31

Health Care Without Harm 185, 187, 208

health inequities see gendered vulnerabilities and health inequities

health professionals, awareness and capacity building of $42-43$

health promotion model 207

health systems 226 ; climate change impacts on 21 ; health carbon footprint 19, 19-21, 21; health sector 21-27, 23, 24-25, 26; impact on climate change 18-19; overview of 18

heat action plan (HAP) 108-109, 225; Ahmedabad 111-112, 113;

limitations 112

heat health 106, 225

heating, ventilation, and airconditioning (HVAC) systems 12,72 , 157

heat-related illnesses 39, 39-41, 106, 113,225

heat waves 59-60, 106-107; impact on human health 107-108; populations at risk 108; urban heat island effect 108-111, 109-111, 111

HELP see Health and Environmental Leadership Platform (HELP)

high-efficiency particulate air (HEPA) filters 72

high strength sewage $154,158 \mathrm{n} 2$

hospital-acquired infections (HAI) 71-72

Hospital Disaster Management Plan (HDMP) 137

Hospital Safety Index (HSI) 136

human bio monitoring (HBM) investigations 94

human health, climate change impacts on: air pollution-related diseases 64; implications of 58-59, 59, 60; malnutrition 63; mental health 64 ; temperature and health 59-60, 61; vector-borne diseases 60-62, 62; water-borne diseases 62-63

HVAC systems see heating, ventilation and air-conditioning (HVAC) systems hybrid solar-diesel system 31
IGBC see Indian Green Building Council (IGBC)

incineration 167; of chlorinated plastics 217, 219

India: allied programmes, in the health sector 43-44; global and national level, climate change at 36-37, 38; National Programme on Climate Change and Human Health see National Programme on Climate Change and Human Health (NPCCHH); state and district level, climate change at 41-42

Indian Green Building Council (IGBC) 13

Indian health sector 184; climate-smart waste practices for the 168-169; waste management in the 163 , 164,165

Indian Institute of Public Health, Gandhinagar (IIPHG) 106

indoor air quality (IAQ) 69-70

influenza viruses 51,51

inorganic contamination 92

Intended Nationally Determined Commitments (INDC) 37

Inter-Agency Emergency Communication Plan 111

Inter-governmental Panel on Climate Change (IPCC) 36, 175-176, 224

International Agency for Research on Cancer (IARC) 220

International Livestock Research Institute 48

International Solar Alliance (ISA) 33

IPCC see Inter-governmental Panel on Climate Change (IPCC)

ISA see International Solar Alliance (ISA)

ISA Cares Initiative 33

KEBA Health Sub-Centre 144-145, 146

Kigali Amendment 209

Kyoto Protocol (1997) 36

Lancet Commission on Health and Climate Change 123-124

Lancet Countdown (2018) 58

Lancet report (2019) 101

leadership, of the health sector: in the community 10-11, 11; in the healthcare facility 11-15, 11, 12; overview of 7-8; at the policy and sectoral level 8-10,9 
LED see light-emitting diodes (LED) Legionellosis 71

light-duty vehicles (LDVs) 175

light-emitting diodes (LED) 141-142

low-income countries: healthcare infrastructure across 30-31; overview of 29; solar energy, for COVID-19 response 31-33, 32-33

malnutrition $63,92,100-101,210$, 224-225

medical applications, plastics used in 216-217, 218-219

medical equipment, safe and functional 136-137

medical supplies 137

mental health 25, 39, 64, 91

Methicillin-resistant Staphylococcus aureus (MRSA) 199

metric tons of carbon dioxide equivalent (MtCO2e) 78, 160, 175

Ministry of Environment, Forest and Climate Change (MoEFCC) 37, 166

Ministry of Health and Family Welfare (MoHFW) 37, 224

mobile boat clinics 145, 147

Model Building Byelaws (2016) 132

monomers 215

Montreal Protocol 209

multi-resistant Escherichia coli (MREC) 199

NAPs see National Adaptation Plans (NAPs)

National Action Plan for Climate Change and Human Health (NAPCCHH) 37

National Action Plan on Climate Change (NAPCC) 37, 143, 145

National Adaptation Plans (NAPs) 2, 122

National and State Climate Action Plans 9

National Centre for Disease Control (NCDC) 37, 43, 54, 224

National Disaster Management Authority (NDMA) 42, 112

National Disaster Management Authority guidelines on hospital safety 135

National Health Conclave 20199

National Health Service (NHS) 188, 189, 207, 209
Nationally Determined Contributions (NDCs) 2, 36, 122, 227

National Mission for Enhanced Energy Efficiency (NMEEE) 147

National Programme on Climate Change and Human Health (NPCCHH) 37-38, 224; air pollution-related illnesses $40-41$; climate sensitive diseases 39 ; green and climate-resilient healthcare facilities 42; health professionals, awareness and capacity building of 42-43; heat-related illnesses 39-41; vision, goal and objectives of 38

National Rural Water Supply Mission 150

National Solar Mission (NSM) 147-148

NDCs see Nationally Determined Contributions (NDCs)

NHS see National Health Service (NHS)

nitrous oxide $68,185,209,210$

non-communicable diseases (NCDs) 67

non-hazardous waste 165

NPCCHH see National Programme on Climate Change and Human Health (NPCCHH)

nutrient acquisition 82

organic contamination 92

organic food 81

outdoor air pollution 70, 75, 174, 211

outdoor workers 103-104

pandemic influenza (1918) 51, 225

Paris Agreement 2-3, 8, 36, 196, 227

particulate matter (PM) 167

PCDD/PCDF see polychlorinated dibenzo-dioxins/polychlorinated dibenzofurans (PCDD/PCDF)

persons with disabilities (PWD) 102, 102-103

pesticides $81,86,150,154,168,207$, 210

pharmaceutical industry 195, 207, 226; $v s$. antimicrobial resistance 198 , 198-199; climate change effect on 195-196; responsible production, importance of 196-197, 197

PHCs see Primary Healthcare Centres (PHCs) 
PHFI see Public Health Foundation of India (PHFI)

Pithovirus sibericum 48

plastics 226; additives used in 217; description of 215-216; impacts, on human health 219-220; life cycle analysis and end-of-life solutions 217 , 219; manufacturing industry 206-207, 215-216; resolving the paradox of 221222, 222; used in medical applications 216-217, 218-219; waste 162

$\mathrm{PM}_{2.5}$ levels 73, 92

PMCCC see Prime Minister's Council on Climate Change (PMCCC)

polychlorinated dibenzo-dioxins/ polychlorinated dibenzofurans (PCDD/PCDF) 217, 219

polyethylene (PE) 217

polymers 215

polypropylene (PP) 217

polyvinyl chloride (PVC) 68, 74, 187, 207, 217, 220-221

post-disaster emergency treatment 137

Post-Traumatic Stress Syndrome (PTSS) 101

pregnant women, gendered vulnerabilities of 94

Primary Healthcare Centres (PHCs) 29, 31-32

Prime Minister's Council on Climate Change (PMCCC) 37, 43

product stewardship 197

Public Distribution System 82

Public Health Foundation of India (PHFI) 9, 10

PVC see polyvinyl chloride (PVC)

PWD see persons with disabilities (PWD)

resilient health infrastructure, green and see green and resilient health infrastructure

resilient health systems 24-25, 24-27, 26, 119-120, 120

Resilient Hospital Dashboard 129n1

sanitary and phytosanitary (SPS) 81

Science-Based Targets Initiative 200

SDD refrigerators see solar-powered direct drive (SDD) refrigerators

SDGs see Sustainable Development Goals (SDGs)

segregation 168

selenium 152

Sendai Framework 2-3, 98 sensitivity 99

severe acute respiratory syndrome coronavirus 2(SARS-CoV-2) 48

sewage treatment plant (STPs) 157, 166 short-lived climate pollutants (SLCPs) 30, 173

Sick Hospital Syndrome 71

SLCPs see short-lived climate pollutants (SLCPs)

social protection programmes 53

social sustainability 185

solar energy, for COVID-19 response 31-33, 32-33

solarisation, of health centres 224

solar-powered direct drive (SDD) refrigerators 32,33

solastalgia 64

solid waste 162

Solid Waste Management Rules (2016) 168

Spanish Influenza (H1N1A) 48

Standard for Green and Clean Hospitals 15, 132

State Plans on Climate Change and Human Health 103

State-specific Action Plan on Climate Change and Human Health

(SAPCCHH) 38, 41

Stockholm Convention 167

Streptococcus faecalis 49

Sustainable Development Goals (SDGs) 2-3, 13, 31, 96, 195

Sustainable Development Unit 209

sustainable energy management, in health sector 225; cooling technologies 142-148, 144-145, 146-147; energy consumption 140; energy efficiency 140-141; fan usage 142; heating 142; lighting 141-142; overview of 139-140 sustainable healthy diets $82-83,85$ sustainable procurement/health systems: case studies 188, 190; economic principles 185,186 ; environmental sustainability 184-185, 185; of goods and services 187, 189; India's healthcare sector 184 ; overview of 183-184; social sustainability 185 ; star rating appliances 186 sustainable procurement policies 226

temperature variations, gendered vulnerabilities to 91-92

total dissolved solids (TDS) 150, 154 toxic pollution $210-211$

toxin standards and associated health effects 152 
transportation 173, 226

transport-related pollutants 173 ; adaptation measures 181; economic incentive measures 179-180; energy consumption and cost savings 180 ; health risks 173-174, 174; landuse design/regulations 176, 177; mitigation activities 178; modified vehicles and fuel 175-176

treatment, storage and disposal facility (TSDF) 163

ultraviolet germicidal irradiation (UVGI) 72

ultraviolet lamp fitted reverse osmosis units (UV-ROs) 154

UNFCCC see United Nations Framework Convention on Climate Change (UNFCCC)

United Nations Environment Programme (UNEP) 165

United Nations Framework Convention on Climate Change (UNFCCC) 36-37, 95, 209, 224

uranium nitrate 152

urban heat island effect 108-111, 109-111, 111

US Center for Disease Control and Prevention 204

utility systems, safe and functional 136

\section{Variola major 49}

vector-borne diseases 60-62, 62, 151

viral threats 48-49

volatile organic compounds (VOC) 68, 75

vulnerability 98-99, 225; of biological systems 211 ; identify and reduce 120-121

vulnerable populations: children 100101 ; the elderly 101-102; outdoor workers 103-104; persons with disabilities 102, 102-103; women 100

waste management 160 ; biomethanation and composting 169 ,
169-170; challenges 166; climatesmart waste practices 168-169; and disposal 160-163, 161, 162-163; environmental concerns 167-168; in the Indian health sector 163, 164, 165, 165; segregation 165

waste segregation 165

wastewater: in the health sector 154; recycling and use of 157

water-borne diseases 62-63, 151

water conservation and effective management 157

water consumption, in the health sector 153-154

water contamination, gendered vulnerabilities to 92

water footprint 226

water quality and quantity $149-150$

water scarcity, gendered vulnerabilities to 93,93

water stagnation 157

water stress 149; consumption patterns 153-154; disease burden 151,152 ; quantity and quality 149 150; role, of health sector 157-158; wastewater 154

water-washed diseases 92

WHO see World Health Organization (WHO)

whole-life costing 185, 186

World Health Organization (WHO): antimicrobial resistance 198 , 200; climate-resilient health system 37, 119-120; coronavirus disease 201972 ; health impacts of climate change 225 ; resilient health system, elements of a 24-25; strategies for health systems 21-22; transport-related health risks 174 ; vulnerability 99

zoonotic diseases 47,225 ; bacterial threats 49, 49-50, 50; climate change and 47-48; coronaviruses 52-55; fungal threats 50-52, 51-52; viral threats 48-49 